\title{
INFLUÊNCIA DO VALOR DA MADEIRA DE MERCADO SOBRE O ORDENAMENTO DE FLORESTAS PLANTADAS PARA O SUPRIMENTO PARCIAL DE UMA INDÚSTRIA DE CELULOSE E PAPEL: UMA APLICAÇÃO DA PROGRAMAÇÃO LINEAR
}

\author{
FABIO LUÍS BRUN
}

\author{
Dissertação apresentada à Escola Superior de \\ Agricultura "Luiz de Queiroz” para obtenção do título \\ de Mestre em Recursos Florestais, Área de \\ Concentração: Recursos Florestais com opção em \\ Manejo de Florestas de Produção
}

PIRACICABA

Estado de São Paulo - Brasil

Fevereiro - 2002 


\title{
INFLUÊNCIA DO VALOR DA MADEIRA DE MERCADO SOBRE O ORDENAMENTO DE FLORESTAS PLANTADAS PARA O SUPRIMENTO PARCIAL DE UMA INDÚSTRIA DE CELULOSE E PAPEL: UMA APLICAÇÃO DA PROGRAMAÇÃO LINEAR
}

\author{
FABIO LUÍS BRUN
}

Engenheiro Florestal

Orientador: Prof. LUIZ CARLOS E. RODRIGUEZ

\author{
Dissertação apresentada à Escola Superior de \\ Agricultura "Luiz de Queiroz" para obtenção do título \\ de Mestre em Recursos Florestais, Área de \\ Concentração: Recursos Florestais com opção em \\ Manejo de Florestas de Produção
}

PIRACICABA

Estado de São Paulo - Brasil

Janeiro - 2002 
Dados Internacionais de Catalogação na Publicação (CIP) DIVISÃO DE BIBLIOTECA E DOCUMENTAÇÃO - ESALQ/USP

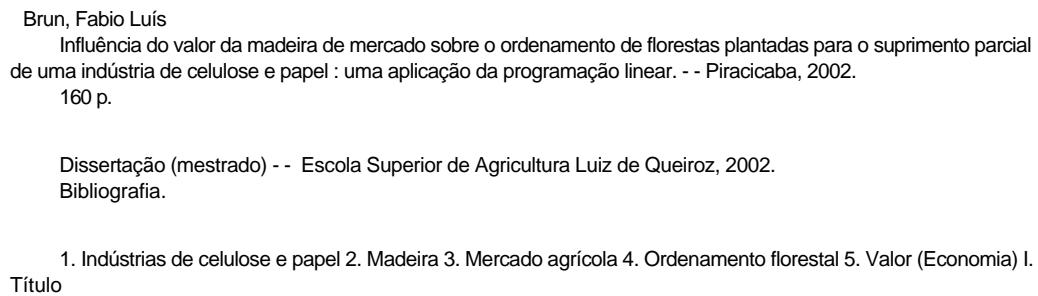

CDD 634.9283

"Permitida a cópia total ou parcial deste documento, desde que citada a fonte - $\mathrm{O}$ autor" 


\section{AGRADECIMENTOS}

À International Paper do Brasil Ltda., nas pessoas dos Srs. Manoel de Freitas e João Comério, por sugerir e apoiar o desenvolvimento deste trabalho.

À Escola Superior de Agricultura Luiz de Queiroz, Universidade de São Paulo.

Aos profissionais da International Paper do Brasil Ltda. Rogério Silva, Helder Francês, Jose Mario Ferreira, Karla Antiqueira, Ingrid Nielsen e Maurício Penteado, que prestaram seu apoio crítico ao desenvolvimento deste trabalho e especialmente à Marilza Souza, pela enorme ajuda.

Aos colegas da ESALQ, Fabiano Rodrigues e Tatiana Amaral, pelo inestimável suporte nos dias finais.

Ao professor Luiz Carlos Estraviz Rodriguez, pela enorme didática, pelo constante apoio e por me permitir desenvolver uma perspectiva diferente da engenharia florestal e do negócio florestal brasileiro.

Aos professores Fernando Seixas, Nivaldo Garcia e Fernando Curi Peres pelas úteis observações ao trabalho.

À minha família, por ficar sempre do meu lado nestes últimos dois anos.

Aos demais amigos do Departamento de Tecnologia Florestal, pelo profissionalismo demonstrado principalmente neste período de dois anos. 
Ao meu País, minha mãe, Neide, e especialmente, à minha esposa, Katiany, por nunca me deixar desistir

Dedico 


\section{SUMÁRIO}

Página

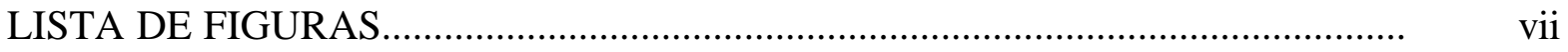

LISTA DE TABELAS............................................................................ ix

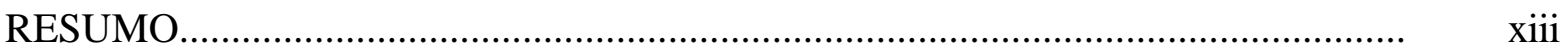

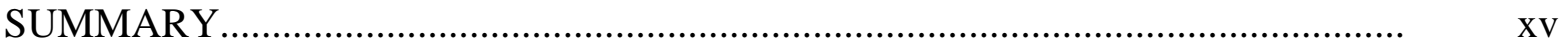

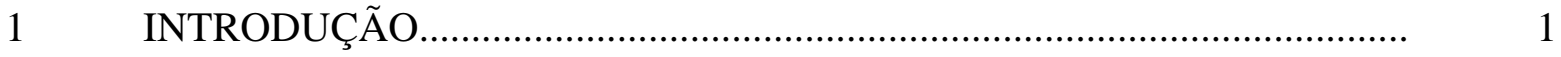

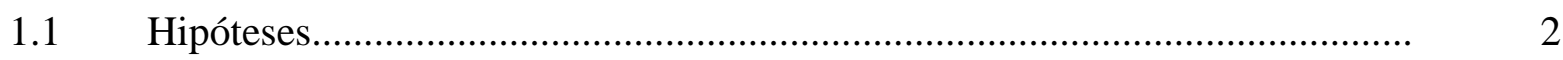

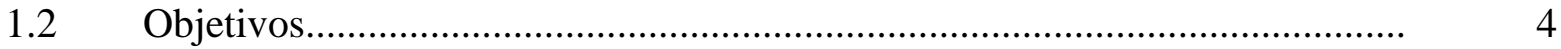

2 REVISÃO DE LITERATURA......................................................... 5

$2.1 \quad$ Planejamento florestal........................................................................ 5

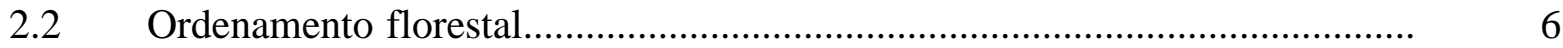

2.3 Programação linear como ferramenta de ordenamento florestal..................... 7

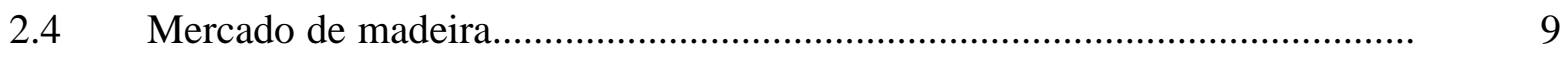

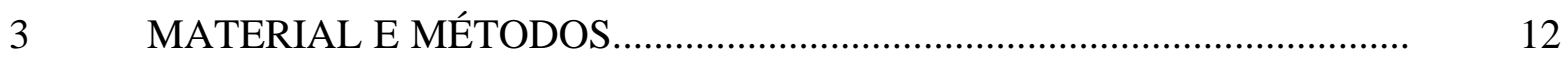

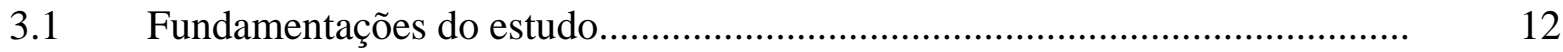

3.1.1 Critérios gerais de utilização florestal para celulose..................................... 13

3.2 Formulação do modelo matemático de programação linear (modelo I)......... 15

3.3 Unidades de produção (UPs) e dados de produtividade................................... 17

3.4 Definição dos volumes produzidos por prescrição....................................... 24

3.5 Premissas básicas de valoração - Taxa Mínima de Atratividade (TMA) e custos de produção.............................................................................. 26 
3.5.1 Determinação do valor da madeira de mercado............................................... 30

3.5.2 Critérios para variar cenários de custos/preços de madeira de mercado........... 31

3.5.3 Critérios de valoração dos regimes de manejo - modelos de maximização do valor presente líquido das receitas............................................................ 34

3.5.3.1 Critério de cálculo do valor presente líquido das receitas................................ 34

3.5.3.2 Determinação do ciclo economicamente ótimo................................................. 38

3.5.3.3 Cálculo do valor presente líquido das receitas de cada prescrição................... 39

3.6 Modelo de maximização do valor presente líquido das receitas....................... 39

3.7 Critérios de valoração dos regimes de manejo - modelos de minimização do

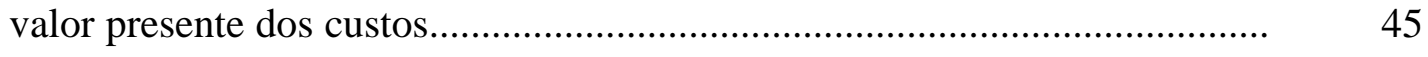

3.7.1 Cálculo do Custo Financeiro da Produção (CFP)............................................. 46

3.7.2 Cálculo do valor presente do custo posto-fábrica............................................. 47

3.7.3 Determinação do ciclo economicamente ótimo................................................ 48

3.8 Modelo de minimização do valor presente dos custos....................................... 49

$4 \quad$ RESULTADOS E DISCUSS ÃO............................................................ 54

4.1 Geração dos coeficientes............................................................................. 54

4.2 Geração dos modelos.................................................................................

4.2.1 Geração dos outputs dos modelos............................................................... 56

4.3.1 Testes das hipóteses: Hipótese I................................................................... 77

4.3.2 Testes das hipóteses: Hipótese II................................................................... 81

4.3.3 Testes das hipóteses: Hipótese III..................................................................... 85

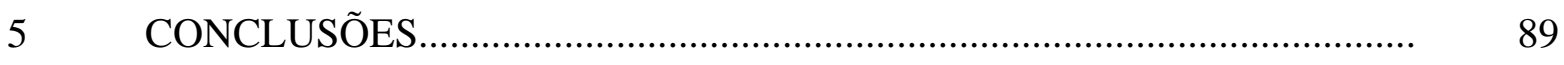

ANEXOS ...................................................................................................... 96

REFERÊNCIAS BIBLIOGRÁFICAS.................................................................. 157 


\section{LISTA DE FIGURAS}

Página

1 Diagrama geral do trabalho............................................................... 12

2 Organização dos modelos gerados 55

3 Valores da função objetivo do modelo global de maximização do valor

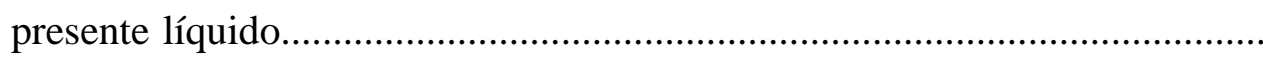

4 Valores da função objetivo do modelo regionalizado de maximização do valor presente líquido.

5 Valores da função objetivo do modelo global de minimização do custo presente

6 Valores da função objetivo do modelo regionalizado de minimização do

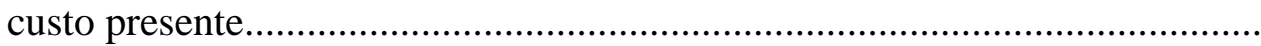

7 Área média das recomendações no horizonte de planejamento, em hectares, a ser colhida para os modelos de maximização do valor líquido presente e minimização do custo presente, nas condições regionalizadas, com restrições operacionais e de produção livre

8 Volume médio, a ser adquirido no mercado, no horizonte de planejamento, em $\mathrm{m}^{3}$, para os modelos de maximização do valor líquido presente e minimização do custo presente, nas condições regionalizadas, com restrições operacionais e de produção livre

9 Variação das diferenças percentuais entre valores da função objetivo dos modelos global e regionalizado, nos diferentes cenários de valor da madeira, para produção ordenada, nas condições de maximização do valor líquido presente e minimização do custo presente. 
10 Variação das diferenças percentuais entre valores da função objetivo dos modelos global e regionalizado, nos diferentes cenários de valor da madeira, para produção livre, nas condições de maximização do valor líquido presente e minimização do custo presente.......................................... 


\section{LISTA DE TABELAS}

Página

1 Raios geográficos intra-regionais (distâncias entre hortos de uma mesma região)

2 Unidades de Produção (UPs) da Região I, áreas por UP, distâncias UP/fábrica, idades correntes de cada UP (Setembro 2001) e volumes esperados por UP para 6,7 e 8 anos de idade

3 Unidades de Produção (UPs) da Região I, áreas por UP, distâncias UP/fábrica, idades correntes de cada UP (Setembro 2001) e volumes esperados por UP para 6,7 e 8 anos de idade

4 Unidades de Produção (UPs) da Região II, áreas por UP, distâncias UP/fábrica, idades correntes de cada UP (Setembro 2001) e volumes esperados por UP para 6, 7 e 8 anos de idade

5 Unidades de Produção (UPs) Região III, áreas por UP, distâncias 21 UP/fábrica, idades correntes de cada UP (Setembro 2001) e volumes esperados por UP para 6, 7 e 8 anos de idade

6 Unidades de Produção (UPs) de áreas de terceiros (parcerias) na Região I... 22

7 Unidades de Produção (UPs) de áreas de terceiros (parcerias) na Região II.. 22

8 Unidades de Produção (UPs) de áreas de terceiros (fomento) na Região I..... 23

9 Exemplos de alternativas de produção para cada uma das Unidades de Produção disponíveis no Horto Gigante, Região I

10 Custos anuais por região - Reforma e Condução........................................... 27

11 Custos de colheita por classe de volume individual..................................... 28

12 Custos de transporte por classe de volume individual por $\mathrm{km}$....................... 29 
13 Variação da inflação medida pelo IGP-M anual, de 1995 a 2001

14 Variação do preço da madeira de mercado para a região leste do Estado de São Paulo de 1995 a 2001, corrigido pela inflação no período....................... 32

15 Variação sobre o valor-semente para uso nos modelos (ValMM)

16 Valores obtidos para a função objetivo, nos modelos de maximização do valor presente líquido (em $\mathrm{R} \$$ )......

17 Valores obtidos para a função objetivo, nos modelos de minimização do custo presente (em R $\$$ )

18 Percentual de utilização da área plantável nos por modelos de maximização do valor líquido presente, para cada cenário de valor de madeira.

19 Percentual de utilização da área plantável nos por modelos de minimização do custo presente, para cada cenário de valor de madeira.

20 Volumes anuais adquiridos de madeira de mercado, em $\mathrm{m}^{3}$, resultantes do modelo Global de maximização do valor presente líquido sem restrições operacionais, para os diferentes cenários de valor de madeira de mercado....

21 Volumes anuais adquiridos de madeira de mercado, em $\mathrm{m}^{3}$, resultantes do modelo Global de maximização do valor presente líquido com restrições operacionais, para os diferentes cenários de valor de madeira de mercado....

22 Volumes anuais adquiridos de madeira de mercado, em $\mathrm{m}^{3}$, resultantes do modelo Regionalizado de maximização do valor presente líquido sem restrições operacionais, para os diferentes cenários de valor de madeira de mercado

23 Volumes anuais adquiridos de madeira de mercado, $\mathrm{em}^{3}$, resultantes do modelo Regionalizado de maximização do valor presente líquido com restrições operacionais, para os diferentes cenários de valor de madeira de mercado

24 Volumes anuais adquiridos de madeira de mercado, $\mathrm{em}^{3}$, resultantes do modelo Global de minimização do custo presente sem restrições operacionais, para os diferentes cenários de valor de madeira de mercado.... 
25 Volumes anuais adquiridos de madeira de mercado, $\mathrm{em}^{3}$, resultantes do modelo Global de minimização do custo presente com restrições operacionais, para os diferentes cenários de valor de madeira de mercado....

26 Volumes anuais adquiridos de madeira de mercado, $\mathrm{em}^{3}$, resultantes do modelo Regionalizado de minimização do custo presente sem restrições operacionais, para os diferentes cenários de valor de madeira de mercado....

27 Volumes anuais adquiridos de madeira de mercado, $\mathrm{em}^{3}$, resultantes do modelo Regionalizado de minimização do custo presente com restrições operacionais, para os diferentes cenários de valor de madeira de mercado....

28 Idades médias de colheita (rotação média), em anos, para maximização de valor presente líquido e minimização dos custos no modelo Global

29 Idades médias de colheita (rotação média), em anos, para maximização de valor presente líquido e minimização dos custos presentes no modelo Regionalizado

30 Prescrição de áreas anuais de colheita, em hectares, resultantes do modelo Global de maximização do valor presente líquido sem restrições operacionais, para os diferentes cenários de valor de madeira de mercado....

31 Prescrição de áreas anuais de colheita, em hectares, resultantes do modelo Global de maximização do valor presente líquido com restrições operacionais, para os diferentes cenários de valor de madeira de mercado....

32 Prescrição de áreas anuais de colheita, em hectares, resultantes do modelo Regionalizado de maximização do valor presente líquido sem restrições operacionais, para os diferentes cenários de valor de madeira de mercado....

33 Prescrição de áreas anuais de colheita, em hectares, resultantes do modelo Regionalizado de maximização do valor presente líquido com restrições operacionais, para os diferentes cenários de valor de madeira de mercado....

34 Prescrição de áreas anuais de colheita, em hectares, resultantes do modelo Global de minimização do custo presente sem restrições operacionais, para os diferentes cenários de valor de madeira de mercado

35 Prescrição de áreas anuais de colheita, em hectares, resultantes do modelo 
Global de minimização do custo presente com restrições operacionais, para os diferentes cenários de valor de madeira de mercado.................................

36 Prescrição de áreas anuais de colheita, em hectares, resultantes do modelo Regionalizado de minimização do custo presente sem restrições operacionais, para os diferentes cenários de valor de madeira de mercado....

37 Prescrição de áreas anuais de colheita, em hectares, resultantes do modelo Regionalizado de minimização do custo presente com restrições operacionais, para os diferentes cenários de valor de madeira de mercado....

38 Ganho percentual, nos valores da função objetivo, do modelo Global em relação ao Regionalizado em todos os cenários de maximização do valor presente líquido.....

39 Ganho percentual, nos valores da função objetivo, do modelo Global em relação ao Regionalizado em todos os cenários de minimização do custo presente

40 . Diferenças entre valores absolutos das funções objetivo do modelo global em relação ao regionalizado, para todos os cenários de valor da madeira, na condição de maximização do valor presente líquido...

41 Diferenças entre valores absolutos das funções objetivo do modelo global em relação ao regionalizado, para todos os cenários de valor da madeira, na condição de maximização do valor presente líquido...

42 Valores presentes do produto madeira adquirida no mercado / valor da madeira no ano da aquisição para um cenário de modelagem (comparação modelos global e regionalizado) 


\title{
INFLUÊNCIA DO VALOR DA MADEIRA DE MERCADO SOBRE O ORDENAMENTO DE FLORESTAS PLANTADAS PARA O SUPRIMENTO PARCIAL DE UMA INDÚSTRIA DE CELULOSE E PAPEL: UMA APLICAÇÃO DA PROGRAMAÇÃO LINEAR
}

\author{
Autor: FABIO LUÍS BRUN \\ Orientador: Prof. Dr. LUIZ CARLOS ESTRAVIZ RODRIGUEZ
}

\section{RESUMO}

De maneira geral, o abastecimento de madeira de indústrias de celulose brasileiras provém de áreas plantadas próprias e de madeira comprada no mercado. Programas de planejamento florestal de longo prazo procuram, normalmente, abranger o manejo da floresta plantada de forma dissociada à aquisição de madeira de fontes externas. $\mathrm{O}$ objetivo deste estudo é avaliar o impacto da variação de valores de aquisição da madeira de mercado em modelos de programação linear que consideram seu volume adquirido como uma das variáveis-resposta. Fundamentado em dados florestais de 155 Unidades de Produção fornecidos pela International Paper do Brasil Ltda., empresa do ramo de papel para imprimir e escrever situada em Mogi-Guaçu, Estado de São Paulo, o trabalho apresenta resultados provenientes da geração de 80 modelos de programação linear submetidos a cinco diferentes cenários de valores de madeira de mercado. As abordagens dos modelos foram divididas em: modelos de maximização do valor presente líquido e modelos de minimização do valor do custo presente, subdivididos em modelos Global e Regionalizado (procurando observar uma condicionante administrativa da empresa), ordenados ou de produção livre e, finalmente, submetidos ou não a restrições operacionais de área máxima de colheita. Os resultados permitem observar que as 
diferentes abordagens de planejamento possuem graus variados de sensibilidade a variações de valores de madeira de mercado, notadamente os modelos de minimização do valor presente do custo. Esta sensibilidade pode ser medida pelas variações provocadas nos programas de colheita de madeira própria e compra de madeira de mercado, pela flutuação das idades médias de colheita, pelos resultados das funções-objetivo e pelo percentual de aproveitamento de área própria. Os dados também sugerem que há vantagem em manejar a floresta pelo modelo Global, que desconsidera os limites administrativos da empresa. Também, pode-se afirmar que a maximização do valor presente líquido das prescrições é a abordagem preferível em função de demonstrar maior robustez na geração de planos de manejo menos sensíveis aos diferentes cenários de valor da madeira de mercado. 


\title{
INFLUENCE OF THE MARKET WOOD VALUE ON THE MANAGEMENT OF PLANTED FORESTS PARTIALLY SUPPLYING A PULP MILL: AN APPLICATION OF LINEAR PROGRAMMING
}

\author{
Author: FABIO LUÍS BRUN \\ Adviser: Prof. Dr. LUIZ CARLOS ESTRAVIZ RODRIGUEZ
}

\section{SUMMARY}

Generally, the Brazilian pulp industry wood supply is largely provided by planted forests owned by the companies and wood purchased in the market. Long term planning programs usually address the two supplying sources - fee forests and market wood separately. The main objective of this study is to assess the impact of different wood acquisition value scenarios in linear programming models that consider the amount of purchased wood as one of the variables. Based on data of 155 Production Units supplied by International Paper do Brasil Ltda., a printing paper company located in Mogi-Guaçu, State of São Paulo, the study presents results from the generation of 80 linear programming models submitted to five different wood acquisition value scenarios. The approach was divided into: maximization of net present value and minimization of the present cost, divided into Global and Regionalized models (pertaining to a company administrative restriction), with regulated or floating production and submitted or not to operational restrictions as a maximum harvesting area. Results allow observing that the different modeling approaches show different degrees of sensitivity to variations in the wood acquisition value - notably the minimization models. That sensitivity can be measured against variations in the harvesting and wood purchase programs, the floatation of the average harvesting ages, results of the objective function values and the percentage 
of utilization of fee lands. Results also suggest that there are advantages in managing the forest through the Global model, not considering the actual administrative limitations. Also, the maximization approach is the preferred one once it demonstrates more robustness through the generation of management programs less sensitive to the different proposed wood acquisition value scenarios. 


\section{INTRODUÇÃO}

Uma das particularidades do desenvolvimento de projetos na área florestal é a necessidade de considerar períodos extensos entre o estabelecimento de um plantio e seu aproveitamento final. Empreendimentos industriais cuja matéria-prima provém de bases florestais estão, portanto, sujeitos a programas de abastecimento que dependem fundamentalmente de prognósticos. Anos de pesquisas e desenvolvimento de modelos de prognose permitem atualmente estimar, com razoável precisão, produções futuras de talhões ou grupos de talhões. Essas estimativas são essenciais para o planejamento adequado das atividades florestais.

No entanto, ordenar extensos povoamentos florestais visando suprimentos futuros constantes e sustentáveis ainda remanesce como uma prática desafiadora. Considerando-se que os custos de produção, colheita e transporte da matéria-prima empregada resultam em uma parcela significativa do custo do produto final, é determinante a necessidade de se otimizarem os meios pelos quais é possível reduzir o desembolso com a sua produção e/ou aquisição, principalmente em se tratando de grandes volumes anuais. O planejamento florestal, confrontado com um universo variado de possibilidades, pode se beneficiar das metodologias de otimização via programação linear para gerar modelos que permitam uma análise simultânea de todos os recursos, prescrevendo a melhor linha de ações ou orientando em direção à melhor alternativa.

Fábricas de papel e celulose normalmente possuem uma mesma necessidade: a de administrar o consumo de grandes quantidades anuais de matéria-prima. A matéria prima - no caso específico estudado neste trabalho, madeira de reflorestamentos de Eucalyptus spp - provém de fontes bastante diversas. De forma geral, as fontes são: áreas próprias, áreas de terceiros com vínculos contratuais com a empresa (parcerias 
florestais e programas de fomento) e mercado livre. Essa diversidade de fontes está refletida nos também diversos custos relativos a cada uma, visto que estes variam de acordo com uma série de fatores a eles relacionados, como por exemplo, os métodos de plantio e manutenção utilizados, o tipo de colheita empregada, a distância média de transporte, a metodologia de remuneração utilizada pelo fornecedor, entre outros.

A International Paper do Brasil Ltda., empresa do ramo de papéis para imprimir e escrever localizada no município de Mogi-Guaçu, Estado de São Paulo, objeto da análise deste trabalho, está inserida neste contexto de oferta-demanda de grandes volumes de madeira, representada pela necessidade de abastecimento anual de aproximadamente $1.600 .000 \mathrm{~m}^{3}$ de madeira de Eucalyptus spp, proveniente de fontes semelhantes às citadas anteriormente.

O abastecimento de madeira é proveniente de uma área florestal própria de aproximadamente 33.000 hectares dividida administrativamente em três regiões florestais distintas: Região I, concentrada no município de Mogi-Guaçu, Região II, no município de Brotas e Região III no município de São Simão, todas no Estado de São Paulo. Essa divisão administrativa decorre basicamente da atual disponibilidade de três módulos de colheita florestal e da interpretação da empresa de que a circulação destes módulos só é viável financeiramente se ocorrer dentro das regiões, ou dentro de um raio considerado máximo de deslocamento.

\subsection{Hipóteses}

Com o objetivo de ordenar as florestas próprias sob diferentes cenários de preços da madeira de mercado, três hipóteses são testadas neste trabalho:

Hipótese I - O modelo de ordenamento florestal que consolida as três divisões físicas existentes em uma única fonte de matéria-prima (modelo "Global”), proporciona um resultado "melhor" para o valor da função objetivo quando comparado aos resultados apresentados pelos modelos que procuram ordenar as três regiões separadamente (modelos "Regionalizados"), apesar da base física em superfície plantada ser a mesma; 
Como mencionado anteriormente, a divisão das áreas florestais da empresa em três regiões procura atender a uma questão logística que envolve o custo de deslocamento de módulos de colheita florestal entre áreas distantes. Quando concentrado em áreas onde o deslocamento está limitado a distâncias reduzidas , convencionado aqui como inferiores a $22 \mathrm{~km}$, valor que representa a média das distâncias entre os plantios de uma mesma região (ver Tabela 1) - o deslocamento de equipamentos tende a ser menor e o custo total de colheita consequientemente reduzido. A proposta é quantificar o total dessa eventual redução de custos de colheita dentro do horizonte de planejamento usado.

Tabela 1. Raios geográficos intra-regionais (distâncias entre hortos de uma mesma região).

\begin{tabular}{|c|c|}
\hline Região & Raio Geográfico Intra-Regional(km) \\
\hline I (Mogi-Guaçu) & $33 \mathrm{~km}$ \\
\hline II (Brotas) & $13 \mathrm{~km}$ \\
\hline III (São Simão) & $20 \mathrm{~km}$ \\
\hline Média & $22 \mathrm{~km}$ \\
\hline
\end{tabular}

Fonte : Departamento de SIG, International Paper do Brasil Ltda.

Hipótese II - A variação no valor da madeira de mercado é suficientemente grande entre cenários para afetar os resultados apresentados pelos dois modelos de ordenamento.

Considerando que o ordenamento global pode ser obtido de forma menos restritiva do que nos modelos regionalizados, espera-se que cada modelo reaja de forma diferenciada a variações no valor da madeira de mercado. Essa sensibilidade poderá ser medida pelo impacto provocado no planejamento de longo prazo por variações similares de custo de aquisição de madeira de mercado aplicadas simultaneamente em ambos os modelos. A proposta é verificar qual modelo é menos sensível à exposição ao mercado, conseqüentemente apresentando menores variações nas prescrições anuais de colheita. 
Hipótese III - O modelo que considera a maximização do valor presente das receitas líquidas resulta em um plano de manejo e ordenamento diferente do qual objetiva a minimização do custo de produção da floresta.

Para um mesmo horizonte de planejamento, dois modelos matemáticos distintos serão comparados nas duas situações (Global e Regional). O primeiro definirá qual o ordenamento ótimo de maior valor presente líquido do investimento florestal, enquanto o segundo definirá o ordenamento ótimo de menor custo de produção dentro do horizonte de planejamento.

\subsection{Objetivos}

Adicionalmente ao teste das hipóteses, o objetivo prático deste trabalho é obter dados numéricos que possam caracterizar se a interpretação da divisão em administrações regionais é realmente a abordagem operacional mais recomendada para fins de colheita florestal dentro dos cenários testados.

O estudo pretende também interpretar o impacto econômico e a necessidade de se obter estabilidade na produção de matéria-prima dentro do negócio florestal, processo conhecido como "ordenamento florestal".

A informação gerada sobre a sensibilidade de modelos de planejamento quanto a variações do valor da madeira de mercado será útil para futuras reflexões sobre o tema e pode ser entendido como um objetivo paralelo deste estudo. 


\section{REVISÃO DE LITERATURA}

\subsection{Planejamento florestal}

O termo clássico "Forest Management", dentre as diversas interpretações e traduções, compreende o estudo e aplicação de técnicas analíticas no auxílio da seleção daquelas alternativas de manejo que mais contribuem para os objetivos da organização (Leuschner, 1992).Uma tradução tentativa mais adaptada à realidade do termo seria "Gestão Florestal" ou, mais simplesmente, "Planejamento Florestal". Planejar significa analisar futuras possibilidades, decisões e operações levando em consideração os fatores pertinentes e suas interações (Siitonen, 1993).

Planejar também mantém um sentido implícito de considerar possibilidades futuras por intermédio de exercícios de prognose. Segundo Siitonen (1993), a precondição para estimar a dinâmica dos recursos florestais e planejar a utilização de

florestas é aceitar condições, incertezas e um período restrito de tempo. É fundamental, portanto, que o planejamento esteja suportado por ferramentas que permitam sua aplicação numa variedade de situações diferentes e submetidas a restrições particulares (Pukkala \& Pohjonen, 1990). No entanto, quanto mais apurada é a técnica utilizada para se planejar, maior a quantidade, especificidade e precisão das informações necessárias (Martini \& Leite, 1988).

Clutter et al. (1992) sugere que o processo de gestão florestal seja subdividido em três componentes:

- Tomada de Decisão - identificação do problema, desenho das soluções alternativas e seleção da melhor; 
- Implementação - condução das atividades requeridas para completar o programa selecionado;

- Controle - o processo de garantir que as atividades sugeridas foram realmente implementadas e verificar se os resultados foram os esperados.

O planejamento encaixa-se perfeitamente no componente "Tomada de Decisão", subdivido ainda por Clutter et al. (1992) em quatro passos:

1. Reconhecimento do problema;

2. Especificação das estratégias;

3. Especificação do critério de decisão;

4. Seleção da melhor (ótima) estratégia.

O reconhecimento do "problema" para a ação do planejamento é o passo fundamental no desenvolvimento dos trabalhos posteriores.

Um problema característico da área florestal é a busca por sustentabilidade produtiva que, entre outras vantagens, possibilita auto-suficiência e previne contra a escassez de madeira (Dykstra, 1984). O planejamento pode abordar esse problema específico através de alternativas silviculturais que busquem a "regulação" da floresta, o que proporcionaria produções anuais de igual volume, tamanho e qualidade (Leuschner, 1992). Alternativas como recomendações de corte raso, no caso típico de florestas de eucalipto para produção de celulose, podem promover regulação quando orientadas para este fim e quando dentro de um cenário de longo prazo de características tipicamente florestais.

\subsection{Ordenamento florestal}

O objetivo final da floresta normalmente deriva diretamente do interesse final do proprietário. Objetivos de proprietários industriais são mais facilmente previsíveis, pois normalmente detém florestas para atender a necessidade de matéria-prima de suas unidades de transformação (Leuschner, 1992).

Segundo Rodriguez (2001), as metas do ordenamento florestal são a não exaustão do recurso florestal e a condução de uma floresta idealizada com produção 
constante, não superior à sua capacidade de regeneração. $\mathrm{O}$ ordenamento florestal consiste, portanto, em basicamente buscar esta sustentabilidade de fornecimento de matéria-prima pela floresta via predições de crescimento da madeira disponível e da determinação das atividades - implantação, colheita, desenvolvimento tecnológico para incrementar produtividade, etc. - que permitam alcançá-la.

Dentre os benefícios provenientes de uma floresta regulada apontados por Dykstra (1984), pode-se mencionar:

- Uniformidade da produção no tocante ao volume produzido com mesmo valor e qualidade;

- Equilíbrio entre receitas e despesas anuais;

- Promoção da auto-suficiência do setor e prevenção contra escassez de madeira.

- Contínua necessidade de mão-de-obra, garantindo ofertas constantes de empregos.

Uma avaliação mais clássica de floresta regulada é a de que as classes de idade e forma estejam distribuídas de tal maneira, e que estejam crescendo em tal proporção, que um determinado produto periódico - de qualidade e intensidade desejadas - seja obtido em perpetuidade (Davis \& Johnson, 1987).

\subsection{Programação linear como ferramenta de ordenamento florestal}

Do ponto de vista prático, o ordenamento perfeito é bastante difícil de ser alcançado. Florestas em constante estado de transição para um maior equilíbrio entre níveis de crescimento e colheita são as mais comuns (Rodriguez, 2001). O planejamento que almeje regular a produção florestal demandará recursos matemáticos que permitam a análise simultânea de um número bastante grande de variáveis submetidas a diversos níveis de restrições.

Rodrigues (1997), citando Hillier \& Lieberman (1988), refere-se à programação linear como método para tratar de problemas de otimização com restrições e que permite a análise de problemas de alocação ótima de recursos limitados entre atividades competitivas. 
Diversos trabalhos expõem o uso da programação linear no desenvolvimento do planejamento florestal. Sousa (2000) compila diversas fontes e interpreta a pesquisa nessa área como dividida em dois ramos distintos: um objetivando o manejo integrado de florestas e outro se concentrando em questões relativas à colheita e transporte de madeira mais especificamente.

A necessidade de compor soluções ótimas, sejam de maximização ou minimização, incorporando um enfoque temporal, tem sido objeto de estudo de pesquisadores na área florestal. Carnieri (1989) apresenta uma modelagem via estrutura de redes que já buscava uma solução ótima para a adoção de um grande número de manejos, estes distribuídos em intervalos de tempo. Como a circunstância florestal, diferentemente da agrícola, determina a necessidade de se planejar em longo prazo (rotações longas medidas em anos), o planejamento deve conter ao menos um componente "preditor" suficientemente bem elaborado.

Brazee \& Bulte (2000) apresentam uma possibilidade bastante interessante de incorporar preços flutuantes de "madeira em pé" nas decisões de colheita e desbaste gerando "modelos flexíveis de manejo".

Falcão \& Borges (1998) sugerem uma aplicação da programação linear em gestão de recursos naturais compondo-a por fluxos de abastecimento fundamentados em limitações de volume e área. Além do uso da programação linear para ordenamento florestal em si, esta ferramenta também pode ser usado na otimização do próprio transporte de produtos florestais, uma vez que, na maioria dos casos, o abastecimento de uma fábrica provém de um número de áreas localizadas a diferentes distâncias e com custos operacionais relativos a elas também diferentes (Machado et al., 2000).

Johnson \& Scheurman (1977) definiram dois tipos básicos de modelos de programação linear que abrangem as diversas abordagens da técnica quando aplicadas ao planejamento florestal. A formulação designada como Modelo I determina que as divisões criadas para estruturação do problema (no caso deste trabalho, chamadas de Unidades de Produção) se mantenham facilmente identificadas durante o processo de planejamento. Portanto, quando uma unidade de produção for parcial ou integralmente submetida a uma prescrição de colheita, esta será facilmente identificável por uma única 
variável do modelo. No Modelo II as variáveis estão associadas com intervenções e, conseqüentemente, para a composição dos diferentes eventos ao longo do horizonte de planejamento, duas ou mais variáveis do modelo são necessárias para definir uma prescrição completa.

Williams (1999) sugere que um dos aspectos mais difíceis no processo de uso e aplicação de modelos de otimização de longo prazo é exatamente o de convencer o público usuário da funcionalidade da ferramenta, principalmente nos casos de planejamento de longo prazo (horizontes superiores a seis anos, na sua concepção), caso particularmente relacionado com produção florestal. No entanto, como também cita o autor, o simples exercício de construir um modelo leva ao importante reconhecimento das relações entre as variáveis, reconhecimento que dificilmente se produziria de qualquer outra forma. Além disto, a confirmação prática de soluções propostas via programação linear tem contribuído para um maior entendimento e aceitação da ferramenta.

\subsection{Mercado de madeira}

A constante busca por desenvolvimento tecnológico na área florestal pode ser simplificada pelo interesse em: 1) atingir custos competitivos e/ou 2) garantir a qualidade de características procuradas para o produto final. A exposição de um empreendimento que faça uso de matéria-prima florestal às volatilidades de um mercado livre de madeira pode fazer com que uma das metas acima - ou ambas - não seja cumprida satisfatoriamente.

Os dados disponíveis sobre madeira de mercado são normalmente relativos ao seu custo posto-fábrica - ou "em pé" - e normalmente expressos por unidade de volume ou peso. $\mathrm{O}$ exercício de calcular o valor líquido presente de uma floresta permite a visualização deste valor por hectare, e é útil que esteja expresso desta forma em função do planejamento contar fundamentalmente com o componente "área" na sua constituição. 
Davis \& Johnson (1987) mencionam que a valoração de florestas, e produtos associados a florestas, pode assumir duas formas gerais:

a) Valor de Mercado, identificado pelo preço pelo qual a madeira, ou a madeira e a área que a contem, poderia ser imediatamente vendido;

b) Valor de Uso, identificado pelo valor descontado de uma série de produtos florestais que poderiam ser produzidos por uma área em um determinado horizonte de tempo.

$\mathrm{O}$ aumento do preço da madeira de mercado tende a provocar incremento nos investimentos industriais de produção de floresta própria (Klemperer, 1996). Esse comportamento caracteriza o interesse em se obter maior controle sobre o desempenho econômico da matéria-prima utilizada no processo, reduzindo a exposição da empresa às volatilidades do mercado.

A base florestal brasileira que supre o mercado consumidor para processos de produção de celulose e de aço (carvão vegetal) é largamente formada por propriedades pertencentes a empresas comprometidas com o próprio abastecimento. Aproximadamente $75 \%$ do total estimado de 2,9 milhões de hectares plantados no país são pertencentes a empresas dos dois ramos (Flynn \& Shield, 1999). A expectativa é de que o consumo futuro de madeira para celulose cresça aproximadamente dentro dos mesmos patamares previstos para o aumento da demanda de celulose, estimado em 5,2\% ao ano (Rodriguez, 2001).

Os cenários futuros de oferta de madeira podem ser os mais variados possíveis pois, de forma simplificada, dependem diretamente de 1) decisões administrativas internas às companhias que plantam florestas de produção, 2) intervenções governamentais, como programas de incentivo, leis que regem o manejo de florestas e ambiental, etc, 3) condições ambientais gerais que interfiram no desenvolvimento de florestas no período e 4) aplicação de novas tecnologias de produção. Além destes itens, a própria valoração da madeira a ser comercializada depende de fatores tais como custos de manufatura, colheita, transporte, elaboração de contratos, problemas legais e trabalhistas, taxas de juros de mercado e equipamentos disponíveis (Davis \& Johnson, 1987). 
Atribuir um "valor" à unidade de madeira de mercado a adquirir pode ser um trabalho penoso. Davis \& Johnson (1987) citam que o valor de mercado é resultado da interação de compradores e vendedores, cada um com suas próprias estimativas de valor do produto. Também, Leuschner (1992) menciona que preços praticados para madeira de mercado por empresas privadas ou proprietários rurais são raramente disponíveis ou de domínio público.

Para a determinação dos valores presentes de mercado de madeira pode-se aplicar a hipótese de apreciação do valor de mercado da madeira comprada pelo método de "vendas comparáveis" (Klemperer, 1996), ou seja, produtos semelhantes provenientes de condições de produção semelhantes tendem a possuir valores (ou preços) semelhantes.

Observa-se, portanto, que o esforço para se determinar tendências no comportamento do preço da madeira oferecida no mercado aberto pode mostrar-se bastante complexo, dada a sua natureza fundamentalmente estocástica. A alternativa é conduzir as análises sob diferentes cenários, um para cada tendência possível. $\mathrm{O}$ tomador de decisões define posteriormente a estratégia que melhor se adequar aos possíveis eventos futuros.

O entendimento do efeito de variações futuras do preço da madeira de mercado sobre regimes de corte e abastecimento de madeira previstos em modelos de planejamento florestal (que consideram esta variável como uma alternativa em casos de auto-suficiência incompleta) ainda não parece ter sido suficientemente explorado. Este trabalho procura dar uma pequena contribuição nesse sentido. 


\section{MATERIAL E MÉTODOS}

\subsection{Fundamentações do estudo}

O estudo trata da análise do abastecimento de uma empresa que não dispõe de auto-suficiência para atender a demanda de 1,6 milhão de $\mathrm{m}^{3}$ de madeira necessários anualmente. Isto significa que há, portanto, a necessidade de adquirir madeira no mercado disponível para cobrir os eventuais "déficits" no suprimento.

$\mathrm{O}$ trabalho procura interpretar a ação de eventuais variações no preço da madeira comprada no mercado aberto sobre o plano de abastecimento de longo prazo da empresa. A estratégia geral do trabalho pode ser representada pelo diagrama na Figura 1:

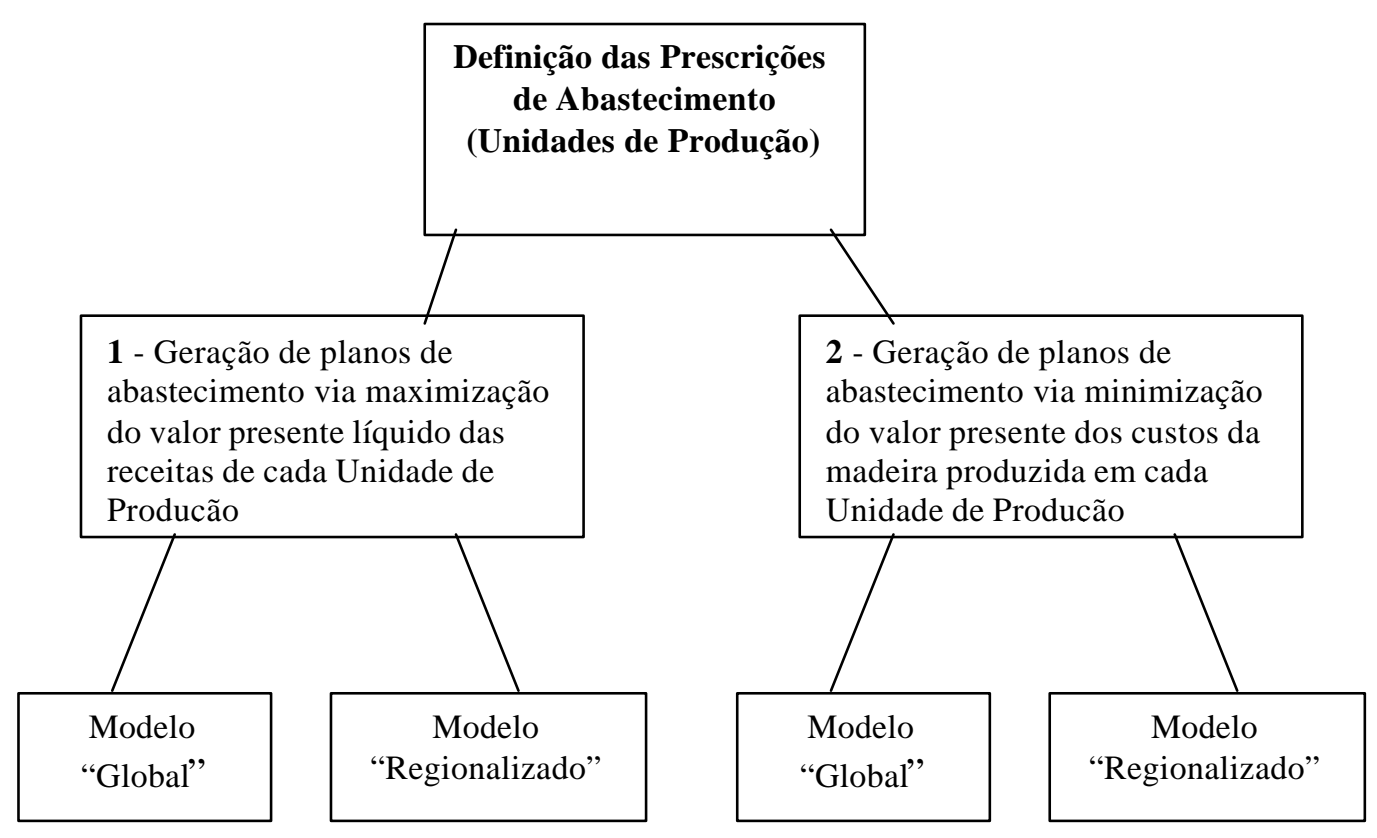

Figura 1- Diagrama geral do trabalho. 
Entendendo "ciclo florestal" como o intervalo de tempo entre o plantio e o corte raso - e esperada reforma - da floresta, o horizonte de planejamento deve abranger pelo menos um ciclo e meio (Clutter et al. 1992) para possibilitar uma interação mais completa entre as ações no tempo. Como, no Brasil, ciclos florestais da cultura do eucalipto normalmente compreendem duas ou mais rotações (Rodrigues, 1997), sendo estas com duração média de sete anos, o horizonte proposto neste trabalho será de 21 anos, "permitindo que o modelo expresse corretamente no futuro o efeito das decisões de curto prazo" (Rodriguez, 1999).

\subsubsection{Critérios gerais de utilização florestal para celulose}

A realidade da produção florestal se expressa por ciclos culturais relativamente longos se comparados à agricultura. Uma das razões determinantes para a necessidade de se manterem estes ciclos é a disponibilização de biomassa suficiente com características apropriadas para o fabrico econômico da celulose, expressada por uma função de consumo específico de volume (ou peso) de madeira por peso (ou volume) de celulose produzida:

$$
C E=\frac{V}{T}
$$

Onde:

$\mathrm{CE}=$ Consumo específico (geralmente $\mathrm{em}^{3}$ ou st / ton.);

$\mathrm{V}=$ Volume de madeira consumida (em $\mathrm{m}^{3}$ ou st);

$\mathrm{T}=$ Peso de celulose produzida (em ton.)

Mais especificamente no caso do eucalipto, esta biomassa propícia à produção de celulose é obtida, geralmente, a partir do sexto ano de instalação da floresta. . Apesar de haver correlação apenas moderada entre idade e a variável Densidade Básica (DB) da madeira (relação entre o peso seco, peso úmido e peso imerso de uma amostra, expressa 
em $\mathrm{kg} / \mathrm{m}^{3}$ ou $\mathrm{g} / \mathrm{cm}^{3}$ ) para espécies de eucalipto em geral (Zobel, 1998), a razão principal (mas não a única) para se observar esta idade mínima ainda reside na DB ser observada na faixa de valores considerados ideais $\left(475\right.$ a $\left.525 \mathrm{~kg} / \mathrm{m}^{3}\right)$ a partir desta idade.

Além da questão da DB ótima, também há a importância de que se respeitem determinadas condições intrínsecas à questão da operacionalidade da colheita e das fases iniciais do processo de transformação fabril. O rendimento de colheita passa a ser afetado negativamente a partir da redução de um volume mínimo por árvore, assim como o próprio custo de transporte, em função dos fatores de empilhamento maiores obtidos pelos menores volumes individuais (aumento da quantidade de "espaços vazios" na carga de toras maciças). Além disto, na maioria dos casos, os diâmetros mínimos que possibilitam a utilização do equipamento de descascamento e picagem na fábrica são atingidos apenas após esta idade.

Controversamente, idades superiores a oito anos da implantação da floresta também apresentariam características tecnológicas médias, como diâmetro máximo (e a própria DB) superiores às ideais. Notadamente, diferentes sítios de produção propiciariam condições de crescimento particulares, não necessariamente determinando que este comportamento, DB correlacionada com idades ideais de colheita variando de 6 a 8 anos, se repita de forma indiscriminada para todas as situações encontradas.

Para efeito de planejamento, no entanto, admitiu-se como premissa neste trabalho que florestas de eucalipto para produção de celulose estejam com sua utilização limitada pelas idades mínima e máxima de 6 e 9 anos respectivamente. Também para efeito de planejamento, haja vista a impossibilidade real de haver florestas plantadas absolutamente equiâneas (em função do próprio intervalo espacial existente em um ano e de programas de plantio normalmente lineares), admitiu-se que os intervalos de idade compreendidos dentro do ano serão tratados como relativos ao ano propriamente dito, como segue:

- Florestas de 6 anos de idade com centro de classe de 6,5 anos (idades compreendidas entre 6,0 e 6,9 anos);

- Florestas de 7 anos de idade com centro de classe de 7,5 anos (idades compreendidas entre 7,0 e 7,9 anos); 
- Florestas de 8 anos de idade com centro de classe de 8,5 anos (idades compreendidas entre 8,0 e 8,9 anos);

Portanto, o planejamento não considerou aptas para utilização florestal quaisquer florestas com idades inferiores a 6,0 anos (postergando seu corte até atingir a "maturidade" técnico-operacional sugerida), procurando também colher a floresta com no máximo 8,9 anos de idade.

\subsection{Formulação do modelo matemático de programação linear (modelo I)}

O planejamento será expresso através da definição de prescrições de manejo para as Unidades de Produção. O modelo tipo I proposto por Johnson \& Scheurman (1977) foi escolhido por facilitar essa expressão. Esse modelo pode ser apresentado da seguinte forma geral (adaptado de Rodriguez 2001):

Maximizar ou Minimizar

$$
V T P=\sum_{i=1}^{N} \sum_{j=1}^{M} D_{i j} X_{i j}
$$

Sujeito a:

Restrições de área:

$$
\sum_{j=1}^{M} X_{i j} \leq A_{i} \quad(i=1,2, \ldots, \mathrm{N})
$$

Restrições de volumes mínimos e máximos:

$$
\begin{array}{ll}
\sum_{i=1}^{N} \sum_{j=1}^{M} V_{i j t o} X_{i j} \geq \text { VMin }_{t o} & (\mathrm{t}=1,2, \ldots \mathrm{T}) \\
\sum_{i=1}^{N} \sum_{j=1}^{M} V_{i j t o} X_{i j} \leq \text { VMax }_{t o} & (\mathrm{o}=1,2, \ldots \mathrm{O})
\end{array}
$$

Restrições de capacidade operacional: 


$$
\begin{array}{ll}
\sum_{i=1}^{N} \sum_{j=1}^{M} \alpha_{i j t} X_{i j} \geq \text { OMin }_{t} & (\mathrm{t}=1,2, \ldots \mathrm{T}) \\
\sum_{i=1}^{N} \sum_{j=1}^{M} \alpha_{i j t} X_{i j} \leq \text { OMax }_{t} & (\mathrm{t}=1,2, \ldots \mathrm{T})
\end{array}
$$

$\alpha_{i j t}=0$ se a prescrição $j$ não recomenda a operação na unidade $i$ no ano $t$

$\alpha_{i j t}=1$ se a prescrição $j$ recomenda a operação na unidade $i$ no ano $t$

Restrições de fluxo de caixa:

$$
\begin{array}{ll}
\sum_{i=1}^{N} \sum_{j=1}^{M} F_{i j t} X_{i j} \geq \text { FMin }_{t} & (\mathrm{t}=1,2, \ldots \mathrm{T}) \\
\sum_{i=1}^{N} \sum_{j=1}^{M} F_{i j t} X_{i j} \leq \text { FMax }_{t} & (\mathrm{t}=1,2, \ldots \mathrm{T})
\end{array}
$$

onde:

VTP = valor total do projeto (resultado da função objetivo)

$\mathrm{N}$ = número de talhões ou unidades de produção (UPs)

$\mathrm{M}=$ número de regimes de manejo (prescrições)

$\mathrm{t}=$ número de anos de planejamento (duração do horizonte de planejamento)

$\mathrm{o}=$ número do produto florestal (output)

$\mathrm{T}=$ número de anos no horizonte de planejamento

$\mathrm{O}=$ número de produtos florestais (outputs)

$\mathrm{A}_{\mathrm{i}}=$ Área total da unidade de produção $i$ (UP)

$\mathrm{X}_{\mathrm{ij}}=$ Área da unidade de produção $i$ (variando até $\mathrm{N}$ unidades) submetida ao regime $j$ (variando até $\mathrm{M}$ diferentes prescrições)

$\mathrm{D}_{\mathrm{ij}}=$ valor da prescrição $j$ por unidade de área se implementada na unidade $i$;

$\mathrm{V}_{\mathrm{ijto}}=$ Volume (output) por unidade de área do produto $o$ no talhão $i$ no ano $t$ obtido com a prescrição $j$ 
$\mathrm{F}_{\mathrm{ijt}}=$ Entrada ou saída no fluxo de caixa do talhão $i$ no ano $t$ com a prescrição $j$

$\mathrm{VMin}_{\mathrm{to}}$ e $\mathrm{VMax}_{\mathrm{to}}=$ Volumes mínimo e máximo permitidos do produto $o$ no ano de planejamento $t$

$\mathrm{OMin}_{\mathrm{t}}$ e $\mathrm{OMax}_{\mathrm{t}}=$ Capacidade operacional máxima e mínima (ex. área de plantio) no ano de planejamento $t$

FMin $_{\mathrm{t}}$ e $\mathrm{FMax}_{\mathrm{t}}=$ Caixa mínimo e máximo disponíveis no ano $t$

Para efeito deste estudo, as restrições serão limitadas a volume necessário anual e área máxima de colheita, que pode ser interpretada como uma restrição operacional. As restrições financeiras, embora mencionadas no modelo geral de programação linear citado acima (modelo I), não serão utilizadas neste trabalho em função de se procurar obter maior flexibilidade na execução dos modelos pela limitação do número de restrições.

\subsection{Unidades de produção (UPs) e dados de produtividade}

O consumo anual médio da fábrica objeto do estudo é de aproximadamente 1.600.000 m3 de madeira com casca por ano. Para suprir esta necessidade de madeira, a empresa dispõe de florestas próprias, que respondem por aproximadamente $75 \%$ desta necessidade, de programas de parceria rural e fomento (onde há apenas o incentivo ao plantio florestal, sem a posse da terra, com compromisso contratual de venda da madeira por ocasião do final da rotação) e de madeira negociada no mercado aberto.

Este trabalho trata de uma simulação de abastecimento proporcionada por três Regiões Florestais (denominadas como RI, RII e RIII) localizados nos municípios de Mogi-Guaçu, Brotas e São Simão (respectivamente), Estado de São Paulo.

Os plantios foram divididos em Unidades de Produção determinadas e agrupadas por similaridades em características físico-químicas dos sítios, por produtividade média

em $\mathrm{m}^{3}$ ha $^{-1}$ e por idade. A caracterização das 155 Unidades de Produção disponíveis e suas respectivas distâncias reais da unidade fabril segue nas tabelas 2 (UPs próprias) e 3 (UPs parcerias rurais e fomento florestal). 
Admitiu-se, também, a manutenção da produtividade por ocasião de uma segunda rotação para a mesma Unidade de Produção, ou seja, no exemplo de um intervalo de doze anos, que compreenderia duas rotações de seis anos dentro de um ciclo, os valores esperados de volume na primeira e segunda rotação foram admitidos como iguais. Muito embora haja escassez de dados que possam confirmar esta premissa, pode-se admitir que, como sendo a manutenção da capacidade produtiva o interesse final da empresa, deva haver a busca e o uso de conhecimento tecnológico para alcança-la.

Nas Tabelas de 2 a 7 estão demonstradas as distribuições das Unidades de Produção, próprias e de terceiros, por Região:

Tabela 2. Unidades de Produção (UPs) da Região I, áreas por UP, distâncias UP/fábrica, idades correntes de cada UP (Setembro 2001) e volumes esperados por UP para 6, 7 e 8 anos de idade.

\begin{tabular}{|c|c|c|c|c|c|c|c|}
\hline \multirow[t]{2}{*}{ HORTO } & \multirow[t]{2}{*}{ UP } & \multirow{2}{*}{$\begin{array}{c}\text { ÁREA } \\
\text { (ha) }\end{array}$} & \multirow{2}{*}{$\begin{array}{c}\text { DISTÂNCIA } \\
(\mathbf{K m})\end{array}$} & \multirow{2}{*}{$\begin{array}{l}\text { IDADEATUAL } \\
\text { (ano) }\end{array}$} & \multicolumn{3}{|c|}{ IMA(m3/ha/ano) } \\
\hline & & & & & 6 & 7 & 8 \\
\hline Mogi-Guaçu & UP1 & 260.00 & 2.00 & 5.14 & 44.42 & 39.68 & 35.84 \\
\hline Mogi-Guaçu & UP2 & 77.00 & 3.00 & 4.24 & 41.55 & 37.23 & 33.68 \\
\hline Mogi-Guaçu & UP3 & 350.00 & 9.00 & 6.30 & 38.76 & 36.73 & 35.07 \\
\hline Mogi-Guaçu & UP4 & 164.59 & 5.67 & 5.09 & 53.62 & 47.63 & 42.81 \\
\hline Mogi-Guaçu & UP5 & 109.20 & 5.29 & 3.03 & 44.00 & 40.46 & 36.00 \\
\hline Mogi-Guaçu & UP6 & 202.51 & 8.67 & 0.03 & 46.79 & 43.30 & 38.53 \\
\hline Mogi-Guaçu & UP7 & 218.45 & 11.79 & 0.06 & 47.00 & 43.30 & 39.00 \\
\hline Mogi-Guaçu & UP8 & 345.61 & 10.03 & 0.67 & 30.53 & 28.25 & 26.18 \\
\hline Mogi-Guaçu & UP9 & 338.02 & 15.09 & 6.05 & 52.77 & 47.91 & 43.77 \\
\hline Mogi-Guaçu & UP10 & 242.34 & 16.11 & 6.06 & 53.60 & 48.29 & 43.87 \\
\hline Mogi-Guaçu & UP11 & 242.40 & 12.19 & 2.57 & 39.61 & 37.93 & 36.54 \\
\hline Sta. Terezinha & UP12 & 339.87 & 28.82 & 1.07 & 42.82 & 39.20 & 35.83 \\
\hline Sta. Tarzana & UP13 & 133.90 & 32.42 & 0.71 & 42.82 & 39.20 & 35.83 \\
\hline Sta. Tarzana & UP14 & 394.60 & 32.76 & 1.26 & 42.82 & 39.20 & 35.83 \\
\hline Sta. Tarzana & UP15 & 625.57 & 36.27 & 5.51 & 44.52 & 40.09 & 36.40 \\
\hline Sta. Tarzana & UP16 & 177.75 & 38.31 & 5.67 & 38.64 & 34.82 & 31.64 \\
\hline Sta. Tarzana & UP17 & 526.09 & 38.55 & 3.04 & 36.70 & 33.55 & 30.83 \\
\hline Sta. Tarzana & UP18 & 418.22 & 42.31 & 3.66 & 35.56 & 32.53 & 29.94 \\
\hline N.S. Aparecida & UP19 & 442.45 & 37.74 & 1.93 & 32.62 & 29.78 & 27.32 \\
\hline N.S. Aparecida & UP20 & 391.76 & 36.39 & 1.74 & 43.49 & 40.00 & 36.71 \\
\hline N.S. Aparecida & UP21 & 260.26 & 38.65 & 4.10 & 38.57 & 34.72 & 31.52 \\
\hline N.S. Aparecida & UP22 & 186.26 & 35.39 & 1.86 & 43.49 & 40.00 & 36.71 \\
\hline N.S. Aparecida & UP23 & 323.54 & 35.60 & 2.04 & 31.17 & 28.31 & 25.87 \\
\hline N.S. Aparecida & UP24 & 412.95 & 33.43 & 2.24 & 32.50 & 29.94 & 27.68 \\
\hline N.S.Aparecida & UP25 & 219.16 & 37.21 & 4.93 & 32.50 & 29.94 & 27.68 \\
\hline
\end{tabular}


Tabela 3. Unidades de Produção (UPs) da Região I, áreas por UP, distâncias UP/fábrica, idades correntes de cada UP (Setembro 2001) e volumes esperados por UP para 6, 7 e 8 anos de idade.

\begin{tabular}{|c|c|c|c|c|c|c|c|}
\hline \multirow[t]{2}{*}{ HORTO } & \multirow[t]{2}{*}{ UP } & \multirow{2}{*}{$\begin{array}{c}\text { ÁREA } \\
\text { (ha) } \\
\end{array}$} & \multirow{2}{*}{$\begin{array}{c}\text { DISTÂNCIA } \\
(\mathbf{K m}) \\
\end{array}$} & \multirow{2}{*}{$\begin{array}{c}\text { IDADEATUAL } \\
\text { (ano) }\end{array}$} & \multicolumn{3}{|c|}{ IMA(m3/ha/ano) } \\
\hline & & & & & 6 & 7 & 8 \\
\hline Gigante & UP26 & 262.76 & 40.66 & 8.58 & 46.44 & 42.17 & 38.55 \\
\hline Gigante & UP27 & 297.77 & 42.27 & 1.40 & 41.99 & 38.60 & 35.39 \\
\hline Gigante & UP28 & 364.99 & 44.86 & 4.40 & 35.07 & 32.12 & 29.55 \\
\hline Areia Branca & UP29 & 563.39 & 61.34 & 2.27 & 37.74 & 36.49 & 35.46 \\
\hline areia branca & UP30 & 578.99 & 59.12 & 3.59 & 33.88 & 30.84 & 28.24 \\
\hline areia branca & UP31 & 310.15 & 55.89 & 3.13 & 27.81 & 26.11 & 24.48 \\
\hline areia branca & UP32 & 448.86 & 57.17 & 3.68 & 30.21 & 27.42 & 25.05 \\
\hline areia branca & UP33 & 664.84 & 60.08 & 1.02 & 45.22 & 42.30 & 39.54 \\
\hline Areia Branca & UP34 & 387.95 & 56.68 & 2.04 & 39.06 & 36.53 & 34.14 \\
\hline São Marcelo & UP35 & 242.73 & 6.30 & 4.64 & 59.40 & 52.75 & 47.40 \\
\hline São Marcelo & UP36 & 200.38 & 5.90 & 4.62 & 55.67 & 49.51 & 44.53 \\
\hline São Marcelo & UP37 & 160.80 & 8.34 & 4.74 & 59.41 & 53.06 & 47.89 \\
\hline São Marcelo & UP38 & 163.42 & 13.21 & 3.04 & 42.88 & 38.53 & 34.93 \\
\hline São Marcelo & UP39 & 127.40 & 13.21 & 1.03 & 41.85 & 37.91 & 34.57 \\
\hline São Marcelo & UP40 & 236.12 & 17.22 & 3.07 & 45.01 & 40.30 & 36.44 \\
\hline Bela Vista & UP41 & 140.09 & 59.40 & 3.47 & 43.89 & 40.00 & 36.39 \\
\hline Bela Vista & UP42 & 379.39 & 36.04 & 0.79 & 43.89 & 40.00 & 36.39 \\
\hline Bela Vista & UP43 & 108.65 & 57.34 & 2.89 & 43.99 & 39.71 & 36.12 \\
\hline Bela Vista & UP44 & 128.21 & 63.16 & 3.03 & 35.68 & 32.23 & 29.33 \\
\hline Ouro Verde & UP45 & 159.30 & 27.36 & 2.86 & 34.44 & 31.35 & 28.70 \\
\hline Ouro Verde & UP46 & 151.95 & 27.86 & 3.01 & 31.68 & 29.00 & 26.66 \\
\hline Ouro Verde & UP47 & 544.83 & 28.80 & 1.12 & 42.05 & 37.95 & 34.52 \\
\hline Cachoeira & UP48 & 118.01 & 42.00 & 3.92 & 48.97 & 43.56 & 39.19 \\
\hline Paineiras & UP49 & 143.17 & 27.67 & 0.08 & 58.48 & 53.00 & 47.99 \\
\hline Paineiras & UP50 & 183.23 & 25.65 & 0.09 & 58.48 & 53.00 & 53.00 \\
\hline Paineiras & UP51 & 133.49 & 26.37 & 0.04 & 58.48 & 53.00 & 53.00 \\
\hline Paineiras & UP52 & 115.47 & 30.08 & 0.09 & 58.48 & 53.00 & 53.00 \\
\hline Paineiras & UP53 & 131.82 & 28.25 & 7.71 & 55.36 & 49.64 & 44.94 \\
\hline N.S.Graças & UP54 & 221.78 & 17.05 & 9.10 & 40.52 & 36.73 & 33.51 \\
\hline N.S.Graças & UP55 & 140.99 & 15.35 & 6.94 & 49.18 & 43.84 & 39.51 \\
\hline
\end{tabular}


Tabela 4. Unidades de Produção (UPs) da Região II, áreas por UP, distâncias UP/fábrica, idades correntes de cada UP (Setembro 2001) e volumes esperados por UP para 6,7 e 8 anos de idade.

\begin{tabular}{|c|c|c|c|c|c|c|c|}
\hline \multirow[t]{2}{*}{ HORTO } & \multirow[t]{2}{*}{ UP } & \multirow{2}{*}{$\begin{array}{c}\text { ÁREA } \\
\text { (ha) }\end{array}$} & \multirow{2}{*}{$\begin{array}{c}\text { DISTÂNCIA } \\
(\mathrm{Km}) \\
\end{array}$} & \multirow{2}{*}{$\begin{array}{c}\text { IDADEATUAL } \\
\text { (ano) }\end{array}$} & \multicolumn{3}{|c|}{ IMA(m3/ha/ano) } \\
\hline & & & & & 6 & 7 & 8 \\
\hline Sta. Fé A & UP56 & 433.41 & 153.30 & 1.17 & 38.34 & 35.20 & 32.25 \\
\hline Sta. Fé A & UP57 & 156.09 & 151.96 & 4.66 & 46.25 & 41.46 & 37.52 \\
\hline Sta. Fé A & UP58 & 462.53 & 160.00 & 6.63 & 34.22 & 31.65 & 29.36 \\
\hline Sta. Fé A & UP59 & 443.95 & 161.94 & 6.93 & 37.83 & 34.17 & 31.10 \\
\hline Sta. Fé A & UP60 & 592.44 & 165.55 & 5.62 & 37.34 & 33.88 & 30.96 \\
\hline Sta. Fé A & UP61 & 202.84 & 163.12 & 5.05 & 34.29 & 31.34 & 28.77 \\
\hline Sta. Fé A & UP62 & 403.41 & 162.90 & 6.13 & 35.42 & 32.12 & 29.33 \\
\hline Sta. Fé A & UP63 & 255.77 & 162.88 & 6.09 & 45.15 & 41.67 & 38.54 \\
\hline Sta. Fé B & UP64 & 368.46 & 168.57 & 4.32 & 31.16 & 29.29 & 27.51 \\
\hline Sta. Fé B & UP65 & 388.32 & 167.26 & 3.41 & 28.59 & 26.67 & 24.87 \\
\hline Sta. Fé B & UP66 & 671.18 & 173.27 & 1.63 & 37.50 & 35.20 & 32.88 \\
\hline Sta. Fé B & UP67 & 354.72 & 172.00 & 2.54 & 24.37 & 23.27 & 22.08 \\
\hline Sta. Fé B & UP68 & 281.79 & 174.33 & 2.61 & 28.45 & 26.65 & 24.92 \\
\hline Sta. Fé B & UP69 & 411.25 & 173.76 & 2.43 & 27.22 & 25.56 & 23.95 \\
\hline Sta. Fé B & UP70 & 516.49 & 171.59 & 3.71 & 27.97 & 25.85 & 23.93 \\
\hline Sta. Fé B & UP71 & 322.35 & 176.18 & 0.17 & 37.50 & 35.20 & 32.88 \\
\hline Sta. Fé B & UP72 & 363.73 & 176.50 & 4.54 & 35.82 & 32.74 & 30.07 \\
\hline Sta. Fé B & UP73 & 794.76 & 177.05 & 0.99 & 37.50 & 35.20 & 32.88 \\
\hline Sta. Fé B & UP74 & 458.72 & 173.31 & 2.27 & 26.13 & 24.46 & 22.86 \\
\hline Sta. Fé C & UP75 & 336.66 & 173.35 & 1.38 & 37.50 & 35.20 & 32.88 \\
\hline Sta. Fé D & UP76 & 194.35 & 182.63 & 0.05 & 37.50 & 35.20 & 32.88 \\
\hline Sta. Fé H & UP77 & 469.58 & 181.08 & 0.78 & 37.50 & 35.20 & 32.88 \\
\hline
\end{tabular}


Tabela 5. Unidades de Produção (UPs) Região III, áreas por UP, distâncias UP/fábrica, idades correntes de cada UP (Setembro 2001) e volumes esperados por UP para 6, 7 e 8 anos de idade.

\begin{tabular}{|c|c|c|c|c|c|c|c|}
\hline \multirow[t]{2}{*}{ HORTO } & \multirow[t]{2}{*}{ UP } & \multirow{2}{*}{$\begin{array}{c}\text { ÁREA } \\
\text { (ha) }\end{array}$} & \multirow{2}{*}{$\begin{array}{c}\text { DISTÂNCIA } \\
(\mathrm{Km}) \\
\end{array}$} & \multirow{2}{*}{$\begin{array}{c}\text { IDADEATUAL } \\
\text { (ano) }\end{array}$} & \multicolumn{3}{|c|}{ IMA(m3/ha/ano) } \\
\hline & & & & & 6 & 7 & 8 \\
\hline Sta. Cristina & UP78 & 183.36 & 120.83 & 2.78 & 34.77 & 33.20 & 31.45 \\
\hline Sta. Cristina & UP79 & 436.50 & 122.61 & 1.70 & 33.20 & 33.20 & 33.20 \\
\hline Sta. Cristina & UP80 & 379.77 & 121.35 & 2.06 & 18.58 & 18.26 & 17.71 \\
\hline Sta. Cristina & UP81 & 187.85 & 123.34 & 2.05 & 30.97 & 29.57 & 28.01 \\
\hline Sta. Cristina & UP82 & 223.49 & 127.19 & 2.09 & 29.27 & 29.27 & 29.27 \\
\hline Sta. Cristina & UP83 & 202.83 & 125.68 & 6.01 & 27.10 & 25.15 & 23.36 \\
\hline Sta. Cristina & UP84 & 278.45 & 128.20 & 1.05 & 34.77 & 33.20 & 31.45 \\
\hline Sta. Cristina & UP85 & 209.37 & 129.98 & 1.01 & 28.73 & 27.21 & 25.66 \\
\hline Gramado & UP86 & 222.28 & 139.68 & 1.02 & 32.77 & 30.30 & 27.93 \\
\hline Gramado & UP87 & 210.99 & 140.25 & 4.59 & 16.27 & 14.79 & 13.52 \\
\hline Gramado & UP88 & 426.31 & 142.52 & 0.05 & 32.77 & 30.30 & 27.93 \\
\hline Gramado & UP89 & 365.33 & 143.87 & 1.52 & 32.77 & 30.30 & 27.93 \\
\hline Gramado & UP90 & 492.62 & 143.46 & 3.65 & 31.35 & 29.10 & 27.03 \\
\hline Gramado & UP91 & 257.50 & 141.08 & 1.01 & 32.77 & 30.30 & 27.93 \\
\hline Gramado & UP92 & 362.70 & 146.23 & 0.03 & 32.77 & 30.30 & 27.93 \\
\hline Gramado & UP93 & 164.15 & 142.36 & 0.02 & 32.77 & 30.30 & 27.93 \\
\hline Gramado & UP94 & 424.33 & 139.62 & 0.04 & 32.77 & 30.30 & 27.93 \\
\hline Gramado & UP95 & 362.73 & 137.33 & 0.05 & 32.77 & 30.30 & 27.93 \\
\hline Gramado & UP96 & 425.08 & 136.96 & 0.09 & 32.77 & 30.30 & 27.93 \\
\hline Gramado & UP97 & 413.60 & 134.36 & 0.86 & 32.77 & 30.30 & 27.93 \\
\hline São Benedito & UP98 & 418.41 & 131.73 & 3.57 & 31.35 & 29.10 & 27.03 \\
\hline São Benedito & UP99 & 532.14 & 134.62 & 3.07 & 41.62 & 38.48 & 35.67 \\
\hline São Benedito & UP100 & 437.74 & 133.89 & 5.60 & 33.02 & 30.50 & 28.24 \\
\hline São Benedito & UP101 & 396.33 & 135.27 & 3.68 & 32.90 & 30.26 & 27.93 \\
\hline São Benedito & UP102 & 510.57 & 137.86 & 3.04 & 34.33 & 32.31 & 30.33 \\
\hline
\end{tabular}


Tabela 6. Unidades de Produção (UPs) de áreas de terceiros (parcerias) na Região I

\begin{tabular}{|c|c|c|c|c|c|c|c|}
\hline \multirow[t]{2}{*}{ PARCERIA } & \multirow[t]{2}{*}{$\mathbf{U P}$} & \multirow{2}{*}{$\begin{array}{c}\text { ÁREA } \\
\text { (ha) }\end{array}$} & \multirow{2}{*}{$\begin{array}{c}\text { DISTÂNCIA } \\
(\mathbf{K m})\end{array}$} & \multirow{2}{*}{$\begin{array}{l}\text { IDADEATUAL } \\
\text { (ano) }\end{array}$} & \multicolumn{3}{|c|}{ IMA(m3/ha/ano) } \\
\hline & & & & & 6 & 7 & 8 \\
\hline 139 & UP103 & 90.55 & 54.00 & 6.12 & 48.40 & 44.00 & 40.48 \\
\hline 570 & UP104 & 211.31 & 185.00 & 3.28 & 27.39 & 24.90 & 22.90 \\
\hline 571 & UP105 & 69.37 & 64.00 & 6.03 & 40.92 & 37.20 & 34.22 \\
\hline 572 & UP106 & 57.17 & 64.00 & 5.70 & 38.68 & 35.16 & 32.35 \\
\hline 573 & UP107 & 195.80 & 26.00 & 4.76 & 38.11 & 34.64 & 31.87 \\
\hline 575 & UP108 & 64.39 & 69.00 & 3.06 & 32.30 & 29.36 & 27.01 \\
\hline 576 & UP109 & 98.99 & 61.00 & 5.22 & 35.54 & 32.31 & 29.72 \\
\hline 590 & UP110 & 129.70 & 37.00 & 5.44 & 39.73 & 36.11 & 33.22 \\
\hline 591 & UP111 & 53.59 & 39.00 & 5.41 & 28.11 & 25.55 & 23.51 \\
\hline 593 & UP112 & 12.54 & 37.00 & 4.17 & 22.99 & 20.90 & 19.23 \\
\hline 594 & UP113 & 121.11 & 37.00 & 4.44 & 24.11 & 21.91 & 20.16 \\
\hline 595 & UP114 & 7.67 & 37.00 & 4.25 & 18.52 & 16.84 & 15.49 \\
\hline 596 & UP115 & 42.27 & 37.00 & 4.35 & 22.93 & 20.84 & 19.18 \\
\hline 597 & UP116 & 8.80 & 34.00 & 4.00 & 22.79 & 20.72 & 19.06 \\
\hline 598 & UP117 & 41.42 & 37.00 & 3.92 & 19.20 & 17.46 & 16.06 \\
\hline 599 & UP118 & 13.80 & 49.00 & 2.53 & 46.20 & 42.00 & 38.64 \\
\hline 600 & UP119 & 58.84 & 37.00 & 4.12 & 23.60 & 21.45 & 19.74 \\
\hline 608 & UP120 & 41.48 & 37.00 & 3.46 & 41.79 & 37.99 & 34.95 \\
\hline 689 & UP121 & 20.78 & 54.00 & 4.33 & 44.00 & 40.00 & 36.80 \\
\hline 690 & UP122 & 31.11 & 50.00 & 2.03 & 44.00 & 40.00 & 36.80 \\
\hline 773 & UP123 & 26.39 & 19.00 & 0.38 & 46.20 & 42.00 & 38.64 \\
\hline 778 & UP124 & $1,003.07$ & 36.00 & 4.57 & 43.90 & 39.91 & 36.71 \\
\hline 806 & UP125 & 46.12 & 7.00 & 4.67 & 45.35 & 41.22 & 37.93 \\
\hline 871 & UP126 & 41.95 & 24.00 & 0.25 & 42.90 & 39.00 & 35.88 \\
\hline
\end{tabular}

Tabela 7. Unidades de Produção (UPs) de áreas de terceiros (parcerias) na Região II

\begin{tabular}{ccccccccc}
\hline \multirow{2}{*}{ PARCERIA } & \multirow{2}{*}{ UP } & $\begin{array}{c}\text { ÁREA } \\
\text { (ha) }\end{array}$ & $\begin{array}{c}\text { DISTÂNCIA } \\
(\mathbf{K m})\end{array}$ & $\begin{array}{c}\text { IDADEATUAL } \\
\text { (ano) }\end{array}$ & $\mathbf{6}$ & $\mathbf{6}$ IMA(m3/ha/ano) \\
\hline 589 & UP127 & 682.30 & 300.00 & 4.28 & 27.86 & 25.33 & 23.31 \\
813 & UP128 & 339.82 & 325.00 & 5.24 & 45.46 & 41.32 & 38.02 \\
\hline
\end{tabular}


Tabela 8. Unidades de Produção (UPs) de áreas de terceiros (fomento) na Região I

\begin{tabular}{|c|c|c|c|c|c|c|c|}
\hline \multirow[t]{2}{*}{ PARCERIA } & \multirow[t]{2}{*}{$\mathbf{U P}$} & \multirow{2}{*}{$\begin{array}{c}\text { ÁREA } \\
\text { (ha) }\end{array}$} & \multirow{2}{*}{$\begin{array}{c}\text { DISTÂNCIA } \\
(\mathbf{K m})\end{array}$} & \multirow{2}{*}{$\begin{array}{l}\text { IDADEATUAL } \\
\text { (ano) }\end{array}$} & \multicolumn{3}{|c|}{ IMA(m3/ha/ano) } \\
\hline & & & & & 6 & 7 & 8 \\
\hline 764 & UP131 & 73.07 & 92 & 7.14 & 46.20 & 42.00 & 38.64 \\
\hline 765 & UP132 & 29.20 & 34 & 6.62 & 46.20 & 42.00 & 38.64 \\
\hline 840 & UP133 & 94.55 & 13 & 3.01 & 41.15 & 37.41 & 34.41 \\
\hline 841 & UP134 & 117.62 & 67 & 2.12 & 34.94 & 31.77 & 29.23 \\
\hline 842 & UP135 & 297.42 & 84 & 2.17 & 38.38 & 34.89 & 32.10 \\
\hline 843 & UP136 & 40.44 & 53 & 3.30 & 40.20 & 36.54 & 33.62 \\
\hline 844 & UP137 & 196.21 & 81 & 2.36 & 37.52 & 34.11 & 31.38 \\
\hline 845 & UP138 & 258.29 & 55 & 6.67 & 38.84 & 35.31 & 32.48 \\
\hline 846 & UP139 & 918.48 & 51 & 3.28 & 33.17 & 30.15 & 27.74 \\
\hline 848 & UP140 & 32.18 & 13 & 2.40 & 46.10 & 41.91 & 38.56 \\
\hline 851 & UP141 & 36.14 & 55 & 2.89 & 39.43 & 35.84 & 32.98 \\
\hline 865 & UP142 & 20.00 & 55 & 1.33 & 36.30 & 33.00 & 30.36 \\
\hline 866 & UP143 & 24.00 & 75 & 0.75 & 42.90 & 39.00 & 35.88 \\
\hline 870 & UP144 & 25.00 & 52 & 1.33 & 36.30 & 33.00 & 30.36 \\
\hline 872 & UP145 & 44.00 & 120 & 7.17 & 42.90 & 39.00 & 35.88 \\
\hline 874 & UP146 & 26.37 & 70 & 6.00 & 63.41 & 57.64 & 53.03 \\
\hline 875 & UP147 & 53.00 & 95 & 5.73 & 42.90 & 39.00 & 35.88 \\
\hline 876 & UP148 & 30.00 & 70 & 5.83 & 42.90 & 39.00 & 35.88 \\
\hline 877 & UP149 & 5.08 & 54 & 2.88 & 38.50 & 35.00 & 32.20 \\
\hline 878 & UP150 & 83.00 & 90 & 4.58 & 42.90 & 39.00 & 35.88 \\
\hline 879 & UP151 & 21.40 & 29 & 2.67 & 42.90 & 39.00 & 35.88 \\
\hline 880 & UP152 & 46.49 & 52 & 3.17 & 40.85 & 37.14 & 34.17 \\
\hline 881 & UP153 & 29.31 & 40 & 2.67 & 42.90 & 39.00 & 35.88 \\
\hline 884 & UP154 & 209.17 & 92 & 2.04 & 42.90 & 39.00 & 35.88 \\
\hline 885 & UP155 & 78.00 & 78 & 4.37 & 42.90 & 39.00 & 35.88 \\
\hline 886 & UP156 & 17.00 & 82 & 1.67 & 42.90 & 39.00 & 35.88 \\
\hline 887 & UP157 & 22.50 & 52 & 0.75 & 42.90 & 39.00 & 35.88 \\
\hline 764 & UP131 & 73.07 & 92 & 7.14 & 46.20 & 42.00 & 38.64 \\
\hline
\end{tabular}

Fonte - Departamento de Planejamento International Paper do Brasil Ltda.:

Para o desenvolvimento do trabalho, assumir-se-á a necessidade de se manterem íntegras as variáveis determinadas por ocasião da aplicação do modelo, ou seja, não haverá a criação de "novas" áreas no processo e consequientemente novas variáveis. Esta proposta foi utilizada por Rodrigues (1997), onde a aplicação do Modelo I de programação linear cobriu as mesmas expectativas. 


\subsection{Definição dos volumes produzidos por prescrição}

As eventuais prognoses de volume foram obtidas por equações desenvolvidas pela companhia. A equação que estima volume por hectare para uma determinada idade futura, baseada no modelo de padrão de Della Bianca, está expressa da seguinte forma:

$$
V o l \_h a=e^{\left(\beta 0+\beta 1(1 / i s)+\beta 2\left(1 / i d_{-} p r o j+\beta 3\left(i d_{-} i n v / i d_{-} p r o j+\ln \left(a_{-} b a s a\right) l+\beta 4\left(1-\left(i d_{-} i n v / i d_{-} p r o j\right)+\beta 5^{*} i s\left(1-i d_{-} i n v / i d_{-} p r o \emptyset\right)\right.\right.\right.\right.}
$$

onde:

- Vol_ha $(\mathrm{m} 3 / \mathrm{ha})=$ Volume produzido por há na idade de projeção;

- $\quad$ is $(\mathrm{m})=$ Índice de Sítio.

- a_basalv $\left(\mathrm{m}^{2} / \mathrm{ha}\right)$ = área basal de árvores vivas por hectare. Equivale à soma das áreas transversais dos fustes da parcela, extrapolada para o hectare.

- id_inv $(\operatorname{anos})=$ idade de inventário.

- id_proj (anos) = idade de projeção.

Estas prognoses são fundamentadas na aplicação das equações em medições anuais das florestas a partir do terceiro ano da implantação, com uma aproximação de 95\% do valor real colhido. Florestas com idades inferiores tiveram volumes prognosticados pelo departamento de Recursos Genéticos Comerciais, fundamentados nos potenciais admitidos para os materiais genéticos anteriormente testados nos sítios específicos para os quais foram indicados e submetidos a intervenções de manejo florestal que garantam a obtenção do volume esperado.

Um exemplo da distribuição anual dos volumes disponíveis para cada prescrição está demonstrada para um horto (área de plantio) na tabela 9. 


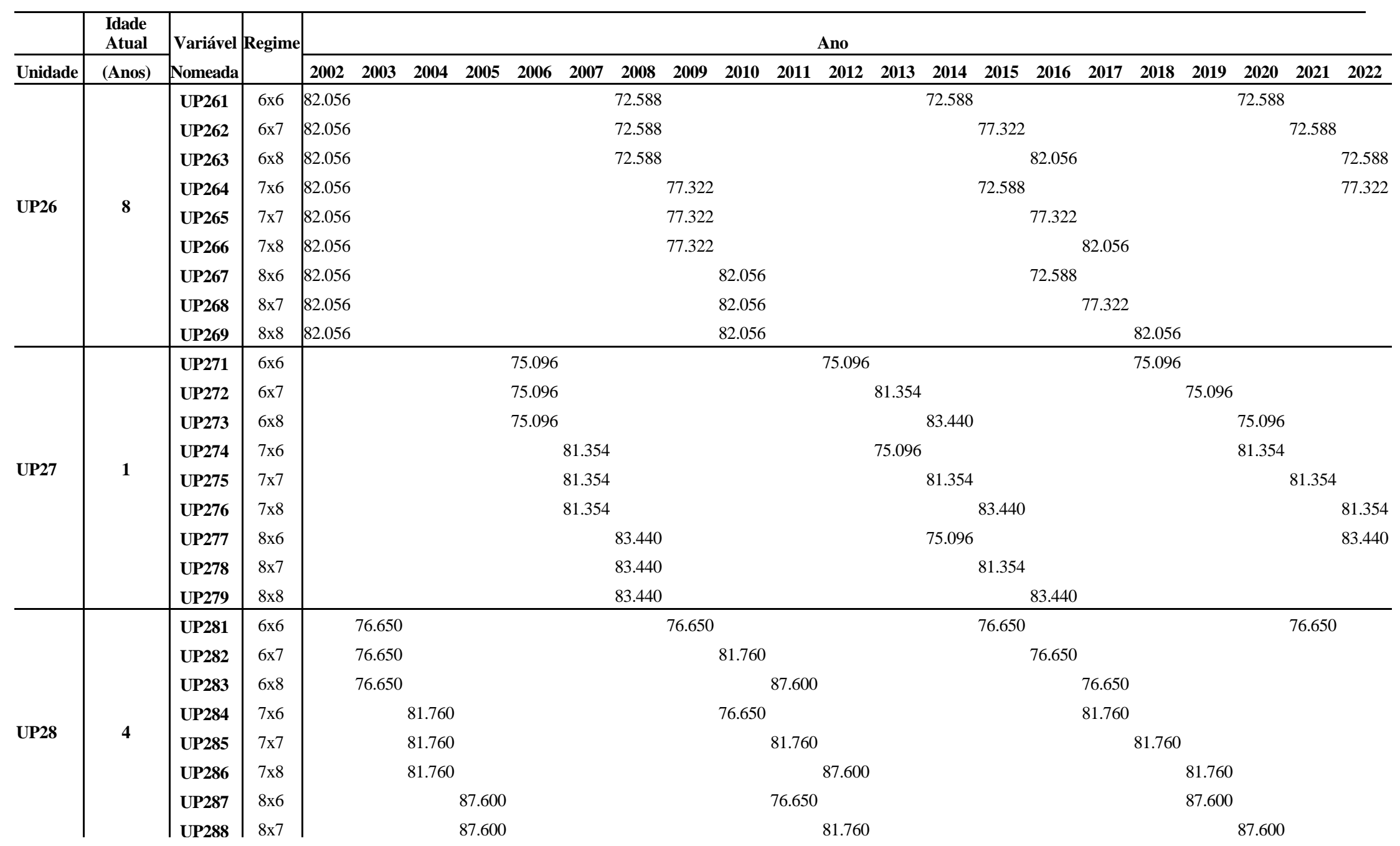




\subsection{Premissas básicas de valoração - Taxa Mínima de Atratividade (TMA) e custos de produção}

O cenário estudado neste trabalho é caracterizado pela necessidade de se adquirir madeira para o processo fabril nos mercados locais disponíveis, pois não há autosuficiência da empresa no abastecimento da matéria-prima. Hoje esta situação configurase como típica no setor florestal, observada por Rodriguez (2001).

Como a demanda de madeira para o processo de produção da fábrica é no mínimo estável ano-a-ano (podendo ser crescente), e a floresta não se encontra ordenada ou está em processo de ordenamento, esta dependência de mercado estará sendo expressa de forma flutuante no tempo, ou seja, haverá anos com maiores e menores participações do mercado no total de madeira demandado.

Algumas premissas importantes deverão ser admitidas para a construção deste trabalho. São elas:

A taxa de juros de $8 \%$ aa será fixada para todos os cálculos de desconto e capitalização usados. Esta é a Taxa Mínima de Atratividade (TMA) atualmente praticada pela empresa em questão. Diversas taxas são utilizadas no meio florestal brasileiro como referência para remuneração do investimento em florestas. Não há consenso nesse tema, no entanto, pode-se afirmar que os valores utilizados estão, em geral, na faixa de 6 a $10 \%$.

Nos modelos de minimização de custo, a madeira produzida pelas áreas pertencentes à empresa será adquirida pelo preço correspondente exatamente ao custo de produção capitalizado - ou seja, auferindo uma teórica "receita líquida zero" no final da rotação. Esta premissa se explica pelo fato da área florestal da empresa ser exclusivamente dedicada a abastecer a fábrica, sem compromisso de produzir resultado financeiro positivo. Considerando que o desconto será de $8 \%$ aa, a Taxa Interna de Retorno de todos os investimentos será artificialmente este valor;

Para cada região administrativa, admitem-se os custos florestais descritos na Tabela 10: 
Tabela 10. Custos anuais por região - Reforma e Condução:

\begin{tabular}{|c|c|c|c|c|c|}
\hline \multicolumn{6}{|c|}{ Região I } \\
\hline \multicolumn{3}{|c|}{ Reforma ( $1^{\text {a }}$ rotação) } & \multicolumn{3}{|c|}{ Condução ( $2^{\mathrm{a}}$ rotação $)$} \\
\hline Ano & Atividade & Custo (R\$/há) & Ano & Atividade & Custo (R\$/ha) \\
\hline 1 & Implantação & $1.847,20$ & 1 & Estabelecimento & $\mathbf{8 3 1 , 8 0}$ \\
\hline 2 & $1^{\mathrm{a}}$ Manutenção & 249,00 & 2 & $1^{\mathrm{a}}$ Manutenção & 309,20 \\
\hline 3 & Manutenção & 118,80 & 3 & Manutenção & 118,80 \\
\hline$\frac{\ldots}{\mathbf{r}}$ & Manutenção & 118,80 & $\frac{\cdots}{\mathbf{r}}$ & Manutenção & 118,80 \\
\hline \multicolumn{6}{|c|}{ Região II } \\
\hline \multicolumn{3}{|c|}{ Reforma $\left(1^{\mathrm{a}}\right.$ rotação $)$} & \multicolumn{3}{|c|}{ Condução ( $2^{\mathrm{a}}$ rotação $)$} \\
\hline Ano & Atividade & Custo (R\$/há) & Ano & Atividade & Custo (R\$/ha) \\
\hline 1 & Implantação & $1.780,40$ & 1 & Estabelecimento & $\mathbf{7 5 8 , 7 0}$ \\
\hline 2 & $1^{\mathrm{a}}$ Manutenção & 193,10 & 2 & $1^{\mathrm{a}}$ Manutenção & 251,80 \\
\hline 3 & Manutenção & $\mathbf{7 3 , 8 0}$ & 3 & Manutenção & $\mathbf{7 3 , 8 0}$ \\
\hline$\ddot{r}$ & Manutenção & 73,80 & $\ddot{r}$ & Manutenção & 73,80 \\
\hline \multicolumn{6}{|c|}{ Região III } \\
\hline \multicolumn{3}{|c|}{ Reforma $\left(1^{\mathrm{a}}\right.$ rotação $)$} & \multicolumn{3}{|c|}{ Condução ( $2^{\mathrm{a}}$ rotação) } \\
\hline Ano & Atividade & Custo (R\$/há) & Ano & Atividade & Custo (R\$/ha) \\
\hline 1 & Implantação & $1.425,50$ & 1 & Estabelecimento & 689,20 \\
\hline 2 & $1^{\mathrm{a}}$ Manutenção & 254,10 & 2 & $1^{\mathrm{a}}$ Manutenção & 325,40 \\
\hline 3 & Manutenção & $\mathbf{9 5 , 9 0}$ & 3 & Manutenção & 95,90 \\
\hline$\ddot{\mathbf{r}}$ & Manutenção & 95,90 & $\ddot{r}$ & Manutencão & 9590 \\
\hline
\end{tabular}

Fonte: Relatório Interno de Custos - International Paper do Brasil, novembro 2001

As atividades anuais posteriores ao segundo ano de implantação possuem valor semelhante por conter processos que se repetem (manutenções anuais), onde $r=$ ano previsto para encerrar a rotação

De maneira geral, o custo de colheita tem relação direta com o espaçamento e com o volume individual da árvore. Supondo para este trabalho um espaçamento fixo de $9 \mathrm{~m}^{2} /$ árvore para todas as UPs, isola-se esta variável e o custo de colheita passa a ser diretamente correlacionado com o volume individual. Como os custos de colheita são normalmente estimados para o talhão como unidade mínima de referência (em geral, um talhão $=40 \mathrm{ha})$, o agrupamento dos volumes individuais por classes possibilita uma identificação dos limites médios para os quais o custo se altera. A base para 
determinação dos custos de colheita por classe de volume individual está expressa na Tabela 11 .

Tabela 11. Custos de colheita por classes de volume individual.

\begin{tabular}{cc}
\hline Classes de Volume Individual $\left(\boldsymbol{m}^{3}\right)$ & Custo da Colheita $\left(\mathbf{R} \$ / \mathbf{m}^{3}\right)$ \\
\hline$\leq 0,12$ & $\mathbf{8 , 2}$ \\
0,12 a 0,19 & $\mathbf{6 , 0}$ \\
$\geq 0,19$ & $\mathbf{5 , 4}$ \\
\hline
\end{tabular}

Fonte - Departamento de Planejamento Florestal IP do Brasil.

É importante considerar que há variáveis qualitativas na madeira que podem expressar sua variação em alterações nos custos de transporte e colheita, como nos casos de forma (tortuosidade, bifurcações) e peso (resultado de diferentes densidades básicas e teores de umidade). No caso deste trabalho considera-se como premissa a homogeneidade qualitativa das florestas próprias e da madeira comprada. Esse artifício permite, associado ao fato de que a madeira na região é negociada e transportada em unidades de volume, relacionar custos de colheita e transporte com volume individual. Esta premissa é útil na diferenciação dos custos operacionais entre Unidades de Produção mais e menos produtivas.

Partindo da premissa que o número de árvores por hectare é, portanto, semelhante para todas as Unidades e que a densidade de plantio não afetaria o custo de colheita, a determinação dos custos de colheita será efetuada pela comparação do resultado de volume individual calculado por UP e os valores da tabela 4.

O cálculo do volume individual poderá ser feito por intermédio da seguinte fórmula:

$$
\operatorname{Vind}_{i}=\frac{V_{i}}{w}
$$

onde: 
$\operatorname{Vind}_{\mathrm{i}}\left(\mathrm{m}^{3}\right)=$ Volume individual médio para Unidade de Produção $i$;

$\mathrm{w}$ = número de árvores por hectare (neste caso, uma constante equivalente a 1.000 - ou 90\% da lotação original de 1.111 plantas por hectare - fonte: Depto de Planejamento Florestal , International Paper do Brasil Ltda.)

Como mencionado anteriormente, o custo de transporte pode ser expresso como uma função do volume individual. No caso específico do estudo, considerando um espaçamento idêntico para todos os plantios, a variação do custo de transporte se dará pela variação do volume médio individual (e pelo fator de empilhamento relativo a este) e pela distância da Unidade de Produção à fábrica. O fator de empilhamento é um coeficiente que determina o quanto há de "espaços vazios" na carga de madeira roliça a ser transportada, pela relação entre as unidades "metro cúbico sólido" e metro cúbico “empilhado" (também expresso em "estéreos”) de uma mesma amostra. Por exemplo, um fator de empilhamento de 1,48 determina que são necessários 1,48 metros cúbicos de madeira "empilhada" como toras roliças para se obter 1,00 metro cúbico sólido da mesma madeira. Na prática diâmetros menores transportados determinam um fator de empilhamento maior por permitirem uma maior quantidade de espaços vazios na carga. Portanto o aumento do custo de transporte é diretamente proporcional ao aumento do fator de empilhamento. Esta relação é expressa na Tabela 12.

Tabela 12. Custos de transporte por classe individual de volume por $\mathrm{km}$ (em $\left.\mathrm{R} \$ / \mathrm{m}^{3} * \mathrm{~km}\right)$.

\begin{tabular}{|c|c|c|}
\hline Volume Individual $\left(\mathrm{m}^{3}\right)$ & Fator de Empilhamento & Custo de Transporte $\left(\mathrm{R} \$ / \mathrm{m}^{3} * \mathrm{~km}\right)$ \\
\hline$<0,08$ & 1,85 & $\mathbf{0 , 0 8 0}$ \\
\hline 0,08 a 0,10 & 1,72 & 0,075 \\
\hline 0,11 a 0,13 & 1,63 & 0,071 \\
\hline 0,14 a 0,16 & 1,58 & 0,069 \\
\hline 0,17 a 0,19 & 1,55 & 0,067 \\
\hline 0,20 a 0,22 & 1,52 & 0,066 \\
\hline 0,23 a 0,25 & 1,51 & 0,065 \\
\hline 0,26 a 0,27 & 1,50 & 0,065 \\
\hline 0,28 a 0,29 & 1,49 & 0,065 \\
\hline$>0,29$ & 1,48 & 0,064 \\
\hline
\end{tabular}

Fonte - Departamento de Planejamento Florestal IP do Brasil. 
O custo de transporte por Unidade de Produção poderá ser calculado, portanto, pela seguinte expressão:

$$
\text { Ctran }_{t i}=\quad \text { Ctran }^{\prime *} \text { Dist }^{\prime}{ }_{i}
$$

onde:

$\operatorname{Ctran}_{\mathrm{ti}}\left(\mathrm{R} \$ / \mathrm{m}^{3}\right)=$ Custo de transporte da Unidade de Produção $i$ no ano $t$;

Ctran' $\left(\mathrm{R} \$ / \mathrm{m}^{3} * \mathrm{~km}\right)=$ Custo de transporte definido a partir da tabela 5 e de acordo com o volume individual médio da Unidade de Produção $i$;

Dist $_{i}^{\prime}(\mathrm{km})=$ Distância da Unidade de Produção $i$ à fábrica

\subsubsection{Determinação do valor da madeira de mercado}

A madeira de mercado é oferecida e negociada normalmente por unidade de peso ou volume. Não há como estimar um "valor" presente líquido de receitas para um produtor rural terceirizado sem conhecer condições necessárias ao cálculo, como produtividade, área plantada, custos de produção, etc. Portanto, para uniformização de conceitos, preço e custo de madeira de mercado serão tratados por uma mesma variável, a ser denominada "ValMM" (de "Valor de Madeira de Mercado"). Essa interpretação é possível uma vez que o "preço" da madeira de mercado é representado automaticamente como um "custo" de produção da fábrica.

A variável ValMM na unidade $\mathrm{R} \$ \mathrm{~m}^{3}$ pode ser perfeitamente utilizada nas funções objetivo de minimização dos valores presentes de custo e maximização dos valores presentes de receita uma vez que multiplicada pelo volume a ser adquirido resulta em unidades monetárias somente. Isto ocorre porque, por exemplo, na função objetivo de minimização de custo, esse é expresso em $\mathrm{R} \$ /$ ha multiplicado à área em hectares, resultando em um valor final monetário diretamente comparável ao produzido por ValMM. O mesmo se repete analogamente nas funções de maximização do valor presente líquido.

A base para determinação da variável "ValMM" estão descritas no item a seguir. 


\subsubsection{Critérios para variar cenários de custos/preços da madeira de mercado}

A avaliação do impacto de variações nos valores de madeira de mercado será pela interpretação dos outputs gerados para cada valor real de madeira de mercado sugerido (presente nas funções objetivo) e a comparação entre eles. $\mathrm{O}$ valor da madeira de mercado passa a ser entendido simplesmente como o preço a ser pago pelo volume comprado ou um custo de apropriação de matéria-prima fabril, diretamente comparável com os valores de custo posto-fábrica obtidos para cada uma das UPs. Este valor será variado artificialmente, dentro da seguinte lógica:

O "valor-semente" para ValMM (ou o valor-base sobre o qual as variações de custo para o modelo serão determinadas) será equivalente ao valor médio praticado no mercado de madeira respectivo à região leste do estado de São Paulo em 2001 (R \$36,80 $\mathrm{m}^{-3}$ posto fábrica - fonte: Departamento de Planejamento Florestal, International Paper do Brasil Ltda.);

O valor-semente será incrementado usando como base a variação média do valor da madeira de mercado nos últimos sete anos corrigido pela inflação .A Tabela 13 mostra os dados referentes à inflação no período:

Tabela 13. Variação da inflação medida pelo IGP-M anual, de 1995 a 2001

\begin{tabular}{cc}
\hline Ano & Inflação (\%) \\
\hline 1995 & 15,24 \\
1996 & 9,19 \\
1997 & 7,74 \\
1998 & 1,79 \\
1999 & 20,1 \\
2000 & 9,95 \\
2001 & 10,58 \\
\hline
\end{tabular}

Fonte: Fundação Getúlio Vargas 
Optou-se pelos dados de 1995 a 2001 em função deste intervalo cobrir um período de razoável estabilidade financeira do país e coincidir com a criação e manutenção de uma mesma moeda.

Usando a tabela 13 como referência, e dados nominais obtidos da empresa, obtém-se a variação do valor real da madeira de mercado no intervalo de sete anos, como demonstrado na tabela 14.

Tabela 14. Variação do preço da madeira de mercado para a região leste do Estado de São Paulo de 1995 a 2001, corrigido pela inflação no período.

\begin{tabular}{cc}
\hline Ano & $\begin{array}{c}\text { Preço da Madeira de Mercado } \\
\left(\mathbf{R} \$ \mathbf{m}^{\mathbf{3}}\right)\end{array}$ \\
\hline 1995 & 44,43 \\
1996 & 42,05 \\
1997 & 35,81 \\
1998 & 32,72 \\
1999 & 36,26 \\
2000 & 37,33 \\
2001 & 36,80 \\
\hline
\end{tabular}

Fonte: Departamento de Colheita Florestal, International Paper do Brasil Ltda.

Considerando os dados anteriores, a variação média do valor real (custo/preço) da madeira de mercado para o período na região foi de - 17,2\%. Portanto, pode-se admitir, para efeito da modelagem, que variações próximas a esse valor expressariam algumas possibilidades de cenários reais.

Partindo desta interpretação, admite-se para o trabalho os 5 diferentes cenários, elaborados como na Tabela 15: 
Tabela 15. Variação do valor real da madeira de mercado sobre o valor-semente para uso nos modelos (ValMM)

\begin{tabular}{lc}
\hline Variação para ValMM & Valor $\left(\mathbf{R} \$ / \mathbf{m}^{3}\right)$ \\
\hline Valor-semente $-20 \%$ & $\mathbf{3 0 , 6 7}$ \\
Valor-semente $-10 \%$ & $\mathbf{3 3 , 4 5}$ \\
Valor-semente & $\mathbf{3 6 , 8 0}$ \\
Valor-semente + $10 \%$ & $\mathbf{4 0 , 8 0}$ \\
Valor-semente + 20\% & $\mathbf{4 4 , 1 6}$ \\
\hline
\end{tabular}

As variações (incrementos e reduções) no valor-presente sugerem valores reais a serem praticados pelo mercado para o período de 21 anos do horizonte de planejamento. Como os mais variados cenários poderiam ser propostos, a opção por 5 valores que cobrissem expectativas tanto de redução como de incremento procuram proporcionar uma gama interessante de possibilidades exploráveis na análise final e ao mesmo tempo limitar o desenvolvimento do trabalho a um tamanho razoável.

O valor da madeira de mercado, para uso nas funções objetivo, poderá ser obtido pela seguinte expressão:

$$
\operatorname{ValMM}_{t}=\frac{V S}{(1+i)^{t}}
$$

onde:

$\operatorname{ValMM}_{\mathrm{t}}\left(\mathrm{R} \$ / \mathrm{m}^{3}\right)=$ Valor da madeira de mercado no ano $t$ (para $\left.\mathrm{t}=0,1, \ldots, 20\right)$

VS $\left(\mathrm{R} \$ / \mathrm{m}^{3}\right)=$ Valor Semente e as suas variações como propostas na tabela 10 $i=$ taxa de juros $(8 \%$ aa)

Os outputs dos modelos para cada variação do valor de madeira de mercado serão analisados no capítulo Resultados e Discussão. 


\subsubsection{Critérios de valoração dos regimes de manejo - modelos de maximização do valor presente líquido das receitas}

As prescrições diferem umas das outras, principalmente, em termos dos momentos em que se definem a colheita e o replantio (ou a condução da brotação). Esses sistemas silviculturais de talhadia simples resultam em prescrições que apresentam resultados financeiros diferentes entre si. Assim, algumas prescrições, do ponto de vista exclusivamente econômico, podem parecer mais desejáveis que outras.

São dois os critérios usados para definir o valor da função objetivo usados neste trabalho: (i) valor presente total líquido e (ii) valor presente total dos custos. Em ambos os casos o valor presente total se refere ao resultado de se multiplicar a área manejada de acordo com uma determinada prescrição pelo valor presente por hectare dessa prescrição. Esse valor presente total na função objetivo guia o processo de otimização.

A função objetivo dos modelos usados neste trabalho, baseada em critérios de valoração presente, enfatiza a seleção de prescrições com melhor desempenho em termos econômicos. As restrições de área, de produção e operacionais se encarregam de adequar a ênfase econômica à realidade da produção florestal. Pode-se afirmar, portanto, que os diferentes desempenhos econômicos das prescrições são a base do critério de seleção destes regimes de manejo. E que, obedecidas as restrições impostas, serão escolhidas as prescrições que mais contribuírem para a otimização do resultado econômico do empreendimento florestal (Rodriguez, 1989).

\subsubsection{Critério de cálculo do valor presente líquido das receitas}

O cálculo dos coeficientes da função objetivo baseado no conceito de valor

presente líquido segue as recomendações sugeridas por Rodriguez (1989). Cada prescrição de manejo florestal pode ser representada como um fluxo de caixa que, para um determinado horizonte de tempo, expressa a seqüência de receitas brutas obtidas com as colheitas de madeira e a seqüência de custos de implantação, de condução de brotação, de manutenção, de colheita e de transporte. $\mathrm{O}$ valor presente líquido desse 
fluxo de caixa é usado neste trabalho como indicador do desempenho econômico das prescrições do manejo florestal.

Podemos representar o fluxo de caixa de um ciclo de duas rotações da seguinte forma:

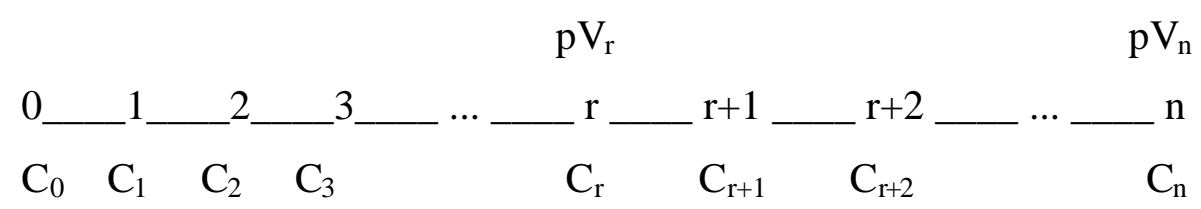

onde:

$\mathrm{C}_{\mathrm{t}}(\mathrm{R} \$ / \mathrm{ha})=$ Custo total das atividades florestais na UP no ano $t$ (variando de 0 a $\left.n\right)$;

$\mathrm{V}_{\mathrm{t}}\left(\mathrm{m}^{3} / \mathrm{ha}\right)=$ Volume total produzido pela UP no ano $t$ (variando de 0 a $r$ a $n$ );

$r=$ ano em que ocorre o primeiro corte da UP;

$\mathrm{n}=$ ano em que ocorre o corte final da UP;

$\mathrm{p}\left(\mathrm{R} \$ / \mathrm{m}^{3}\right)=$ valor a ser pago pela unidade de volume colhida.

O custo presente total posto-fábrica (CP) das atividades florestais da Unidade de Produção $i$ sob a prescrição $j\left(\mathrm{C}_{\mathrm{ij}}\right)$ pode ser calculado pela expressão:

$$
C P_{i j}=\frac{C I_{i j t}}{\left(1+i^{t}\right)}+\frac{C M_{i j t}}{\left(1+i^{t}\right)}+\frac{\left(C c o l_{i j t}+C t r a n_{i j t}\right) V_{i j t}}{(1+i)^{t}}
$$

onde:

$\mathrm{CI}_{\mathrm{ijt}}(\mathrm{R} \$ / \mathrm{ha})=$ Custo total de Implantação da UP $i$ sob a prescrição $j$ no ano $t$ (neste caso, no primeiro ano);

$\mathrm{CM}_{\mathrm{ijt}}(\mathrm{R} \$ / \mathrm{ha})=$ Custo total de Manutenção da UP $i$ sob a prescrição $j$ no ano $t$ (considerando as operações pós-corte da primeira rotação também como manutenção); $\mathrm{Ccol}_{\mathrm{ijt}}\left(\mathrm{R} \$ / \mathrm{m}^{3}\right)=$ custo de colheita da Unidade de Produção $i$ submetida è prescrição $j$ no ano $t$; 
Ctran $n_{\mathrm{ijt}}\left(\mathrm{R} \$ / \mathrm{m}^{3}\right)=$ custo de transporte da Unidade de Produção $i$ submetida è prescrição $j$ no ano $t$

Vijt $\left(\mathrm{m}^{3} / \mathrm{ha}\right)=$ Volume total produzido pela UP $i$ no ano $j$;

Para que o valor presente líquido possa ser usado como critério de comparação entre as prescrições é necessário resolver a questão temporal. Cada prescrição resulta em fluxos de caixa com diferentes períodos de duração se considerado o momento em que o ciclo florestal definido pela prescrição se encerra. Para que esta questão seja resolvida, Rodriguez (1989) sugere a utilização de fluxos de caixa constituídos por dois períodos básicos: (i) o período inicial compreende o horizonte de planejamento do estudo, dentro do qual são consideradas as intervenções definidas pela prescrição e, (ii) um período final resultante da repetição infinita do ciclo economicamente ótimo da unidade de manejo para o qual se prescreve o regime de manejo sendo avaliado.

Essa metodologia de cálculo torna infinitos os horizontes dos fluxos de caixa, uniformizando-os e resolvendo o problema da questão temporal. Agora, com os valores comparáveis obtidos para cada prescrição, é possível hierarquizar os regimes de manejo colocando aquele de mais alto valor como o primeiro classificado em termos de desempenho econômico. Entretanto, apesar de economicamente ótimo, esse regime nem sempre pode ser implementado, pois pode não recomendar a colheita da madeira em anos de real necessidade de produção. Daí a importância das restrições que tratam da imposição de níveis adequados de produção e que são apresentadas mais adiante.

A explicitação do método de cálculo do valor presente líquido do regime de manejo envolve (i) a composição do fluxo de caixa durante o período inicial que toma como referência o horizonte de planejamento do estudo e que se encerra com o término do ciclo sendo avaliado e (ii) a seleção do ciclo economicamente ótimo, que se repetirá em perpetuidade imediatamente após o encerramento do período inicial.

$\mathrm{O}$ ciclo economicamente ótimo de cada unidade florestal deve ser inicialmente determinado. Sua definição é feita com base na fórmula de Faustmann (1849), também conhecida como a fórmula financeira de cálculo do Valor Esperado da Terra - VET. 
Estabelecidas idades mínimas e máximas de colheita e consideradas todas as combinações possíveis de duração de cada conjunto de uma, duas ou mais rotações, é grande o número de ciclos alternativos que poderiam ser prescritos para o manejo dos plantios de eucalipto da empresa. Por exemplo, se forem considerados apenas ciclos de duas rotações e três diferentes idades de corte, seriam nove as alternativas de manejo possíveis, cada uma com um VET diferente. O ciclo economicamente ótimo será definido como aquele de mais alto VET.

Conforme ressaltado por Rodriguez (1989), o VET pode ser interpretado como o valor presente de uma séria perpétua de fluxos de caixa idênticos e representativos do ciclo sob análise. Considerando-se um determinado ciclo completo, isto é, todas as operações florestais compreendidas entre o plantio inicial e a última colheita antes de um plantio, chega-se ao VET pelo seguinte roteiro:

Cálculo da Receita Líquida Futura produzida (variáveis descritas no fluxo de caixa anterior):

$$
R L T_{i j n}=p V_{i j r}(1+i)^{n-r}+p V_{i j n}-\sum_{i=1}^{n} C_{i j}(1+i)^{t}
$$

onde:

$\operatorname{RLT}_{\mathrm{ijn}}(\mathrm{R} \$ / \mathrm{ha})=$ Receita líquida futura (no ano $\left.n\right)$ da UP $i$ submetida à prescrição $j$

$\mathrm{V}_{\mathrm{ijt}}(\mathrm{m} 3 / \mathrm{ha})=$ Volume produzido pela colheita da UP $i$ submetida à prescrição $j$ no ano $t$ (com $t$ variando de $r$ a $n$ )

$\mathrm{C}_{\mathrm{ij}}(\mathrm{R} \$ / \mathrm{ha})=$ Custo total da UP $i$ submetida à prescrição $j$

$\mathrm{p}\left(\mathrm{R} \$ / \mathrm{m}^{3}\right)=$ valor a ser pago pela unidade de volume colhida*

$\mathrm{i}=$ taxa de juros (taxa de remuneração do capital)

* valor base será igual ao custo médio real da madeira própria posto-fábrica em 2001 (R \$ $\left.33,81 \mathrm{~m}^{-3}\right)$. 
Para cálculo do VET, pode ser usado a fórmula de cálculo de valor presente para uma série perpétua de contribuições periódicos, admitindo RLT $_{\text {ijn }}$ como essa contribuição, da seguinte forma:

$$
V E T_{i j}=\frac{R L T_{i j n}}{\left((1+i)^{n}-1\right)}
$$

onde:

$\operatorname{VET}_{\mathrm{ij}}(\mathrm{R} \$ / \mathrm{ha})=$ Valor Esperado da Terra para a UP $i$ submetida à prescrição $j$

Observação: Para uso nas equações futuras, o VET de maior valor será designado VET'.

Definido o ciclo economicamente ótimo, e o seu respectivo VET, é possível então efetuar o cálculo do valor presente líquido de cada regime de manejo. Esse valor presente, como já mencionado, expressa o desempenho financeiro dos eventos programados para duas etapas seguidas. A primeira etapa considera os eventos ocorridos durante o horizonte de planejamento. A segunda etapa se refere à sequiência infinita de repetições do ciclo economicamente ótimo. Dessa forma, o valor presente de cada regime pode ser calculado somando-se o valor do VET do ciclo economicamente ótimo à receita líquida existente no último ano da primeira etapa deste regime.

\subsubsection{Determinação do ciclo economicamente ótimo}

Para desenvolvimento dos modelos de maximização do valor presente líquido das receitas, e como observado por Rodriguez (1989), o ciclo economicamente ótimo de corte para cada Unidade de Produção deve ser inicialmente estimado. A lógica reside em determinar qual seria a alternativa de melhor desempenho econômico para cada uma das UPs independentemente de sua inter-relação com as demais alternativas, de forma a se obter um valor que corresponderia ao uso da UP além dos limites estabelecidos pelo horizonte de planejamento e em perpetuidade. 
Como a experiência da empresa recomenda o uso de ciclos de corte com duas rotações (reforma e condução), haverá um ciclo economicamente ótimo dentro do universo criado, portanto, de nove alternativas para cada UP. A forma de se determinar o ciclo economicamente ótimo será, como já mencionado, pela adoção do VET (Valor Esperado da Terra), amplamente utilizado e reconhecido como uma ferramenta prática de cálculo.

\subsubsection{Cálculo do valor presente líquido das receitas de cada prescrição}

O maior valor obtido no cálculo dos VETs de cada UP será considerado o seu VET ótimo (VET') e será adicionado ao valor da receita obtida pelo último ciclo/rotação previsto pelo regime, de acordo com o seguinte raciocínio:

1. Se o horizonte de planejamento permite a repetição de mais um ciclo completo dentro dos seus limites, adiciona-se o valor de mais este ciclo e o valor do VET ótimo à receita final obtida;

2. Se o horizonte de planejamento não permite a repetição do ciclo completo, ou mesmo de uma rotação completa, soma-se à receita obtida no último corte, o valor obtido no VET ótimo;

3. Se coincidirem o período do horizonte e o final de um ciclo completo, simplesmente adiciona-se o valor de VET ótimo à receita líquida obtida.

O cálculo do Valor Presente Líquido em $\mathrm{R} \$ /$ ha pode, portanto, ser determinado pela expressão geral:

$$
V P L_{i j}=\sum_{i=0}^{n^{\prime}}\left(\frac{p V_{i j t}-C_{i j t}}{(1+i)^{t}}\right)+\frac{V E T^{\prime}}{(1+i)^{n^{\prime}}}
$$

onde:

$\mathrm{VPL}_{\mathrm{ij}}=$ Valor presente líquido das receitas da UP $i$ submetida à prescrição $j$ n' = ano em que ocorre o último corte do regime $\mathrm{j}$

\subsection{Modelo de maximização do valor presente líquido das receitas}


Para a maximização do Valor Presente Líquido de cada Unidade de Produção, a função objetivo do modelo "Global” será descrita da seguinte forma:

$$
\operatorname{MaxZ}=\sum_{i=1}^{N} \sum_{j=1}^{M} V P L_{i j} X_{i j}-\sum_{t=1}^{21} \operatorname{ValMM}_{t} \boldsymbol{\delta}_{t}
$$

onde:

VPLij $(\mathrm{R} \$ /$ ha $)=$ Valor presente da Unidade de Produção $i$ submetida ao regime $j$;

$\mathrm{Xij}(\mathrm{ha})=$ Área da Unidade de Produção $i$ submetida ao regime $j$;

$\operatorname{ValMM}_{\mathrm{t}}\left(\mathrm{R} \$ / \mathrm{m}^{3}\right)=$ Valor da madeira de mercado no ano $t$;

$\delta_{\mathrm{t}}\left(\mathrm{m}^{3}\right)$ - Volume a ser adquirido da madeira de mercado no ano $t$;

$\mathrm{M}=$ Número de regimes de manejo;

$\mathrm{N}$ = Número de Unidades de Produção;

Para maximização do Valor Presente Líquido de cada Unidade de Produção, a função objetivo do modelo "egionalizado" será descrita da seguinte forma:

$$
\operatorname{MaxZ}=\sum_{i=1}^{N} \sum_{j=1}^{M} V P L_{i j} X_{i j}-\sum_{t=1}^{21} \operatorname{ValMM}_{t} \boldsymbol{\delta}_{t 1}-\sum_{t=1}^{21} \operatorname{ValMM}_{t} \boldsymbol{\delta}_{t 2}-\sum_{t=1}^{21} \operatorname{ValMM}_{t} \boldsymbol{\delta}_{t 3}
$$

$\delta_{\text {th }}\left(\mathrm{m}^{3}\right)$ - Volume a ser adquirido de madeira de mercado no ano $t$ para cobrir a região $h$ $($ para $h=1,2,3)$;

Como o objetivo maior é maximizar o valor da floresta própria plantada, as áreas correspondentes à madeira comprada no mercado ano-a-ano deverão concorrer com este valor no processo de cálculo, pois são alternativas contrárias a investir em floresta própria. Portanto, quanto maior for a necessidade de se adquirir madeira de mercado para cumprir as obrigações de abastecimento, menor será o valor alcançado pela função objetivo, impactando diretamente o valor global do empreendimento florestal.

Para a alternativa de planejamento "Global", todas as Unidades de Produção participarão como alternativas, indiscriminadamente. Na opção "Regionalizada", as 
Unidades de Produção serão divididas por regiões e o modelo será utilizado separadamente considerando apenas as alternativas referentes às regiões respectivas (tabelas 2 e 3).

Esta(s) funções serão submetidas às seguintes restrições:

1 - Para garantir que o limite de área de cada UP não seja violado, a seguinte restrição faz-se necessária:

$$
\sum_{j=1}^{M} X_{i j} \leq A_{i}
$$

onde:

$\mathrm{A}_{\mathrm{i}}=$ Área total da Unidade de Produção i

Esta restrição garante que a soma das áreas de todas as frações determinadas para uma Unidade de Produção não ultrapasse o total da área disponível para esta unidade. Para a geração das alternativas "Global" e "Regionalizada" usa-se exatamente a mesma restrição.

2 - O modelo deve obedecer a uma necessidade anual de produção (1,6 milhão de $\left.\mathrm{m}^{3}\right)$ dada pelo compromisso de se abastecer a fábrica e buscar a regulação da floresta. Para tanto, desenvolve-se a seguinte expressão para o modelo "Global":

$$
\sum_{i=1}^{N} \sum_{j=1}^{M} X_{i j} V_{i j t}+\delta_{t} \geq 1.600 .000
$$

adicionando-se a expressão de ordenamento:

$$
\delta_{t}-\delta_{t-1} \leq 0 \quad(\mathrm{t}=2,3 \ldots, 21)
$$

onde:

$\mathrm{V}_{\mathrm{ijt}}\left(\mathrm{m}^{3} / \mathrm{ha}\right)=$ Volume obtido no ano $t$ (variando de 1 a 21 ) caso a Unidade de Produção $i$ seja submetida ao manejo $j$;

$\delta_{\mathrm{t}}\left(\mathrm{m}^{3}\right)=$ Volume a ser adquirido no mercado no ano $t$. 
E, para os modelos regionalizados, podemos considerar as expectativas de produtividades médias por região, suas áreas disponíveis totais e sua participação no abastecimento próprio atual (ordenando-as, pela metodologia clássica, para 7 anos):

\section{$\underline{\text { Região I: }}$}

$$
\sum_{i=1}^{N} \sum_{j=1}^{M} X_{i j}^{\prime} V_{i j t}^{\prime}+\delta_{t 1} \geq 870.000
$$

onde:

$\mathrm{X}^{\prime} \mathrm{ij}$ (ha) = Área da Unidade de Produção $i$ submetida ao regime $j$ na Região I.

$\mathrm{V}^{\prime}{ }_{\mathrm{ijt}}\left(\mathrm{m}^{3} / \mathrm{ha}\right)=$ Volume obtido no ano $t$ (variando de 1 a 21 ) caso a Unidade de Produção $i$ seja submetida ao manejo $j$ (dentro da Região I);

$\delta_{\mathrm{t} 1}\left(\mathrm{~m}^{3}\right)$ - Volume a ser adquirido de madeira de mercado no ano $t$ para cobrir volume esperado para a região I;

adicionando-se a expressão de ordenamento:

$$
\delta_{t 1}-\delta_{t 1-1} \leq 0 \quad(\mathrm{t}=2,3 \ldots, 21)
$$

\section{Região II:}

$$
\sum_{i=1}^{N} \sum_{j=1}^{M} X^{\prime \prime}{ }_{i j} V^{\prime \prime}{ }_{i j t}+\delta_{t 2} \geq 400.000
$$

onde:

$\mathrm{X}$ ' 'ij (ha) = Área da Unidade de Produção $i$ submetida ao regime $j$ na Região II.

V' ${ }_{\text {ijt }}\left(\mathrm{m}^{3} / \mathrm{ha}\right)=$ Volume obtido no ano $t$ (variando de 1 a 21 ) caso a Unidade de Produção $i$ seja submetida ao manejo $j$ (dentro da Região II);

$\delta_{\mathrm{t} 2}\left(\mathrm{~m}^{3}\right)$ - Volume a ser adquirido de madeira de mercado no ano $t$ para cobrir volume esperado para a região II; 
adicionando-se a expressão de ordenamento:

$$
\delta_{t 2}-\delta_{t 2-1} \leq 0 \quad(\mathrm{t}=2,3 \ldots, 21)
$$

\section{Região III:}

$$
\sum_{i=1}^{N} \sum_{j=1}^{M} X^{\prime \prime \prime}{ }_{i j} V^{\prime \prime}{ }_{i j t}+\boldsymbol{\delta}_{t 3} \geq 330.000
$$

onde:

$X$ ', 'ij (ha) = Área da Unidade de Produção $i$ submetida ao regime $j$ na Região III.

$\mathrm{V}{ }^{\prime,}{ }_{\text {ijt }}\left(\mathrm{m}^{3} / \mathrm{ha}\right)=$ Volume obtido no ano $t$ (variando de 1 a 21 ) caso a Unidade de Produção $i$ seja submetida ao manejo $j$ (dentro da Região III);

$\delta_{\mathrm{t} 3}\left(\mathrm{~m}^{3}\right)$ - Volume a ser adquirido de madeira de mercado no ano $t$ para cobrir volume esperado para a região III;

adicionando-se a expressão de ordenamento:

$$
\delta_{t 3}-\delta_{t 3-1} \leq 0 \quad(\mathrm{t}=2,3 \ldots, 21)
$$

As expressões estão na configuração para uso em programas de otimização, onde o RHS (Right-Hand Side) pode conter apenas variáveis numéricas. A expressão que iguala os volumes a serem comprados é o instrumento que busca a ordenação da floresta.

A variável " $\delta$ " aparece nas restrições de volume agindo como um elemento endógeno de ordenamento. A “expressão de ordenamento" mencionada é responsável por tentar criar uma produção anual estável e a conseqüente regulação da floresta.

Eventualmente, outras restrições poderiam ser incluídas no modelo. Como a intenção é comparar resultados de dois modelos distintos trabalhando com as mesmas variáveis, demais restrições de volume produzido anual devido a limitações financeiras, por exemplo, não serão inseridas no modelo. 
No entanto, uma restrição operacional importante diz respeito à área a ser plantada anualmente, e que retrataria uma limitação orçamentária real. Esta restrição pode ser expressa da forma:

Para ordenamento Global:

$$
\sum_{i=1}^{N} \sum_{j=1}^{M} \alpha_{i j t} X_{i j t} \leq 4500 \text { ha } \quad(\mathrm{t}=1,2 \ldots, 21)
$$

onde:

$\alpha_{i j t}=0$ se a prescrição $j$ não recomenda a operação na unidade $i$ no ano $t$

$\alpha_{i j t}=1$ se a prescrição $j$ recomenda a operação na unidade $i$ no ano $t$

O limite considerado operacional pela empresa para plantio não excede 4.500 hectares anuais. Em teoria sustentada pelos métodos clássicos de ordenamento, a área total plantável da empresa de 32.621 hectares poderia ser manejada de forma ordenada em rotações de 7 anos reformando/conduzindo-se 4.660 hectares anuais. No entanto, como áreas de terceiros (parcerias) também participam do programa anual florestal, adicionar-se-iam 3.510 hectares a essa área, totalizando 36.131 hectares e projetando, conseqüentemente, pela mesma metodologia de cálculo, a necessidade de programar anualmente 5.161 hectares para plantio e/ou condução.

No capítulo 4 são analisados os impactos desta restrição de área nos resultados dos modelos.

As restrições operacionais para os modelos regionalizados são as seguintes:

\section{Região I}

$$
\sum_{i=1}^{N} \sum_{j=1}^{M} \alpha_{i j t}^{\prime} X_{i j t}^{\prime} \leq 2100 \text { ha } \quad(\mathrm{t}=1,2 \ldots, 21)
$$


Região II

$$
\sum_{i=1}^{N} \sum_{j=1}^{M} \alpha_{i j t}^{\prime \prime} X^{\prime \prime}{ }_{i j t} \leq 1220 \text { ha } \quad(\mathrm{t}=1,2 \ldots, 21)
$$

Região III

$$
\sum_{i=1}^{N} \sum_{j=1}^{M} \alpha_{i j t}^{\prime \prime \prime} X^{\prime \prime \prime}{ }_{i j t} \leq 1180 \text { ha } \quad(\mathrm{t}=1,2 \ldots, 21)
$$

onde:

$\alpha_{i j t}^{\prime}, \alpha_{i j t}^{\prime \prime}$ e $\alpha_{i j t}^{\prime \prime \prime}=\alpha_{i j t}$, respectivos às UPs das regiões I, II e III.

Considerando-se as estruturas atuais disponíveis nas regiões, pode-se assumir os limites operacionais de plantio de 2.100 , 1.220 e 1.180 hectares nas Regiões I, II e III respectivamente.

Os modelos também serão rodados sem as limitações de área para efeito de possibilitar produção de dados adicionais para análise no final do trabalho.

\subsection{Critérios de valoração dos regimes de manejo - modelos de minimização do valor presente dos custos}

Como valores relativos à madeira de mercado estão mais prontamente disponíveis na forma de custo ou preço por unidade (volume ou peso) posto-fábrica, para a formulação deste modelo o interesse é determinar custos semelhantes para as UPs e utilizá-los na estruturação da função objetivo. Neste caso, o objetivo é abastecer a fábrica no menor custo possível, não considerando valor presente específico do empreendimento florestal.

$\mathrm{O}$ artifício de se estabelecer uma receita futura para o produto florestal deixa de ser importante neste modelo, uma vez que, como mencionado no item 4.5, o interesse 
neste modelo não é produzir receita líquida com a madeira, passando esta a ser apenas mais um componente do custo total de produção da fábrica.

\subsection{Cálculo do Custo Financeiro da Produção (CFP)}

O Custo Financeiro da Produção - CFP (Rodriguez, 1999) - que é basicamente uma adaptação do cálculo da relação Custo/Benefício, pode ser definido como o valor obtido pela razão entre o somatório dos custos de produção de um ciclo descontados a valor presente e o volume total produzido também descontado a valor presente. Este valor também pode ser determinado para o futuro (final do ciclo), no mesmo raciocínio desenvolvido para o cálculo de valor presente para cada uma das prescrições.

Seguindo o fluxo de caixa anual do item 3.5.3.1, este pode ser expresso pela fórmula:

$$
C F P_{i j}=\frac{\sum_{t=0}^{n} \frac{C_{i j t}}{(1+i)^{t}}}{\sum_{t=0}^{n} \frac{V_{i j t}}{(1+i)^{t}}}
$$

onde:

$\mathrm{CFP}_{\mathrm{ij}}\left(\mathrm{R} \$ / \mathrm{m}^{3}\right)=$ Custo Financeiro da Produção da Unidade de Produção $i$ submetida à prescrição $j$;

$\mathrm{n}$ = período em anos correspondente ao ciclo florestal completo;

$\mathrm{t}=$ ano em que ocorre a atividade e/ou produção;

Vijt $\left(\mathrm{m}^{3}\right)=$ Volume produzido da Produção da Unidade de produção $i$ submetida à prescrição $j$ no ano $t \mathrm{em} \mathrm{m}^{3} / \mathrm{ha}$;

$\mathrm{C}_{\mathrm{ijt}}(\mathrm{R} \$ / \mathrm{ha})=$ Custo da operação/atividade na UP $i$ submetida à prescrição $j$ no ano $t$ 
Portanto, admitindo que o programa de produção florestal está integrado ao processo fabril, o CFP determinado para cada unidade de produção será exatamente igual ao valor a ser pago pela madeira "em pé” produzida.

As características edafoclimáticas gerais de cada região, bem como as produtividades médias, permitem admitir que as variações de custo são notadamente maiores entre regiões e menores entre hortos de uma mesma região. Assumindo esta premissa, os custos médios por região expressos na tabela x serão admitidos para cada uma das Unidades de Produção pertencentes à região.

\subsubsection{Cálculo do valor futuro do custo posto-fábrica}

A determinação do custo futuro posto-fábrica, ou CPFuturo, é necessária para solucionar a questão temporal, de forma análoga ao processo do uso do VET na valoração para os modelos de maximização do VPL.

O custo "posto-fábrica" futuro por prescrição por UP poderá ser obtido pela expressão:

$$
\text { CPFuturo }_{i j}=C P_{i j}(1+i)^{t}
$$

onde:

$\operatorname{CPFuturo}_{\mathrm{ij}}\left(\mathrm{m}^{3} / \mathrm{ha}\right)=$ Custo futuro posto-fábrica da Unidade de Produção $i$ submetida à prescrição $j$

$\mathrm{CP}_{\mathrm{ij}}\left(\mathrm{R} \$ / \mathrm{m}^{3}\right)=$ Custo presente posto-fábrica, proveniente da expressão (13), da Unidade de Produção $i$ submetida è prescrição $j$;

As variáveis de interesse para este planejamento deverão ser expressas em área (hectares). A lógica desta proposição é que o planejamento florestal, embora fundamentado em volumes produzíveis por hectare, necessita determinar a área a ser colhida anualmente. Uma das razões é que toda a programação silvicultural posterior à colheita é fundamentada em área disponível e não em volume colhido. Portanto, as 
variáveis-resposta da função objetivo devem estar expressas em unidades de área e não em unidades de volume.

\subsubsection{Determinação do ciclo economicamente ótimo}

Como mencionado, a questão temporal também deve ser abordada na valoração para o modelo de minimização do valor presente dos custos, pois o problema de haver horizontes de tempo distintos entre as prescrições também proíbe a comparação direta sem a conversão dos custos obtidos para cada alternativa para um horizonte comum. De forma análoga ao calculado no item 4.5.3.2, podemos determinar qual seria o ciclo economicamente ótimo de custos, a ser repetido em perpetuidade.

Neste caso, contrariamente à obtenção do VET de mais alto valor, a seleção do ciclo ótimo será obtida pelo Custo da Alternativa (CA) de menor valor.

Este custo pode ser determinado pela fórmula:

$$
C A_{i j}=\frac{\text { CPFuturo }_{i j}}{\left((1+i)^{n}-1\right)}
$$

Onde:

$\mathrm{CA}_{\mathrm{ij}}(\mathrm{R} \$ / \mathrm{ha})=$ Custo da Alternativa (prescrição) para a unidade de produção $i$, obtido em perpetuidade.

Quando comparados todos os CAs de todas as prescrições para uma UP, o CA de menor valor obtido (contrariamente ao VET) passa a ser denominado $\mathrm{CA}_{\mathrm{i}}$ '.

Finalmente, o custo final determinado por hectare será determinado pela seguinte equação:

$$
\text { CPha }_{i j}=\frac{\text { CPFuturo }_{i j}+C A_{i}^{\prime}}{(1+i)^{n}}
$$

Onde: 
$\mathrm{CPha}_{\mathrm{ij}}(\mathrm{R} \$ / \mathrm{ha})=$ Custo presente do hectare colhido da Unidade de Produção "i" na prescrição “j”;

\subsection{Modelo de minimização do valor presente dos custos}

Neste caso, o objetivo é a obtenção do menor desembolso possível com a matéria-prima "madeira" dentro do horizonte de planejamento proposto de 21 anos. Para a minimização do custo posto-fábrica de cada Unidade de Produção, a função objetivo para ordenamento "Global” será descrita da seguinte forma:

$$
\operatorname{MinZ}=\sum_{i=1}^{N} \sum_{j=1}^{M} C P h a_{i j} X_{i j}+\sum_{t=1}^{21} \operatorname{ValMM}_{t} \boldsymbol{\delta}_{t}
$$

Onde:

$\mathrm{X}_{\mathrm{ij}}(\mathrm{ha})=$ Área a ser colhida da Unidade de Produção “i” na prescrição “j”;

$\mathrm{CPha}_{\mathrm{ij}}(\mathrm{R} \$ / \mathrm{ha})=$ Custo presente do hectare colhido da Unidade de Produção "i" na prescrição “j”;

$\delta_{\mathrm{t}}\left(\mathrm{m}^{3}\right)=$ Volume a ser adquirido no mercado no ano índice $t$.

$\operatorname{ValMM}_{\mathrm{t}}\left(\mathrm{R} \$ \mathrm{~m}^{3}\right)=$ Valor do volume da madeira de mercado no ano " $\mathrm{t}$ " (variando de acordo com o estabelecido no item 4.5.2).

$\mathrm{M}=$ Número de regimes de manejo;

N = Número de Unidades de Produção;

Analogamente, também, ao modelo de maximização do valor presente das receitas, o modelo "Regionalizado" terá a função objetivo expressa da seguinte forma:

$$
\operatorname{MinZ}=\sum_{i=1}^{N} \sum_{j=1}^{M} \operatorname{CPha}_{i j} X_{i j}+\sum_{t=1}^{21} \operatorname{ValMM}_{t} \boldsymbol{\delta}_{t 1}+\sum_{t=1}^{21} \operatorname{ValMM}_{t} \boldsymbol{\delta}_{t 2}+\sum_{t=1}^{21} \operatorname{ValMM}_{t} \boldsymbol{\delta}_{t 3}
$$


onde:

$\delta_{\text {th }}\left(\mathrm{m}^{3}\right)$ - Volume a ser adquirido de madeira de mercado no ano $t$ para cobrir a região $h$ (para $h=1,2$ e 3$)$;

Como o objetivo maior é minimizar o custo da madeira posto-fábrica, contrariamente ao modelo de maximização de valor presente das receitas, o produto resultante do volume adquirido por ValMM é somado ao resultado da função objetivo. Como exemplo, se o valor de ValMM for efetivamente superior ao custo da madeira própria representado pela variável CPha, o modelo tenderá a maximizar a utilização de madeira própria procurando obter o menor resultado possível para a função objetivo.

Da mesma forma que na construção do modelo para maximização do valor presente, para garantir que o limite de área de cada UP não seja violado, a seguinte restrição faz-se necessária:

$$
\sum_{j=1}^{M} X_{i j} \leq A_{i}
$$

onde:

$\mathrm{A}_{\mathrm{i}}=$ Área total da Unidade de Produção i

Analogamente ao modelo anterior, este modelo deve obedecer a uma necessidade anual de produção $\left(1,6 \mathrm{MM}\right.$ de $\left.\mathrm{m}^{3}\right)$ Para tanto, desenvolve-se a seguinte expressão para o modelo "Global":

$$
\sum_{i=1}^{N} \sum_{j=1}^{M} X_{i j} V_{i j t}+\delta_{t} \geq 1.600 .000
$$

adicionando-se a expressão de ordenamento:

$$
\delta_{t}-\delta_{t-1} \geq 0 \quad(\mathrm{t}=2,3 \ldots, 21)
$$

onde: 
$\mathrm{V}_{\mathrm{ijt}}\left(\mathrm{m}^{3} / \mathrm{ha}\right)=$ Volume obtido no ano índice $t$ (variando de 1 a 21 ) caso a Unidade de Produção $i$ seja submetida ao manejo $j$;

$\delta_{\mathrm{t}}\left(\mathrm{m}^{3}\right)=$ Volume a ser adquirido no mercado no ano $t$.

E, para o modelo "Regionalizado":

\section{$\underline{\text { Região I: }}$}

$$
\sum_{i=1}^{N} \sum_{j=1}^{M} X_{i j}^{\prime} V_{i j t}^{\prime}+\delta_{t 1} \geq 870.000
$$

onde:

$\mathrm{X}^{\prime} \mathrm{ij}(\mathrm{ha})=$ Área da Unidade de Produção $i$ submetida ao regime $j$ na Região I.

$\mathrm{V}^{\prime}{ }_{\mathrm{ijt}}\left(\mathrm{m}^{3} / \mathrm{ha}\right)=$ Volume obtido no ano $t$ (variando de 1 a 21 ) caso a Unidade de Produção $i$ seja submetida ao manejo $j$ (dentro da Região I);

$\delta_{\mathrm{t} 1}\left(\mathrm{~m}^{3}\right)$ - Volume a ser adquirido de madeira de mercado no ano $t$ para cobrir volume esperado para a região I;

adicionando-se a expressão de ordenamento:

$$
\delta_{t 1}-\delta_{t 1-1} \leq 0 \quad(\mathrm{t}=2,3 \ldots, 21)
$$

\section{Região II:}

$$
\sum_{i=1}^{N} \sum_{j=1}^{M} X^{\prime \prime}{ }_{i j} V^{\prime \prime}{ }_{i j t}+\delta_{t 2} \geq 400.000
$$

onde:

X' 'ij (ha) = Área da Unidade de Produção $i$ submetida ao regime $j$ na Região II.

$\mathrm{V}^{\prime}{ }_{\mathrm{ijt}}\left(\mathrm{m}^{3} / \mathrm{ha}\right)=$ Volume obtido no ano $t$ (variando de 1 a 21 ) caso a Unidade de Produção $i$ seja submetida ao manejo $j$ (dentro da Região II);

$\delta_{\mathrm{t} 2}\left(\mathrm{~m}^{3}\right)$ - Volume a ser adquirido de madeira de mercado no ano $t$ para cobrir volume esperado para a região II; 
adicionando-se a expressão de ordenamento:

$$
\delta_{t 2}-\delta_{t 2-1} \leq 0 \quad(\mathrm{t}=2,3 \ldots, 21)
$$

\section{Região III:}

$$
\sum_{i=1}^{N} \sum_{j=1}^{M} X^{\prime \prime \prime}{ }_{i j} V^{\prime \prime \prime}{ }_{i j t}+\boldsymbol{\delta}_{t 3} \geq 330.000
$$

onde:

$\mathrm{X}$ "'ij (ha) = Área da Unidade de Produção $i$ submetida ao regime $j$ na Região III.

$\mathrm{V}^{\prime \prime}{ }_{\mathrm{ijt}}\left(\mathrm{m}^{3} / \mathrm{ha}\right)=$ Volume obtido no ano $t$ (variando de 1 a 21 ) caso a Unidade de Produção $i$ seja submetida ao manejo $j$ (dentro da Região III);

$\delta_{\mathrm{t} 3}\left(\mathrm{~m}^{3}\right)$ - Volume a ser adquirido de madeira de mercado no ano $t$ para cobrir volume esperado para a região III;

adicionando-se a expressão de ordenamento:

$$
\delta_{t 3}-\delta_{t 3-1} \leq 0 \quad(\mathrm{t}=2,3 \ldots, 21)
$$

Analogamente aos modelos de maximização, as restrições de área podem ser expressas das seguintes formas:

Para ordenamento Global:

$$
\sum_{i=1}^{N} \sum_{j=1}^{M} \alpha_{i j t} X_{i j t} \leq 4500 \text { ha } \quad(\mathrm{t}=1,2 \ldots, 21)
$$

onde:

$\alpha_{i j t}=0$ se a prescrição $j$ não recomenda a operação na unidade $i$ no ano $t$

$\alpha_{i j t}=1$ se a prescrição $j$ recomenda a operação na unidade $i$ no ano $t$

Para ordenamento regionalizado: 
Região I

$$
\sum_{i=1}^{N} \sum_{j=1}^{M} \alpha_{i j t}^{\prime} X^{\prime}{ }_{i j t} \leq 2100 \text { ha } \quad(\mathrm{t}=1,2 \ldots, 21)
$$

Região II

$$
\sum_{i=1}^{N} \sum_{j=1}^{M} \alpha_{i j t}^{\prime \prime} X_{i j t}^{\prime \prime} \leq 1220 \text { ha } \quad(\mathrm{t}=1,2 \ldots, 21)
$$

Região III

$$
\sum_{i=1}^{N} \sum_{j=1}^{M} \alpha_{i j t}^{\prime \prime \prime} X^{\prime \prime \prime}{ }_{i j t} \leq 1180 \text { ha } \quad(\mathrm{t}=1,2 \ldots, 21)
$$

onde:

$\alpha_{i j t}^{\prime}, \alpha_{i j t}^{\prime \prime}$ e $\alpha_{i j t}^{\prime \prime \prime}=\alpha_{i j t}$, respectivos às UPs das regiões I, II e III. 


\section{RESULTADOS E DISCUSSÃO}

\subsection{Geração dos coeficientes}

A geração dos 2.790 coeficientes econômicos de valor presente líquido e custo presente para as 1.395 prescrições foi obtida pelo uso de tabelas dinâmicas em planilhas eletrônicas. O processo é bastante trabalhoso e é conveniente o uso de geradores de coeficientes automatizados para esta etapa. No Anexo A encontra-se a lista dos coeficientes obtidos para cada uma das prescrições.

Uma premissa foi admitida para atender a necessidade de prescrever produções para UPs que estavam acima da idade máxima admitida de 8,9 anos no ano anterior ao início do horizonte de planejamento e ainda não haviam sido cortadas. Nestes casos, considerou-se a área como cortada, e sua idade atual como zero.

É interessante observar que para uma unidade de produção, UP 129, todos os coeficientes de valor presente líquido apresentaram resultado negativo. Esse comportamento mostra coerência dos coeficientes e é esperado, em função das características de produtividade medianas da área e principalmente de sua distância à fábrica $(300 \mathrm{~km})$. Para a UP com características de distância mais semelhantes à anterior (UP130, a $325 \mathrm{~km}$ da fábrica), o mesmo coeficiente apresentou valor bastante baixo quando comparado a todos os demais, mas não negativo. Isto se explica pelo fato da produtividade ser comparativamente maior nessa UP, produzindo redução nos custos de colheita e transporte em função da geração de árvores com maior volume individual e conseqüentemente tornando o valor pago pelo volume produzido $\left(33,81 \mathrm{R} \$ \mathrm{~m}^{-3}\right)$ suficiente para permitir geração de receita líquida positiva. 


\subsection{Geração dos modelos}

Também foram utilizadas planilhas eletrônicas e editores de texto para a geração e formatação das funções objetivo e restrições para cada um dos modelos de maximização e minimização do estudo. Essa também é uma atividade complexa e que pode ser facilitada pelo uso de geradores de modelos automatizados (como o FOREX, por exemplo, desenvolvido na ESALQ).

Um total de 80 modelos foi gerado para fornecer a base para análise deste estudo, abrangendo as diferentes abordagens e os cenários variados de valores de madeira de mercado criados. O diagrama da distribuição dos modelos está na Figura 2.

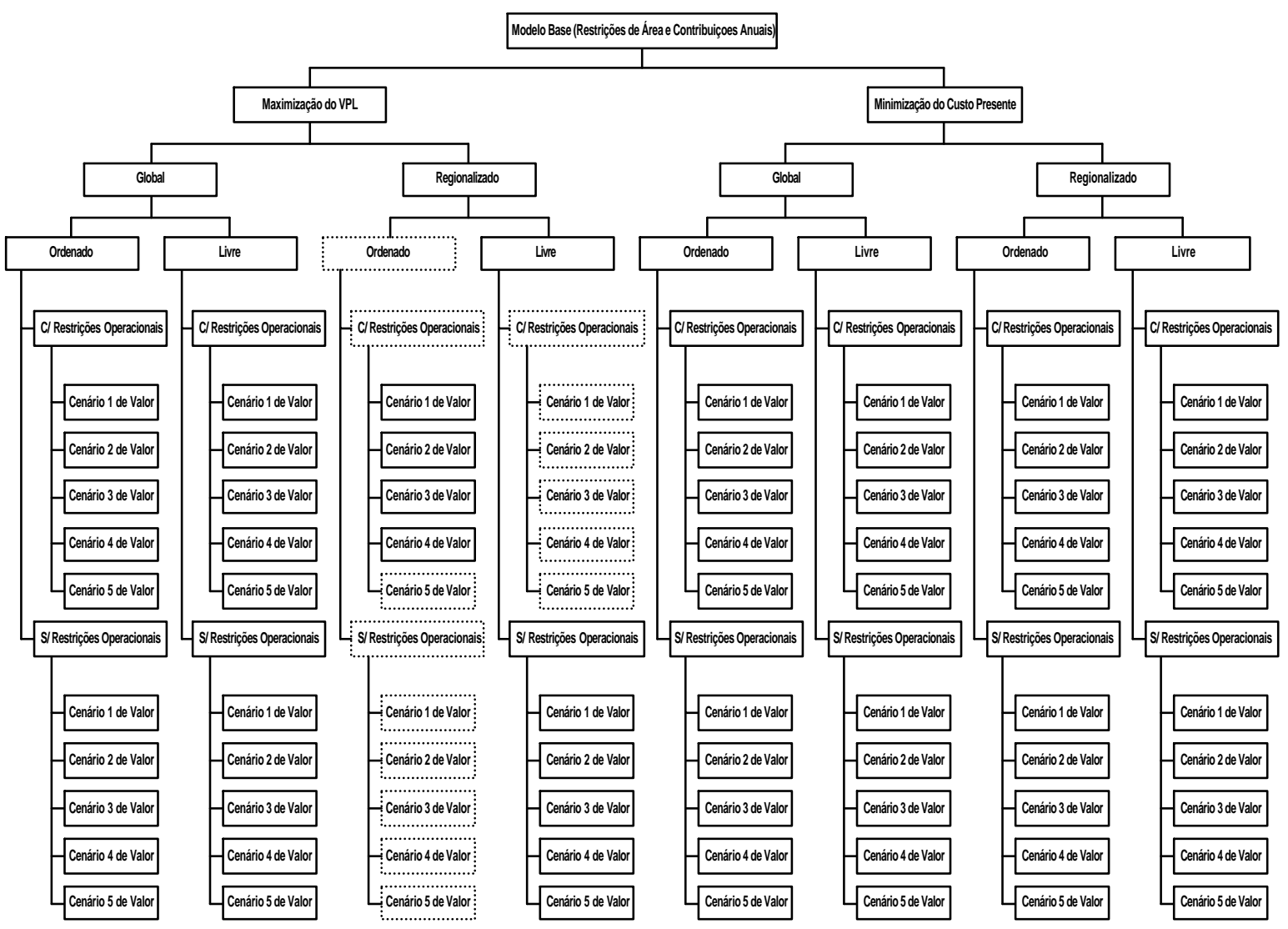

Figura 2- Organização dos modelos gerados 
Inicialmente, criou-se um modelo rudimentar com expressões que seriam comuns a todos os seguintes (chamado Modelo Base, no diagrama). Este modelo era composto fundamentalmente pelas restrições de área de cada UP. A primeira diferenciação entre os modelos é proporcionada pelos coeficientes econômicos na função objetivo, gerando os ramos de maximização e de minimização. A segunda diferenciação é provocada pelas restrições de volume e pela participação diferenciada da madeira de mercado na composição da função objetivo, produzindo os ramos "Global" e "Regionalizado". A adição das expressões de ordenamento diferenciavam os modelos "Ordenado" e "Livre". Para entender o impacto do estabelecimento de uma área máxima de colheita e plantio, foram rodados modelos com e sem essas restrições operacionais. Finalmente, a variação dos valores reais da madeira de mercado produziu os diferentes cenários de análise para cada um dos modelos anteriores.

\subsubsection{Geração dos outputs dos modelos}

Os modelos foram lidos em otimizadores C-PLEX e LINDO. O exemplo de um modelo Global livre, de maximização do valor líquido presente, com restrições operacionais, no cenário 1 de valor, está disponível no Anexo B.

Nas Tabelas 16 e 17, estão apresentados os resultados alcançados dos valores

finais das funções objetivo dos modelos de maximização e minimização, respectivamente: 
Tabela 16. Valores obtidos para a função objetivo, nos modelos de maximização do valor presente líquido (em $\mathrm{R} \$$ )

\begin{tabular}{lrrr}
\hline & \multicolumn{2}{c}{ Com Restriçóes Operacionais } & \multicolumn{2}{c}{ Sem Restriçóes Operacionais } \\
\cline { 2 - 4 } Cenários & Ordenado & Livre & Ordenado \\
\hline Global com ValMM - 20\% & & & $244,044,921.82$ \\
Global com ValMM - 10\% & $110,917,000.00$ & $117,688,900.00$ & $251,575,244.39$ \\
Global com ValMM original & $96,361,700.00$ & $103,513,900.00$ & $238,709,776.39$ \\
Global com ValMM + 10\% & $78,927,190.00$ & $86,528,170.00$ & $232,318,754.60$ \\
Global com ValMM + 20\% & $59,766,570.00$ & $67,843,070.00$ & $225,290,175.08$ \\
& $40,611,960.00$ & $49,189,830.00$ & $218,259,716.42$ \\
Regional com ValMM - 20\% & & & $241,074,255.00$ \\
Regional com ValMM - 10\% & $69,582,060.00$ & $81,333,190.00$ & $215,579,193.30$ \\
Regional com ValMM original & $53,502,830.00$ & $65,864,130.00$ & $208,297,248.34$ \\
Regional com ValMM + 10\% & $34,227,770.00$ & $47,319,150.00$ & $199,563,999.97$ \\
Regional com ValMM + 20\% & $13,049,790.00$ & $26,917,770.00$ & $189,033.23$ \\
\hline
\end{tabular}

Tabela 17. Valores obtidos para a função objetivo, nos modelos de minimização do custo presente (em $\mathrm{R} \$)$

\begin{tabular}{lcccc}
\hline & \multicolumn{2}{c}{ Com Restrições Operacionais } & \multicolumn{2}{c}{ Sem Restrições Operacionais } \\
\cline { 2 - 5 } Cenários & Ordenado & Livre & Ordenado & Livre \\
\hline Global com ValMM - 20\% & $430,104,800.00$ & $427,338,500.00$ & $427,039,879.07$ & $423,164,231.75$ \\
Global com ValMM - 10\% & $447,152,500.00$ & $443,260,800.00$ & $437,211,147.65$ & $433,496,021.29$ \\
Global com ValMM original & $466,631,000.00$ & $461,880,500.00$ & $446,838,549.61$ & $442,860,242.13$ \\
Global com ValMM + 10\% & $487,493,900.00$ & $481,806,400.00$ & $455,998,692.09$ & $451,550,435.82$ \\
Global com ValMM + 20\% & $507,830,200.00$ & $501,346,600.00$ & $464,086,375.09$ & $459,206,150.31$ \\
& & & & \\
Regional com ValMM - 20\% & $453,864,200.00$ & $446,581,200.00$ & $427,746,227.02$ & $426,001,853.11$ \\
Regional com ValMM - 10\% & $473,580,900.00$ & $466,538,900.00$ & $438,689,983.07$ & $437,123,761.72$ \\
Regional com ValMM original & $494,215,000.00$ & $487,441,400.00$ & $448,729,741.70$ & $446,817,688.83$ \\
Regional com ValMM + 10\% & $516,405,100.00$ & $509,055,700.00$ & $458,650,698.00$ & $456,359,919.89$ \\
Regional com ValMM + 20\% & $538,357,800.00$ & $530,193,400.00$ & $467,315,264.04$ & $465,109,406.99$ \\
\hline
\end{tabular}

Os modelos prescreveram recomendações diferenciadas quanto ao uso da área total plantável disponível pela empresa (38.959 hectares). Estas diferenças são mostradas na Tabela 18 para os modelos de maximização do valor líquido presente e na Tabela 19 para os de minimização do custo presente: 
Tabela 18. Percentual de utilização da área plantável nos por modelos de maximização do valor líquido presente, para cada cenário de valor de madeira

\begin{tabular}{|c|c|c|c|c|}
\hline Modelo & $\begin{array}{c}\text { Intensidade de } \\
\text { ordenamento }\end{array}$ & $\begin{array}{l}\text { Cenários de valor da } \\
\text { madeira de mercado }\end{array}$ & $\begin{array}{c}\% \text { (sem restrições } \\
\text { operacionais) }\end{array}$ & $\begin{array}{c}\text { \% (com restrições } \\
\text { operacionais) }\end{array}$ \\
\hline \multirow{14}{*}{ Global } & \multirow{5}{*}{ Ordenado } & $+20 \%$ & 100.00 & 77.64 \\
\hline & & $+10 \%$ & 100.00 & 77.75 \\
\hline & & Original & 100.00 & 77.89 \\
\hline & & $-10 \%$ & 100.00 & 77.90 \\
\hline & & $-20 \%$ & 100.00 & 77.91 \\
\hline & \multirow{5}{*}{ Livre } & $+20 \%$ & 100.00 & 78.36 \\
\hline & & $+10 \%$ & 100.00 & 78.43 \\
\hline & & Original & 100.00 & 78.49 \\
\hline & & $-10 \%$ & 100.00 & 78.55 \\
\hline & & $-20 \%$ & 100.00 & 78.68 \\
\hline & \multirow{5}{*}{ Ordenado } & $+20 \%$ & 100.00 & 79.45 \\
\hline & & $+10 \%$ & 100.00 & 79.51 \\
\hline & & Original & 100.00 & 79.51 \\
\hline & & $-10 \%$ & 100.00 & 79.48 \\
\hline \multirow[t]{6}{*}{ Regionalizado } & & $-20 \%$ & 100.00 & 79.48 \\
\hline & & $+20 \%$ & 98.13 & 79.64 \\
\hline & & $+10 \%$ & 98.13 & 79.63 \\
\hline & Livre & Original & 98.13 & 79.61 \\
\hline & & $-10 \%$ & 98.13 & 79.57 \\
\hline & & $-20 \%$ & 98.13 & 79.49 \\
\hline
\end{tabular}

Tabela 19. Percentual de utilização da área plantável nos por modelos de minimização do custo presente, para cada cenário de valor de madeira

\begin{tabular}{|c|c|c|c|c|}
\hline Modelo & $\begin{array}{c}\text { Intensidade de } \\
\text { ordenamento }\end{array}$ & $\begin{array}{l}\text { Cenários de valor da } \\
\text { madeira de mercado }\end{array}$ & $\begin{array}{c}\text { \% (sem restrições } \\
\text { operacionais) }\end{array}$ & $\begin{array}{c}\text { \% (com restrições } \\
\text { operacionais) }\end{array}$ \\
\hline \multirow{9}{*}{ Global } & \multirow{5}{*}{ Ordenado } & $+20 \%$ & 97.71 & 73.55 \\
\hline & & $+10 \%$ & 96.83 & 73.53 \\
\hline & & Original & 93.23 & 71.12 \\
\hline & & $-10 \%$ & 89.00 & 69.82 \\
\hline & & $-20 \%$ & 76.98 & 67.74 \\
\hline & \multirow{5}{*}{ Livre } & $+20 \%$ & 98.25 & 74.11 \\
\hline & & $+10 \%$ & 97.71 & 73.07 \\
\hline & & Original & 94.41 & 72.09 \\
\hline & & $-10 \%$ & 91.45 & 70.65 \\
\hline \multirow{11}{*}{ Regionalizado } & & $-20 \%$ & 81.24 & 67.17 \\
\hline & \multirow{5}{*}{ Ordenado } & $+20 \%$ & 97.71 & 75.14 \\
\hline & & $+10 \%$ & 96.48 & 74.52 \\
\hline & & Original & 93.23 & 72.06 \\
\hline & & $-10 \%$ & 89.35 & 66.45 \\
\hline & & $-20 \%$ & 76.22 & 55.62 \\
\hline & \multirow{5}{*}{ Livre } & $+20 \%$ & 98.25 & 76.41 \\
\hline & & $+10 \%$ & 96.29 & 75.87 \\
\hline & & Original & 93.23 & 75.04 \\
\hline & & $-10 \%$ & 89.67 & 72.16 \\
\hline & & $-20 \%$ & 79.41 & 55.03 \\
\hline
\end{tabular}


Nas Tabelas 20, 21, 22 e 23 estão expressos os resultados obtidos para as recomendações de compra de madeira de mercado nos modelos de maximização do valor líquido presente e, nas Tabelas 24, 25, 26 e 25, nos modelos de minimização do custo presente em todos os anos do horizonte de planejamento: 
Tabela 20. Volumes anuais adquiridos de madeira de mercado, em $\mathrm{m}^{3}$, resultantes do modelo Global de maximização do valor presente líquido sem restrições operacionais, para os diferentes cenários de valor de madeira de mercado (onde $1=$ valor $+20 \%$; $2=$ valor $+10 \% ; 3=$ valor original; $4=$ valor $-10 \% ; 5=$ valor $-20 \%$ ).

\begin{tabular}{|c|c|c|c|c|c|c|c|c|c|c|}
\hline \multirow[b]{2}{*}{ Ano } & \multicolumn{5}{|c|}{ Produção Livre } & \multicolumn{5}{|c|}{ Produção Ordenada } \\
\hline & Cenário 1 & Cenário 2 & Cenário 3 & Cenário 4 & Cenário 5 & Cenário 1 & Cenário 2 & Cenário 3 & Cenário 4 & Cenário 5 \\
\hline 1 & - & - & - & - & - & $198,200.40$ & $198,189.00$ & $198,352.90$ & $198,647.20$ & $199,146.90$ \\
\hline 2 & $318,935.20$ & $318,935.20$ & $318,935.20$ & $318,935.20$ & $318,935.20$ & $181,475.90$ & $181,515.90$ & $181,500.20$ & $181,573.00$ & $181,742.90$ \\
\hline 3 & - & - & - & - & - & $181,475.90$ & $181,515.90$ & $181,500.20$ & $181,573.00$ & $181,742.90$ \\
\hline 4 & $474,079.40$ & $474,850.30$ & $479,920.90$ & $479,920.90$ & $479,920.90$ & $181,475.90$ & $181,515.90$ & $181,500.20$ & $181,573.00$ & $181,742.90$ \\
\hline 5 & $19,321.34$ & $18,469.35$ & $12,864.82$ & $12,864.82$ & $12,864.82$ & $181,475.90$ & $181,515.90$ & $181,500.20$ & $181,573.00$ & $181,742.90$ \\
\hline 6 & - & - & - & - & - & $181,475.90$ & $181,515.90$ & $181,500.20$ & $181,573.00$ & $181,742.90$ \\
\hline 7 & $123,462.00$ & $123,462.00$ & $124,682.00$ & $144,956.70$ & $176,944.60$ & $181,475.90$ & $181,515.90$ & $181,500.20$ & $181,573.00$ & $181,742.90$ \\
\hline 8 & $537,379.40$ & $537,379.40$ & $535,358.20$ & $501,769.30$ & $448,780.80$ & $181,475.90$ & $181,515.90$ & $181,500.20$ & $181,573.00$ & $181,742.90$ \\
\hline 9 & - & - & - & - & - & $181,475.90$ & $181,515.90$ & $181,500.20$ & $181,573.00$ & $181,742.90$ \\
\hline 10 & $166,484.10$ & $170,172.50$ & $171,315.60$ & $183,336.00$ & $201,666.40$ & $181,475.90$ & $181,515.90$ & $181,500.20$ & $181,573.00$ & $181,742.90$ \\
\hline 11 & $52,931.52$ & $52,931.52$ & $52,931.52$ & $52,931.52$ & $51,773.02$ & $181,475.90$ & $181,515.90$ & $181,500.20$ & $181,573.00$ & $181,742.90$ \\
\hline 12 & - & $1,648.17$ & $3,550.28$ & $1,562.62$ & - & $181,475.90$ & $181,515.90$ & $181,500.20$ & $181,573.00$ & $181,742.90$ \\
\hline 13 & $774,571.00$ & $772,851.90$ & $771,613.20$ & $773,884.80$ & $777,134.10$ & $170,367.00$ & $170,417.70$ & $170,434.30$ & $170,391.60$ & $170,235.60$ \\
\hline 14 & - & - & - & - & - & $170,367.00$ & $170,417.70$ & $170,434.30$ & $170,391.60$ & $170,235.60$ \\
\hline 15 & - & - & - & - & - & $170,367.00$ & $170,417.70$ & $170,434.30$ & $170,391.60$ & $170,235.60$ \\
\hline 16 & $32,881.99$ & $32,881.99$ & $32,881.99$ & $32,881.99$ & $32,881.99$ & $170,367.00$ & $170,417.70$ & $170,434.30$ & $170,391.60$ & $170,235.60$ \\
\hline 17 & - & - & - & - & - & $170,367.00$ & $170,417.70$ & $170,434.30$ & $170,391.60$ & $170,235.60$ \\
\hline 18 & $2,455.47$ & $3,226.30$ & $8,296.95$ & $8,296.95$ & $7,016.48$ & $170,367.00$ & $170,417.70$ & $170,434.30$ & $170,391.60$ & $170,235.60$ \\
\hline 19 & $819,497.40$ & $819,497.40$ & $814,454.80$ & $812,467.20$ & $810,904.60$ & $170,367.00$ & $170,417.70$ & $170,434.30$ & $170,391.60$ & $170,235.60$ \\
\hline 20 & - & - & - & - & - & $79,495.89$ & $79,616.23$ & $79,595.39$ & $81,929.86$ & $88,584.02$ \\
\hline 21 & 851.99 & - & - & $11,326.52$ & $29,484.11$ & $79,495.89$ & $79,616.23$ & $79,595.39$ & $81,929.86$ & $88,584.02$ \\
\hline Total & $3,322,850.81$ & $3,326,306.03$ & $3,326,805.46$ & $3,335,134.52$ & 3,348,307.02 & 3,545,996.08 & $3,547,020.26$ & $3,547,085.98$ & $3,552,551.12$ & $3,567,136.04$ \\
\hline Media & $158,230.99$ & $158,395.53$ & $158,419.31$ & $158,815.93$ & $159,443.19$ & $168,856.96$ & $168,905.73$ & $168,908.86$ & $169,169.10$ & $169,863.62$ \\
\hline
\end{tabular}


Tabela 21. Volumes anuais adquiridos de madeira de mercado, em $\mathrm{m}^{3}$, resultantes do modelo Global de maximização do valor presente líquido com restrições operacionais, para os diferentes cenários de valor de madeira de mercado (onde $1=$ valor $+20 \%$; $2=$ valor $+10 \% ; 3=$ valor original; $4=$ valor $-10 \% ; 5=$ valor $-20 \%$ )

\begin{tabular}{|c|c|c|c|c|c|c|c|c|c|c|}
\hline \multirow[b]{2}{*}{ Ano } & \multicolumn{5}{|c|}{ Produção Livre } & \multicolumn{5}{|c|}{ Produção Ordenada } \\
\hline & Cenário 1 & Cenário 2 & Cenário 3 & Cenário 4 & Cenário 5 & Cenário 1 & Cenário 2 & Cenário 3 & Cenário 4 & Cenário 5 \\
\hline 1 & $365,362.70$ & $375,104.70$ & $376,508.90$ & $377,071.90$ & $377,254.40$ & $504,367.20$ & $506,667.60$ & $506,347.30$ & $505,542.70$ & $509,150.00$ \\
\hline 2 & $438,941.50$ & $451,361.70$ & $450,996.00$ & $451,724.90$ & $451,516.00$ & $504,367.20$ & $506,667.60$ & $506,347.30$ & $505,542.70$ & $509,150.00$ \\
\hline 3 & $556,606.40$ & $539,873.40$ & $538,966.70$ & $538,504.00$ & $538,789.60$ & $504,367.20$ & $506,667.60$ & $506,347.30$ & $505,542.70$ & $509,150.00$ \\
\hline 4 & $635,436.40$ & $636,186.00$ & $637,293.50$ & $636,109.90$ & $630,780.30$ & $504,367.20$ & $506,667.60$ & $506,347.30$ & $505,542.70$ & $509,150.00$ \\
\hline 5 & $509,761.90$ & $511,602.10$ & $515,339.90$ & $514,837.60$ & $520,306.80$ & $488,522.60$ & $484,350.90$ & $490,187.50$ & $494,979.60$ & $494,258.70$ \\
\hline 6 & $405,186.60$ & $391,106.50$ & $387,308.00$ & $390,004.20$ & $390,706.10$ & $468,569.40$ & $467,911.20$ & $468,262.10$ & $468,682.20$ & $467,597.80$ \\
\hline 7 & $335,091.30$ & $350,084.60$ & $352,906.70$ & $350,159.90$ & $349,449.10$ & $468,569.40$ & $467,911.20$ & $468,262.10$ & $468,682.20$ & $467,597.80$ \\
\hline 8 & $375,597.20$ & $380,489.10$ & $381,703.40$ & $384,294.70$ & $384,952.30$ & $468,569.40$ & $467,911.20$ & $468,262.10$ & $468,682.20$ & $467,597.80$ \\
\hline 9 & $475,907.50$ & $488,202.80$ & $487,096.40$ & $485,030.70$ & $484,218.80$ & $468,569.40$ & $467,911.20$ & $468,262.10$ & $468,682.20$ & $467,597.80$ \\
\hline 10 & $594,335.50$ & $575,126.10$ & $585,677.50$ & $587,850.70$ & $588,251.00$ & $468,569.40$ & $467,911.20$ & $468,262.10$ & $468,682.20$ & $467,597.80$ \\
\hline 11 & $596,266.50$ & $595,551.30$ & $589,678.00$ & $586,152.30$ & $595,003.70$ & $468,569.40$ & $467,911.20$ & $468,262.10$ & $468,682.20$ & $467,597.80$ \\
\hline 12 & $470,316.90$ & $469,829.90$ & $467,336.70$ & $470,866.00$ & $461,997.00$ & $468,569.40$ & $467,911.20$ & $468,262.10$ & $468,682.20$ & $467,597.80$ \\
\hline 13 & $443,478.30$ & $453,915.50$ & $456,394.90$ & $456,189.20$ & $456,120.90$ & $468,569.40$ & $467,911.20$ & $468,262.10$ & $468,682.20$ & $467,597.80$ \\
\hline 14 & $296,199.50$ & $303,777.00$ & $295,110.80$ & $295,659.90$ & $295,537.60$ & $468,569.40$ & $467,911.20$ & $468,262.10$ & $468,682.20$ & $467,597.80$ \\
\hline 15 & $448,074.60$ & $438,579.20$ & $437,317.20$ & $436,106.80$ & $436,040.60$ & $468,569.40$ & $467,911.20$ & $468,262.10$ & $468,682.20$ & $467,597.80$ \\
\hline 16 & $516,848.00$ & $506,331.60$ & $508,264.70$ & $507,763.40$ & $507,210.20$ & $468,569.40$ & $467,911.20$ & $468,262.10$ & $468,682.20$ & $467,597.80$ \\
\hline 17 & $546,616.50$ & $563,507.80$ & $572,750.20$ & $573,673.40$ & $573,604.80$ & $461,411.80$ & $462,211.30$ & $462,633.30$ & $464,097.60$ & $464,461.00$ \\
\hline 18 & $520,840.70$ & $504,704.30$ & $502,231.60$ & $501,264.60$ & $505,378.20$ & $461,411.80$ & $462,211.30$ & $462,633.30$ & $464,097.60$ & $464,461.00$ \\
\hline 19 & $510,084.40$ & $508,021.70$ & $503,515.40$ & $509,654.70$ & $508,398.80$ & $461,411.80$ & $462,211.30$ & $462,633.30$ & $464,097.60$ & $464,461.00$ \\
\hline 20 & $345,124.70$ & $350,056.70$ & $347,972.10$ & $339,856.70$ & $337,245.40$ & $461,411.80$ & $462,211.30$ & $462,633.30$ & $464,097.60$ & $464,461.00$ \\
\hline 21 & $400,699.40$ & $425,128.90$ & $427,483.00$ & $430,414.40$ & $431,213.20$ & $461,411.80$ & $462,211.30$ & $462,633.30$ & $464,097.60$ & $464,461.00$ \\
\hline Total & $\mathbf{9 , 7 8 6 , 7 7 6 . 5 0}$ & $\mathbf{9 , 8 1 8 , 5 4 0 . 9 0}$ & $\mathbf{9 , 8 2 1 , 8 5 1 . 6 0}$ & $\mathbf{9 , 8 2 3 , 1 8 9 . 9 0}$ & $\mathbf{9 , 8 2 3 , 9 7 4 . 8 0}$ & $\mathbf{9 , 9 6 7 , 3 1 3 . 8 0}$ & $\mathbf{9 , 9 6 9 , 1 0 1 . 0 0}$ & $\mathbf{9 , 9 7 9 , 6 2 6 . 3 0}$ & $9,993,142.60$ & $\mathbf{9 , 9 9 6 , 7 3 9 . 5 0}$ \\
\hline Media & $466,036.98$ & $467,549.57$ & $467,707.22$ & $467,770.95$ & $467,808.32$ & $474,633.99$ & $474,719.10$ & $475,220.30$ & $475,863.93$ & $476,035.21$ \\
\hline
\end{tabular}


Tabela 22. Volumes anuais adquiridos de madeira de mercado, em $\mathrm{m}^{3}$, resultantes do modelo Regionalizado de maximização do valor presente líquido sem restrições operacionais, para os diferentes cenários de valor de madeira de mercado (onde $1=$ valor $+20 \% ; 2=$ valor $+10 \% ; 3=$ valor original; $4=$ valor $-10 \% ; 5=$ valor $-20 \%$ )

\begin{tabular}{|c|c|c|c|c|c|c|c|c|c|c|}
\hline \multirow[b]{2}{*}{ Ano } & \multicolumn{5}{|c|}{ Produção Livre } & \multicolumn{5}{|c|}{ Produção Ordenada } \\
\hline & Cenário 1 & Cenário 2 & Cenário 3 & Cenário 4 & Cenário 5 & Cenário 1 & Cenário 2 & Cenário 3 & Cenário 4 & Cenário 5 \\
\hline 1 & $207,749.30$ & $207,749.30$ & $207,749.30$ & $207,749.30$ & $207,749.30$ & $454,643.90$ & $454,617.80$ & $454,633.10$ & $454,630.40$ & $454,609.00$ \\
\hline 2 & $309,742.90$ & $309,742.90$ & $309,742.90$ & $309,742.90$ & $309,742.90$ & $301,987.10$ & $301,961.00$ & $301,976.20$ & $301,973.60$ & $301,952.20$ \\
\hline 3 & $87,122.31$ & $87,122.31$ & $77,657.19$ & $77,657.19$ & $77,558.01$ & $214,683.20$ & $214,657.10$ & $214,672.40$ & $214,669.70$ & $214,648.30$ \\
\hline 4 & $218,151.80$ & $218,151.80$ & $228,483.50$ & $228,483.50$ & $228,483.50$ & $214,683.20$ & $214,657.10$ & $214,672.40$ & $214,669.70$ & $214,648.30$ \\
\hline 5 & - & - & - & - & - & $214,683.20$ & $214,657.10$ & $214,672.40$ & $214,669.70$ & $214,648.30$ \\
\hline 6 & $136,468.90$ & $138,872.10$ & $138,872.10$ & $139,090.60$ & $139,369.20$ & $214,683.20$ & $214,657.10$ & $214,672.40$ & $214,669.70$ & $214,648.30$ \\
\hline 7 & $65,430.50$ & $70,279.60$ & $81,314.04$ & $83,392.64$ & $99,392.41$ & $214,683.20$ & $214,657.10$ & $214,672.40$ & $214,669.70$ & $214,648.30$ \\
\hline 8 & $552,036.70$ & $546,697.50$ & $534,228.30$ & $531,892.20$ & $514,176.10$ & $214,683.20$ & $214,657.10$ & $214,672.40$ & $214,669.70$ & $214,648.30$ \\
\hline 9 & $149,065.40$ & $149,065.40$ & $155,777.60$ & $158,361.10$ & $153,648.50$ & $214,683.20$ & $214,657.10$ & $214,672.40$ & $214,669.70$ & $214,648.30$ \\
\hline 10 & $381,155.60$ & $378,895.10$ & $368,459.10$ & $364,007.90$ & $351,215.10$ & $214,683.20$ & $214,657.10$ & $214,672.40$ & $214,669.70$ & $214,648.30$ \\
\hline 11 & - & - & - & $1,065.97$ & $18,503.47$ & $214,683.20$ & $214,657.10$ & $214,672.40$ & $214,669.70$ & $214,648.30$ \\
\hline 12 & - & - & - & - & - & $214,683.20$ & $214,657.10$ & $214,672.40$ & $214,669.70$ & $214,648.30$ \\
\hline 13 & $311,838.50$ & $314,093.90$ & $323,273.20$ & $324,483.80$ & $332,851.00$ & $214,683.20$ & $214,657.10$ & $214,672.40$ & $214,669.70$ & $214,648.30$ \\
\hline 14 & $187,438.50$ & $187,438.50$ & $187,488.00$ & $187,498.80$ & $187,498.80$ & $214,683.20$ & $214,657.10$ & $214,672.40$ & $214,669.70$ & $214,648.30$ \\
\hline 15 & $247,234.10$ & $247,234.10$ & $247,671.40$ & $250,254.90$ & $239,201.50$ & $214,683.20$ & $214,657.10$ & $214,672.40$ & $214,669.70$ & $214,648.30$ \\
\hline 16 & $170,361.00$ & $170,361.00$ & $158,526.70$ & $155,943.10$ & $155,943.10$ & $214,683.20$ & $214,657.10$ & $214,672.40$ & $214,669.70$ & $214,648.30$ \\
\hline 17 & - & - & - & - & - & $214,683.20$ & $214,657.10$ & $214,672.40$ & $214,669.70$ & $214,648.30$ \\
\hline 18 & - & - & - & - & - & $214,683.20$ & $214,657.10$ & $214,672.40$ & $214,669.70$ & $214,648.30$ \\
\hline 19 & $335,331.10$ & $337,734.30$ & $353,709.80$ & $354,738.60$ & $365,971.50$ & $214,683.20$ & $214,657.10$ & $214,672.40$ & $214,669.70$ & $214,648.30$ \\
\hline 20 & $19,638.32$ & $19,410.33$ & $19,047.82$ & $18,950.09$ & $18,349.42$ & $164,031.30$ & $169,427.00$ & $169,442.20$ & $169,851.30$ & $175,975.80$ \\
\hline 21 & $251,076.80$ & $251,076.80$ & $251,076.80$ & $251,076.80$ & $251,076.80$ & $114,659.40$ & $114,659.40$ & $114,674.60$ & $114,674.60$ & $114,701.00$ \\
\hline Total & $3,629,841.73$ & 3,633,924.94 & $3,643,077.75$ & $3,644,389.39$ & $3,650,730.61$ & 4,684,936.10 & 4,689,835.90 & $4,690,156.90$ & $4,690,514.80$ & $4,696,259.10$ \\
\hline Media & $172,849.61$ & $173,044.04$ & $173,479.89$ & $\mathbf{1 7 3 , 5 4 2 . 3 5}$ & $173,844.31$ & $223,092.20$ & $223,325.52$ & $223,340.80$ & $223,357.85$ & $223,631.39$ \\
\hline
\end{tabular}


Tabela 23. Volumes anuais adquiridos de madeira de mercado, em $\mathrm{m}^{3}$, resultantes do modelo Regionalizado de maximização do valor presente líquido com restrições operacionais, para os diferentes cenários de valor de madeira de mercado (onde $1=$ valor $+20 \% ; 2=$ valor $+10 \% ; 3=$ valor original; $4=$ valor $-10 \% ; 5=$ valor $-20 \%$ )

\begin{tabular}{|c|c|c|c|c|c|c|c|c|c|c|}
\hline \multirow[b]{2}{*}{ Ano } & \multicolumn{5}{|c|}{ Produção Livre } & \multicolumn{5}{|c|}{ Produção Ordenada } \\
\hline & Cenário 1 & Cenário 2 & Cenário 3 & Cenário 4 & Cenário 5 & Cenário 1 & Cenário 2 & Cenário 3 & Cenário 4 & Cenário 5 \\
\hline 1 & $640,187.80$ & $655,914.90$ & $655,245.80$ & $641,212.70$ & $643,455.00$ & $744,837.90$ & $741,194.60$ & $742,553.30$ & $742,763.00$ & $742,743.60$ \\
\hline 2 & $580,711.80$ & $580,276.30$ & $580,012.50$ & $597,538.70$ & $595,216.40$ & $625,358.90$ & $629,719.10$ & $631,077.90$ & $631,287.50$ & $631,274.70$ \\
\hline 3 & $495,955.60$ & $486,904.20$ & $487,824.30$ & $486,446.60$ & $486,446.60$ & $522,361.60$ & $522,599.20$ & $523,957.90$ & $524,167.60$ & $524,151.50$ \\
\hline 4 & $607,178.10$ & $609,278.70$ & $609,258.10$ & $609,206.70$ & $609,346.50$ & $522,361.60$ & $522,599.20$ & $523,957.90$ & $524,167.60$ & $524,151.50$ \\
\hline 5 & $536,229.90$ & $536,833.40$ & $537,158.30$ & $537,158.30$ & $537,158.30$ & $522,361.60$ & $522,599.20$ & $523,957.90$ & $524,167.60$ & $524,151.50$ \\
\hline 6 & $475,283.50$ & $478,032.30$ & $478,020.20$ & $478,020.20$ & $478,020.20$ & $498,278.10$ & $498,391.30$ & $499,656.20$ & $499,716.60$ & $498,726.10$ \\
\hline 7 & $386,742.60$ & $388,669.40$ & $388,435.30$ & $388,435.30$ & $388,435.30$ & $489,150.10$ & $489,190.20$ & $489,319.50$ & $489,558.80$ & $490,085.40$ \\
\hline 8 & $348,948.20$ & $351,122.90$ & $352,288.10$ & $351,648.00$ & $351,648.00$ & $489,150.10$ & $489,190.20$ & $489,319.50$ & $489,558.80$ & $490,085.40$ \\
\hline 9 & $485,766.30$ & $480,849.20$ & $479,655.40$ & $480,845.00$ & $480,963.20$ & $489,150.10$ & $489,190.20$ & $489,319.50$ & $489,558.80$ & $490,085.40$ \\
\hline 10 & $533,382.10$ & $525,023.30$ & $525,981.70$ & $524,799.70$ & $524,856.40$ & $489,150.10$ & $489,190.20$ & $489,319.50$ & $489,558.80$ & $490,085.40$ \\
\hline 11 & $556,944.30$ & $557,172.90$ & $555,781.50$ & $555,514.80$ & $555,514.80$ & $489,150.10$ & $489,190.20$ & $489,319.50$ & $489,558.80$ & $490,085.40$ \\
\hline 12 & $586,388.50$ & $591,673.30$ & $592,721.70$ & $592,974.60$ & $592,974.60$ & $489,150.10$ & $489,190.20$ & $489,319.50$ & $489,558.80$ & $490,085.40$ \\
\hline 13 & $498,148.40$ & $505,743.20$ & $504,575.20$ & $504,778.40$ & $504,778.40$ & $489,150.10$ & $489,190.20$ & $489,319.50$ & $489,558.80$ & $490,085.40$ \\
\hline 14 & $342,512.60$ & $342,629.30$ & $341,979.20$ & $341,788.90$ & $341,788.90$ & $489,150.10$ & $489,190.20$ & $489,319.50$ & $489,558.80$ & $490,085.40$ \\
\hline 15 & $404,178.50$ & $400,378.20$ & $400,987.30$ & $402,321.20$ & $402,321.20$ & $489,150.10$ & $489,190.20$ & $489,319.50$ & $489,558.80$ & $490,085.40$ \\
\hline 16 & $502,871.40$ & $500,278.10$ & $502,098.70$ & $501,699.70$ & $502,001.70$ & $489,150.10$ & $489,190.20$ & $489,319.50$ & $489,558.80$ & $490,085.40$ \\
\hline 17 & $519,917.10$ & $520,504.30$ & $520,352.10$ & $520,412.90$ & $520,410.00$ & $489,150.10$ & $489,190.20$ & $489,319.50$ & $489,558.80$ & $490,085.40$ \\
\hline 18 & $544,147.80$ & $537,144.00$ & $536,726.20$ & $535,626.20$ & $535,386.80$ & $489,150.10$ & $489,190.20$ & $489,319.50$ & $489,558.80$ & $490,085.40$ \\
\hline 19 & $520,667.80$ & $528,435.00$ & $528,955.70$ & $529,326.90$ & $529,326.90$ & $489,150.10$ & $489,190.20$ & $489,319.50$ & $489,558.80$ & $490,085.40$ \\
\hline 20 & $472,743.20$ & $472,526.70$ & $472,780.20$ & $471,719.40$ & $471,719.40$ & $489,150.10$ & $489,190.20$ & $489,319.50$ & $489,558.80$ & $490,085.40$ \\
\hline 21 & $403,358.30$ & $404,960.10$ & $405,273.70$ & $406,471.30$ & $406,471.30$ & $465,735.40$ & $464,511.20$ & $464,640.60$ & $464,879.80$ & $465,409.70$ \\
\hline Total & $10,442,263.80$ & $10,454,349.70$ & $10,456,111.20$ & $10,457,945.50$ & $10,458,239.90$ & $10,749,396.50$ & $10,750,276.60$ & $10,760,274.70$ & $10,764,972.90$ & $10,771,804.20$ \\
\hline Media & $497,250.66$ & $497,826.18$ & $497,910.06$ & $497,997.40$ & $498,011.42$ & $511,876.02$ & $511,917.93$ & $512,394.03$ & $512,617.76$ & $512,943.06$ \\
\hline
\end{tabular}


Tabela 24. Volumes anuais adquiridos de madeira de mercado, em $\mathrm{m}^{3}$, resultantes do modelo Global de minimização do custo presente sem restrições operacionais, para os diferentes cenários de valor de madeira de mercado (onde $1=$ valor $+20 \%$; $2=$ valor $+10 \% ; 3=$ valor original; $4=$ valor $-10 \% ; 5=$ valor $-20 \%$ )

\begin{tabular}{|c|c|c|c|c|c|c|c|c|c|c|}
\hline \multirow[b]{2}{*}{ Ano } & \multicolumn{5}{|c|}{ Produção Livre } & \multicolumn{5}{|c|}{ Produção Ordenada } \\
\hline & Cenário 1 & Cenário 2 & Cenário 3 & Cenário 4 & Cenário 5 & Cenário 1 & Cenário 2 & Cenário 3 & Cenário 4 & Cenário 5 \\
\hline 1 & - & - & $3,257.09$ & $141,211.10$ & $172,283.30$ & $279,967.60$ & $293,970.80$ & $375,474.00$ & $405,010.20$ & $407,549.70$ \\
\hline 2 & $536,849.00$ & $702,376.70$ & $698,273.10$ & $562,410.90$ & $522,984.60$ & $199,412.50$ & $203,893.80$ & $241,882.20$ & $276,880.30$ & $407,549.70$ \\
\hline 3 & $70,228.59$ & - & - & $52,184.10$ & $170,108.00$ & $199,412.50$ & $203,893.80$ & $241,882.20$ & $276,880.30$ & $407,549.70$ \\
\hline 4 & $326,343.80$ & $324,384.90$ & $541,484.70$ & $792,366.40$ & $1,290,819.00$ & $199,412.50$ & $203,893.80$ & $241,882.20$ & $276,880.30$ & $407,549.70$ \\
\hline 5 & - & - & - & - & - & $199,412.50$ & $203,893.80$ & $241,882.20$ & $276,880.30$ & $407,549.70$ \\
\hline 6 & - & - & - & - & $298,861.80$ & $199,412.50$ & $203,893.80$ & $241,882.20$ & $276,880.30$ & $407,549.70$ \\
\hline 7 & $97,220.91$ & $124,955.20$ & $108,129.80$ & $187,472.80$ & $305,138.90$ & $199,412.50$ & $203,893.80$ & $241,882.20$ & $276,880.30$ & $407,549.70$ \\
\hline 8 & $573,998.30$ & $708,647.90$ & $741,603.40$ & $681,027.30$ & $647,671.20$ & $199,412.50$ & $203,893.80$ & $241,882.20$ & $276,880.30$ & $407,549.70$ \\
\hline 9 & - & - & - & - & $170,108.00$ & $199,412.50$ & $203,893.80$ & $241,882.20$ & $276,880.30$ & $407,549.70$ \\
\hline 10 & $974,581.50$ & $968,322.30$ & $1,100,533.00$ & $1,331,209.00$ & $1,161,501.00$ & $199,412.50$ & $203,893.80$ & $241,882.20$ & $276,880.30$ & $407,549.70$ \\
\hline 11 & - & - & - & $87,687.83$ & $827,244.80$ & $199,412.50$ & $203,893.80$ & $241,882.20$ & $276,880.30$ & $407,549.70$ \\
\hline 12 & - & - & - & - & - & $199,412.50$ & $203,893.80$ & $241,882.20$ & $276,880.30$ & $407,549.70$ \\
\hline 13 & - & - & $39,970.43$ & - & $326,287.60$ & $199,412.50$ & $203,893.80$ & $241,882.20$ & $276,880.30$ & $407,549.70$ \\
\hline 14 & - & - & - & - & - & $199,412.50$ & $203,893.80$ & $241,882.20$ & $276,880.30$ & $407,549.70$ \\
\hline 15 & - & - & - & $61,049.23$ & $87,135.21$ & $199,412.50$ & $203,893.80$ & $241,882.20$ & $276,880.30$ & $407,549.70$ \\
\hline 16 & $843,602.30$ & $938,860.70$ & $1,148,789.00$ & $1,377,370.00$ & $1,381,234.00$ & $199,412.50$ & $203,893.80$ & $241,882.20$ & $276,880.30$ & $407,549.70$ \\
\hline 17 & $126,522.40$ & $130,586.30$ & $117,911.50$ & $148,103.30$ & $1,111,632.00$ & $199,412.50$ & $203,893.80$ & $241,882.20$ & $276,880.30$ & $407,549.70$ \\
\hline 18 & - & - & - & - & - & $199,412.50$ & $203,893.80$ & $241,882.20$ & $276,880.30$ & $407,549.70$ \\
\hline 19 & - & - & - & - & - & $199,412.50$ & $203,893.80$ & $241,882.20$ & $276,880.30$ & $407,549.70$ \\
\hline 20 & - & - & - & - & - & $43,262.31$ & $54,350.82$ & $124,921.80$ & $132,100.30$ & $407,549.70$ \\
\hline 21 & - & - & - & - & - & $43,262.31$ & $15,425.91$ & $13,876.27$ & - & $119,087.80$ \\
\hline Total & 3,549,346.80 & $3,898,134.00$ & $4,499,952.02$ & $5,422,091.96$ & $8,473,009.41$ & 3,955,917.22 & $4,033,835.93$ & $4,868,151.67$ & $5,520,955.90$ & $8,270,081.80$ \\
\hline Media & $169,016.51$ & $185,625.43$ & $214,283.43$ & $258,194.86$ & $403,476.64$ & $188,377.01$ & $192,087.43$ & $231,816.75$ & $262,902.66$ & $393,813.42$ \\
\hline
\end{tabular}


Tabela 25. Volumes anuais adquiridos de madeira de mercado, em $\mathrm{m}^{3}$, resultantes do modelo Global de minimização do custo presente com restrições operacionais, para os diferentes cenários de valor de madeira de mercado (onde $1=$ valor $+20 \%$; $2=$ valor $+10 \% ; 3=$ valor original; $4=$ valor $-10 \% ; 5=$ valor $-20 \%$ )

\begin{tabular}{|c|c|c|c|c|c|c|c|c|c|c|}
\hline \multirow[b]{2}{*}{ Ano } & \multicolumn{5}{|c|}{ Produção Livre } & \multicolumn{5}{|c|}{ Produção Ordenada } \\
\hline & Cenário 1 & Cenário 2 & Cenário 3 & Cenário 4 & Cenário 5 & Cenário 1 & Cenário 2 & Cenário 3 & Cenário 4 & Cenário 5 \\
\hline 1 & $384,554.70$ & $384,646.00$ & $395,945.50$ & $393,718.80$ & $397,777.00$ & $512,942.20$ & $521,035.10$ & $537,585.80$ & $551,322.10$ & $584,681.90$ \\
\hline 2 & $447,129.50$ & $446,368.80$ & $435,057.50$ & $444,182.20$ & $445,879.30$ & $512,942.20$ & $521,035.10$ & $537,585.80$ & $551,322.10$ & $584,681.90$ \\
\hline 3 & $582,056.20$ & $584,888.80$ & $595,285.20$ & $594,474.10$ & $599,262.70$ & $512,942.20$ & $521,035.10$ & $537,585.80$ & $551,322.10$ & $584,681.90$ \\
\hline 4 & $639,876.70$ & $638,581.30$ & $640,067.70$ & $636,479.20$ & $643,575.80$ & $512,942.20$ & $521,035.10$ & $537,585.80$ & $551,322.10$ & $584,681.90$ \\
\hline 5 & $494,937.00$ & $506,122.40$ & $500,849.20$ & $519,496.00$ & $492,362.10$ & $506,036.90$ & $521,035.10$ & $537,413.20$ & $551,322.10$ & $584,681.90$ \\
\hline 6 & $429,083.00$ & $435,146.20$ & $439,670.50$ & $412,937.10$ & $569,392.90$ & $506,036.90$ & $521,035.10$ & $537,413.20$ & $551,322.10$ & $584,681.90$ \\
\hline 7 & $374,272.70$ & $374,770.50$ & $414,767.00$ & $428,255.10$ & $490,839.00$ & $506,036.90$ & $521,035.10$ & $537,413.20$ & $551,322.10$ & $584,681.90$ \\
\hline 8 & $443,566.90$ & $442,066.30$ & $460,330.60$ & $482,099.10$ & $606,759.50$ & $506,036.90$ & $521,035.10$ & $537,413.20$ & $551,322.10$ & $584,681.90$ \\
\hline 9 & $541,560.10$ & $543,574.00$ & $583,037.30$ & $593,990.30$ & $582,088.10$ & $506,036.90$ & $521,035.10$ & $537,413.20$ & $551,322.10$ & $584,681.90$ \\
\hline 10 & $652,209.00$ & $656,394.60$ & $660,506.50$ & $665,714.20$ & $653,574.50$ & $506,036.90$ & $521,035.10$ & $537,413.20$ & $551,322.10$ & $584,681.90$ \\
\hline 11 & $551,290.60$ & $546,556.10$ & $538,129.70$ & $552,438.90$ & $527,575.80$ & $506,036.90$ & $521,035.10$ & $537,413.20$ & $551,322.10$ & $584,681.90$ \\
\hline 12 & $449,097.30$ & $440,937.00$ & $469,313.20$ & $451,168.90$ & $460,476.70$ & $506,036.90$ & $521,035.10$ & $537,413.20$ & $551,322.10$ & $584,681.90$ \\
\hline 13 & $442,910.80$ & $474,277.80$ & $741,508.80$ & $926,642.90$ & $957,260.00$ & $506,036.90$ & $521,035.10$ & $537,413.20$ & $551,322.10$ & $584,681.90$ \\
\hline 14 & $350,648.00$ & $351,198.90$ & $350,648.00$ & $337,754.80$ & $339,938.80$ & $506,036.90$ & $521,035.10$ & $537,413.20$ & $551,322.10$ & $584,681.90$ \\
\hline 15 & $522,733.90$ & $524,869.10$ & $544,707.00$ & $556,039.20$ & $556,917.40$ & $506,036.90$ & $521,035.10$ & $537,413.20$ & $551,322.10$ & $584,681.90$ \\
\hline 16 & $629,172.30$ & $626,368.00$ & $597,367.30$ & $594,421.80$ & $735,511.30$ & $506,036.90$ & $521,035.10$ & $537,413.20$ & $551,322.10$ & $584,681.90$ \\
\hline 17 & $542,574.30$ & $547,375.80$ & $565,629.20$ & $567,259.40$ & $572,088.30$ & $487,530.00$ & $508,698.60$ & $536,787.30$ & $551,322.10$ & $584,681.90$ \\
\hline 18 & $470,214.50$ & $464,998.70$ & $458,564.50$ & $461,120.80$ & $439,649.60$ & $487,530.00$ & $493,651.30$ & $490,013.20$ & $544,917.50$ & $584,681.90$ \\
\hline 19 & $490,084.70$ & $508,275.50$ & $489,955.60$ & $484,691.40$ & $504,144.50$ & $487,530.00$ & $493,651.30$ & $490,013.20$ & $495,151.60$ & $584,681.90$ \\
\hline 20 & $348,553.10$ & $345,949.80$ & $369,352.60$ & $364,379.90$ & $369,280.80$ & $487,530.00$ & $493,651.30$ & $488,220.30$ & $475,081.20$ & $508,873.80$ \\
\hline 21 & $477,542.00$ & $482,604.20$ & $538,832.70$ & $560,062.30$ & $564,828.70$ & $487,530.00$ & $493,651.30$ & $488,220.30$ & $475,081.20$ & $508,873.80$ \\
\hline Total & $10,264,067.30$ & $10,325,969.80$ & $10,789,525.60$ & $11,027,326.40$ & $11,509,182.80$ & $10,561,861.60$ & $10,819,865.40$ & $11,092,555.90$ & $11,362,707.20$ & $12,126,703.70$ \\
\hline Media & $488,765.11$ & $491,712.85$ & $513,786.93$ & $525,110.78$ & $548,056.32$ & $502,945.79$ & $515,231.69$ & $528,216.95$ & $541,081.30$ & $577,462.08$ \\
\hline
\end{tabular}


Tabela 26. Volumes anuais adquiridos de madeira de mercado, em $\mathrm{m}^{3}$, resultantes do modelo Regionalizado de minimização do custo presente sem restrições operacionais, para os diferentes cenários de valor de madeira de mercado (onde $1=$ valor $+20 \%$; $2=$ valor $+10 \% ; 3=$ valor original; $4=$ valor $-10 \% ; 5=$ valor $-20 \%$ )

\begin{tabular}{|c|c|c|c|c|c|c|c|c|c|c|}
\hline \multirow[b]{2}{*}{ Ano } & \multicolumn{5}{|c|}{ Produção Livre } & \multicolumn{5}{|c|}{ Produção Ordenada } \\
\hline & Cenário 1 & Cenário 2 & Cenário 3 & Cenário 4 & Cenário 5 & Cenário 1 & Cenário 2 & Cenário 3 & Cenário 4 & Cenário 5 \\
\hline 1 & $207,749.30$ & $207,749.30$ & $223,667.70$ & $218,332.40$ & $211,943.30$ & $268,144.70$ & $321,452.70$ & $341,071.10$ & $347,545.10$ & $432,917.40$ \\
\hline 2 & $348,593.00$ & $453,627.10$ & $462,196.30$ & $518,907.40$ & $670,527.40$ & $268,144.70$ & $321,452.70$ & $341,071.10$ & $347,545.10$ & $432,917.40$ \\
\hline 3 & $240,212.40$ & $247,106.90$ & $281,217.60$ & $427,533.20$ & $495,046.50$ & $204,857.00$ & $229,076.20$ & $256,996.70$ & $301,273.50$ & $432,917.40$ \\
\hline 4 & $261,035.70$ & $256,865.20$ & $387,176.00$ & $297,152.30$ & $455,275.80$ & $204,857.00$ & $229,076.20$ & $256,996.70$ & $301,273.50$ & $432,917.40$ \\
\hline 5 & - & - & $8,755.39$ & $142,640.00$ & $400,000.00$ & $204,857.00$ & $229,076.20$ & $256,996.70$ & $301,273.50$ & $432,917.40$ \\
\hline 6 & $141,714.10$ & $141,457.20$ & $116,923.10$ & $114,219.30$ & $355,792.40$ & $204,857.00$ & $229,076.20$ & $256,996.70$ & $301,273.50$ & $432,917.40$ \\
\hline 7 & $98,359.08$ & $98,359.08$ & $145,353.70$ & $156,130.50$ & $377,088.90$ & $204,857.00$ & $229,076.20$ & $256,996.70$ & $301,273.50$ & $432,917.40$ \\
\hline 8 & $549,577.00$ & $656,190.70$ & $596,161.00$ & $623,751.60$ & $676,145.60$ & $204,857.00$ & $229,076.20$ & $256,996.70$ & $301,273.50$ & $432,917.40$ \\
\hline 9 & $196,423.90$ & $210,942.90$ & $246,127.10$ & $358,272.50$ & $495,046.50$ & $204,857.00$ & $229,076.20$ & $256,996.70$ & $301,273.50$ & $432,917.40$ \\
\hline 10 & $472,983.80$ & $492,995.60$ & $630,078.30$ & $668,882.00$ & $760,116.00$ & $204,857.00$ & $229,076.20$ & $256,996.70$ & $301,273.50$ & $432,917.40$ \\
\hline 11 & $12,173.01$ & $5,271.65$ & $129,445.20$ & $241,178.30$ & $534,188.70$ & $204,857.00$ & $229,076.20$ & $256,996.70$ & $301,273.50$ & $432,917.40$ \\
\hline 12 & - & - & - & - & $398,460.20$ & $204,857.00$ & $229,076.20$ & $256,996.70$ & $301,273.50$ & $432,917.40$ \\
\hline 13 & $159,085.40$ & $153,263.80$ & $75,587.68$ & $73,961.52$ & $322,078.20$ & $204,857.00$ & $229,076.20$ & $256,996.70$ & $301,273.50$ & $432,917.40$ \\
\hline 14 & $197,951.70$ & $202,181.30$ & $171,958.00$ & $153,921.80$ & $59,559.70$ & $204,857.00$ & $229,076.20$ & $256,996.70$ & $301,273.50$ & $432,917.40$ \\
\hline 15 & $259,068.40$ & $277,046.00$ & $331,840.50$ & $427,533.20$ & $495,046.50$ & $204,857.00$ & $229,076.20$ & $256,996.70$ & $301,273.50$ & $432,917.40$ \\
\hline 16 & $499,280.00$ & $611,632.20$ & $724,842.60$ & $866,648.40$ & $911,231.00$ & $204,857.00$ & $229,076.20$ & $256,996.70$ & $301,273.50$ & $432,917.40$ \\
\hline 17 & - & - & $144,986.80$ & $189,387.30$ & $730,000.00$ & $204,857.00$ & $229,076.20$ & $256,996.70$ & $301,273.50$ & $432,917.40$ \\
\hline 18 & - & $22,689.85$ & $30,851.46$ & $19,210.62$ & $289,846.90$ & $204,857.00$ & $229,076.20$ & $256,996.70$ & $301,273.50$ & $432,917.40$ \\
\hline 19 & $369,440.70$ & $277,410.40$ & $152,378.70$ & $158,970.70$ & $355,288.00$ & $204,857.00$ & $229,076.20$ & $256,996.70$ & $301,273.50$ & $432,917.40$ \\
\hline 20 & - & - & - & - & - & $57,658.49$ & $74,470.25$ & $133,933.70$ & $216,472.20$ & $432,917.40$ \\
\hline 21 & - & $86,943.32$ & $111,324.00$ & $175,214.90$ & $200,829.80$ & $57,658.49$ & $74,470.25$ & $24,231.30$ & $5,559.11$ & $107,382.40$ \\
\hline Total & $4,013,647.49$ & $4,401,732.50$ & 4,970,871.13 & $\mathbf{5 , 8 3 1 , 8 4 7 . 9 4}$ & $9,193,511.40$ & $4,134,175.38$ & $4,686,141.30$ & $5,209,251.10$ & $6,038,771.01$ & $8,765,730.40$ \\
\hline Media & 191,126.07 & $209,606.31$ & $236,708.15$ & $277,707.04$ & $437,786.26$ & $196,865.49$ & $223,149.59$ & $248,059.58$ & $287,560.52$ & $417,415.73$ \\
\hline
\end{tabular}


Tabela 27. Volumes anuais adquiridos de madeira de mercado, em $\mathrm{m}^{3}$, resultantes do modelo Regionalizado de minimização do custo presente com restrições operacionais, para os diferentes cenários de valor de madeira de mercado (onde $1=$ valor $+20 \% ; 2=$ valor $+10 \% ; 3=$ valor original; $4=$ valor $-10 \% ; 5=$ valor $-20 \%$ )

\begin{tabular}{|c|c|c|c|c|c|c|c|c|c|c|}
\hline \multirow[b]{2}{*}{ Ano } & \multicolumn{5}{|c|}{ Produção Livre } & \multicolumn{5}{|c|}{ Produção Ordenada } \\
\hline & Cenário 1 & Cenário 2 & Cenário 3 & Cenário 4 & Cenário 5 & Cenário 1 & Cenário 2 & Cenário 3 & Cenário 4 & Cenário 5 \\
\hline 1 & $619,358.30$ & $590,171.90$ & $593,760.90$ & $555,995.70$ & $555,757.50$ & $779,988.80$ & $781,268.30$ & $785,883.00$ & $801,639.30$ & $877,888.10$ \\
\hline 2 & $639,103.20$ & $671,637.50$ & $663,294.40$ & $703,055.10$ & $722,038.40$ & $627,332.00$ & $628,611.50$ & $633,226.20$ & $648,982.50$ & $818,984.60$ \\
\hline 3 & $525,834.40$ & $535,138.70$ & $538,807.40$ & $669,634.30$ & $862,640.20$ & $542,363.90$ & $543,643.40$ & $548,258.10$ & $567,488.00$ & $773,816.90$ \\
\hline 4 & $614,825.60$ & $608,482.50$ & $753,200.30$ & $699,084.10$ & $843,176.00$ & $542,363.90$ & $543,643.40$ & $548,258.10$ & $567,488.00$ & $773,816.90$ \\
\hline 5 & $540,798.50$ & $541,102.70$ & $540,870.90$ & $600,570.10$ & $813,500.70$ & $525,986.50$ & $531,748.00$ & $539,936.40$ & $567,488.00$ & $773,816.90$ \\
\hline 6 & $439,460.70$ & $443,782.50$ & $443,621.30$ & $455,364.00$ & $616,189.00$ & $509,436.90$ & $515,478.70$ & $525,088.10$ & $561,513.70$ & $770,583.90$ \\
\hline 7 & $395,470.50$ & $393,003.90$ & $396,408.50$ & $432,350.60$ & $610,635.90$ & $509,436.90$ & $515,478.70$ & $525,088.10$ & $561,513.70$ & $770,583.90$ \\
\hline 8 & $432,138.10$ & $440,725.50$ & $442,775.60$ & $706,683.30$ & $736,917.50$ & $509,436.90$ & $515,478.70$ & $525,088.10$ & $561,513.70$ & $770,583.90$ \\
\hline 9 & $533,260.90$ & $559,832.40$ & $586,630.50$ & $700,620.20$ & $876,541.40$ & $509,436.90$ & $515,478.70$ & $525,088.10$ & $561,513.70$ & $770,583.90$ \\
\hline 10 & $607,555.60$ & $613,951.40$ & $707,181.50$ & $773,086.60$ & $866,205.50$ & $509,436.90$ & $515,478.70$ & $525,088.10$ & $561,513.70$ & $770,583.90$ \\
\hline 11 & $557,726.70$ & $548,719.90$ & $559,017.00$ & $548,279.20$ & $821,159.60$ & $509,436.90$ & $515,478.70$ & $525,088.10$ & $561,513.70$ & $770,583.90$ \\
\hline 12 & $468,673.30$ & $469,102.70$ & $470,089.90$ & $478,558.80$ & $741,665.10$ & $509,436.90$ & $515,478.70$ & $525,088.10$ & $561,513.70$ & $770,583.90$ \\
\hline 13 & $474,640.20$ & $472,460.50$ & $469,826.10$ & $468,658.90$ & $471,638.80$ & $509,436.90$ & $515,478.70$ & $525,088.10$ & $561,513.70$ & $770,583.90$ \\
\hline 14 & $507,248.20$ & $514,432.30$ & $503,432.50$ & $516,511.50$ & $545,835.20$ & $509,436.90$ & $515,478.70$ & $525,088.10$ & $561,513.70$ & $770,583.90$ \\
\hline 15 & $520,740.50$ & $525,216.00$ & $724,950.60$ & $794,707.60$ & $855,915.80$ & $509,436.90$ & $515,478.70$ & $525,088.10$ & $561,513.70$ & $770,583.90$ \\
\hline 16 & $555,157.30$ & $576,054.90$ & $555,417.20$ & $952,846.20$ & $1,073,124.00$ & $509,436.90$ & $515,478.70$ & $525,088.10$ & $561,513.70$ & $770,583.90$ \\
\hline 17 & $554,771.00$ & $556,105.70$ & $550,383.00$ & $569,930.20$ & $1,025,930.00$ & $509,436.90$ & $515,478.70$ & $525,088.10$ & $561,513.70$ & $770,583.90$ \\
\hline 18 & $473,736.50$ & $483,283.50$ & $465,810.20$ & $471,619.40$ & $524,911.70$ & $505,759.10$ & $510,129.00$ & $516,010.50$ & $553,924.00$ & $754,698.70$ \\
\hline 19 & $500,189.00$ & $496,137.40$ & $497,621.90$ & $495,317.10$ & $751,996.10$ & $505,759.10$ & $510,129.00$ & $513,475.70$ & $516,192.90$ & $747,249.20$ \\
\hline 20 & $398,760.20$ & $399,105.40$ & $396,536.30$ & $414,596.90$ & $389,881.50$ & $505,759.10$ & $508,501.60$ & $513,475.70$ & $514,441.80$ & $717,471.30$ \\
\hline 21 & $457,653.50$ & $459,105.00$ & $464,249.10$ & $451,894.90$ & $481,785.80$ & $462,228.90$ & $458,390.10$ & $455,808.20$ & $441,869.30$ & $572,992.10$ \\
\hline Total & $10,817,102.20$ & $10,897,552.30$ & $11,323,885.10$ & $12,459,364.70$ & $15,187,445.70$ & $11,110,784.10$ & $11,201,808.70$ & $11,355,389.10$ & $11,917,678.20$ & $16,057,741.50$ \\
\hline Media & $515,100.10$ & $518,931.06$ & $539,232.62$ & 593,303.08 & $723,211.70$ & $529,084.96$ & $\mathbf{5 3 3}, \mathbf{4 1 9 . 4 6}$ & $540,732.81$ & $567,508.49$ & $764,654.36$ \\
\hline
\end{tabular}


Nas Tabelas 28 e 29, são mostradas as idades médias de rotação, nas Tabelas 30, 31, 32 e 33 a área anual de colheita recomendada para os modelos de maximização do valor líquido presente e nas Tabelas 34, 35, 36 e 37 para os modelos de minimização do custo presente.

Tabela 28. Idades médias de colheita (rotação média), em anos, para maximização de valor presente líquido e minimização dos custos no modelo Global

\begin{tabular}{|c|c|c|c|c|c|c|c|c|c|c|c|}
\hline & & \multicolumn{10}{|c|}{ Intensidade de ordenamento } \\
\hline \multirow{2}{*}{\multicolumn{2}{|c|}{ Modelos }} & & & Livre & & & & & rdena & & \\
\hline & & 1 & 2 & 3 & 4 & 5 & 1 & 2 & 3 & 4 & 5 \\
\hline \multirow[t]{2}{*}{ VPL } & $\mathbf{C} / \mathbf{R}$ & 6.93 & 6.92 & 6.82 & 6.80 & 6.81 & 7.04 & 6.96 & 6.95 & 6.90 & 6.81 \\
\hline & $\mathbf{S} / \mathbf{R}$ & 6.71 & 6.73 & 6.73 & 6.75 & 6.80 & 6.79 & 6.79 & 6.81 & 6.85 & 6.83 \\
\hline \multirow[t]{2}{*}{$\mathbf{C P}$} & $\mathrm{C} / \mathrm{R}$ & 7.28 & 7.29 & 7.30 & 7.30 & 7.30 & 7.36 & 7.36 & 7.37 & 7.38 & 7.39 \\
\hline & $\mathbf{S} / \mathbf{R}$ & 6.62 & 6.62 & 6.62 & 6.62 & 6.62 & 6.76 & 6.76 & 6.76 & 6.76 & 6.76 \\
\hline
\end{tabular}

Tabela 29. Idades médias de colheita (rotação média), em anos, para maximização de valor presente líquido e minimização dos custos presentes no modelo Regionalizado

\begin{tabular}{|c|c|c|c|c|c|c|c|c|c|c|c|}
\hline & & \multicolumn{10}{|c|}{ Intensidade de ordenamento } \\
\hline & & & & Livre & & & & & rdena & & \\
\hline \multicolumn{2}{|c|}{ Modelos } & 1 & 2 & 3 & 4 & 5 & 1 & 2 & 3 & 4 & 5 \\
\hline \multirow[t]{2}{*}{ VPL } & $\mathbf{C} / \mathbf{R}$ & 7.16 & 7.12 & 7.11 & 7.05 & 7.12 & 7.31 & 7.30 & 7.27 & 7.25 & 7.18 \\
\hline & $\mathbf{S} / \mathbf{R}$ & 6.82 & 6.82 & 6.84 & 6.85 & 6.91 & 6.83 & 6.84 & 6.85 & 6.86 & 6.86 \\
\hline \multirow[t]{2}{*}{$\mathbf{C P}$} & $\mathbf{C} / \mathbf{R}$ & 7.43 & 7.44 & 7.44 & 7.44 & 7.44 & 7.52 & 7.52 & 7.52 & 7.52 & 7.51 \\
\hline & $\mathbf{S} / \mathbf{R}$ & 6.75 & 6.75 & 6.75 & 6.75 & 6.75 & 6.93 & 6.93 & 6.93 & 6.93 & 6.93 \\
\hline
\end{tabular}

Onde: $\mathrm{VPL}=$ modelos de maximização do valor presente líquido, $\mathrm{CP}=$ modelos de minimização dos custos presentes, $C / R$ e $S / R=$ com e sem restrições operacionais de área, respectivamente, e $1=$ valor $+20 \% ; 2=$ valor $+10 \%$; $3=$ valor original; $4=$ valor $10 \%$; $=$ valor $-20 \%$ 
Tabela 30. Prescrição de áreas anuais de colheita, em hectares, resultantes do modelo Global de maximização do valor presente líquido sem restrições operacionais, para os diferentes cenários de valor de madeira de mercado (onde $1=$ valor $+20 \%$; $2=$ valor $+10 \% ; 3=$ valor original; $4=$ valor $-10 \% ; 5=$ valor $-20 \%$ ).

\begin{tabular}{|c|c|c|c|c|c|c|c|c|c|c|}
\hline \multirow[b]{2}{*}{ Ano } & \multicolumn{5}{|c|}{ Produção Livre } & \multicolumn{5}{|c|}{ Produção Ordenada } \\
\hline & Cenário 1 & Cenário 2 & Cenário 3 & Cenário 4 & Cenário 5 & Cenário 1 & Cenário 2 & Cenário 3 & Cenário 4 & Cenário 5 \\
\hline 1 & 6,298.30 & $6,298.30$ & $6,298.30$ & $6,298.30$ & $6,298.30$ & $5,437.40$ & $5,437.51$ & $5,436.87$ & $5,436.71$ & $5,437.69$ \\
\hline 2 & $5,472.30$ & $5,472.30$ & $5,472.30$ & $5,472.30$ & $5,472.30$ & $5,854.34$ & $5,854.08$ & $5,853.88$ & $5,851.86$ & $5,846.77$ \\
\hline 3 & $7,779.30$ & $7,779.30$ & $7,779.30$ & $7,779.30$ & $7,779.30$ & $6,795.50$ & $6,792.10$ & $6,776.33$ & $6,745.94$ & $6,737.90$ \\
\hline 4 & $5,603.46$ & $5,596.71$ & $5,552.25$ & $5,552.25$ & $5,552.25$ & $7,253.62$ & $7,256.69$ & $7,273.63$ & $7,304.37$ & $7,310.22$ \\
\hline 5 & $6,931.39$ & $6,938.14$ & $6,982.60$ & $6,982.60$ & $6,982.60$ & $6,015.37$ & $6,020.58$ & $6,020.68$ & $6,021.90$ & $6,028.25$ \\
\hline 6 & $6,874.18$ & $6,874.18$ & $6,874.18$ & $6,874.18$ & $6,874.18$ & $6,056.39$ & $6,056.22$ & $6,056.29$ & $6,055.54$ & $6,053.59$ \\
\hline 7 & $5,941.03$ & $5,941.03$ & $5,935.06$ & $5,835.77$ & $5,717.41$ & $5,654.79$ & $5,650.51$ & $5,650.80$ & $5,645.74$ & $5,645.44$ \\
\hline 8 & $4,342.08$ & $4,248.57$ & $4,259.58$ & $4,442.61$ & $4,730.92$ & $5,851.00$ & $5,851.01$ & $5,850.88$ & $5,855.30$ & $5,852.16$ \\
\hline 9 & $7,673.79$ & $7,673.79$ & $7,643.17$ & $7,630.99$ & $7,570.66$ & $6,651.10$ & $6,626.82$ & $6,627.19$ & $6,620.03$ & $6,599.00$ \\
\hline 10 & $7,143.80$ & $7,237.31$ & $7,262.88$ & $7,191.32$ & $7,081.71$ & $6,751.57$ & $6,772.64$ & $6,772.06$ & $6,731.13$ & $6,729.68$ \\
\hline 11 & $6,663.92$ & $6,663.92$ & $6,663.92$ & $6,663.92$ & $6,674.07$ & $6,115.60$ & $6,118.44$ & $6,118.15$ & $6,137.12$ & $6,145.34$ \\
\hline 12 & $6,876.39$ & $6,863.72$ & $6,854.54$ & $6,870.30$ & $6,882.69$ & $6,262.03$ & $6,252.38$ & $6,252.39$ & $6,275.67$ & $6,276.79$ \\
\hline 13 & $3,541.12$ & $3,553.79$ & $3,562.98$ & $3,547.21$ & $3,524.66$ & $6,126.06$ & $6,136.20$ & $6,136.09$ & $6,137.84$ & $6,140.12$ \\
\hline 14 & $6,323.62$ & $6,230.11$ & $6,232.11$ & $6,265.34$ & $6,354.30$ & $5,707.59$ & $5,707.31$ & $5,707.21$ & $5,704.69$ & $5,714.58$ \\
\hline 15 & $7,565.40$ & $7,565.40$ & $7,534.89$ & $7,524.45$ & $7,507.71$ & $6,678.94$ & $6,654.63$ & $6,654.83$ & $6,648.74$ & $6,614.24$ \\
\hline 16 & $7,726.48$ & $7,819.99$ & $7,848.50$ & $7,825.71$ & $7,753.48$ & $6,675.41$ & $6,697.34$ & $6,680.43$ & $6,659.34$ & $6,662.98$ \\
\hline 17 & $6,924.46$ & $6,924.46$ & $6,924.46$ & $6,924.46$ & $6,924.46$ & $6,107.17$ & $6,104.60$ & $6,122.31$ & $6,107.45$ & $6,121.71$ \\
\hline 18 & $6,867.21$ & $6,860.45$ & $6,816.00$ & $6,816.00$ & $6,826.15$ & $6,186.93$ & $6,183.82$ & $6,183.95$ & $6,200.97$ & $6,212.50$ \\
\hline 19 & $3,223.20$ & $3,223.20$ & $3,263.20$ & $3,278.96$ & $3,291.35$ & $6,372.84$ & $6,385.35$ & $6,384.76$ & 6,417.02 & $6,426.51$ \\
\hline 20 & $6,603.19$ & $6,510.52$ & $6,512.25$ & $6,529.71$ & $6,596.12$ & $6,146.74$ & $6,146.13$ & $6,146.25$ & $6,132.25$ & $6,108.87$ \\
\hline 21 & $7,614.40$ & $7,620.31$ & $7,591.49$ & $7,530.54$ & $7,432.82$ & $7,072.66$ & $7,043.98$ & $7,044.39$ & $7,026.18$ & $6,971.43$ \\
\hline Total & $133,988.98$ & $133,895.47$ & $133,863.92$ & $133,836.20$ & $133,827.44$ & $131,773.06$ & $131,748.31$ & $131,749.36$ & $131,715.79$ & $131,635.75$ \\
\hline Meala & $6,380.43$ & $6,375.97$ & $6,374.47$ & $6,373.15$ & $6,372.74$ & $6,274.91$ & $6,273.73$ & $6,273.78$ & 6,272.18 & $6,268.37$ \\
\hline
\end{tabular}


Tabela 31. Prescrição de áreas anuais de colheita, em hectares, resultantes do modelo Global de maximização do valor presente líquido com restrições operacionais, para os diferentes cenários de valor de madeira de mercado (onde $1=$ valor $+20 \%$; $2=$ valor $+10 \% ; 3=$ valor original; $4=$ valor $-10 \% ; 5=$ valor $-20 \%$ )

\begin{tabular}{|c|c|c|c|c|c|c|c|c|c|c|}
\hline \multirow[b]{2}{*}{ Ano } & \multicolumn{5}{|c|}{ Produção Livre } & \multicolumn{5}{|c|}{ Produção Ordenada } \\
\hline & Cenário 1 & Cenário 2 & Cenário 3 & Cenário 4 & Cenário 5 & Cenário 1 & Cenário 2 & Cenário 3 & Cenário 4 & Cenário 5 \\
\hline 1 & $4,500.00$ & $4,500.00$ & $4,500.00$ & $4,500.00$ & $4,500.00$ & $4,116.36$ & $4,083.91$ & $4,088.24$ & $4,098.28$ & $4,043.61$ \\
\hline 2 & $4,500.00$ & $4,500.00$ & $4,500.00$ & $4,500.00$ & $4,500.00$ & $4,500.00$ & $4,500.00$ & $4,500.00$ & $4,500.00$ & $4,500.00$ \\
\hline 3 & $4,500.00$ & $4,500.00$ & $4,500.00$ & $4,500.00$ & $4,500.00$ & $4,500.00$ & $4,500.00$ & $4,500.00$ & $4,500.00$ & $4,500.00$ \\
\hline 4 & $4,500.00$ & $4,500.00$ & $4,500.00$ & $4,500.00$ & $4,500.00$ & $4,500.00$ & $4,500.00$ & $4,500.00$ & $4,500.00$ & $4,500.00$ \\
\hline 5 & $4,500.00$ & $4,500.00$ & $4,500.00$ & $4,500.00$ & $4,500.00$ & $4,500.00$ & $4,500.00$ & $4,500.00$ & $4,500.00$ & $4,500.00$ \\
\hline 6 & $4,500.00$ & $4,500.00$ & $4,500.00$ & $4,500.00$ & $4,500.00$ & $4,500.00$ & $4,500.00$ & $4,500.00$ & $4,500.00$ & $4,500.00$ \\
\hline 7 & $4,500.00$ & $4,500.00$ & $4,500.00$ & $4,500.00$ & $4,500.00$ & $4,334.10$ & $4,333.47$ & $4,307.48$ & $4,320.70$ & $4,294.64$ \\
\hline 8 & $4,500.00$ & $4,500.00$ & $4,500.00$ & $4,500.00$ & $4,500.00$ & $4,500.00$ & $4,500.00$ & $4,500.00$ & $4,500.00$ & $4,500.00$ \\
\hline 9 & $4,500.00$ & $4,500.00$ & $4,500.00$ & $4,500.00$ & $4,500.00$ & $4,500.00$ & $4,500.00$ & $4,500.00$ & $4,500.00$ & $4,500.00$ \\
\hline 10 & $4,500.00$ & $4,500.00$ & $4,500.00$ & $4,500.00$ & $4,500.00$ & $4,500.00$ & $4,500.00$ & $4,500.00$ & $4,500.00$ & $4,500.00$ \\
\hline 11 & $4,500.00$ & $4,500.00$ & $4,500.00$ & $4,500.00$ & $4,500.00$ & $4,500.00$ & $4,500.00$ & $4,500.00$ & $4,500.00$ & $4,500.00$ \\
\hline 12 & $4,500.00$ & $4,500.00$ & $4,500.00$ & $4,500.00$ & $4,500.00$ & $4,500.00$ & $4,500.00$ & $4,500.00$ & $4,500.00$ & $4,500.00$ \\
\hline 13 & $4,500.00$ & $4,500.00$ & $4,500.00$ & $4,500.00$ & $4,500.00$ & $4,500.00$ & $4,500.00$ & $4,500.00$ & $4,500.00$ & $4,500.00$ \\
\hline 14 & $4,500.00$ & $4,500.00$ & $4,500.00$ & $4,500.00$ & $4,500.00$ & $4,500.00$ & $4,500.00$ & $4,500.00$ & $4,500.00$ & $4,500.00$ \\
\hline 15 & $4,500.00$ & $4,500.00$ & $4,500.00$ & $4,500.00$ & $4,500.00$ & $4,500.00$ & $4,500.00$ & $4,500.00$ & $4,500.00$ & $4,500.00$ \\
\hline 16 & $4,500.00$ & $4,500.00$ & $4,500.00$ & $4,500.00$ & $4,500.00$ & $4,500.00$ & $4,500.00$ & $4,500.00$ & $4,500.00$ & $4,500.00$ \\
\hline 17 & $4,500.00$ & $4,500.00$ & $4,500.00$ & $4,500.00$ & $4,500.00$ & $4,500.00$ & $4,500.00$ & $4,500.00$ & $4,500.00$ & $4,500.00$ \\
\hline 18 & $4,500.00$ & $4,500.00$ & $4,500.00$ & $4,500.00$ & $4,500.00$ & $4,500.00$ & $4,500.00$ & $4,500.00$ & $4,500.00$ & $4,500.00$ \\
\hline 19 & $4,500.00$ & $4,500.00$ & $4,500.00$ & $4,500.00$ & $4,500.00$ & $4,500.00$ & $4,500.00$ & $4,500.00$ & $4,500.00$ & $4,500.00$ \\
\hline 20 & $4,500.00$ & $4,500.00$ & $4,500.00$ & $4,500.00$ & $4,500.00$ & $4,500.00$ & $4,500.00$ & $4,500.00$ & $4,500.00$ & $4,500.00$ \\
\hline 21 & $4,500.00$ & $4,500.00$ & $4,500.00$ & $4,500.00$ & $4,500.00$ & $4,500.00$ & $4,500.00$ & $4,500.00$ & $4,500.00$ & $4,500.00$ \\
\hline Total & $\mathbf{9 4 , 5 0 0 . 0 0}$ & $\mathbf{9 4 , 5 0 0 . 0 0}$ & $\mathbf{9 4 , 5 0 0 . 0 0}$ & $\mathbf{9 4 , 5 0 0 . 0 0}$ & $\mathbf{9 4 , 5 0 0 . 0 0}$ & $93,950.46$ & $\mathbf{9 3 , 9 1 7 . 3 8}$ & $93,895.72$ & 93,918.98 & $93,838.24$ \\
\hline Media & $4,500.00$ & $4,500.00$ & $4,500.00$ & $4,500.00$ & $4,500.00$ & $4,473.83$ & $4,472.26$ & $4,471.22$ & $4,472.33$ & $4,468.49$ \\
\hline
\end{tabular}


Tabela 32. Prescrição de áreas anuais de colheita, em hectares, resultantes do modelo Regionalizado de maximização do valor presente líquido sem restrições operacionais, para os diferentes cenários de valor de madeira de mercado (onde $1=$ valor $+20 \%$; $2=$ valor $+10 \% ; 3=$ valor original; $4=$ valor $-10 \% ; 5=$ valor $-20 \%$ )

\begin{tabular}{|c|c|c|c|c|c|c|c|c|c|c|}
\hline \multirow[b]{2}{*}{ Ano } & \multicolumn{5}{|c|}{ Produção Livre } & \multicolumn{5}{|c|}{ Produção Ordenada } \\
\hline & Cenário 1 & Cenário 2 & Cenário 3 & Cenário 4 & Cenário 5 & Cenário 1 & Cenário 2 & Cenário 3 & Cenário 4 & Cenário 5 \\
\hline 1 & $5,459.83$ & $5,458.69$ & $5,462.87$ & $5,462.38$ & $5,465.18$ & $4,338.88$ & $4,335.97$ & $4,332.68$ & $4,331.93$ & $4,331.98$ \\
\hline 2 & $5,307.71$ & $5,309.66$ & $5,311.57$ & $5,308.73$ & $5,312.71$ & $5,333.61$ & $5,343.40$ & $5,343.32$ & $5,344.08$ & $5,341.62$ \\
\hline 3 & $7,135.06$ & $7,050.40$ & $7,090.49$ & $7,090.94$ & $7,085.13$ & $6,386.29$ & $6,384.57$ & $6,384.98$ & $6,384.81$ & $6,381.55$ \\
\hline 4 & $6,918.70$ & $7,011.08$ & $6,964.90$ & $6,968.55$ & $6,968.56$ & $6,931.57$ & $6,929.12$ & $6,929.38$ & $6,929.05$ & $6,924.51$ \\
\hline 5 & $7,009.25$ & $7,008.90$ & $7,008.90$ & $7,008.87$ & $7,008.83$ & $6,097.22$ & $6,100.53$ & $6,100.00$ & $6,100.42$ & $6,106.13$ \\
\hline 6 & $6,056.63$ & $6,048.46$ & $6,048.46$ & $6,047.72$ & $6,046.77$ & $5,501.04$ & $5,504.92$ & $5,509.26$ & $5,509.98$ & $5,525.94$ \\
\hline 7 & $6,347.08$ & $6,326.33$ & $6,277.54$ & $6,268.18$ & $6,200.27$ & $5,517.27$ & $5,507.43$ & $5,503.17$ & $5,502.46$ & $5,491.65$ \\
\hline 8 & $4,364.17$ & $4,384.55$ & $4,439.43$ & $4,448.63$ & $4,522.04$ & $5,494.88$ & $5,498.35$ & $5,498.10$ & $5,497.77$ & $5,486.07$ \\
\hline 9 & $6,929.37$ & $6,826.54$ & $6,790.89$ & $6,772.83$ & $6,763.36$ & $6,522.70$ & $6,523.48$ & $6,523.90$ & $6,526.11$ & $6,555.90$ \\
\hline 10 & $5,886.85$ & $5,992.19$ & $6,038.05$ & $6,062.35$ & $6,163.96$ & $6,626.65$ & $6,623.40$ & $6,623.62$ & $6,621.73$ & $6,592.44$ \\
\hline 11 & $7,144.92$ & $7,149.79$ & $7,151.13$ & $7,146.77$ & $7,063.72$ & $6,065.09$ & $6,069.29$ & $6,069.17$ & $6,069.19$ & $6,070.98$ \\
\hline 12 & $6,614.64$ & $6,624.27$ & $6,621.25$ & $6,528.76$ & $6,526.24$ & $5,739.13$ & $5,742.52$ & $5,746.37$ & $5,747.06$ & $5,764.13$ \\
\hline 13 & $5,365.34$ & $5,348.69$ & $5,312.22$ & $5,402.75$ & $5,370.55$ & $5,652.14$ & $5,643.49$ & $5,643.33$ & $5,642.71$ & $5,633.08$ \\
\hline 14 & $5,651.51$ & $5,650.00$ & $5,652.04$ & $5,651.63$ & $5,650.86$ & $5,437.50$ & $5,432.74$ & $5,429.30$ & $5,428.76$ & $5,420.31$ \\
\hline 15 & $6,324.97$ & $6,240.22$ & $6,227.36$ & $6,214.71$ & $6,264.01$ & $6,412.92$ & $6,410.47$ & $6,410.47$ & $6,410.53$ & $6,423.10$ \\
\hline 16 & $6,716.27$ & $6,705.47$ & $6,779.89$ & $6,786.93$ & $6,794.75$ & $6,509.49$ & $6,521.86$ & $6,522.92$ & $6,525.00$ & $6,537.11$ \\
\hline 17 & $7,067.16$ & $7,167.55$ & $7,159.94$ & $7,163.31$ & $7,146.23$ & $6,018.84$ & $6,016.92$ & $6,016.86$ & $6,015.44$ & $5,996.07$ \\
\hline 18 & $6,808.99$ & $6,821.15$ & $6,819.26$ & $6,729.84$ & $6,738.31$ & $5,826.67$ & $5,828.69$ & $5,832.82$ & $5,832.68$ & $5,838.48$ \\
\hline 19 & $5,368.09$ & $5,352.59$ & $5,280.90$ & $5,369.13$ & $5,321.38$ & $5,799.49$ & $5,804.12$ & $5,803.56$ & $5,804.17$ & $5,812.56$ \\
\hline 20 & $6,623.64$ & $6,622.12$ & $6,621.95$ & $6,621.06$ & $6,620.30$ & $5,826.53$ & $5,795.09$ & $5,790.47$ & $5,787.94$ & $5,750.51$ \\
\hline 21 & $6,331.83$ & $6,247.08$ & $6,238.46$ & $6,237.83$ & $6,237.83$ & $6,627.55$ & $6,624.90$ & $6,624.95$ & $6,624.96$ & $6,625.33$ \\
\hline Total & $131,431.99$ & $131,345.72$ & $131,297.47$ & $131,291.87$ & $131,270.99$ & $124,665.43$ & $124,641.23$ & $124,638.63$ & $124,636.75$ & $124,609.41$ \\
\hline Media & 6,258.67 & $6,254.56$ & $6,252.26$ & $6,251.99$ & $6,251.00$ & $5,936.45$ & $\mathbf{5 , 9 3 5 . 3 0}$ & $\mathbf{5 , 9 3 5 . 1 7}$ & $\mathbf{5 , 9 3 5 . 0 8}$ & $\mathbf{5 , 9 3 3 . 7 8}$ \\
\hline
\end{tabular}


Tabela 33. Prescrição de áreas anuais de colheita, em hectares, resultantes do modelo Regionalizado de maximização do valor presente líquido com restrições operacionais, para os diferentes cenários de valor de madeira de mercado (onde $1=$ valor $+20 \%$; $2=$ valor $+10 \% ; 3=$ valor original; $4=$ valor $-10 \% ; 5=$ valor $-20 \%$ )

\begin{tabular}{|c|c|c|c|c|c|c|c|c|c|c|}
\hline \multirow[b]{2}{*}{ Ano } & \multicolumn{5}{|c|}{ Produção Livre } & \multicolumn{5}{|c|}{ Produção Ordenada } \\
\hline & Cenário 1 & Cenário 2 & Cenário 3 & Cenário 4 & Cenário 5 & Cenário 1 & Cenário 2 & Cenário 3 & Cenário 4 & Cenário 5 \\
\hline 1 & $3,462.02$ & $3,407.18$ & $3,407.61$ & $3,471.12$ & $3,461.10$ & $3,102.40$ & $3,118.02$ & $3,112.39$ & $3,104.90$ & $3,101.79$ \\
\hline 2 & $3,968.73$ & $3,968.73$ & $3,968.73$ & $3,894.63$ & $3,904.65$ & $4,050.78$ & $4,030.55$ & $4,000.53$ & $4,001.61$ & $4,008.74$ \\
\hline 3 & $4,500.00$ & $4,500.00$ & $4,500.00$ & $4,500.00$ & $4,500.00$ & $4,394.89$ & $4,389.03$ & $4,389.03$ & $4,389.03$ & $4,389.02$ \\
\hline 4 & $4,500.00$ & $4,500.00$ & $4,500.00$ & $4,500.00$ & $4,500.00$ & $4,500.00$ & $4,500.00$ & $4,500.00$ & $4,500.00$ & $4,500.00$ \\
\hline 5 & $4,500.00$ & $4,500.00$ & $4,500.00$ & $4,500.00$ & $4,500.00$ & $4,500.00$ & $4,500.00$ & $4,500.00$ & $4,500.00$ & $4,500.00$ \\
\hline 6 & $4,500.00$ & $4,500.00$ & $4,500.00$ & $4,500.00$ & $4,500.00$ & $4,454.32$ & $4,451.37$ & $4,448.75$ & $4,441.74$ & $4,443.61$ \\
\hline 7 & $4,500.00$ & $4,500.00$ & $4,500.00$ & $4,500.00$ & $4,500.00$ & $4,277.12$ & $4,277.93$ & $4,279.99$ & $4,284.22$ & $4,282.70$ \\
\hline 8 & $4,500.00$ & $4,500.00$ & $4,500.00$ & $4,500.00$ & $4,500.00$ & $4,381.04$ & $4,378.73$ & $4,364.51$ & $4,363.23$ & $4,358.98$ \\
\hline 9 & $4,500.00$ & $4,500.00$ & $4,500.00$ & $4,500.00$ & $4,500.00$ & $4,486.97$ & $4,480.12$ & $4,480.12$ & $4,480.12$ & $4,480.11$ \\
\hline 10 & $4,500.00$ & $4,500.00$ & $4,500.00$ & $4,500.00$ & $4,500.00$ & $4,436.80$ & $4,442.25$ & $4,442.25$ & $4,442.25$ & $4,442.26$ \\
\hline 11 & $4,500.00$ & $4,500.00$ & $4,500.00$ & $4,500.00$ & $4,500.00$ & $4,497.15$ & $4,491.77$ & $4,491.77$ & $4,491.77$ & $4,491.75$ \\
\hline 12 & $4,500.00$ & $4,500.00$ & $4,500.00$ & $4,500.00$ & $4,500.00$ & $4,464.22$ & $4,463.73$ & $4,463.73$ & $4,463.73$ & $4,463.73$ \\
\hline 13 & $4,500.00$ & $4,500.00$ & $4,500.00$ & $4,500.00$ & $4,500.00$ & $4,461.38$ & $4,461.25$ & $4,461.25$ & $4,461.25$ & $4,461.25$ \\
\hline 14 & $4,500.00$ & $4,500.00$ & $4,500.00$ & $4,500.00$ & $4,500.00$ & $4,446.39$ & $4,445.29$ & $4,445.29$ & $4,445.29$ & $4,445.32$ \\
\hline 15 & $4,500.00$ & $4,500.00$ & $4,500.00$ & $4,500.00$ & $4,500.00$ & $4,500.00$ & $4,495.54$ & $4,495.54$ & $4,495.54$ & $4,495.52$ \\
\hline 16 & $4,500.00$ & $4,500.00$ & $4,500.00$ & $4,500.00$ & $4,500.00$ & $4,420.48$ & $4,420.09$ & $4,420.09$ & $4,420.09$ & $4,420.06$ \\
\hline 17 & $4,500.00$ & $4,500.00$ & $4,500.00$ & $4,500.00$ & $4,500.00$ & $4,472.51$ & $4,472.25$ & $4,472.25$ & $4,472.25$ & $4,472.25$ \\
\hline 18 & $4,478.06$ & $4,478.06$ & $4,478.06$ & $4,478.06$ & $4,478.06$ & $4,496.56$ & $4,496.76$ & $4,489.96$ & $4,491.30$ & $4,481.56$ \\
\hline 19 & $4,500.00$ & $4,500.00$ & $4,500.00$ & $4,500.00$ & $4,500.00$ & $4,471.21$ & $4,470.38$ & $4,475.29$ & $4,472.75$ & $4,479.76$ \\
\hline 20 & $4,500.00$ & $4,500.00$ & $4,500.00$ & $4,500.00$ & $4,500.00$ & $4,478.88$ & $4,478.60$ & $4,478.60$ & $4,478.60$ & $4,478.60$ \\
\hline 21 & $4,500.00$ & $4,500.00$ & $4,500.00$ & $4,500.00$ & $4,500.00$ & $4,500.00$ & $4,500.00$ & $4,500.00$ & $4,500.00$ & $4,500.00$ \\
\hline Total & 92,908.81 & 92,853.97 & $92,854.40$ & 92,843.81 & $92,843.81$ & $91,793.10$ & $91,763.65$ & $91,711.35$ & $91,699.67$ & $91,697.00$ \\
\hline Media & $4,424.23$ & 4,421.62 & 4,421.64 & $4,421.13$ & $4,421.13$ & $4,371.10$ & $4,369.70$ & $4,367.21$ & $4,366.65$ & $4,366.52$ \\
\hline
\end{tabular}


Tabela 34. Prescrição de áreas anuais de colheita, em hectares, resultantes do modelo Global de minimização do custo presente sem restrições operacionais, para os diferentes cenários de valor de madeira de mercado (onde $1=$ valor $+20 \% ; 2=$ valor $+10 \%$; $3=$ valor original; $4=$ valor $-10 \% ; 5=$ valor $-20 \%$ )

\begin{tabular}{|c|c|c|c|c|c|c|c|c|c|c|}
\hline \multirow[b]{2}{*}{ Ano } & \multicolumn{5}{|c|}{ Produção Livre } & \multicolumn{5}{|c|}{ Produção Ordenada } \\
\hline & Cenário 1 & Cenário 2 & Cenário 3 & Cenário 4 & Cenário 5 & Cenário 1 & Cenário 2 & Cenário 3 & Cenário 4 & Cenário 5 \\
\hline 1 & $6,236.61$ & $6,230.12$ & $6,229.48$ & $5,597.02$ & $5,457.10$ & $5,068.82$ & $5,016.70$ & $4,668.31$ & $4,567.25$ & $4,499.28$ \\
\hline 2 & $4,217.12$ & $3,559.83$ & $3,568.15$ & $4,148.10$ & $4,340.53$ & $5,605.70$ & $5,554.23$ & $5,446.46$ & $5,222.61$ & $4,643.43$ \\
\hline 3 & $7,343.85$ & $7,634.20$ & $7,643.74$ & $7,301.46$ & $6,745.08$ & $6,615.38$ & $6,588.88$ & $6,346.20$ & $6,055.48$ & $5,505.63$ \\
\hline 4 & $6,310.30$ & $6,337.20$ & $4,959.03$ & $3,604.80$ & $1,392.52$ & $7,096.22$ & $6,953.70$ & $6,668.14$ & $6,305.92$ & $5,476.94$ \\
\hline 5 & $7,045.60$ & $7,039.40$ & $6,943.57$ & $6,910.10$ & $6,707.99$ & $6,106.14$ & $6,097.11$ & $5,767.18$ & $5,578.89$ & $5,037.42$ \\
\hline 6 & $6,871.87$ & $6,877.60$ & $6,858.13$ & $6,848.45$ & $5,347.53$ & $5,970.56$ & $5,949.48$ & $5,786.77$ & $5,618.11$ & $4,963.32$ \\
\hline 7 & $6,007.01$ & $5,900.72$ & $5,981.64$ & $5,543.85$ & $5,019.36$ & $5,459.30$ & $5,418.99$ & $5,254.55$ & $5,078.90$ & $4,576.94$ \\
\hline 8 & $4,118.94$ & $3,556.86$ & $3,356.71$ & $3,616.82$ & $3,789.48$ & $5,648.68$ & $5,633.70$ & $5,453.69$ & $5,217.29$ & $4,750.32$ \\
\hline 9 & $7,649.12$ & $7,629.69$ & $7,642.08$ & $7,527.87$ & $6,745.08$ & $6,536.88$ & $6,472.29$ & $6,192.17$ & $5,996.07$ & $5,270.27$ \\
\hline 10 & $2,859.11$ & $2,823.54$ & $2,284.27$ & $1,268.72$ & $1,984.98$ & $6,603.69$ & $6,571.77$ & $6,355.46$ & $6,078.54$ & $5,441.91$ \\
\hline 11 & $6,901.47$ & $6,881.06$ & $6,779.98$ & $6,296.09$ & $3,296.54$ & $6,135.52$ & $5,996.99$ & $5,811.08$ & $5,677.82$ & $5,055.09$ \\
\hline 12 & $7,149.76$ & $7,170.47$ & $6,853.25$ & $6,692.69$ & $6,120.47$ & $6,269.52$ & $6,255.03$ & $5,902.62$ & $5,699.97$ & $4,850.93$ \\
\hline 13 & $6,643.71$ & $6,694.32$ & $6,425.94$ & $6,558.52$ & $5,480.48$ & $5,877.90$ & $5,923.08$ & $5,826.60$ & $5,602.26$ & $5,204.65$ \\
\hline 14 & $6,154.97$ & $6,065.04$ & $6,081.92$ & $6,081.57$ & $6,114.31$ & $5,395.03$ & $5,377.52$ & $5,225.88$ & $4,963.19$ & $4,430.63$ \\
\hline 15 & $7,537.62$ & $7,521.65$ & $7,533.87$ & $7,134.10$ & $6,993.97$ & $6,538.54$ & $6,387.28$ & $6,150.11$ & $5,916.22$ & $5,247.47$ \\
\hline 16 & $3,322.46$ & $3,001.25$ & $2,058.53$ & $1,009.99$ & 996.19 & $6,441.64$ & $6,451.01$ & $6,164.80$ & $5,861.49$ & $5,266.58$ \\
\hline 17 & $6,353.32$ & $6,254.39$ & $6,260.27$ & $6,124.44$ & $2,017.73$ & $6,124.99$ & $6,075.11$ & $5,804.68$ & $5,665.76$ & $5,131.16$ \\
\hline 18 & $7,436.22$ & $7,471.28$ & $7,123.85$ & $6,876.92$ & $6,273.25$ & $5,889.82$ & $5,890.24$ & $5,724.35$ & $5,488.82$ & $4,797.59$ \\
\hline 19 & $6,937.49$ & $7,036.22$ & $7,016.03$ & $6,993.57$ & $7,051.69$ & $6,378.19$ & $6,320.35$ & $6,119.35$ & $5,935.10$ & $5,253.35$ \\
\hline 20 & $6,423.62$ & $6,370.59$ & $6,281.71$ & $6,217.73$ & $6,220.18$ & $6,024.55$ & $5,983.47$ & $5,684.48$ & $5,514.82$ & $4,482.39$ \\
\hline 21 & $7,592.52$ & $7,582.10$ & $7,575.94$ & $7,451.70$ & $7,431.71$ & $7,220.46$ & $7,222.03$ & $7,154.57$ & $7,162.26$ & $6,482.67$ \\
\hline Total & $131,112.68$ & $129,637.53$ & $125,458.06$ & $119,804.50$ & $105,526.16$ & $129,007.51$ & $128,138.96$ & $123,507.42$ & $119,206.75$ & $106,367.96$ \\
\hline Media & $6,243.46$ & 6,173.22 & $5,974.19$ & $5,704.98$ & $5,025.06$ & 6,143.21 & $6,101.86$ & $5,881.31$ & $5,676.51$ & $5,065.14$ \\
\hline
\end{tabular}


Tabela 35. Prescrição de áreas anuais de colheita, em hectares, resultantes do modelo Global de minimização do custo presente com restrições operacionais, para os diferentes cenários de valor de madeira de mercado (onde $1=$ valor $+20 \% ; 2=$ valor $+10 \%$; $3=$ valor original; $4=$ valor $-10 \% ; 5=$ valor $-20 \%$ )

\begin{tabular}{|c|c|c|c|c|c|c|c|c|c|c|}
\hline \multirow[b]{2}{*}{ Ano } & \multicolumn{5}{|c|}{ Produção Livre } & \multicolumn{5}{|c|}{ Produção Ordenada } \\
\hline & Cenário 1 & Cenário 2 & Cenário 3 & Cenário 4 & Cenário 5 & Cenário 1 & Cenário 2 & Cenário 3 & Cenário 4 & Cenário 5 \\
\hline 1 & $4,500.00$ & $4,500.00$ & $4,500.00$ & $4,500.00$ & $4,500.00$ & $4,159.08$ & $4,077.31$ & $3,948.09$ & $3,928.11$ & $3,719.38$ \\
\hline 2 & $4,500.00$ & $4,500.00$ & $4,500.00$ & $4,500.00$ & $4,500.00$ & $4,500.00$ & $4,497.20$ & $4,442.96$ & $4,266.87$ & $3,930.62$ \\
\hline 3 & $4,500.00$ & $4,500.00$ & $4,500.00$ & $4,500.00$ & $4,500.00$ & $4,500.00$ & $4,500.00$ & $4,500.00$ & $4,500.00$ & $4,500.00$ \\
\hline 4 & $4,500.00$ & $4,500.00$ & $4,500.00$ & $4,500.00$ & $4,500.00$ & $4,500.00$ & $4,500.00$ & $4,500.00$ & $4,500.00$ & $4,500.00$ \\
\hline 5 & $4,500.00$ & $4,500.00$ & $4,500.00$ & $4,500.00$ & $4,500.00$ & $4,500.00$ & $4,500.00$ & $4,500.00$ & $4,500.00$ & $4,322.71$ \\
\hline 6 & $4,500.00$ & $4,500.00$ & $4,500.00$ & $4,500.00$ & $3,890.89$ & $4,417.33$ & $4,451.37$ & $4,338.92$ & $4,223.26$ & $4,033.08$ \\
\hline 7 & $4,500.00$ & $4,500.00$ & $4,500.00$ & $4,500.00$ & $4,251.11$ & $4,208.96$ & $4,119.82$ & $3,939.80$ & $3,910.68$ & $3,742.57$ \\
\hline 8 & $4,500.00$ & $4,500.00$ & $4,500.00$ & $4,500.00$ & $3,917.77$ & $4,500.00$ & $4,500.00$ & $4,500.00$ & $4,323.92$ & $3,938.21$ \\
\hline 9 & $4,500.00$ & $4,500.00$ & $4,500.00$ & $4,500.00$ & $4,500.00$ & $4,500.00$ & $4,500.00$ & $4,454.53$ & $4,381.26$ & $4,366.84$ \\
\hline 10 & $4,500.00$ & $4,500.00$ & $4,500.00$ & $4,500.00$ & $4,500.00$ & $4,500.00$ & $4,500.00$ & $4,500.00$ & $4,500.00$ & $4,500.00$ \\
\hline 11 & $4,500.00$ & $4,500.00$ & $4,500.00$ & $4,500.00$ & $4,500.00$ & $4,500.00$ & $4,500.00$ & $4,500.00$ & $4,500.00$ & 4,309.46 \\
\hline 12 & $4,500.00$ & $4,500.00$ & $4,500.00$ & $4,500.00$ & $4,500.00$ & $4,500.00$ & $4,500.00$ & $4,500.00$ & $4,500.00$ & $3,881.52$ \\
\hline 13 & $4,500.00$ & $4,500.00$ & $3,493.72$ & $2,796.07$ & $2,561.50$ & $4,403.98$ & $4,401.21$ & $4,128.09$ & $4,031.04$ & $4,251.70$ \\
\hline 14 & $4,500.00$ & $4,500.00$ & $4,500.00$ & $4,500.00$ & $4,500.00$ & $4,408.32$ & $4,247.29$ & $4,129.19$ & $4,078.78$ & $3,744.70$ \\
\hline 15 & $4,500.00$ & $4,500.00$ & $4,500.00$ & $4,500.00$ & $4,500.00$ & $4,500.00$ & $4,500.00$ & $4,500.00$ & $4,300.92$ & $4,260.23$ \\
\hline 16 & $4,500.00$ & $4,500.00$ & $4,500.00$ & $4,500.00$ & $3,890.89$ & $4,500.00$ & $4,500.00$ & $4,500.00$ & $4,500.00$ & $4,500.00$ \\
\hline 17 & $4,500.00$ & $4,500.00$ & $4,500.00$ & $4,500.00$ & $4,500.00$ & $4,500.00$ & $4,500.00$ & $4,500.00$ & $4,476.39$ & $4,301.15$ \\
\hline 18 & $4,500.00$ & $4,500.00$ & $4,500.00$ & $4,500.00$ & $4,500.00$ & $4,500.00$ & $4,500.00$ & $4,500.00$ & $4,360.34$ & $3,783.56$ \\
\hline 19 & $4,500.00$ & $4,500.00$ & $4,500.00$ & $4,500.00$ & $4,500.00$ & $4,500.00$ & $4,500.00$ & $4,500.00$ & $4,500.00$ & $4,416.16$ \\
\hline 20 & $4,500.00$ & $4,500.00$ & $4,500.00$ & $4,500.00$ & $4,500.00$ & $4,500.00$ & $4,500.00$ & $4,500.00$ & $4,482.27$ & $4,093.95$ \\
\hline 21 & $4,500.00$ & $4,500.00$ & $4,500.00$ & $4,500.00$ & $4,500.00$ & $4,500.00$ & $4,500.00$ & $4,500.00$ & $4,500.00$ & $4,500.00$ \\
\hline Total & $94,500.00$ & $\mathbf{9 4 , 5 0 0 . 0 0}$ & $93,493.72$ & 92,796.07 & 90,512.17 & 93,597.66 & $93,294.18$ & $92,381.57$ & 91,263.84 & $87,595.82$ \\
\hline Media & $4,500.00$ & $4,500.00$ & $4,452.08$ & $4,418.86$ & $4,310.10$ & $4,457.03$ & $4,442.58$ & 4,399.12 & 4,345.90 & $4,171.23$ \\
\hline
\end{tabular}


Tabela 36. Prescrição de áreas anuais de colheita, em hectares, resultantes do modelo Regionalizado de minimização do custo presente sem restrições operacionais, para os diferentes cenários de valor de madeira de mercado (onde $1=$ valor $+20 \%$; $2=$ valor $+10 \% ; 3=$ valor original; $4=$ valor $-10 \% ; 5=$ valor $-20 \%$ )

\begin{tabular}{|c|c|c|c|c|c|c|c|c|c|c|}
\hline \multirow[b]{2}{*}{ Ano } & \multicolumn{5}{|c|}{ Produção Livre } & \multicolumn{5}{|c|}{ Produção Ordenada } \\
\hline & Cenário 1 & Cenário 2 & Cenário 3 & Cenário 4 & Cenário 5 & Cenário 1 & Cenário 2 & Cenário 3 & Cenário 4 & Cenário 5 \\
\hline 1 & $5,407.28$ & $5,461.80$ & $5,387.41$ & $5,398.46$ & $5,358.19$ & $5,109.82$ & $4,987.40$ & $4,891.16$ & $4,824.42$ & $4,439.08$ \\
\hline 2 & $4,850.72$ & $4,416.35$ & $4,358.11$ & $4,110.15$ & $3,482.02$ & $5,339.77$ & $4,955.34$ & $4,839.99$ & $4,841.87$ & $4,417.60$ \\
\hline 3 & $6,413.39$ & $6,377.34$ & $6,188.63$ & $5,375.37$ & $4,971.88$ & $6,597.85$ & $6,478.12$ & $6,320.88$ & $6,109.83$ & $5,306.58$ \\
\hline 4 & $6,675.87$ & $6,544.80$ & $5,728.40$ & $6,070.22$ & $5,279.11$ & $7,043.73$ & $6,804.51$ & $6,494.90$ & $6,067.90$ & $5,420.26$ \\
\hline 5 & $6,976.25$ & $7,077.75$ & $6,923.41$ & $6,257.25$ & $5,171.02$ & $6,152.57$ & $6,100.96$ & $5,752.64$ & $5,595.16$ & $5,022.04$ \\
\hline 6 & $6,152.97$ & $6,103.45$ & $6,142.34$ & $6,098.22$ & $4,929.94$ & $5,690.74$ & $5,536.25$ & $5,453.43$ & $5,261.80$ & $4,683.81$ \\
\hline 7 & $6,153.91$ & $6,160.30$ & $5,936.30$ & $5,851.64$ & $4,727.65$ & $5,656.65$ & $5,556.47$ & $5,357.17$ & $5,083.61$ & $4,480.12$ \\
\hline 8 & $4,036.63$ & $3,602.70$ & $3,859.54$ & $3,733.29$ & $3,490.87$ & $5,539.35$ & $5,443.79$ & $5,316.65$ & $5,234.75$ & $4,564.68$ \\
\hline 9 & $6,453.68$ & $6,373.47$ & $6,213.07$ & $5,575.40$ & $4,862.39$ & $6,432.52$ & $6,274.66$ & $6,178.40$ & $5,976.69$ & $5,176.50$ \\
\hline 10 & $5,354.39$ & $5,115.99$ & $4,454.21$ & $4,299.41$ & $3,866.79$ & $6,814.66$ & $6,563.98$ & $6,335.14$ & $5,904.86$ & $5,324.81$ \\
\hline 11 & $7,068.41$ & $7,089.68$ & $6,590.25$ & $6,043.65$ & $4,640.26$ & $6,185.81$ & $6,045.08$ & $5,969.54$ & $5,720.76$ & $5,156.02$ \\
\hline 12 & $6,610.68$ & $6,784.50$ & $6,550.88$ & $6,453.21$ & $4,605.86$ & $5,767.85$ & $5,752.43$ & $5,347.57$ & $5,157.72$ & $4,566.39$ \\
\hline 13 & $6,258.71$ & $6,200.58$ & $6,324.68$ & $6,246.38$ & $5,185.19$ & $5,950.06$ & $5,826.97$ & $5,619.23$ & $5,505.37$ & $4,882.88$ \\
\hline 14 & $5,260.09$ & $5,302.23$ & $5,443.37$ & $5,508.76$ & $5,874.12$ & $5,357.54$ & $5,260.80$ & $5,074.00$ & $4,853.71$ & $4,272.67$ \\
\hline 15 & $6,126.87$ & $6,031.23$ & $5,784.64$ & $5,219.77$ & $4,814.95$ & $6,402.00$ & $6,251.93$ & $6,141.79$ & $5,938.86$ & $5,152.07$ \\
\hline 16 & $5,115.76$ & $4,499.39$ & $3,919.81$ & $3,242.42$ & $3,014.64$ & $6,608.74$ & $6,353.86$ & $6,137.17$ & $5,815.06$ & $5,084.89$ \\
\hline 17 & $7,101.18$ & $7,077.18$ & $6,411.46$ & $6,204.08$ & $3,672.18$ & $6,199.55$ & $6,089.56$ & $5,975.48$ & $5,690.44$ & $5,173.64$ \\
\hline 18 & $6,881.92$ & $6,785.95$ & $6,659.92$ & $6,678.63$ & $5,412.92$ & $5,788.35$ & $5,689.30$ & $5,517.37$ & $5,259.22$ & $4,671.72$ \\
\hline 19 & $5,298.16$ & $5,825.42$ & $6,131.61$ & $6,013.58$ & $5,250.14$ & $6,075.55$ & $5,996.09$ & $5,631.94$ & $5,549.55$ & $4,929.18$ \\
\hline 20 & $6,352.02$ & $6,357.64$ & $6,341.65$ & $6,361.98$ & $6,269.60$ & $6,212.39$ & $6,025.87$ & $5,650.10$ & $5,266.05$ & $4,357.66$ \\
\hline 21 & $7,316.59$ & $6,963.15$ & $6,816.71$ & $6,310.21$ & $6,074.56$ & $6,947.10$ & $6,936.58$ & $7,159.93$ & $7,204.36$ & $6,477.14$ \\
\hline Total & $127,865.46$ & $126,150.90$ & $122,166.39$ & $117,052.07$ & $100,954.27$ & $127,872.59$ & $124,929.94$ & $121,164.47$ & $116,861.97$ & $103,559.74$ \\
\hline Media & $\mathbf{6 , 0 8 8 . 8 3}$ & $6,007.19$ & $5,817.45$ & $5,573.91$ & $4,807.35$ & $6,089.17$ & $5,949.04$ & $5,769.74$ & $5,564.86$ & $4,931.42$ \\
\hline
\end{tabular}


Tabela 37. Prescrição de áreas anuais de colheita, em hectares, resultantes do modelo Regionalizado de minimização do custo presente com restrições operacionais, para os diferentes cenários de valor de madeira de mercado (onde $1=$ valor $+20 \%$; $2=$ valor $+10 \% ; 3=$ valor original; $4=$ valor $-10 \% ; 5=$ valor $-20 \%$ )

\begin{tabular}{|c|c|c|c|c|c|c|c|c|c|c|}
\hline \multirow[b]{2}{*}{ Ano } & \multicolumn{5}{|c|}{ Produção Livre } & \multicolumn{5}{|c|}{ Produção Ordenada } \\
\hline & Cenário 1 & Cenário 2 & Cenário 3 & Cenário 4 & Cenário 5 & Cenário 1 & Cenário 2 & Cenário 3 & Cenário 4 & Cenário 5 \\
\hline 1 & $3,575.56$ & $3,739.19$ & $3,717.74$ & $3,920.57$ & $3,920.57$ & $2,992.64$ & $2,968.91$ & $2,990.32$ & $2,931.85$ & $2,628.70$ \\
\hline 2 & $3,665.01$ & $3,501.38$ & $3,522.83$ & $3,320.00$ & $3,234.19$ & $4,030.45$ & $4,037.55$ & $3,902.11$ & $3,806.05$ & $2,947.28$ \\
\hline 3 & $4,500.00$ & $4,500.00$ & $4,500.00$ & $3,846.59$ & $2,873.39$ & $4,361.66$ & $4,361.66$ & $4,361.66$ & $4,262.84$ & $3,300.79$ \\
\hline 4 & $4,470.21$ & $4,482.50$ & $3,663.13$ & $3,933.42$ & $3,280.00$ & $4,489.37$ & $4,489.37$ & $4,489.37$ & $4,329.88$ & $3,267.91$ \\
\hline 5 & $4,500.00$ & $4,500.00$ & $4,500.00$ & $4,231.31$ & $3,280.00$ & $4,491.02$ & $4,450.61$ & $4,399.03$ & $4,280.83$ & $3,347.27$ \\
\hline 6 & $4,500.00$ & $4,500.00$ & $4,500.00$ & $4,500.00$ & $3,756.35$ & $4,370.39$ & $4,379.19$ & $4,378.13$ & $4,224.06$ & $3,234.52$ \\
\hline 7 & $4,500.00$ & $4,500.00$ & $4,500.00$ & $4,382.55$ & $3,522.83$ & $4,259.36$ & $4,189.89$ & $4,131.59$ & $3,855.97$ & $2,991.99$ \\
\hline 8 & $4,500.00$ & $4,500.00$ & $4,500.00$ & $3,313.13$ & $3,170.18$ & $4,268.83$ & $4,257.24$ & $4,225.05$ & $4,158.60$ & $3,292.20$ \\
\hline 9 & $4,500.00$ & $4,415.09$ & $4,281.13$ & $3,702.99$ & $2,842.26$ & $4,422.87$ & $4,422.87$ & $4,422.87$ & $4,283.27$ & $3,208.47$ \\
\hline 10 & $4,500.00$ & $4,500.00$ & $3,904.26$ & $3,639.28$ & $3,080.29$ & $4,489.71$ & $4,477.94$ & $4,456.98$ & $4,244.82$ & $3,253.81$ \\
\hline 11 & $4,500.00$ & $4,500.00$ & $4,500.00$ & $4,500.00$ & $3,280.00$ & $4,446.66$ & $4,402.32$ & $4,376.31$ & $4,277.85$ & $3,314.77$ \\
\hline 12 & $4,500.00$ & $4,500.00$ & $4,500.00$ & $4,500.00$ & $3,280.00$ & $4,455.28$ & $4,455.28$ & $4,413.65$ & $4,314.20$ & $3,305.00$ \\
\hline 13 & $4,500.00$ & $4,500.00$ & $4,500.00$ & $4,500.00$ & $4,388.79$ & $4,397.67$ & $4,350.42$ & $4,285.88$ & $4,050.30$ & $3,125.15$ \\
\hline 14 & $3,867.84$ & $3,864.11$ & $3,960.57$ & $3,989.15$ & $3,866.89$ & $4,336.04$ & $4,311.70$ & $4,217.18$ & $3,923.88$ & $2,984.98$ \\
\hline 15 & $4,500.00$ & $4,500.00$ & $3,591.98$ & $3,201.72$ & $2,842.19$ & $4,434.35$ & $4,434.35$ & $4,434.35$ & $4,323.86$ & $3,313.92$ \\
\hline 16 & $4,500.00$ & $4,500.00$ & $4,405.42$ & $2,665.56$ & $2,100.00$ & $4,448.32$ & $4,448.32$ & $4,448.32$ & $4,223.31$ & $3,262.67$ \\
\hline 17 & $4,500.00$ & $4,500.00$ & $4,500.00$ & $4,390.65$ & $2,333.96$ & $4,469.72$ & $4,401.01$ & $4,355.25$ & $4,261.82$ & $3,343.01$ \\
\hline 18 & $4,500.00$ & $4,415.09$ & $4,500.00$ & $4,500.00$ & $4,258.10$ & $4,432.98$ & $4,400.12$ & $4,364.61$ & $4,197.27$ & $3,257.52$ \\
\hline 19 & $4,500.00$ & $4,500.00$ & $4,500.00$ & $4,500.00$ & $3,396.09$ & $4,479.59$ & $4,479.59$ & $4,472.73$ & $4,412.29$ & $3,269.24$ \\
\hline 20 & $4,500.00$ & $4,500.00$ & $4,500.00$ & $4,500.00$ & $4,500.00$ & $4,475.73$ & $4,475.73$ & $4,387.65$ & $4,363.40$ & $3,357.25$ \\
\hline 21 & $4,500.00$ & $4,500.00$ & $4,500.00$ & $4,500.00$ & $4,272.70$ & $4,500.00$ & $4,500.00$ & $4,500.00$ & $4,500.00$ & $3,951.40$ \\
\hline Total & $92,078.62$ & 91,917.35 & $89,547.06$ & $84,536.88$ & 71,478.77 & 91,052.64 & $90,694.06$ & 90,013.04 & $87,226.33$ & $67,957.83$ \\
\hline Media & 4,384.70 & 4,377.02 & $4,264.15$ & $\mathbf{4 , 0 2 5 . 5 7}$ & $3,403.75$ & 4,335.84 & $4,318.76$ & $4,286.34$ & 4,153.63 & $3,236.09$ \\
\hline
\end{tabular}




\subsubsection{Testes das hipóteses : Hipótese I}

Praticamente todos os parâmetros analisados confirmam o proposto na hipótese I. Os modelos globais são efetivamente superiores em relação aos modelos regionalizados ao se considerar simplesmente o resultado da função objetivo obtido (para os demais parâmetros essa hipótese também se confirma e é discutida mais adiante). Esta condição, embora repetida em todos os modelos, é bastante variável entre cenários. A variação nos modelos de maximização está demonstrada na Tabela 38:

Tabela 38. Ganho percentual, nos valores da função objetivo, do modelo Global em relação ao Regionalizado em todos os cenários de maximização do valor presente líquido.

\begin{tabular}{cccccc}
\hline & & \multicolumn{2}{c}{ C/R } & \multicolumn{2}{c}{ S/R } \\
& & Ordenado & Livre & Ordenado & Livre \\
\hline \multirow{2}{*}{ Cenários de } & $\mathbf{1}$ & 59.40 & 44.70 & 13.20 & 3.67 \\
valor & $\mathbf{2}$ & 80.11 & 57.16 & 14.60 & 4.03 \\
& $\mathbf{3}$ & 130.59 & 82.86 & 16.41 & 4.48 \\
& $\mathbf{4}$ & 357.99 & 152.04 & 18.60 & 5.01 \\
& $\mathbf{5}$ & $-*$ & 654.27 & 21.02 & 5.57 \\
\hline
\end{tabular}

* Superior a 700\%. Nota: $\mathrm{C} / \mathrm{R}$ e $\mathrm{S} / \mathrm{R}=\mathrm{com}$ e sem restrições operacionais, respectivamente e $1=$ valor $+20 \% ; 2=$ valor $+10 \% ; 3=$ valor original; $4=$ valor $-10 \% ; 5=$ valor $-20 \%$.

Os resultados do modelo global em relação ao regionalizado são proporcionalmente melhores nos cenários onde as restrições são mais intensas (no caso, as operacionais, as de estabilização da produção derivadas da imposição de ordenamento e as provocadas pela disponibilidade de madeira de mercado em valores mais baixos). Isso se explica pelo fato de haver disponíveis mais alternativas disponíveis, para cada ano de produção, pois não há, teoricamente, limites geográficos que impeçam a 
mobilização de máquinas entre as regiões. Como os modelos regionalizados não possuem esta flexibilidade, há a tendência de apresentarem maior sensibilidade a imposições como área máxima de colheita e a variações no valor da madeira de mercado. O resultado desta inflexibilidade é expresso pela opção de adquirir maior volume de madeira para cumprir as demandas anuais de produção, provocando redução no valor da função objetivo.

A condição na qual os modelos mais se aproximam é a que não impõe nenhuma necessidade de que se cumpram volumes estáveis anuais. É importante ressaltar que esta é uma condição criada para efeito de utilização neste estudo como uma referência ótima sob a ótica puramente financeira. $\mathrm{O}$ eventual desordenamento provocado no longo prazo, além do horizonte de planejamento considerado no trabalho, descarta este conjunto de cenários como uma alternativa prática. E mesmo sob esta condição financeiramente "ótima", o modelo global ainda expressa performance superior.

Na Tabela 39 estão demonstradas as variações de ganhos percentuais na função objetivo para os modelos de minimização do custo presente:

Tabela 39. Ganho percentual, nos valores da função objetivo, do modelo Global em relação ao Regionalizado em todos os cenários de minimização do custo presente.

\begin{tabular}{|c|c|c|c|c|c|}
\hline & & \multicolumn{4}{|c|}{$\%$} \\
\hline & & \multicolumn{2}{|c|}{$\mathrm{C} / \mathrm{R}$} & \multicolumn{2}{|c|}{$\mathbf{S} / \mathbf{R}$} \\
\hline & & Ordenado & Livre & Ordenado & Livre \\
\hline \multirow{5}{*}{$\begin{array}{c}\text { Cenários de } \\
\text { valor }\end{array}$} & 1 & 5.52 & 4.50 & 0.17 & 0.67 \\
\hline & 2 & 5.91 & 5.25 & 0.34 & 0.84 \\
\hline & 3 & 5.91 & 5.53 & 0.42 & 0.89 \\
\hline & 4 & 5.93 & 5.66 & 0.58 & 1.07 \\
\hline & 5 & 6.01 & 5.75 & 0.70 & 1.29 \\
\hline
\end{tabular}

Nota: $\mathrm{C} / \mathrm{R}$ e $\mathrm{S} / \mathrm{R}=$ com e sem restrições operacionais, respectivamente e $1=$ valor $+20 \%$; $2=$ valor $+10 \% ; 3=$ valor original; $4=$ valor $-10 \% ; 5=$ valor $-20 \%$. 
Embora os resultados percentuais sejam claramente inferiores nos modelos de mínimo custo quando comparados aos de máximo valor presente, dado o fato de os valores absolutos obtidos nas funções objetivo serem muito maiores nesses modelos, a tendência geral de performance superior dos modelos globais continua evidente. $\mathrm{O}$ comportamento dos modelos em relação às restrições operacionais e ao ordenamento difere do anterior em alguns pontos, no entanto.

Nas condições onde há maior restrição, produzidas pelas já mencionadas restrições operacionais e a necessidade de ordenamento, o modelo global expressa a sua maior flexibilidade pela produção de resultados menores de custo final e gerando, conseqüentemente, maior ganho percentual em qualquer cenário de valor de madeira de mercado.

Nos cenários onde não há restrições operacionais, no entanto, o resultado é praticamente idêntico entre os modelos. E relativamente menor onde há a necessidade de se ordenar a floresta. Isso se explica pelo fato de que a vantagem proporcionada ao modelo global, por sua maior flexibilidade de alternativas, fica comprometida pela necessidade de adquirir madeira no mercado nos anos onde sob a condição de produção "livre" não haveria. A diferença entre as condições "ordenada" e "livre" para os modelos regionalizados no cenário sem restrições operacionais é comparativamente bem menor, pois a dependência da madeira de mercado ocorre em ambos os casos (como pode ser observado na Tabela 26). Qualquer aquisição de madeira reflete diretamente nesta modelagem em função de haver adição imediata do valor da madeira adquirida no resultado da função objetivo

Em geral, os modelos regionalizados apresentam tendência em colher a floresta em rotações um pouco mais longas, especialmente nos modelos de mínimo custo. Uma das prováveis razões é que a limitação de alternativas implica na extração das maiores produtividades pontuais possíveis das Unidades de Produção disponíveis, o que é alcançado na rotações mais longas. A hipótese se confirma nos modelos de máximo valor presente em função de gerarem mais volume por unidade de área, e conseqüentemente maior receita, e nos modelos de mínimo custo por gerarem um menor número de intervenções no horizonte de planejamento, produzindo menor desembolso. 
Muito embora os planos de aquisição de madeira, e os planos de manejo conseqüentes, sejam diferentes entre os modelos, a utilização da área plantável total é praticamente idêntica entre eles. Há uma aparente tendência de que o modelo global utilize a área própria com menor intensidade nos cenários de máximo valor presente onde há restrições operacionais, com sub-utilização ainda maior quando há obrigação de se produzir ordenamento. A lógica anterior é pertinente a esse caso também, pois as restrições operacionais penalizam o modelo global mais intensamente que o regionalizado, que por concepção já tem caráter mais restritivo. A razão desse comportamento é a coincidência de produções de volume de um número maior de prescrições de diferentes Ups do que no regionalizado. Induzido pela necessidade de se produzirem volumes constantes, o modelo descarta alternativas quando poderia eventualmente ocorrer produção excedente no ano. Controversamente, no entanto, o percentual de aproveitamento de área é menor no modelo regionalizado nas condições de minimização de custo (chegando a um patamar mínimo de 55,03\% em um dos cenários). Este comportamento caracteriza bem as diferenças observáveis entre os modelos de minimização e maximização, a serem discutidas mais adiante. Aqui ele pode ser resumido pela provável opção pelo modelo de se reduzir o custo total pela eliminação das UPs que contribuem um número elevado de vezes no horizonte de planejamento em razão destas estarem em idades correntes próximas da colheita, limitando, desta forma, o desembolso em um número maior de intervenções operacionais. Nos modelos de maximização, como a alternativa para aumentar o valor da função objetivo é produzir receita, a opção é exatamente pelo contrário, por isso a maior utilização da área.

Outra medida da eventual vantagem do modelo global sobre o regionalizado, e a expressão que condensa todas as interpretações anteriores, é a prescrição de compra de menores volumes anuais e totais de madeira de mercado em todos os cenários, notadamente nos cenários de maior flexibilidade. Se um dos condicionantes principais deste trabalho é a busca por auto-suficiência no suprimento de madeira, modelos que apresentem resultado financeiro positivo só podem ser considerados interessantes se incrementarem concomitantemente a participação de madeira produzida por recursos 
próprios no planejamento, característica evidente do modelo global em todas as condições analisadas.

\subsubsection{Testes das hipóteses : Hipótese II}

As variações propostas para o valor da madeira de mercado produziram alterações nos resultados de todos os modelos, muito embora estas não tenham sido expressadas de maneira constante em todas as condições nos parâmetros avaliados.

As Figuras 3 e 4 apresentam graficamente a variação dos resultados da função objetivo para os modelos de maximização do valor presente líquido, global e regionalizado, respectivamente.

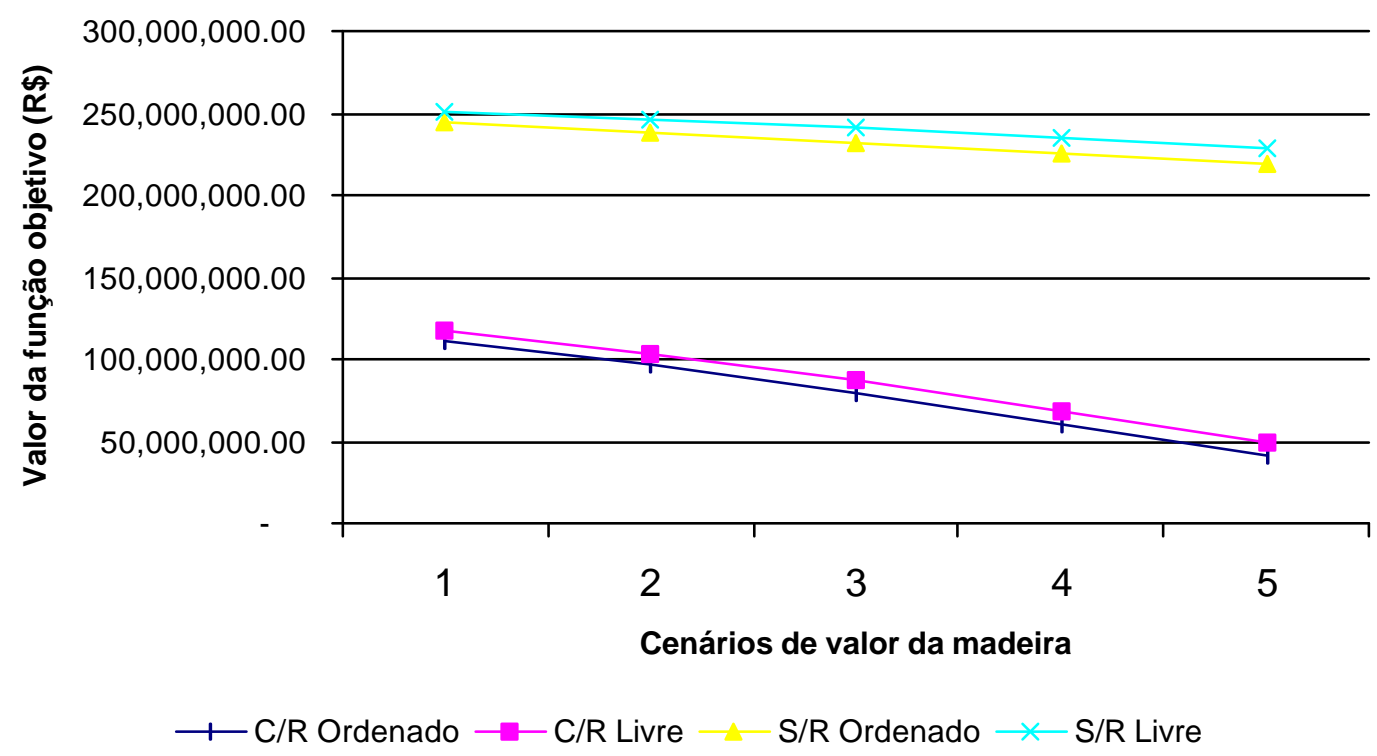

Figura 3- Valores da função objetivo do modelo global de maximização do valor presente líquido, onde $\mathrm{C} / \mathrm{R}$ e $\mathrm{S} / \mathrm{R}=$ com e sem restrições operacionais, respectivamente e $1=$ valor $-20 \% ; 2=$ valor $-10 \% ; 3=$ valor original $4=$ valor $+10 \% ; 5=$ valor $+20 \%$ 


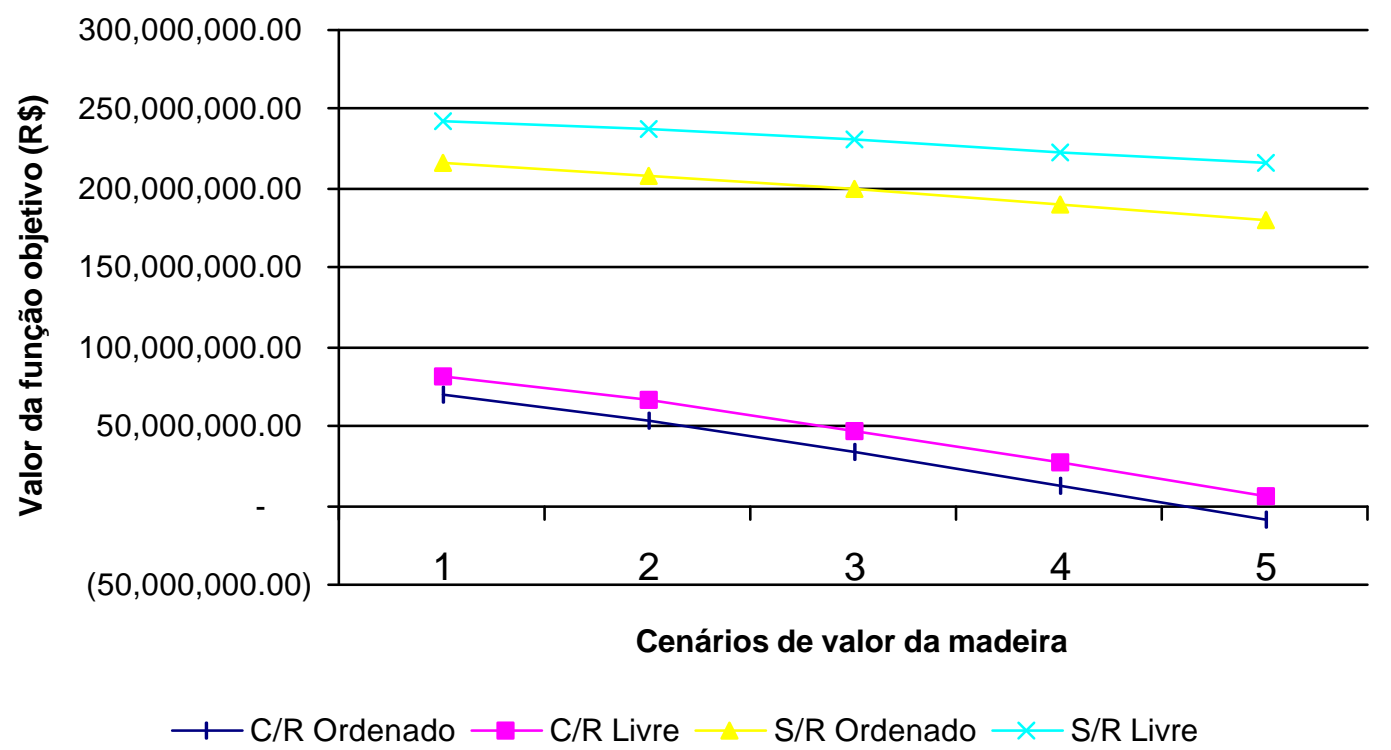

Figura 4- Valores da função objetivo do modelo regionalizado de maximização do valor presente líquido, onde $\mathrm{C} / \mathrm{R}$ e $\mathrm{S} / \mathrm{R}=$ com e sem restrições operacionais, respectivamente e $1=$ valor $-20 \% ; 2=$ valor $-10 \% ; 3=$ valor original $4=$ valor $+10 \% ; 5=$ valor $+20 \%$

Os diferentes cenários de preço provocam reações diferenciadas nos resultados da função objetivo para os modelos de maximização em praticamente todas as condições testadas: a) entre cenários de restrição (mais evidentes); b) entre modelos (global e regionalizado) e c) entre intensidades de ordenamento (de forma mais limitada).

As restrições operacionais produziram condições de maior sensibilidade às variações de cenários de valores, nos dois modelos. Esse comportamento deriva da menor flexibilidade na alocação das alternativas disponíveis pelas diferentes prescrições, criando maior dependência do mercado e, conseqüentemente, aumentando a exposição às mudanças de cenário. Com era esperado, o modelo global reage, em geral, melhor do que o regionalizado nas condições de restrição operacional por produzir resultados normalmente mais altos. No entanto, mostra-se também bastante sensível às variações de cenário sob essa condicionante. De maneira geral, pode-se concluir que a maior sensibilidade dos modelos decorre diretamente da necessidade de se cumprirem 
patamares máximos de colheita anual em função de se produzirem recomendações de manejo onde há menor uso do recurso próprio disponível. A expressão mais clara desse argumento é o baixo percentual de utilização de área nas situações onde o valor da madeira de mercado (preço) é baixo, especialmente nos modelos de minimização do custo.

A necessidade de ordenamento produziu algum aumento na sensibilidade dos modelos, mas ainda menor do que o resultante das restrições operacionais. Na verdade, foi exatamente nas condições sob regime de restrição operacional que se evidenciou maior sensibilidade dos modelos ordenados à variação de cenários. O ordenamento produziu maior efeito de reação aos cenários no modelo regionalizado quando comparado ao global e as explicações anteriores também respondem por esta observação.

Para os modelos de maximização houve uma interessante alteração nas idades médias de colheita nos diferentes cenários. De forma geral, a variação de cenários de valores menores para maiores provocou redução na idade média de colheita para as condições com restrições operacionais e incremento na idade média para ambientes sem restrições operacionais. Esse comportamento parece mais claramente demonstrado no modelo global, quando comparado com o regionalizado. Uma explicação, para as condições onde há restrição, é a necessidade de se cumprirem os patamares máximos operacionais, o que provocaria a utilização das prescrições de menor volume (e rotação mais curta), permitindo aquisição de mais madeira com preços baixos no mercado. $\mathrm{O}$ incremento na idade nas condições sem restrições operacionais está diretamente relacionado com o aproveitamento quase integral da área própria, o que tornaria mais adequado o uso de rotações mais longas e menor número de contribuições em volume de todas as UPs no horizonte de planejamento, permitindo a aquisição de maior volume madeira nos valores mais baixos.

As Figuras 5 e 6 apresentam graficamente a variação dos resultados da função objetivo para os modelos de minimização do custo presente , global e regionalizado, respectivamente. 


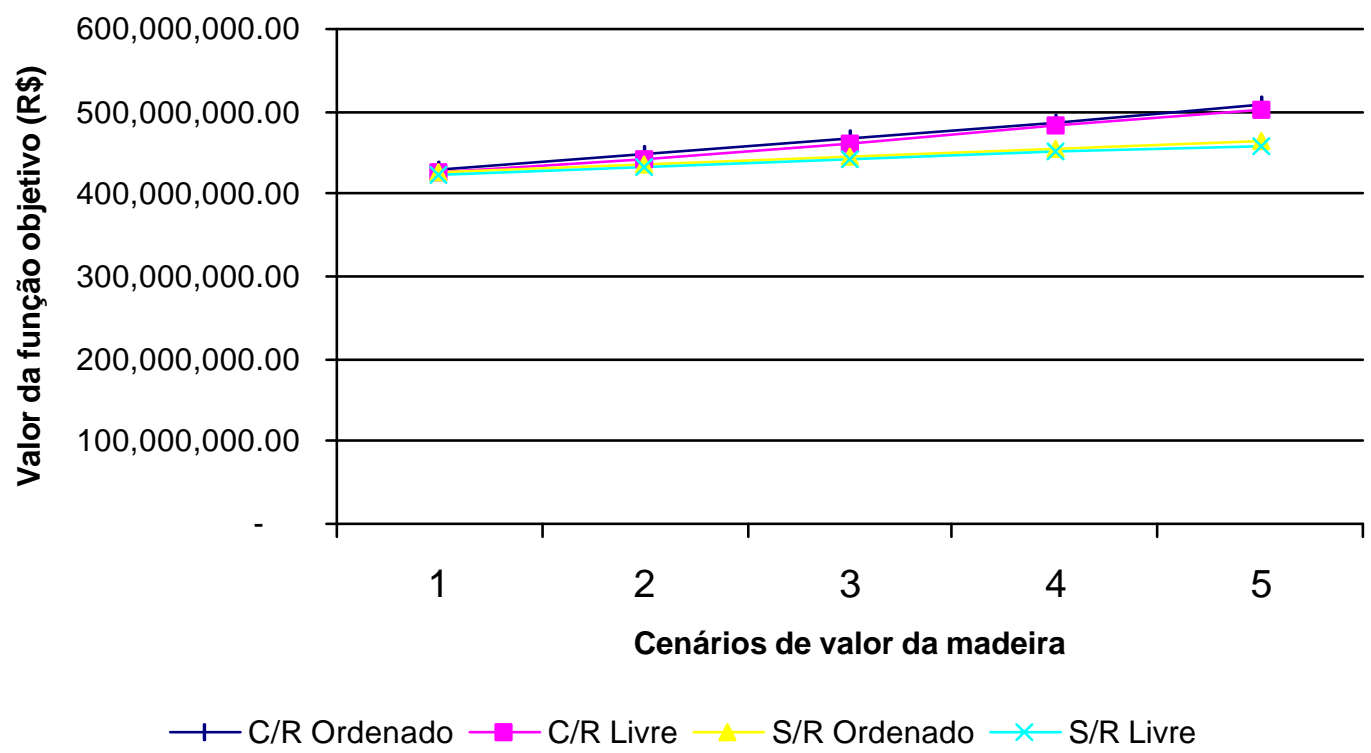

Figura 5- Valores da função objetivo do modelo global de minimização do custo presente, onde $\mathrm{C} / \mathrm{R}$ e $\mathrm{S} / \mathrm{R}=\mathrm{com}$ e sem restrições operacionais, respectivamente e $1=$ valor $-20 \% ; 2=$ valor $-10 \% ; 3=$ valor original; $4=$ valor $+10 \% ; 5=$ valor $+20 \%$ 


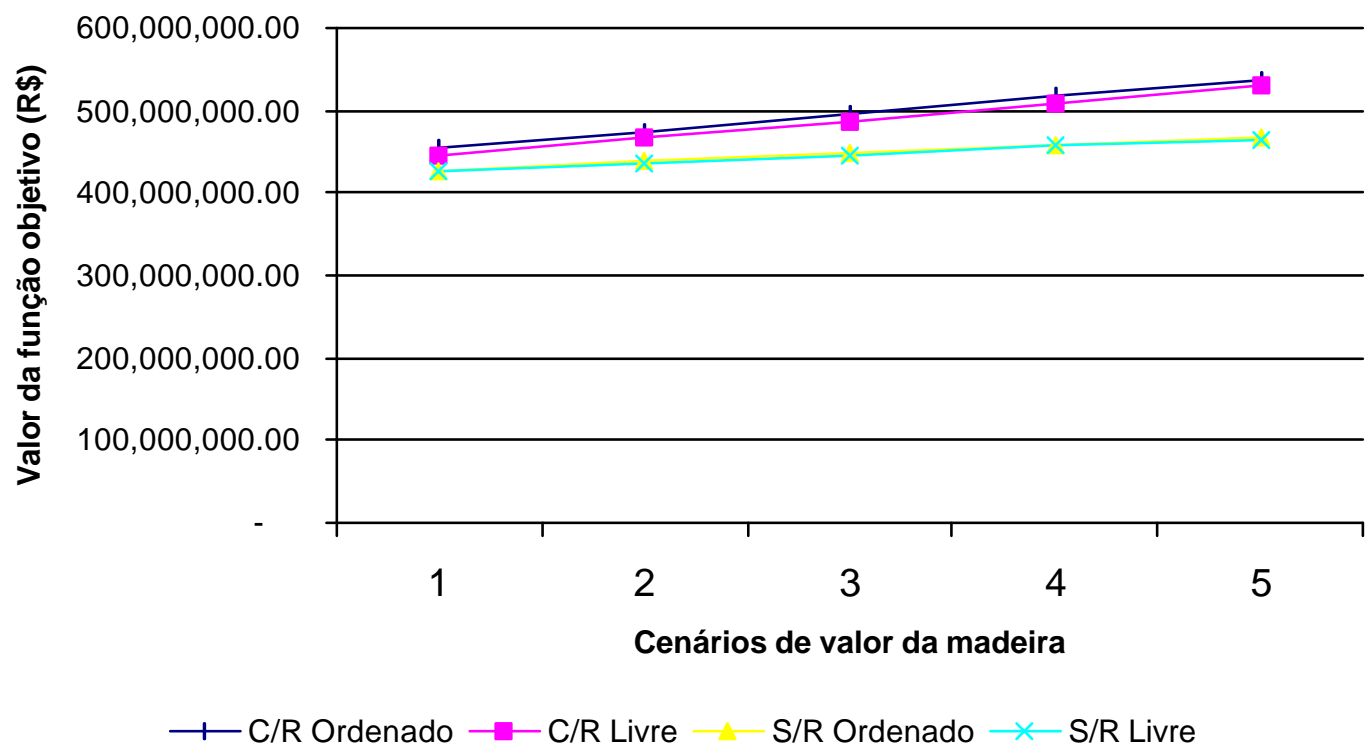

Figura 6- Valores da função objetivo do modelo regionalizado de minimização do custo presente, onde $\mathrm{C} / \mathrm{R}$ e $\mathrm{S} / \mathrm{R}=$ com e sem restrições operacionais, respectivamente e $1=$ valor $-20 \%$; $2=$ valor $-10 \% ; 3=$ valor original; $4=$ valor $+10 \% ; 5=$ valor $+20 \%$

A variação da função objetivo dos modelos de minimização ante aos diferentes cenários foi diversa da que ocorreu nos modelos de maximização. Muito embora aparentemente menos afetados comparativamente nos resultados totais desse parâmetro, os modelos de minimização foram os que tiveram as maiores alterações nas recomendações de manejo em relação aos diferentes cenários de preço.

Isso se dá pelo fato de que os volumes adquiridos no mercado têm seu custo correspondente somado diretamente à função objetivo. Portanto, como pode ser observado nas tabelas anteriores 18 e 19, quando há decréscimo no valor (preço) da madeira de mercado, a recomendação de colheita se resume a deixar de utilizar a área própria e comprar do mercado (argumento ratificado pela idade média de colheita, onde praticamente não há alteração, significando que a área simplesmente deixaria de ser colhida). Os percentuais de utilização de área própria decrescem, conseqüentemente, quando há decréscimo no preço da madeira comprada. 
Pode-se admitir, portanto, que os diferentes cenários de valor da madeira de mercado afetaram os modelos em praticamente todas as condições avaliadas. No entanto, a sensibilidade à variação foi bastante diferente entre eles, especialmente quando submetidos às restrições operacionais sugeridas no trabalho.

\subsubsection{Testes das hipóteses : Hipótese III}

Nas avaliações anteriores das hipóteses I e II há menções a algumas diferenças claras observadas entre as duas metodologias de modelagem - maximização do valor líquido presente e minimização do custo presente. Pode-se afirmar que os dois métodos produzem recomendações de manejo diferenciadas em praticamente todos os cenários avaliados e para todos os parâmetros discutidos, muito embora tenham disponíveis os mesmos recursos proporcionados pelas prescrições às quais as Unidades de Produção foram submetidas.

O parâmetro "valor da função objetivo" não permite sua utilização para comparação direta entre os dois tipos de modelagem em função de mostrarem valores de custo e receita, para minimização e maximização respectivamente, embora a unidade de ambas seja monetária. Tampouco valores relativos produzidos para este parâmetro, por alterações de cenários, são comparáveis em função das diferentes dimensões dos valores absolutos.

De qualquer forma, os parâmetros "idade média de colheita", "área anual de colheita", "volumes anuais adquiridos no mercado" e "percentual de utilização da área própria" garantem suficiente terreno para demonstrar as diferenças obtidas.

A idade média de colheita, nas condições sob restrição operacional, apresentouse normalmente maior na modelagem de mínimo custo em comparação à idade média dos modelos de máximo valor presente, isso se repetindo em todos os cenários. Como as rotações mais longas normalmente garantem a produção de árvores de maior volume individual (e conseqüentemente um custo comparativamente menor de colheita e transporte) e menor número de participações de produção de volume dentro do horizonte de planejamento (implicando em menor desembolso), a escolha do modelo de 
minimização dos custos foi por postergar as idades médias de colheita. Pode-se deduzir que esse comportamento é mais claramente definido para as UPs de baixa produtividade e distantes da fábrica, onde o peso dos custos da colheita e do transporte são proporcionalmente maiores do que em UPs próximas à fábrica e/ou de alta produtividade. Nos modelos de maximização o comportamento é praticamente inverso, pois a receita total maior é obtida pelas prescrições onde há maior número de participações de produção dentro do horizonte de planejamento, o que ocorre em rotações mais curtas.

Nos modelos onde não há restrição operacional, a área total recomendada de colheita, pelos modelos de mínimo custo, varia diretamente com os diferentes cenários de valor de madeira de mercado, ou seja, tendem a decrescer quando o valor da madeira adquirível é menor. Isso é particularmente claro nas condições de ordenamento, e um pouco menos intenso nas condições onde se prescreve livre produção. Nos modelos de maximização uma esperada tendência similar não é tão evidente, muito embora se caracterize de forma mais sutil nas condições onde há mais limitadores (modelos regionalizados, ordenados e com restrições operacionais). Pode-se afirmar, no entanto, que as recomendações de manejo diferem de um modelo para o outro. Na Figura 7 um exemplo de recomendações de manejo nos dois modelos, para os diferentes cenários de valor, representando uma situação característica da empresa (modelo regionalizado com restrições operacionais e produção livre), onde se evidencia a discrepância na área de colheita anual prescrita. 


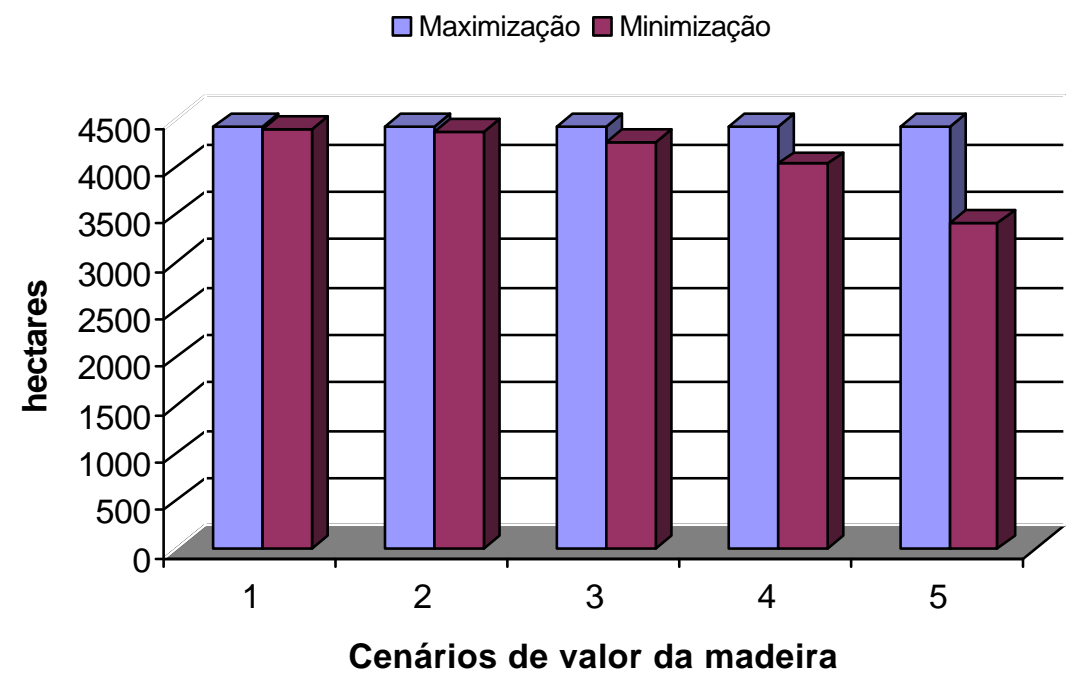

Figura 7- Área média das recomendações no horizonte de planejamento, em hectares, a ser colhida para os modelos de maximização do valor líquido presente e minimização do custo presente, nas condições regionalizadas, com restrições operacionais e de produção livre, onde $1=$ valor $+20 \% ; 2=$ valor $+10 \% ; 3=$ valor original; $4=$ valor $-10 \% ; 5=$ valor $20 \%$.

Nas prescrições de volume a ser adquirido no mercado também ocorre uma clara diferenciação entre os dois modelos básicos. Sendo mais sensíveis às variações no valor da madeira de mercado em função da estruturação da função objetivo, o modelos de minimização tendem a responder mais intensamente a estas flutuações, enquanto que os modelos de maximização mantém-se razoavelmente estáveis frente aos diferentes cenários.

Na Figura 8 o gráfico mostra as diferenças no volume médio a ser adquirido no mercado nos dois modelos, para as mesmas condições consideradas na Figura anterior. 
$\square$ Maximização $\square$ Minimização

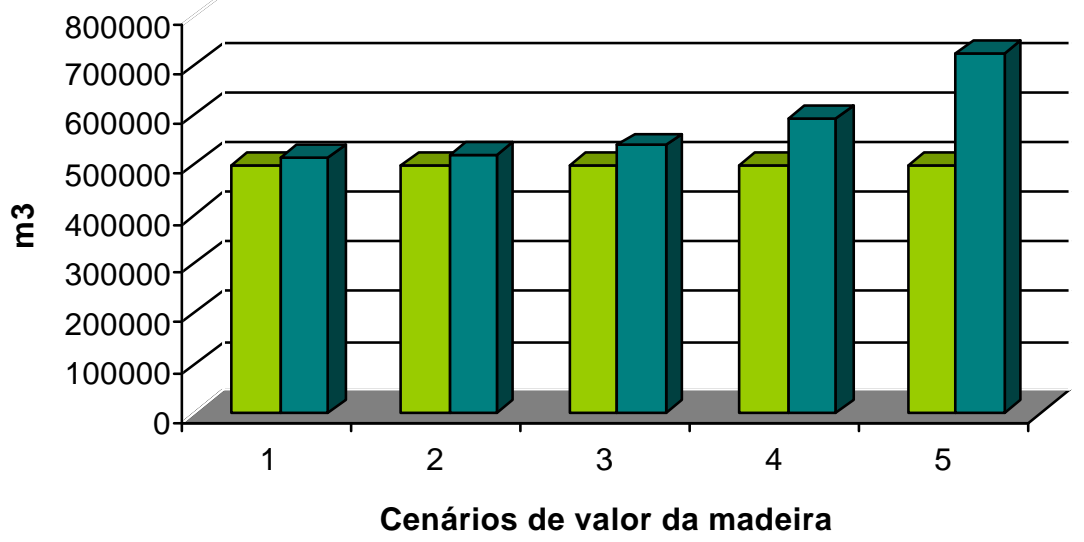

Figura 8- Volume médio, a ser adquirido no mercado, no horizonte de planejamento, em $\mathrm{m}^{3}$, para os modelos de maximização do valor líquido presente e minimização do custo presente, nas condições regionalizadas, com restrições operacionais e de produção livre, onde $1=$ valor $+20 \% ; 2=$ valor $+10 \% ; 3=$ valor original $4=$ valor $-10 \% ; 5=$ valor $-20 \%$.

Nas condições onde é exigido o ordenamento, o comportamento é semelhante ao mostrado na Figura 8.

Em geral, o aproveitamento da área plantada, decorrente diretamente dos itens observados anteriormente, é maior e mais estável nos modelos de máximo valor do que nos de mínimo custo. Novamente, quando a opção é simplesmente minimizar o custo de aquisição da madeira como um todo, qualquer alternativa mais cara é preterida em favor da mais acessível, independentemente se o volume produzido é próprio ou adquirido no mercado. 


\section{CONCLUSÕES}

Uma determinação mais rápida dos valores respectivos ao ganho do modelo global em relação ao regional, como proposta na hipótese I, e um dos objetivos deste trabalho, pode ser obtida pela simples subtração do valor da função objetivo dos dois modelos para os mesmos cenários. Estes valores estão expressos na Tabela 40 para as condições de maximização e na Tabela 41 para as de minimização:

Tabela 40. Diferenças entre valores absolutos das funções objetivo do modelo global em relação ao regionalizado, para todos os cenários de valor da madeira, na condição de maximização do valor presente líquido.

\begin{tabular}{lcc}
\hline Cenários de valor & \multicolumn{2}{c}{ Valores da função objetivo (R\$) } \\
& $\begin{array}{c}\text { Global - Regionalizado } \\
\text { Ordenado }\end{array}$ & $\begin{array}{c}\text { Global - Regionalizado } \\
\text { Livre }\end{array}$ \\
\hline ValMM +20\% & $48.743 .499,00$ & $42.668 .274,00$ \\
ValMM +10\% & $46.716 .780,00$ & $40.925 .300,00$ \\
ValMM original & $44.699 .420,00$ & $39.209 .020,00$ \\
ValMM -10\% & $42.858 .870,00$ & $37.649 .770,00$ \\
ValMM -20\% & $41.334 .940,00$ & $36.355 .710,00$ \\
Media & $44.870 .701,80$ & $39.361 .614,80$ \\
\hline
\end{tabular}

Pode se perceber que o ganho para os modelos de máximo valor, em termos absolutos, varia proporcionalmente ao incremento, ou decréscimo, do valor (preço) da madeira oferecida no mercado. 
Tabela 41. Diferenças entre valores absolutos das funções objetivo do modelo global em relação ao regionalizado, para todos os cenários de valor da madeira, na condição de maximização do valor presente líquido.

\begin{tabular}{lcc}
\hline Cenários de valor & \multicolumn{2}{c}{ Valores da função objetivo (R\$) } \\
& $\begin{array}{c}\text { Global - Regionalizado } \\
\text { Ordenado }\end{array}$ & $\begin{array}{c}\text { Global - Regionalizado } \\
\end{array}$ \\
\hline ValMM +20\% & $30.527 .600,00$ \\
ValMM +10\% & $28.911 .200,00$ & $28.846 .800,00$ \\
ValMM original & $27.584 .000,00$ & $27.249 .300,00$ \\
ValMM -10\% & $26.428 .400,00$ & $25.560 .900,00$ \\
ValMM -20\% & $23.759 .400,00$ & $23.278 .100,00$ \\
Media & $27.442 .120,00$ & $19.242 .700,00$ \\
\hline
\end{tabular}

No caso dos modelos de mínimo custo, o comportamento é diverso aos de máximo valor, onde o ganho é mais do que proporcional quando há variação decrescente no valor da madeira de mercado. A Figura 9 demonstra graficamente esta tendência, para condições onde se prescreve ordenamento.

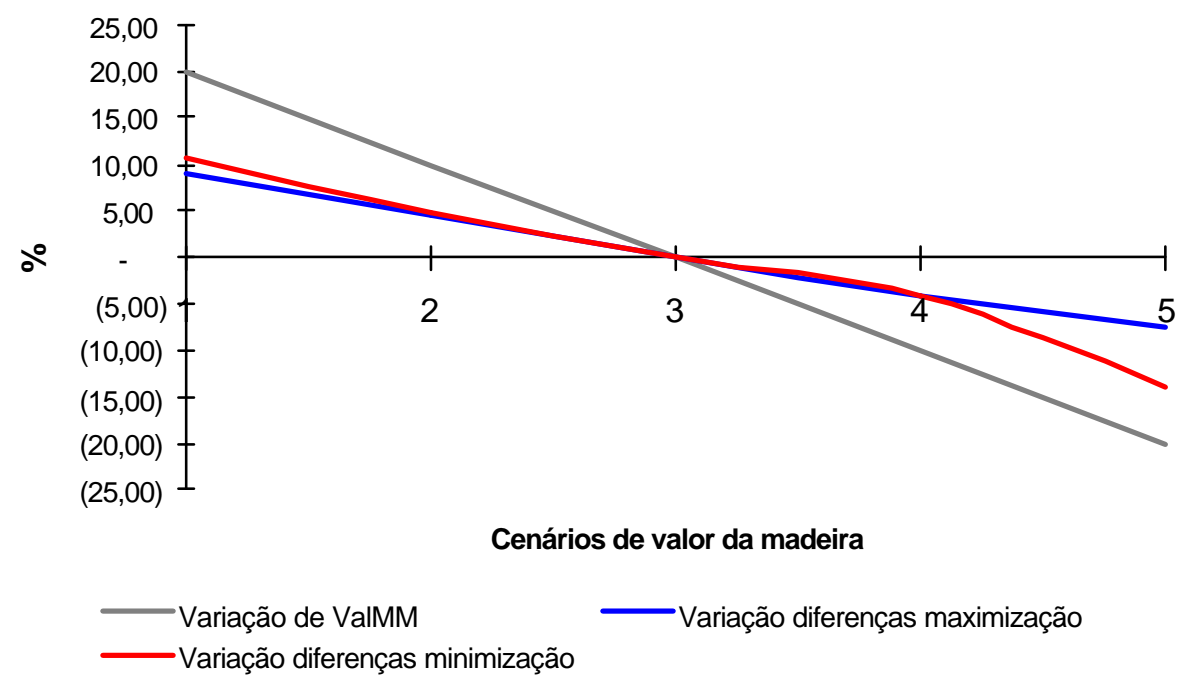

Figura 9- Variação das diferenças percentuais entre valores da função objetivo dos modelos global e regionalizado, nos diferentes cenários de valor da madeira, para produção ordenada, nas condições de maximização do valor líquido presente e minimização do custo presente. 
Pode-se concluir que esta tendência demonstra que, em geral, os modelos de mínimo custo apresentam maior sensibilidade às variações do valor da madeira de mercado.

A Figura 10 demonstra graficamente as mesmas variações da figura anterior, na condição de produção livre.

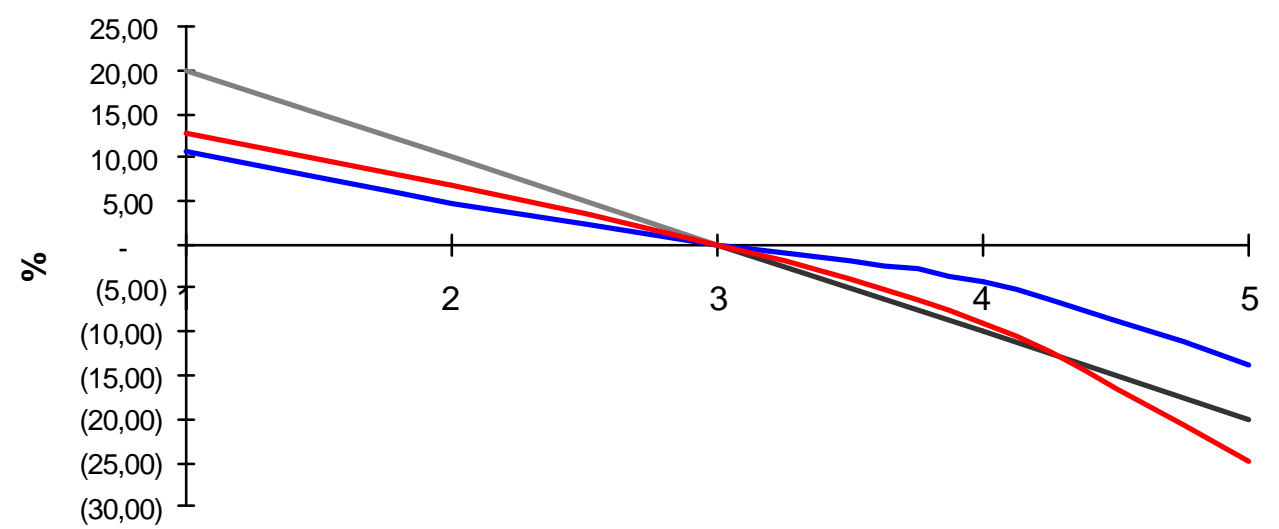

Cenários de valor da madeira

Variação de ValMM
Variação diferenças de minimização

Figura 10- Variação das diferenças percentuais entre valores da função objetivo dos modelos global e regionalizado, nos diferentes cenários de valor da madeira, para produção livre, nas condições de maximização do valor líquido presente e minimização do custo presente.

A sensibilidade maior admitida para os modelos de minimização fica mais evidente, quando comparadas às diferenças percentuais entre os modelos global e regionalizado, do que nos modelos de maximização na condição de produção livre.

Para os modelos de máximo valor, nas condições onde se prescreve ordenamento, as diferenças de valor encontradas quando comparadas aos modelos de produção livre tendem a apresentar uma certa estabilidade, no caso em torno de $14 \%$, 
para todos os cenários de preço. Esta tendência não se repete nos modelos de mínimo custo, onde ocorre um maior flutuação destas relações (de 5 a 23\%), de onde se pode concluir que esses modelos também são mais sensíveis ao ordenamento.

Como a gradual redução dos valores da madeira de mercado tende a conduzir a uma eventual anulação da diferença dos resultados da função objetivo, entre modelos global e regionalizado, e para os modelos de minimização aparentemente de forma mais rápida que nos modelos de maximização, pode-se considerar que o melhor estimador para as reais diferenças entre a opção por ordenar a floresta como um todo e regionalizála é a maximização do valor líquido presente, onde há maior estabilidade nesses valores.

Portanto, a razão entre a média das diferenças obtidas entre os modelos global e regionalizado e o número de anos do horizonte de planejamento proposto pode fornecer ao tomador de decisão um parâmetro anual sobre o qual se possa definir o quanto é efetivamente econômico conduzir o manejo de forma regionalizada, comparando este valor aos eventuais ganhos operacionais obtidos por esse regime administrativo.

A análise da sensibilidade de modelos às variações não pode ser restrita a um único parâmetro, no entanto. Uma outra forma possível de se estimar a eventual ganho econômico obtido pela adoção de regimes ordenados globais é a determinação do custo total derivado exclusivamente da aquisição da madeira de mercado recomendada em cada regime de manejo. Este custo presente pode ser obtido pela soma dos produtos do volume prescrito e o valor da madeira no seu respectivo ano. A Tabela 42 mostra um exemplo de valores totais presentes obtidos para o produto do volume prescrito de aquisição de madeira de mercado e o seu respectivo preço, para os modelos global e regionalizado, no cenário de preço atual (ValMM original), na condição de maximização do valor líquido presente com restrições operacionais de área (cenário mais próximo do atual da empresa). 
Tabela 42. Valores presentes do produto madeira adquirida no mercado / valor da madeira no ano da aquisição para um cenário de modelagem (comparação modelos global e regionalizado)

\begin{tabular}{ccc}
\hline $\begin{array}{c}\text { Ano no horizonte } \\
\text { de planejamento }\end{array}$ & $\begin{array}{c}\text { Volume adquirido x Valor da madeira no } \\
\text { ano } \\
\text { Modelo global ordenado } \\
(\mathbf{R} \$)\end{array}$ & $\begin{array}{c}\text { Volume adquirido x Valor da madeira no } \\
\text { ano }\end{array}$ \\
\hline $\mathbf{1}$ & $18.633 .580,64$ & $\begin{array}{c}\text { Modelo regionalizado ordenado } \\
(\mathbf{R} \mathbf{\text { ) }})\end{array}$ \\
$\mathbf{2}$ & $17.251 .252,51$ & $27.325 .961,44$ \\
$\mathbf{3}$ & $15.975 .257,32$ & $21.500 .824,05$ \\
$\mathbf{4}$ & $14.790 .404,63$ & $16.530 .871,75$ \\
$\mathbf{5}$ & $13.259 .571,88$ & $15.304 .810,26$ \\
$\mathbf{6}$ & $11.729 .965,61$ & $14.173 .061,20$ \\
$\mathbf{7}$ & $10.858 .998,10$ & $12.516 .387,81$ \\
$\mathbf{8}$ & $10.053 .587,29$ & $11.347 .319,21$ \\
$\mathbf{9}$ & $9.309 .050,55$ & $10.505 .689,67$ \\
$\mathbf{1 0}$ & $8.620 .705,26$ & $9.727 .671,66$ \\
$\mathbf{1 1}$ & $7.983 .868,81$ & $9.008 .372,00$ \\
$\mathbf{1 2}$ & $7.389 .175,94$ & $8.342 .897,48$ \\
$\mathbf{1 3}$ & $6.841 .309,28$ & $7.721 .461,71$ \\
$\mathbf{1 4}$ & $6.335 .586,21$ & $7.148 .957,90$ \\
$\mathbf{1 5}$ & $5.867 .324,11$ & $6.620 .492,84$ \\
$\mathbf{1 6}$ & $5.431 .840,36$ & $6.131 .173,34$ \\
$\mathbf{1 7}$ & $4.968 .681,64$ & $5.676 .106,20$ \\
$\mathbf{1 8}$ & $4.603 .201,34$ & $5.255 .291,43$ \\
$\mathbf{1 9}$ & $4.260 .852,69$ & $4.868 .729,03$ \\
$\mathbf{2 0}$ & $3.946 .262,05$ & $4.506 .632,60$ \\
$\mathbf{2 1}$ & $3.654 .803,07$ & $4.173 .895,34$ \\
$\mathbf{T o t a l}$ & $\mathbf{1 9 1 . 7 6 5 . 2 7 9 , 2 7}$ & $3.670 .660,74$ \\
\hline & & $\mathbf{2 1 2 . 0 5 7 . 2 6 7 , 6 0}$ \\
\hline
\end{tabular}

A razão entre a diferença dos totais dois modelos e o número de anos do horizonte de planejamento pode ser diretamente obtida, produzindo um parâmetro de custos alternativo útil ao tomador de decisão, podendo ser comparado com os eventuais ganhos econômicos anuais obtidos pela administração regionalizada da área.

Os dados gerados neste trabalho possibilitam a conclusão de que as três hipóteses sugeridas foram confirmadas, muito embora expressando-as em níveis diferentes. 
Uma forma de checar a validade dos modelos de minimização do custo presente pode decorrer da inserção de variáveis qualitativas da produção fabril no planejamento, como rendimento de celulose e densidade básica, em substituição à unidade "volume" adquirido. A opção por compra de madeira de mercado se faz considerando que as propriedades tecnológicas são semelhantes às da madeira produzida na empresa, o que raramente é o caso.

Os programas de melhoramento e desenvolvimento tecnológico internos das grandes empresas do setor garantem não apenas produção volumétrica superior, mas também ganhos qualitativos que poucas vezes são considerados em programas de abastecimento. Uma variável interessante de ser explorada na predição via inventário florestal é dada em "toneladas de celulose produzíveis por hectare", derivada do produto de variáveis como volume (que determina o total produzido, de fácil obtenção), densidade básica (que proporciona o conhecimento da quantidade de massa de matéria seca existente naquele volume estimado) e rendimento de celulose (que converte a matéria seca para o produto secundário). Assumindo esta nova variável como elemento de planejamento, cria-se a possibilidade de estimar com maior aproximação a real vantagem de se adquirir madeira de mercado via a determinação de um "valor" mais compatível com a qualidade normalmente pouco estável, e muitas vezes desconhecida, deste produto. 
ANEXOS 


\section{ANEXO A Lista de coeficientes por prescrição}

\begin{tabular}{|c|c|c|}
\hline $\begin{array}{l}\text { Variável } \\
\text { nomeada }\end{array}$ & Valor Liquido Presente/UP (R\$) & Custo Presente /UP (R\$) \\
\hline UP11 & $16,882.69$ & $9,574.01$ \\
\hline UP12 & $15,845.05$ & $9,171.29$ \\
\hline UP13 & $16,768.79$ & $8,793.53$ \\
\hline UP14 & $15,487.91$ & $8,877.50$ \\
\hline UP15 & $16,137.59$ & $8,446.20$ \\
\hline UP16 & $15,352.87$ & $8,194.50$ \\
\hline UP17 & $15,120.25$ & $8,039.95$ \\
\hline UP18 & $14,507.60$ & $7,826.02$ \\
\hline UP19 & $13,818.78$ & $7,604.17$ \\
\hline UP21 & $14,259.80$ & $8,713.12$ \\
\hline UP22 & $14,710.47$ & $8,164.99$ \\
\hline UP23 & $14,046.35$ & $7,938.88$ \\
\hline UP24 & $13,883.76$ & $7,797.32$ \\
\hline UP25 & $13,182.00$ & $7,567.58$ \\
\hline UP26 & $12,603.32$ & $7,368.96$ \\
\hline UP27 & $12,616.10$ & $7,270.28$ \\
\hline UP28 & $11,996.81$ & $7,066.89$ \\
\hline UP29 & $11,489.22$ & $6,891.62$ \\
\hline UP31 & $10,321.23$ & $6,460.93$ \\
\hline UP32 & $9,583.95$ & $6,134.58$ \\
\hline UP33 & $10,537.14$ & $5,876.79$ \\
\hline UP34 & $14,814.62$ & $9,010.27$ \\
\hline UP35 & $15,828.74$ & $8,408.78$ \\
\hline UP36 & $15,250.00$ & $8,224.40$ \\
\hline UP37 & $15,129.85$ & $8,078.84$ \\
\hline UP38 & $14,673.69$ & $7,921.79$ \\
\hline UP39 & $14,167.80$ & $7,758.42$ \\
\hline UP41 & $21,876.74$ & $10,719.01$ \\
\hline UP42 & $20,385.18$ & $10,225.43$ \\
\hline UP43 & $21,498.13$ & $9,840.41$ \\
\hline UP44 & $19,807.58$ & $9,880.95$ \\
\hline UP45 & $20,435.62$ & $9,406.49$ \\
\hline UP46 & $19,436.75$ & $9,111.58$ \\
\hline UP47 & $19,221.78$ & $8,957.44$ \\
\hline UP48 & $18,344.76$ & $8,691.04$ \\
\hline UP49 & $17,468.11$ & $8,431.10$ \\
\hline UP51 & $13,453.05$ & $8,329.48$ \\
\hline UP52 & $13,826.85$ & $7,791.36$ \\
\hline UP53 & $13,139.92$ & $7,567.81$ \\
\hline UP54 & $13,203.98$ & $7,479.17$ \\
\hline UP55 & $12,667.26$ & $7,289.57$ \\
\hline UP56 & $12,058.80$ & $7,091.19$ \\
\hline
\end{tabular}


ANEXO A Lista de coeficientes por prescrição

\begin{tabular}{|c|c|c|}
\hline UP57 & $11,861.97$ & $6,956.69$ \\
\hline UP58 & $11,395.37$ & $6,790.10$ \\
\hline UP59 & $10,860.09$ & $6,614.71$ \\
\hline UP61 & $10,854.04$ & $6,837.58$ \\
\hline UP62 & $10,436.87$ & $6,681.81$ \\
\hline UP63 & $9,951.89$ & $6,517.65$ \\
\hline UP64 & $10,004.10$ & $6,445.89$ \\
\hline UP65 & $9,636.61$ & $6,307.84$ \\
\hline UP66 & $9,604.65$ & $6,098.87$ \\
\hline UP67 & $9,745.53$ & $6,067.46$ \\
\hline UP68 & $9,373.28$ & $5,944.65$ \\
\hline UP69 & $8,943.97$ & $5,813.86$ \\
\hline UP71 & $10,679.71$ & $6,924.95$ \\
\hline UP72 & $10,268.71$ & $6,766.15$ \\
\hline UP73 & $9,790.23$ & $6,598.93$ \\
\hline UP74 & $9,843.08$ & $6,526.63$ \\
\hline UP75 & $9,481.01$ & $6,385.91$ \\
\hline UP76 & $9,449.46$ & $6,173.93$ \\
\hline UP77 & $9,588.57$ & $6,143.00$ \\
\hline UP78 & $9,221.78$ & $6,017.75$ \\
\hline UP79 & $8,798.20$ & $5,884.47$ \\
\hline UP81 & $5,525.40$ & $6,012.83$ \\
\hline UP82 & $5,304.64$ & $5,830.72$ \\
\hline UP83 & $5,067.38$ & $5,709.88$ \\
\hline UP84 & $5,099.17$ & $5,563.81$ \\
\hline UP85 & $4,904.77$ & $5,402.50$ \\
\hline UP86 & $4,926.44$ & $5,243.63$ \\
\hline UP87 & $5,038.17$ & $5,264.56$ \\
\hline UP88 & $4,839.61$ & $5,119.50$ \\
\hline UP89 & $4,627.59$ & $5,026.15$ \\
\hline UP91 & $14,966.00$ & $7,560.52$ \\
\hline UP92 & $13,560.89$ & $7,094.57$ \\
\hline UP93 & $14,602.39$ & $6,760.83$ \\
\hline UP94 & $20,839.99$ & $10,557.97$ \\
\hline UP95 & $21,703.68$ & $9,842.48$ \\
\hline UP96 & $20,760.47$ & $9,582.63$ \\
\hline UP97 & $20,594.04$ & $9,422.65$ \\
\hline UP98 & $19,752.34$ & $9,185.88$ \\
\hline UP99 & $18,925.77$ & $8,955.69$ \\
\hline UP101 & $15,120.55$ & $7,652.37$ \\
\hline UP102 & $13,560.43$ & $7,145.28$ \\
\hline UP103 & $14,593.05$ & $6,812.09$ \\
\hline UP104 & $20,883.36$ & $10,644.57$ \\
\hline UP105 & $21,603.68$ & $9,896.52$ \\
\hline UP106 & $20,664.45$ & $9,634.56$ \\
\hline
\end{tabular}


ANEXO A Lista de coeficientes por prescrição

\begin{tabular}{lcc} 
UP107 & $20,594.73$ & $9,496.51$ \\
UP108 & $19,660.90$ & $9,235.37$ \\
UP109 & $18,837.82$ & $9,003.34$ \\
UP111 & $11,155.11$ & $7,469.17$ \\
UP112 & $10,822.44$ & $7,305.11$ \\
UP113 & $10,538.67$ & $7,156.76$ \\
UP114 & $10,511.73$ & $7,056.86$ \\
UP115 & $10,220.39$ & $6,912.07$ \\
UP116 & $9,973.09$ & $6,781.29$ \\
UP117 & $9,999.72$ & $6,696.33$ \\
UP118 & $9,743.30$ & $6,568.22$ \\
UP119 & $10,388.43$ & $6,602.04$ \\
UP121 & $10,308.03$ & $7,587.98$ \\
UP122 & $9,868.69$ & $7,394.40$ \\
UP123 & $9,449.24$ & $7,211.69$ \\
UP124 & $9,420.74$ & $7,111.61$ \\
UP125 & $9,034.38$ & $6,940.32$ \\
UP126 & $8,664.93$ & $6,778.51$ \\
UP127 & $8,611.63$ & $6,678.47$ \\
UP128 & $9,093.71$ & $6,603.50$ \\
UP129 & $8,707.44$ & $6,454.44$ \\
UP131 & $8,811.05$ & $7,292.87$ \\
UP132 & $8,435.88$ & $7,116.79$ \\
UP133 & $8,076.89$ & $6,950.43$ \\
UP134 & $8,051.29$ & $6,856.93$ \\
UP135 & $7,720.76$ & $6,700.94$ \\
UP136 & $7,756.07$ & $6,496.30$ \\
UP137 & $7,937.11$ & $6,481.50$ \\
UP138 & $7,602.90$ & $6,341.64$ \\
UP139 & $7,283.49$ & $6,209.29$ \\
UP141 & $10,177.97$ & $7,720.55$ \\
UP142 & $9,743.36$ & $7,522.50$ \\
UP143 & $9,328.41$ & $7,335.52$ \\
UP144 & $9,300.81$ & $7,234.45$ \\
UP145 & $8,918.62$ & $7,059.20$ \\
UP146 & $8,553.12$ & $6,893.62$ \\
UP147 & $8,500.91$ & $6,792.39$ \\
UP148 & $8,978.36$ & $6,717.70$ \\
UP149 & $8,596.20$ & $6,565.02$ \\
UP151 & $15,585.98$ & $11,354.18$ \\
UP152 & $14,489.30$ & $10,824.39$ \\
UP153 & $15,416.96$ & $10,439.03$ \\
UP154 & $14,537.85$ & $11,135.74$ \\
UP155 & $14,626.73$ & $9,977.65$ \\
UP156 & $13,907.88$ & $9,659.10$ \\
& & \\
\hline
\end{tabular}


ANEXO A Lista de coeficientes por prescrição

\begin{tabular}{lll} 
UP157 & $13,791.86$ & $9,497.36$ \\
UP158 & $13,141.93$ & $9,210.22$ \\
UP159 & $12,511.17$ & $8,929.44$ \\
UP161 & $12,653.75$ & $10,685.40$ \\
UP162 & $11,789.47$ & $10,205.77$ \\
UP163 & $12,652.57$ & $9,854.06$ \\
UP164 & $11,495.18$ & $9,871.84$ \\
UP165 & $12,027.00$ & $9,420.39$ \\
UP166 & $11,469.49$ & $9,144.45$ \\
UP167 & $11,410.09$ & $9,007.37$ \\
UP168 & $10,893.50$ & $8,748.31$ \\
UP169 & $10,404.59$ & $8,505.22$ \\
UP171 & $9,350.65$ & $8,930.99$ \\
UP172 & $9,765.87$ & $8,389.46$ \\
UP173 & $9,290.82$ & $8,152.84$ \\
UP174 & $9,366.76$ & $8,058.52$ \\
UP175 & $9,003.77$ & $7,854.36$ \\
UP176 & $8,582.85$ & $7,644.61$ \\
UP177 & $8,458.28$ & $7,509.68$ \\
UP178 & $8,143.39$ & $7,330.19$ \\
UP179 & $7,773.27$ & $7,144.80$ \\
UP181 & $8,824.16$ & $8,939.42$ \\
UP182 & $9,229.79$ & $8,393.06$ \\
UP183 & $8,768.01$ & $8,153.85$ \\
UP184 & $8,844.45$ & $8,059.02$ \\
UP185 & $8,492.56$ & $7,852.60$ \\
UP186 & $8,083.31$ & $7,640.55$ \\
UP187 & $7,962.43$ & $7,504.67$ \\
UP188 & $7,657.18$ & $7,323.18$ \\
UP189 & $7,297.29$ & $7,135.75$ \\
UP191 & $6,683.70$ & $6,947.69$ \\
UP192 & $6,381.53$ & $6,778.07$ \\
UP193 & $6,030.18$ & $6,599.23$ \\
UP194 & $6,090.48$ & $6,523.12$ \\
UP195 & $5,824.83$ & $6,372.96$ \\
UP196 & $5,512.59$ & $6,213.75$ \\
UP197 & $5,416.19$ & $6,096.93$ \\
UP198 & $5,802.09$ & $6,021.66$ \\
UP199 & $5,481.15$ & $5,876.31$ \\
\hline & & \\
\hline & &
\end{tabular}


ANEXO A Lista de coeficientes por prescrição

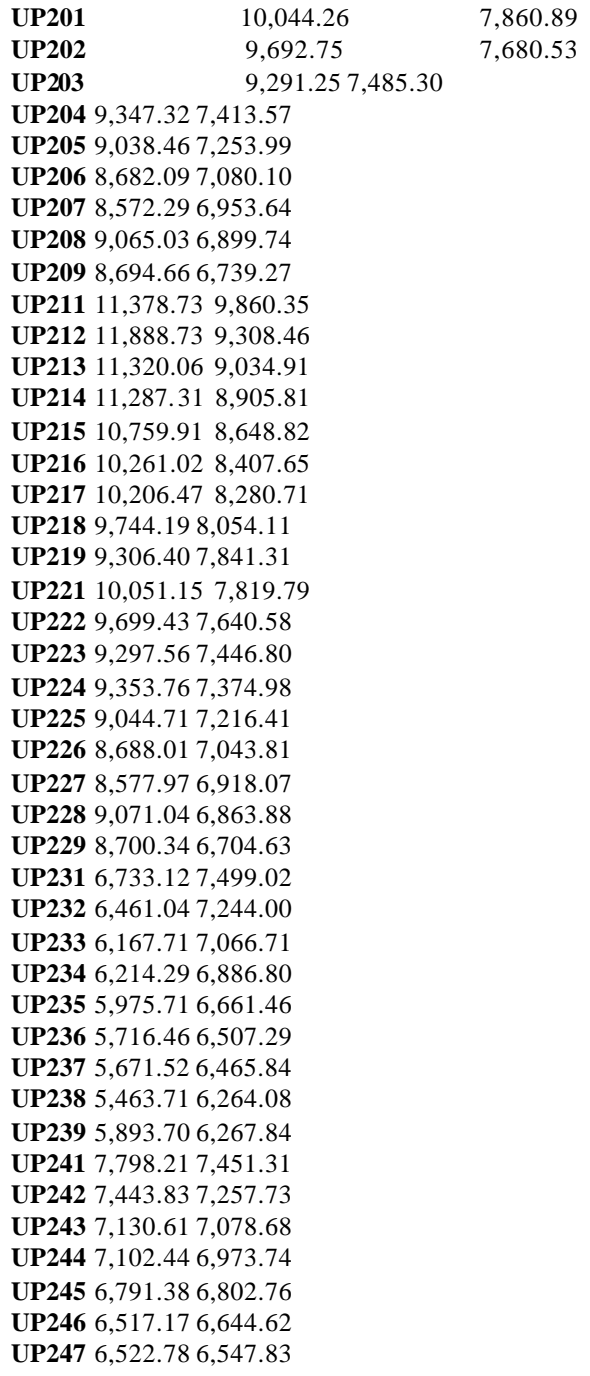




\title{
ANEXO A Lista de coeficientes por prescrição
}

\author{
UP248 6,248.81 6,396.60 \\ UP249 6,756.56 6,402.89 \\ UP251 8,862.919,117.67 \\ UP252 9,393.60 8,602.63 \\ UP253 8,990.18 8,368.43 \\ UP254 8,958.14 8,245.33 \\ UP255 8,559.93 8,022.60 \\ UP256 8,207.56 7,816.29 \\ UP257 8,215.47 7,702.13 \\ UP258 7,865.65 7,505.66 \\ UP259 7,556.897,323.68 \\ UP261 9,429.30 7,803.11 \\ UP262 9,057.14 7,611.57 \\ UP263 8,694.40 7,434.43 \\ UP264 8,676.35 7,333.41 \\ UP265 8,348.50 7,163.75 \\ UP266 8,386.80 6,951.78 \\ UP267 8,563.86 6,943.27 \\ UP268 8,231.61 6,790.59 \\ UP269 7,908.41 6,649.40 \\ UP271 9,514.65 7,932.83 \\ UP272 9,174.09 7,749.99 \\ UP273 8,698.83 7,529.92
}




\begin{tabular}{|c|c|c|}
\hline UP274 & $8,840.93$ & $7,479.63$ \\
\hline UP275 & $8,541.68$ & $7,317.81$ \\
\hline UP276 & $8,116.52$ & $7,120.96$ \\
\hline UP277 & $7,907.94$ & $6,966.40$ \\
\hline UP278 & $8,428.96$ & $6,911.07$ \\
\hline UP279 & $7,996.37$ & $6,730.25$ \\
\hline UP281 & $9,447.44$ & $9,650.56$ \\
\hline UP282 & $10,011.93$ & $9,132.15$ \\
\hline UP283 & $9,595.31$ & $8,888.31$ \\
\hline UP284 & $9,576.11$ & $8,752.30$ \\
\hline UP285 & $9,176.48$ & $8,512.04$ \\
\hline UP286 & $8,812.14$ & $8,297.68$ \\
\hline UP287 & $8,807.40$ & $8,190.36$ \\
\hline UP288 & $8,456.96$ & $7,978.12$ \\
\hline UP289 & $8,137.74$ & $7,789.11$ \\
\hline UP291 & $8,680.83$ & $8,925.69$ \\
\hline UP292 & $8,408.80$ & $8,722.10$ \\
\hline UP293 & $8,178.69$ & $8,541.96$ \\
\hline UP294 & $8,165.16$ & $8,428.49$ \\
\hline UP295 & $7,926.94$ & $8,248.89$ \\
\hline UP296 & $7,726.52$ & $8,090.35$ \\
\hline UP297 & $7,760.31$ & $8,003.08$ \\
\hline UP298 & $7,550.57$ & $7,844.10$ \\
\hline UP299 & $8,083.03$ & $7,910.15$ \\
\hline UP301 & $7,497.97$ & $9,233.62$ \\
\hline UP302 & $7,878.38$ & $8,675.04$ \\
\hline UP303 & $7,461.68$ & $8,413.21$ \\
\hline UP304 & $7,526.65$ & $8,329.80$ \\
\hline UP305 & $7,201.90$ & $8,115.01$ \\
\hline UP306 & $6,832.89$ & $7,882.37$ \\
\hline UP307 & $6,736.10$ & $7,727.57$ \\
\hline UP308 & $6,453.93$ & $7,539.22$ \\
\hline UP309 & $6,129.41$ & $7,333.55$ \\
\hline UP311 & $5,126.32$ & $8,603.38$ \\
\hline UP312 & $5,549.54$ & $8,069.31$ \\
\hline UP313 & $5,328.59$ & $7,798.54$ \\
\hline UP314 & $5,346.09$ & $7,768.86$ \\
\hline UP315 & $5,135.96$ & $7,588.31$ \\
\hline UP316 & $4,942.56$ & $7,345.77$ \\
\hline UP317 & $4,961.44$ & $7,145.14$ \\
\hline UP318 & $4,777.19$ & $6,988.79$ \\
\hline UP319 & $4,607.66$ & $6,774.23$ \\
\hline UP321 & $5,812.18$ & $8,897.83$ \\
\hline UP322 & $6,227.99$ & $8,255.97$ \\
\hline UP323 & $5,930.20$ & $8,039.79$ \\
\hline UP324 & $5,986.63$ & $7,839.50$ \\
\hline UP325 & $5,747.09$ & $7,571.75$ \\
\hline UP326 & $5,484.02$ & $7,383.67$ \\
\hline
\end{tabular}




\begin{tabular}{|c|c|c|}
\hline UP327 & $5,441.44$ & $7,335.70$ \\
\hline UP328 & $5,233.14$ & $7,096.37$ \\
\hline UP329 & $5,002.05$ & $6,930.19$ \\
\hline UP331 & $9,821.48$ & $8,906.38$ \\
\hline UP332 & $9,494.68$ & $8,691.17$ \\
\hline UP333 & $9,185.91$ & $8,499.16$ \\
\hline UP334 & $9,177.95$ & $8,384.07$ \\
\hline UP335 & $8,890.89$ & $8,193.79$ \\
\hline UP336 & $8,619.36$ & $8,024.33$ \\
\hline UP337 & $8,598.85$ & $7,933.19$ \\
\hline UP338 & $9,043.01$ & $7,884.39$ \\
\hline UP339 & $8,752.56$ & $7,725.46$ \\
\hline UP341 & $9,202.83$ & $8,847.35$ \\
\hline UP342 & $8,920.25$ & $8,649.72$ \\
\hline UP343 & $8,510.11$ & $8,412.19$ \\
\hline UP344 & $8,665.08$ & $8,362.18$ \\
\hline UP345 & $8,417.62$ & $8,187.76$ \\
\hline UP346 & $8,051.01$ & $7,975.74$ \\
\hline UP347 & $7,878.65$ & $7,813.40$ \\
\hline UP348 & $7,667.64$ & $7,661.42$ \\
\hline UP349 & $8,162.51$ & $7,680.01$ \\
\hline UP351 & $22,036.66$ & $10,367.42$ \\
\hline UP352 & $22,650.96$ & $9,792.49$ \\
\hline UP353 & $21,478.39$ & $9,468.32$ \\
\hline UP354 & $21,536.41$ & $9,370.21$ \\
\hline UP355 & $20,603.94$ & $9,098.63$ \\
\hline UP356 & $19,567.04$ & $8,811.21$ \\
\hline UP357 & $19,222.16$ & $8,637.78$ \\
\hline UP358 & $18,411.47$ & $8,399.66$ \\
\hline UP359 & $17,500.17$ & $8,145.90$ \\
\hline UP361 & $20,581.91$ & $10,068.73$ \\
\hline UP362 & $21,145.01$ & $9,497.70$ \\
\hline UP363 & $20,117.86$ & $9,201.52$ \\
\hline UP364 & $20,063.92$ & $9,080.37$ \\
\hline UP365 & $19,159.34$ & $8,812.53$ \\
\hline UP366 & $18,255.42$ & $8,550.85$ \\
\hline UP367 & $18,053.03$ & $8,407.27$ \\
\hline UP368 & $17,261.98$ & $8,171.49$ \\
\hline UP369 & $16,468.08$ & $7,940.52$ \\
\hline UP371 & $21,912.96$ & $10,508.02$ \\
\hline UP372 & $22,526.10$ & $9,940.20$ \\
\hline UP373 & $21,471.07$ & $9,632.38$ \\
\hline UP374 & $21,417.54$ & $9,510.35$ \\
\hline UP375 & $20,489.81$ & $9,232.59$ \\
\hline UP376 & $19,561.50$ & $8,960.67$ \\
\hline UP377 & $19,352.74$ & $8,813.79$ \\
\hline UP378 & $18,541.70$ & $8,569.36$ \\
\hline UP379 & $17,726.57$ & $8,329.39$ \\
\hline
\end{tabular}




\begin{tabular}{|c|c|c|}
\hline UP381 & $12,689.57$ & $8,554.58$ \\
\hline UP382 & $13,053.03$ & $8,006.98$ \\
\hline UP383 & $12,389.28$ & $7,772.62$ \\
\hline UP384 & $12,453.72$ & $7,683.60$ \\
\hline UP385 & $11,935.77$ & $7,485.56$ \\
\hline UP386 & $11,347.76$ & $7,277.55$ \\
\hline UP387 & $11,158.33$ & $7,138.54$ \\
\hline UP388 & $10,708.05$ & $6,964.56$ \\
\hline UP389 & $10,190.72$ & $6,780.66$ \\
\hline UP391 & $10,459.66$ & $6,983.74$ \\
\hline UP392 & $10,007.14$ & $6,808.97$ \\
\hline UP393 & $9,575.93$ & $6,644.36$ \\
\hline UP394 & $9,543.91$ & $6,548.22$ \\
\hline UP395 & $9,145.94$ & $6,393.53$ \\
\hline UP396 & $8,766.13$ & $6,247.74$ \\
\hline UP397 & $8,710.51$ & $6,152.82$ \\
\hline UP398 & $9,199.07$ & $6,075.03$ \\
\hline UP399 & $8,802.43$ & $5,941.42$ \\
\hline UP401 & $13,348.36$ & $8,890.40$ \\
\hline UP402 & $13,622.53$ & $8,308.30$ \\
\hline UP403 & $12,948.31$ & $8,062.67$ \\
\hline UP404 & $12,904.41$ & $7,950.38$ \\
\hline UP405 & $12,296.45$ & $7,726.45$ \\
\hline UP406 & $11,702.90$ & $7,509.16$ \\
\hline UP407 & $11,591.88$ & $7,382.33$ \\
\hline UP408 & $11,058.73$ & $7,184.81$ \\
\hline UP409 & $10,536.70$ & $6,992.71$ \\
\hline UP411 & $11,167.84$ & $10,511.75$ \\
\hline UP412 & $11,540.74$ & $9,913.84$ \\
\hline UP413 & $10,959.80$ & $9,597.25$ \\
\hline UP414 & $11,018.48$ & $9,513.96$ \\
\hline UP415 & $10,560.52$ & $9,257.72$ \\
\hline UP416 & $10,046.18$ & $8,976.29$ \\
\hline UP417 & $9,893.04$ & $8,797.70$ \\
\hline UP418 & $9,494.73$ & $8,573.19$ \\
\hline UP419 & $9,042.31$ & $8,324.42$ \\
\hline UP421 & $8,968.88$ & $7,454.95$ \\
\hline UP422 & $8,594.89$ & $7,276.48$ \\
\hline UP423 & $8,163.56$ & $7,081.02$ \\
\hline UP424 & $8,211.75$ & $7,013.31$ \\
\hline UP425 & $7,882.27$ & $6,855.16$ \\
\hline UP426 & $7,852.03$ & $6,610.80$ \\
\hline UP427 & $7,984.50$ & $6,576.75$ \\
\hline UP428 & $7,651.14$ & $6,435.91$ \\
\hline UP429 & $7,269.56$ & $6,279.61$ \\
\hline UP431 & $10,967.10$ & $9,409.39$ \\
\hline UP432 & $10,495.13$ & $9,149.92$ \\
\hline UP433 & $9,959.56$ & $8,873.23$ \\
\hline
\end{tabular}




\begin{tabular}{|c|c|c|}
\hline UP434 & $10,021.07$ & $8,788.85$ \\
\hline UP435 & $9,606.73$ & $8,559.71$ \\
\hline UP436 & $9,131.83$ & $8,313.81$ \\
\hline UP437 & $8,979.15$ & $8,158.15$ \\
\hline UP438 & $8,618.88$ & $7,956.98$ \\
\hline UP439 & $9,236.07$ & $7,962.56$ \\
\hline UP441 & $8,044.87$ & $9,605.65$ \\
\hline UP442 & $8,353.96$ & $8,994.01$ \\
\hline UP443 & $7,920.83$ & $8,730.21$ \\
\hline UP444 & $7,906.43$ & $8,594.78$ \\
\hline UP445 & $7,509.07$ & $8,339.51$ \\
\hline UP446 & $7,128.18$ & $8,106.85$ \\
\hline UP447 & $7,085.06$ & $7,989.96$ \\
\hline UP448 & $6,736.37$ & $7,764.18$ \\
\hline UP449 & $6,401.50$ & $7,558.54$ \\
\hline UP451 & $8,334.22$ & $7,370.36$ \\
\hline UP452 & $7,967.78$ & $7,181.51$ \\
\hline UP453 & $7,642.13$ & $7,006.90$ \\
\hline UP454 & $7,613.11$ & $6,903.09$ \\
\hline UP455 & $7,291.49$ & $6,736.30$ \\
\hline UP456 & $7,006.34$ & $6,582.08$ \\
\hline UP457 & $7,008.49$ & $6,486.49$ \\
\hline UP458 & $6,725.32$ & $6,338.95$ \\
\hline UP459 & $7,256.66$ & $6,345.78$ \\
\hline UP461 & $7,738.21$ & $8,067.09$ \\
\hline UP462 & $8,103.31$ & $7,538.22$ \\
\hline UP463 & $7,750.66$ & $7,348.28$ \\
\hline UP464 & $7,725.57$ & $7,229.55$ \\
\hline UP465 & $7,380.98$ & $7,042.41$ \\
\hline UP466 & $7,072.19$ & $6,875.08$ \\
\hline UP467 & $7,072.60$ & $6,778.82$ \\
\hline UP468 & $6,769.52$ & $6,613.18$ \\
\hline UP469 & $6,498.42$ & $6,465.33$ \\
\hline UP471 & $9,972.67$ & $7,496.90$ \\
\hline UP472 & $9,538.11$ & $7,304.53$ \\
\hline UP473 & $9,123.93$ & $7,123.17$ \\
\hline UP474 & $9,095.41$ & $7,023.10$ \\
\hline UP475 & $8,713.24$ & $6,852.87$ \\
\hline UP476 & $8,348.44$ & $6,692.26$ \\
\hline UP477 & $8,296.92$ & $6,592.71$ \\
\hline UP478 & $8,768.15$ & $6,515.72$ \\
\hline UP479 & $8,387.04$ & $6,367.93$ \\
\hline UP481 & $13,849.47$ & $10,337.69$ \\
\hline UP482 & $14,167.08$ & $9,719.12$ \\
\hline UP483 & $13,409.31$ & $9,401.39$ \\
\hline UP484 & $13,470.27$ & $9,309.53$ \\
\hline UP485 & $12,877.54$ & $9,046.38$ \\
\hline UP486 & $12,206.06$ & $8,764.15$ \\
\hline
\end{tabular}




\begin{tabular}{|c|c|c|}
\hline UP487 & $11,980.71$ & $8,590.49$ \\
\hline UP488 & $11,465.12$ & $8,359.57$ \\
\hline UP489 & $10,874.14$ & $8,110.05$ \\
\hline UP491 & $13,478.01$ & $8,265.44$ \\
\hline UP492 & $12,967.81$ & $8,065.91$ \\
\hline UP493 & $12,379.56$ & $7,849.98$ \\
\hline UP494 & $12,427.43$ & $7,777.76$ \\
\hline UP495 & $11,977.94$ & $7,600.99$ \\
\hline UP496 & $11,934.92$ & $7,340.06$ \\
\hline UP497 & $12,099.13$ & $7,310.55$ \\
\hline UP498 & $11,644.50$ & $7,152.35$ \\
\hline UP499 & $11,124.24$ & $6,979.12$ \\
\hline UP501 & $13,561.66$ & $8,185.66$ \\
\hline UP502 & $13,048.66$ & $7,988.59$ \\
\hline UP503 & $12,457.26$ & $7,775.50$ \\
\hline UP504 & $12,505.04$ & $7,703.37$ \\
\hline UP505 & $12,053.08$ & $7,528.77$ \\
\hline UP506 & $12,009.75$ & $7,270.67$ \\
\hline UP507 & $12,174.64$ & $7,241.00$ \\
\hline UP508 & $11,717.53$ & $7,084.79$ \\
\hline UP509 & $11,194.49$ & $6,913.89$ \\
\hline UP511 & $13,488.69$ & $8,203.69$ \\
\hline UP512 & $12,978.13$ & $8,006.06$ \\
\hline UP513 & $12,389.48$ & $7,792.32$ \\
\hline UP514 & $12,437.34$ & $7,720.18$ \\
\hline UP515 & $11,987.54$ & $7,545.09$ \\
\hline UP516 & $11,944.47$ & $7,286.34$ \\
\hline UP517 & $12,108.77$ & $7,256.72$ \\
\hline UP518 & $11,653.82$ & $7,100.05$ \\
\hline UP519 & $11,133.21$ & $6,928.63$ \\
\hline UP521 & $13,326.30$ & $8,347.48$ \\
\hline UP522 & $12,821.18$ & $8,145.42$ \\
\hline UP523 & $12,238.65$ & $7,926.57$ \\
\hline UP524 & $12,286.69$ & $7,854.26$ \\
\hline UP525 & $11,841.68$ & $7,675.25$ \\
\hline UP526 & $11,799.22$ & $7,411.42$ \\
\hline UP527 & $11,962.18$ & $7,382.07$ \\
\hline UP528 & $11,512.06$ & $7,221.82$ \\
\hline UP529 & $10,996.84$ & $7,046.20$ \\
\hline UP531 & $14,945.97$ & $8,205.71$ \\
\hline UP532 & $14,271.95$ & $7,996.94$ \\
\hline UP533 & $13,534.23$ & $7,772.84$ \\
\hline UP534 & $13,582.04$ & $7,700.58$ \\
\hline UP535 & $12,992.32$ & $7,515.91$ \\
\hline UP536 & $14,039.93$ & $7,322.80$ \\
\hline UP537 & $20,552.40$ & $11,364.60$ \\
\hline UP538 & $21,302.57$ & $10,665.96$ \\
\hline UP539 & $20,323.12$ & $10,363.11$ \\
\hline
\end{tabular}




\begin{tabular}{|c|c|c|}
\hline UP541 & $8,681.95$ & $6,690.74$ \\
\hline UP542 & $8,297.20$ & $6,531.21$ \\
\hline UP543 & $7,930.49$ & $6,381.01$ \\
\hline UP544 & $7,901.32$ & $6,291.02$ \\
\hline UP545 & $7,562.32$ & $6,149.67$ \\
\hline UP546 & 7,593.98 & $5,958.70$ \\
\hline UP547 & $7,778.54$ & $5,940.47$ \\
\hline UP548 & $7,433.64$ & $5,813.60$ \\
\hline UP549 & $7,110.32$ & $5,695.18$ \\
\hline UP551 & $13,573.88$ & $7,236.81$ \\
\hline UP552 & $12,364.98$ & $6,641.28$ \\
\hline UP553 & $13,303.77$ & $6,317.43$ \\
\hline UP554 & $19,029.40$ & $9,864.72$ \\
\hline UP555 & $19,934.06$ & $9,040.00$ \\
\hline UP556 & $19,030.30$ & $8,788.17$ \\
\hline UP557 & $18,789.51$ & $8,715.84$ \\
\hline UP558 & $18,064.04$ & $8,401.73$ \\
\hline UP559 & $17,271.76$ & $8,178.67$ \\
\hline UP561 & $5,403.27$ & $10,135.47$ \\
\hline UP562 & $5,193.41$ & $9,859.90$ \\
\hline UP563 & $4,945.24$ & $9,559.88$ \\
\hline UP564 & $5,008.60$ & $9,480.80$ \\
\hline UP565 & $4,824.20$ & $9,237.14$ \\
\hline UP566 & $4,603.59$ & $8,970.00$ \\
\hline UP567 & $4,547.69$ & $8,801.34$ \\
\hline UP568 & $4,844.68$ & $8,765.39$ \\
\hline UP569 & $4,616.42$ & $8,515.64$ \\
\hline UP571 & $9,468.88$ & $15,290.19$ \\
\hline UP572 & $9,926.99$ & $14,604.52$ \\
\hline UP573 & $9,524.46$ & $14,116.91$ \\
\hline UP574 & $9,425.42$ & $13,912.08$ \\
\hline UP575 & $8,977.56$ & $13,433.05$ \\
\hline UP576 & $8,628.18$ & $13,004.34$ \\
\hline UP577 & $8,686.51$ & $12,848.73$ \\
\hline UP578 & $8,290.61$ & $12,425.64$ \\
\hline UP579 & $7,984.50$ & $12,047.61$ \\
\hline UP581 & $4,873.98$ & $8,819.67$ \\
\hline UP582 & $4,548.30$ & $8,300.57$ \\
\hline UP583 & $4,647.04$ & $8,143.15$ \\
\hline UP584 & $6,564.90$ & $13,327.51$ \\
\hline UP585 & $7,277.12$ & $12,558.61$ \\
\hline UP586 & $6,906.73$ & $12,167.54$ \\
\hline UP587 & $6,751.65$ & $11,883.54$ \\
\hline UP588 & $6,552.42$ & $11,606.62$ \\
\hline UP589 & $6,227.65$ & $11,260.26$ \\
\hline UP591 & $5,643.63$ & $9,461.98$ \\
\hline UP592 & $5,056.33$ & $8,772.39$ \\
\hline UP593 & $5,188.39$ & $8,618.76$ \\
\hline
\end{tabular}




\begin{tabular}{|c|c|c|}
\hline UP594 & $7,384.69$ & $14,097.83$ \\
\hline UP595 & $7,914.68$ & $13,197.67$ \\
\hline UP596 & $7,531.96$ & $12,795.32$ \\
\hline UP597 & $7,519.50$ & $12,599.19$ \\
\hline UP598 & $7,164.94$ & $12,221.32$ \\
\hline UP599 & $6,829.48$ & $11,865.07$ \\
\hline UP601 & $6,903.90$ & $14,986.40$ \\
\hline UP602 & $6,491.01$ & $14,306.22$ \\
\hline UP603 & $7,137.62$ & $13,984.45$ \\
\hline UP604 & $7,224.31$ & $13,876.34$ \\
\hline UP605 & $6,931.09$ & $13,450.09$ \\
\hline UP606 & $6,595.37$ & $12,996.60$ \\
\hline UP607 & $6,528.08$ & $12,761.40$ \\
\hline UP608 & $6,274.25$ & $12,388.89$ \\
\hline UP609 & $5,979.75$ & $11,989.53$ \\
\hline UP611 & $5,949.95$ & $14,186.56$ \\
\hline UP612 & $5,564.46$ & $13,521.49$ \\
\hline UP613 & $6,260.80$ & $13,240.30$ \\
\hline UP614 & $6,250.65$ & $13,082.67$ \\
\hline UP615 & $5,976.05$ & $12,666.43$ \\
\hline UP616 & $5,749.21$ & $12,269.85$ \\
\hline UP617 & $5,802.83$ & $12,098.22$ \\
\hline UP618 & $5,561.20$ & $11,732.42$ \\
\hline UP619 & $5,362.86$ & $11,383.38$ \\
\hline UP621 & $5,035.51$ & $8,857.03$ \\
\hline UP622 & $4,613.68$ & $8,244.22$ \\
\hline UP623 & $4,703.65$ & $8,063.09$ \\
\hline UP624 & $6,513.09$ & $13,468.23$ \\
\hline UP625 & $7,130.07$ & $12,598.73$ \\
\hline UP626 & $6,765.87$ & $12,207.95$ \\
\hline UP627 & $6,675.16$ & $11,978.71$ \\
\hline UP628 & $6,418.69$ & $11,646.34$ \\
\hline UP629 & $6,099.33$ & $11,300.15$ \\
\hline UP631 & $7,479.02$ & $10,768.06$ \\
\hline UP632 & $6,942.22$ & $10,096.97$ \\
\hline UP633 & $7,259.78$ & $9,934.38$ \\
\hline UP634 & $10,137.64$ & $16,180.50$ \\
\hline UP635 & $10,935.80$ & $15,311.22$ \\
\hline UP636 & $10,484.45$ & $14,884.42$ \\
\hline UP637 & $10,368.37$ & $14,646.58$ \\
\hline UP638 & $10,044.34$ & $14,280.60$ \\
\hline UP639 & $9,649.21$ & $13,902.76$ \\
\hline UP641 & $3,905.34$ & $12,784.30$ \\
\hline UP642 & $4,518.52$ & $12,200.00$ \\
\hline UP643 & $4,377.17$ & $11,888.45$ \\
\hline UP644 & $4,492.10$ & $11,625.32$ \\
\hline UP645 & $4,410.94$ & $11,235.10$ \\
\hline UP646 & $4,285.47$ & $10,965.38$ \\
\hline
\end{tabular}




\begin{tabular}{|c|c|c|}
\hline UP647 & $4,276.30$ & $10,932.19$ \\
\hline UP648 & $4,208.34$ & $10,584.27$ \\
\hline UP649 & $4,098.83$ & $10,346.94$ \\
\hline UP651 & $2,935.46$ & $11,138.33$ \\
\hline UP652 & $3,341.75$ & $10,559.36$ \\
\hline UP653 & $3,243.89$ & $10,172.93$ \\
\hline UP654 & $3,250.81$ & $10,153.86$ \\
\hline UP655 & $3,129.01$ & $9,892.88$ \\
\hline UP656 & $3,044.99$ & $9,547.14$ \\
\hline UP657 & $3,117.46$ & $9,290.33$ \\
\hline UP658 & $3,009.54$ & $9,064.35$ \\
\hline UP659 & $2,936.24$ & $8,758.72$ \\
\hline UP661 & $4,786.73$ & $10,780.91$ \\
\hline UP662 & $4,597.22$ & $10,483.31$ \\
\hline UP663 & $4,426.11$ & $10,211.98$ \\
\hline UP664 & $4,435.60$ & $10,079.36$ \\
\hline UP665 & $4,269.10$ & $9,816.36$ \\
\hline UP666 & $4,118.97$ & $9,576.75$ \\
\hline UP667 & $4,137.03$ & $9,462.97$ \\
\hline UP668 & $4,381.34$ & $9,431.50$ \\
\hline UP669 & $4,220.32$ & $9,204.53$ \\
\hline UP671 & $1,716.12$ & $9,198.66$ \\
\hline UP672 & $1,694.75$ & $8,964.48$ \\
\hline UP673 & $1,628.51$ & $8,745.34$ \\
\hline UP674 & $1,733.37$ & $8,635.04$ \\
\hline UP675 & $1,715.21$ & $8,428.48$ \\
\hline UP676 & $1,655.38$ & $8,235.09$ \\
\hline UP677 & $1,653.67$ & $8,128.04$ \\
\hline UP678 & $1,640.10$ & $7,945.69$ \\
\hline UP679 & $1,803.60$ & $8,023.98$ \\
\hline UP681 & $2,652.11$ & $10,027.85$ \\
\hline UP682 & $2,591.49$ & $9,812.59$ \\
\hline UP683 & $2,520.96$ & $9,458.17$ \\
\hline UP684 & $2,585.01$ & $9,504.85$ \\
\hline UP685 & $2,532.28$ & $9,314.94$ \\
\hline UP686 & $2,470.14$ & $8,995.50$ \\
\hline UP687 & $2,498.83$ & $8,708.79$ \\
\hline UP688 & $2,453.51$ & $8,547.24$ \\
\hline UP689 & $2,657.10$ & $8,556.47$ \\
\hline UP691 & $2,431.19$ & $9,766.55$ \\
\hline UP692 & $2,374.06$ & $9,555.04$ \\
\hline UP693 & $2,304.45$ & $9,207.81$ \\
\hline UP694 & $2,371.33$ & $9,251.48$ \\
\hline UP695 & $2,321.66$ & $9,064.87$ \\
\hline UP696 & $2,260.19$ & $8,751.90$ \\
\hline UP697 & $2,286.58$ & $8,470.30$ \\
\hline UP698 & $2,244.01$ & $8,311.48$ \\
\hline UP699 & $2,437.35$ & $8,315.77$ \\
\hline
\end{tabular}




\begin{tabular}{|c|c|c|}
\hline UP701 & $2,563.99$ & $11,003.20$ \\
\hline UP702 & $2,963.44$ & $10,419.68$ \\
\hline UP703 & $2,872.65$ & $10,035.96$ \\
\hline UP704 & $2,882.13$ & $10,014.31$ \\
\hline UP705 & $2,768.10$ & $9,753.58$ \\
\hline UP706 & $2,690.20$ & $9,410.31$ \\
\hline UP707 & $2,762.59$ & $9,156.25$ \\
\hline UP708 & $2,661.51$ & $8,930.38$ \\
\hline UP709 & $2,593.55$ & $8,626.92$ \\
\hline UP711 & $3,948.71$ & $10,054.12$ \\
\hline UP712 & $3,791.04$ & $9,790.74$ \\
\hline UP713 & $3,649.04$ & $9,550.83$ \\
\hline UP714 & $3,658.52$ & $9,427.45$ \\
\hline UP715 & $3,519.68$ & $9,194.32$ \\
\hline UP716 & $3,560.87$ & $8,944.91$ \\
\hline UP717 & $3,672.02$ & $8,958.19$ \\
\hline UP718 & $3,530.18$ & $8,745.30$ \\
\hline UP719 & $3,402.26$ & $8,551.58$ \\
\hline UP721 & $5,400.41$ & $13,936.98$ \\
\hline UP722 & $5,920.68$ & $13,324.78$ \\
\hline UP723 & $5,608.49$ & $12,864.98$ \\
\hline UP724 & $5,715.89$ & $12,737.69$ \\
\hline UP725 & $5,498.23$ & $12,338.67$ \\
\hline UP726 & $5,221.07$ & $11,931.99$ \\
\hline UP727 & $5,146.81$ & $11,728.61$ \\
\hline UP728 & $4,959.56$ & $11,378.41$ \\
\hline UP729 & $4,716.17$ & $11,019.68$ \\
\hline UP731 & $3,934.53$ & $10,086.70$ \\
\hline UP732 & $3,777.32$ & $9,822.36$ \\
\hline UP733 & $3,635.72$ & $9,581.59$ \\
\hline UP734 & $3,645.31$ & $9,457.94$ \\
\hline UP735 & $3,506.87$ & $9,223.95$ \\
\hline UP736 & $3,548.01$ & $8,973.81$ \\
\hline UP737 & $3,658.98$ & $8,987.34$ \\
\hline UP738 & $3,517.54$ & $8,773.67$ \\
\hline UP739 & $3,389.99$ & $8,579.23$ \\
\hline UP741 & $2,091.62$ & $9,643.72$ \\
\hline UP742 & $2,016.69$ & $9,347.75$ \\
\hline UP743 & $1,943.37$ & $9,121.73$ \\
\hline UP744 & $1,992.54$ & $8,945.16$ \\
\hline UP745 & $1,927.09$ & $8,683.98$ \\
\hline UP746 & $1,862.84$ & $8,486.62$ \\
\hline UP747 & $1,900.01$ & $8,425.31$ \\
\hline UP748 & $1,842.94$ & $8,192.58$ \\
\hline UP749 & $2,028.70$ & $8,278.16$ \\
\hline UP751 & $4,794.91$ & $10,792.77$ \\
\hline UP752 & $4,605.13$ & $10,494.80$ \\
\hline UP753 & $4,433.77$ & $10,223.14$ \\
\hline
\end{tabular}




\begin{tabular}{|c|c|c|}
\hline UP754 & $4,443.21$ & $10,090.43$ \\
\hline UP755 & $4,276.47$ & $9,827.10$ \\
\hline UP756 & $4,126.12$ & $9,587.21$ \\
\hline UP757 & $4,144.13$ & $9,473.35$ \\
\hline UP758 & $4,388.72$ & $9,441.94$ \\
\hline UP759 & $4,227.48$ & $9,214.69$ \\
\hline UP761 & $3,763.00$ & $10,220.11$ \\
\hline UP762 & $3,611.23$ & $9,951.86$ \\
\hline UP763 & $3,474.58$ & $9,707.53$ \\
\hline UP764 & $3,485.51$ & $9,582.78$ \\
\hline UP765 & $3,351.87$ & $9,345.33$ \\
\hline UP766 & $3,392.41$ & $9,092.20$ \\
\hline UP767 & $3,501.25$ & $9,106.72$ \\
\hline UP768 & $3,364.65$ & $8,889.82$ \\
\hline UP769 & $3,241.50$ & $8,692.47$ \\
\hline UP771 & $3,825.85$ & $10,197.79$ \\
\hline UP772 & $3,672.08$ & $9,930.19$ \\
\hline UP773 & $3,533.63$ & $9,686.46$ \\
\hline UP774 & $3,544.07$ & $9,561.89$ \\
\hline UP775 & $3,408.66$ & $9,325.02$ \\
\hline UP776 & $3,449.42$ & $9,072.39$ \\
\hline UP777 & $3,559.05$ & $9,086.75$ \\
\hline UP778 & $3,420.68$ & $8,870.39$ \\
\hline UP779 & $3,295.91$ & $8,673.53$ \\
\hline UP781 & $6,471.41$ & $9,577.89$ \\
\hline UP782 & $6,272.49$ & $9,332.88$ \\
\hline UP783 & $6,026.59$ & $9,085.53$ \\
\hline UP784 & $6,094.20$ & $9,006.80$ \\
\hline UP785 & $5,920.18$ & $8,790.54$ \\
\hline UP786 & $5,701.91$ & $8,571.33$ \\
\hline UP787 & $5,633.25$ & $8,454.84$ \\
\hline UP788 & $5,483.30$ & $8,264.51$ \\
\hline UP789 & $5,889.90$ & $8,300.92$ \\
\hline UP791 & $5,635.09$ & $8,817.19$ \\
\hline UP792 & $5,469.35$ & $8,604.27$ \\
\hline UP793 & $5,258.51$ & $8,387.88$ \\
\hline UP794 & $5,321.54$ & $8,314.80$ \\
\hline UP795 & $5,176.24$ & $8,126.46$ \\
\hline UP796 & $4,988.58$ & $7,934.25$ \\
\hline UP797 & $4,924.88$ & $7,825.64$ \\
\hline UP798 & $5,259.25$ & $7,768.06$ \\
\hline UP799 & $5,060.06$ & $7,589.76$ \\
\hline UP801 & $1,212.99$ & $7,525.83$ \\
\hline UP802 & $1,277.42$ & $7,228.90$ \\
\hline UP803 & $1,277.35$ & $7,086.82$ \\
\hline UP804 & $1,403.26$ & $6,839.29$ \\
\hline UP805 & $1,461.27$ & $6,576.91$ \\
\hline UP806 & $1,459.69$ & $6,456.98$ \\
\hline
\end{tabular}




\begin{tabular}{|c|c|c|}
\hline UP807 & $1,449.22$ & $6,510.39$ \\
\hline UP808 & $1,503.93$ & $6,272.90$ \\
\hline UP809 & $1,759.61$ & $6,300.72$ \\
\hline UP811 & $4,956.71$ & $9,208.33$ \\
\hline UP812 & $4,908.68$ & $8,953.33$ \\
\hline UP813 & $4,709.99$ & $8,698.46$ \\
\hline UP814 & $4,904.62$ & $8,614.62$ \\
\hline UP815 & $4,863.54$ & $8,389.45$ \\
\hline UP816 & $4,682.72$ & $8,163.58$ \\
\hline UP817 & $4,534.88$ & $8,046.03$ \\
\hline UP818 & $4,505.93$ & $7,847.66$ \\
\hline UP819 & $4,791.76$ & $7,861.82$ \\
\hline UP821 & $4,818.61$ & $9,281.27$ \\
\hline UP822 & $4,709.25$ & $8,980.82$ \\
\hline UP823 & $4,580.28$ & $8,768.53$ \\
\hline UP824 & $4,633.19$ & $8,588.68$ \\
\hline UP825 & $4,537.96$ & $8,323.35$ \\
\hline UP826 & $4,424.12$ & $8,138.70$ \\
\hline UP827 & $4,414.17$ & $8,112.37$ \\
\hline UP828 & $4,332.26$ & $7,875.09$ \\
\hline UP829 & $4,668.00$ & $7,921.13$ \\
\hline UP831 & $3,497.50$ & $7,411.39$ \\
\hline UP832 & $3,084.09$ & $7,064.80$ \\
\hline UP833 & $3,482.87$ & $6,717.18$ \\
\hline UP834 & $5,144.73$ & $10,547.23$ \\
\hline UP835 & $5,661.03$ & $9,946.35$ \\
\hline UP836 & $5,382.37$ & $9,672.09$ \\
\hline UP837 & $5,327.32$ & $9,501.22$ \\
\hline UP838 & $5,116.76$ & $9,278.07$ \\
\hline UP839 & $4,872.88$ & $9,035.06$ \\
\hline UP841 & $5,447.55$ & $8,955.60$ \\
\hline UP842 & $5,287.55$ & $8,738.67$ \\
\hline UP843 & $5,082.66$ & $8,518.42$ \\
\hline UP844 & $5,146.26$ & $8,444.51$ \\
\hline UP845 & $5,006.01$ & $8,252.64$ \\
\hline UP846 & $4,823.61$ & $8,057.02$ \\
\hline UP847 & $4,761.81$ & $7,947.32$ \\
\hline UP848 & $5,089.46$ & $7,890.68$ \\
\hline UP849 & $4,895.72$ & $7,709.06$ \\
\hline UP851 & $3,627.84$ & $8,218.20$ \\
\hline UP852 & $3,534.70$ & $7,970.72$ \\
\hline UP853 & $3,436.35$ & $7,791.20$ \\
\hline UP854 & $3,469.84$ & $7,640.08$ \\
\hline UP855 & $3,388.43$ & $7,421.16$ \\
\hline UP856 & $3,301.82$ & $7,264.42$ \\
\hline UP857 & $3,307.07$ & $7,230.08$ \\
\hline UP858 & $3,546.71$ & $7,121.75$ \\
\hline UP859 & $3,447.80$ & $6,976.41$ \\
\hline
\end{tabular}




\begin{tabular}{|c|c|c|}
\hline UP861 & $4,632.22$ & $8,863.74$ \\
\hline UP862 & $4,418.10$ & $8,615.98$ \\
\hline UP863 & $4,240.17$ & $8,380.19$ \\
\hline UP864 & $4,212.66$ & $8,284.61$ \\
\hline UP865 & $4,024.55$ & $8,065.40$ \\
\hline UP866 & $3,869.20$ & $7,856.52$ \\
\hline UP867 & $3,886.96$ & $7,754.45$ \\
\hline UP868 & $4,159.75$ & $7,664.94$ \\
\hline UP869 & $3,990.68$ & $7,472.13$ \\
\hline UP871 & $(277.61)$ & $8,813.88$ \\
\hline UP872 & 127.65 & $8,385.94$ \\
\hline UP873 & 75.23 & $8,148.75$ \\
\hline UP874 & 178.95 & $8,038.49$ \\
\hline UP875 & 177.84 & $7,808.59$ \\
\hline UP876 & 130.16 & $7,599.78$ \\
\hline UP877 & 118.99 & $7,507.04$ \\
\hline UP878 & 120.76 & $7,304.00$ \\
\hline UP879 & 79.20 & $7,119.77$ \\
\hline UP881 & $3,747.37$ & $8,411.80$ \\
\hline UP882 & $3,567.79$ & $8,188.94$ \\
\hline UP883 & $3,420.52$ & $7,976.51$ \\
\hline UP884 & $3,395.40$ & $7,887.59$ \\
\hline UP885 & $3,237.31$ & $7,690.17$ \\
\hline UP886 & $3,305.64$ & $7,432.18$ \\
\hline UP887 & $3,422.91$ & $7,438.06$ \\
\hline UP888 & $3,260.75$ & $7,260.83$ \\
\hline UP889 & $3,126.89$ & $7,091.52$ \\
\hline UP891 & $4,519.90$ & $8,973.53$ \\
\hline UP892 & $4,309.81$ & $8,722.12$ \\
\hline UP893 & $4,135.86$ & $8,482.69$ \\
\hline UP894 & $4,108.96$ & $8,386.46$ \\
\hline UP895 & $3,924.40$ & $8,164.03$ \\
\hline UP896 & $3,772.57$ & $7,951.92$ \\
\hline UP897 & $3,791.46$ & $7,848.70$ \\
\hline UP898 & $4,060.17$ & $7,759.47$ \\
\hline UP899 & $3,894.75$ & $7,563.57$ \\
\hline UP901 & $4,441.20$ & $10,738.55$ \\
\hline UP902 & $4,880.46$ & $10,182.98$ \\
\hline UP903 & $4,658.58$ & $9,892.48$ \\
\hline UP904 & $4,805.48$ & $9,733.46$ \\
\hline UP905 & $4,706.46$ & $9,425.84$ \\
\hline UP906 & $4,507.10$ & $9,170.91$ \\
\hline UP907 & $4,395.75$ & $9,092.34$ \\
\hline UP908 & $4,314.37$ & $8,819.24$ \\
\hline UP909 & $4,139.31$ & $8,594.04$ \\
\hline UP911 & $4,619.10$ & $8,918.24$ \\
\hline UP912 & $4,405.45$ & $8,668.66$ \\
\hline UP913 & $4,228.10$ & $8,431.09$ \\
\hline
\end{tabular}




\begin{tabular}{|c|c|c|}
\hline UP914 & $4,200.54$ & $8,335.16$ \\
\hline UP915 & $4,012.85$ & $8,114.35$ \\
\hline UP916 & $3,858.02$ & $7,903.89$ \\
\hline UP917 & $3,876.06$ & $7,801.28$ \\
\hline UP918 & $4,148.31$ & $7,711.91$ \\
\hline UP919 & $3,979.77$ & $7,517.58$ \\
\hline UP921 & $3,666.81$ & $8,505.91$ \\
\hline UP922 & $3,490.03$ & $8,280.02$ \\
\hline UP923 & $3,345.58$ & $8,064.57$ \\
\hline UP924 & $3,320.87$ & $7,975.07$ \\
\hline UP925 & $3,165.24$ & $7,774.98$ \\
\hline UP926 & $3,233.62$ & $7,514.14$ \\
\hline UP927 & $3,350.01$ & $7,520.55$ \\
\hline UP928 & $3,190.33$ & $7,340.86$ \\
\hline UP929 & $3,058.97$ & $7,169.08$ \\
\hline UP931 & $3,750.09$ & $8,407.03$ \\
\hline UP932 & $3,570.42$ & $8,184.32$ \\
\hline UP933 & $3,423.04$ & $7,972.04$ \\
\hline UP934 & $3,397.92$ & $7,883.15$ \\
\hline UP935 & $3,239.74$ & $7,685.87$ \\
\hline UP936 & $3,308.06$ & $7,428.02$ \\
\hline UP937 & $3,425.36$ & $7,433.88$ \\
\hline UP938 & $3,263.13$ & $7,256.77$ \\
\hline UP939 & $3,129.18$ & $7,087.58$ \\
\hline UP941 & $3,818.62$ & $8,344.31$ \\
\hline UP942 & $3,636.58$ & $8,123.61$ \\
\hline UP943 & $3,486.85$ & $7,913.35$ \\
\hline UP944 & $3,461.33$ & $7,824.84$ \\
\hline UP945 & $3,301.06$ & $7,629.34$ \\
\hline UP946 & $3,369.38$ & $7,373.41$ \\
\hline UP947 & $3,487.47$ & $7,378.91$ \\
\hline UP948 & $3,323.12$ & $7,203.44$ \\
\hline UP949 & $3,187.09$ & $7,035.91$ \\
\hline UP951 & $3,886.18$ & $8,298.98$ \\
\hline UP952 & $3,701.80$ & $8,079.74$ \\
\hline UP953 & $3,549.79$ & $7,870.95$ \\
\hline UP954 & $3,523.84$ & $7,782.70$ \\
\hline UP955 & $3,361.50$ & $7,588.49$ \\
\hline UP956 & $3,429.87$ & $7,333.95$ \\
\hline UP957 & $3,548.76$ & $7,339.21$ \\
\hline UP958 & $3,382.34$ & $7,164.93$ \\
\hline UP959 & $3,244.30$ & $6,998.60$ \\
\hline UP961 & $3,888.64$ & $8,285.59$ \\
\hline UP962 & $3,704.17$ & $8,066.78$ \\
\hline UP963 & $3,552.04$ & $7,858.42$ \\
\hline UP964 & $3,526.11$ & $7,770.26$ \\
\hline UP965 & $3,363.70$ & $7,576.42$ \\
\hline UP966 & $3,432.03$ & $7,322.29$ \\
\hline
\end{tabular}




\begin{tabular}{|c|c|c|}
\hline UP967 & $3,550.93$ & $7,327.46$ \\
\hline UP968 & $3,384.44$ & $7,153.53$ \\
\hline UP969 & $3,246.29$ & $6,987.55$ \\
\hline UP971 & $3,961.40$ & $8,231.02$ \\
\hline UP972 & $3,774.40$ & $8,013.96$ \\
\hline UP973 & $3,619.82$ & $7,807.36$ \\
\hline UP974 & $3,593.43$ & $7,719.53$ \\
\hline UP975 & $3,428.79$ & $7,527.24$ \\
\hline UP976 & $3,497.16$ & $7,274.78$ \\
\hline UP977 & $3,616.92$ & $7,279.65$ \\
\hline UP978 & $3,448.19$ & $7,107.15$ \\
\hline UP979 & $3,307.86$ & $6,942.61$ \\
\hline UP981 & $4,789.83$ & $10,379.92$ \\
\hline UP982 & $5,230.19$ & $9,831.24$ \\
\hline UP983 & $4,995.75$ & $9,552.38$ \\
\hline UP984 & $5,140.81$ & $9,395.21$ \\
\hline UP985 & $5,030.50$ & $9,097.94$ \\
\hline UP986 & $4,820.11$ & $8,853.30$ \\
\hline UP987 & $4,705.72$ & $8,778.09$ \\
\hline UP988 & $4,614.44$ & $8,514.07$ \\
\hline UP989 & $4,429.69$ & $8,297.95$ \\
\hline UP991 & $8,289.30$ & $12,341.63$ \\
\hline UP992 & $8,569.22$ & $11,791.98$ \\
\hline UP993 & $8,259.64$ & $11,478.70$ \\
\hline UP994 & $8,163.53$ & $11,299.66$ \\
\hline UP995 & $7,811.00$ & $10,958.36$ \\
\hline UP996 & $7,542.58$ & $10,684.08$ \\
\hline UP997 & $7,586.81$ & $10,614.20$ \\
\hline UP998 & $7,274.76$ & $10,311.00$ \\
\hline UP999 & $7,039.53$ & $10,068.92$ \\
\hline UP1001 & $7,180.41$ & $12,492.95$ \\
\hline UP1002 & $7,550.15$ & $11,257.10$ \\
\hline UP1003 & $7,389.55$ & $11,693.61$ \\
\hline UP1004 & $7,524.34$ & $11,690.95$ \\
\hline UP1005 & $7,262.36$ & $11,380.35$ \\
\hline UP1006 & $6,902.35$ & $10,981.39$ \\
\hline UP1007 & $6,757.34$ & $10,723.10$ \\
\hline UP1008 & $6,533.81$ & $10,454.58$ \\
\hline UP1009 & $6,218.09$ & $10,102.84$ \\
\hline UP1011 & $5,561.86$ & $10,585.00$ \\
\hline UP1012 & $5,855.06$ & $10,071.59$ \\
\hline UP1013 & $5,616.74$ & $9,774.01$ \\
\hline UP1014 & $5,583.84$ & $9,663.28$ \\
\hline UP1015 & $5,336.10$ & $9,386.53$ \\
\hline UP1016 & $5,128.38$ & $9,123.68$ \\
\hline UP1017 & $5,147.69$ & $9,006.00$ \\
\hline UP1018 & $4,929.35$ & $8,761.78$ \\
\hline UP1019 & $4,747.25$ & $8,529.54$ \\
\hline
\end{tabular}




\begin{tabular}{|c|c|c|}
\hline UP1021 & $5,809.95$ & $10,930.92$ \\
\hline UP1022 & $6,205.66$ & $10,473.25$ \\
\hline UP1023 & $5,951.00$ & $10,181.61$ \\
\hline UP1024 & $6,026.20$ & $10,094.34$ \\
\hline UP1025 & $5,846.88$ & $9,838.73$ \\
\hline UP1026 & $5,621.05$ & $9,580.58$ \\
\hline UP1027 & $5,553.33$ & $9,450.42$ \\
\hline UP1028 & $5,399.11$ & $9,225.69$ \\
\hline UP1029 & $5,200.95$ & $8,997.71$ \\
\hline UP1031 & $11,689.11$ & $8,564.28$ \\
\hline UP1032 & $10,655.85$ & $8,038.52$ \\
\hline UP1033 & $11,484.41$ & $7,643.73$ \\
\hline UP1034 & $16,471.58$ & $12,064.33$ \\
\hline UP1035 & $17,337.92$ & $11,301.96$ \\
\hline UP1036 & $16,532.61$ & $10,981.29$ \\
\hline UP1037 & $16,301.97$ & $10,778.30$ \\
\hline UP1038 & $15,678.64$ & $10,508.59$ \\
\hline UP1039 & $14,972.59$ & $10,224.55$ \\
\hline UP1041 & $1,272.30$ & $11,820.11$ \\
\hline UP1042 & $1,669.41$ & $11,244.91$ \\
\hline UP1043 & $1,532.06$ & $10,913.72$ \\
\hline UP1044 & $1,610.97$ & $10,822.62$ \\
\hline UP1045 & $1,515.20$ & $10,548.09$ \\
\hline UP1046 & $1,393.24$ & $10,254.19$ \\
\hline UP1047 & $1,389.87$ & $10,078.63$ \\
\hline UP1048 & $1,307.48$ & $9,837.95$ \\
\hline UP1049 & $1,200.37$ & $9,578.35$ \\
\hline UP1051 & $8,768.20$ & $8,130.78$ \\
\hline UP1052 & $7,879.26$ & $7,615.23$ \\
\hline UP1053 & $8,577.94$ & $7,263.03$ \\
\hline UP1054 & $12,356.29$ & $11,388.87$ \\
\hline UP1055 & $13,029.99$ & $10,636.77$ \\
\hline UP1056 & $12,441.22$ & $10,353.84$ \\
\hline UP1057 & $12,383.81$ & $10,193.85$ \\
\hline UP1058 & $11,840.28$ & $9,928.54$ \\
\hline UP1059 & $11,324.45$ & $9,677.95$ \\
\hline UP1061 & $11,400.52$ & $11,773.08$ \\
\hline UP1062 & $10,610.73$ & $11,233.90$ \\
\hline UP1063 & $11,433.23$ & $10,888.63$ \\
\hline UP1064 & $10,349.44$ & $10,869.73$ \\
\hline UP1065 & $10,866.05$ & $10,407.59$ \\
\hline UP1066 & $10,354.87$ & $10,094.89$ \\
\hline UP1067 & $10,305.78$ & $9,948.35$ \\
\hline UP1068 & $9,832.29$ & $9,655.07$ \\
\hline UP1069 & $9,384.02$ & $9,379.63$ \\
\hline UP1071 & $11,532.70$ & $9,281.67$ \\
\hline UP1072 & $12,149.57$ & $8,775.38$ \\
\hline UP1073 & $11,569.45$ & $8,521.01$ \\
\hline
\end{tabular}




\begin{tabular}{|c|c|c|}
\hline UP1074 & $11,644.99$ & $8,425.62$ \\
\hline UP1075 & $11,189.80$ & $8,208.51$ \\
\hline UP1076 & $10,677.15$ & $7,983.28$ \\
\hline UP1077 & $10,537.62$ & $7,839.37$ \\
\hline UP1078 & $10,142.78$ & $7,648.93$ \\
\hline UP1079 & $9,692.77$ & $7,450.18$ \\
\hline UP1081 & $6,381.55$ & $9,261.92$ \\
\hline UP1082 & $6,743.91$ & $8,708.24$ \\
\hline UP1083 & $6,440.04$ & $8,479.62$ \\
\hline UP1084 & $6,423.68$ & $8,353.08$ \\
\hline UP1085 & $6,124.19$ & $8,130.36$ \\
\hline UP1086 & $5,858.26$ & $7,928.90$ \\
\hline UP1087 & $5,869.28$ & $7,822.65$ \\
\hline UP1088 & $5,605.77$ & $7,625.70$ \\
\hline UP1089 & $5,372.33$ & $7,447.73$ \\
\hline UP1091 & $10,247.47$ & $11,230.07$ \\
\hline UP1092 & $9,520.91$ & $10,665.05$ \\
\hline UP1093 & $10,376.39$ & $10,387.35$ \\
\hline UP1094 & $9,244.82$ & $10,327.89$ \\
\hline UP1095 & $9,735.96$ & $9,857.95$ \\
\hline UP1096 & $9,340.44$ & $9,592.20$ \\
\hline UP1097 & $9,416.30$ & $9,504.94$ \\
\hline UP1098 & $8,959.62$ & $9,210.73$ \\
\hline UP1099 & $8,613.52$ & $8,976.84$ \\
\hline UP1101 & $13,208.45$ & $10,772.94$ \\
\hline UP1102 & $12,325.56$ & $10,292.49$ \\
\hline UP1103 & $13,215.22$ & $9,945.81$ \\
\hline UP1104 & $12,025.60$ & $9,958.92$ \\
\hline UP1105 & $12,576.54$ & $9,511.92$ \\
\hline UP1106 & $12,006.30$ & $9,235.13$ \\
\hline UP1107 & $11,943.89$ & $9,097.79$ \\
\hline UP1108 & $11,416.41$ & $8,838.22$ \\
\hline UP1109 & $10,916.41$ & $8,594.40$ \\
\hline UP1111 & $7,252.30$ & $9,608.41$ \\
\hline UP1112 & $6,829.03$ & $9,226.74$ \\
\hline UP1113 & $7,526.85$ & $8,883.42$ \\
\hline UP1114 & $6,750.69$ & $8,948.61$ \\
\hline UP1115 & 7,314.02 & $8,550.39$ \\
\hline UP1116 & $6,970.57$ & $8,314.39$ \\
\hline UP1117 & $6,902.52$ & $8,168.72$ \\
\hline UP1118 & $6,642.40$ & $7,966.46$ \\
\hline UP1119 & $6,341.34$ & $7,758.60$ \\
\hline UP1121 & $4,673.24$ & $8,243.82$ \\
\hline UP1122 & $5,162.88$ & $7,738.10$ \\
\hline UP1123 & $4,848.15$ & $7,516.63$ \\
\hline UP1124 & $4,929.10$ & $7,421.92$ \\
\hline UP1125 & $4,690.08$ & $7,231.07$ \\
\hline UP1126 & $4,411.52$ & $7,034.96$ \\
\hline
\end{tabular}




\begin{tabular}{|c|c|c|}
\hline UP1127 & $4,354.96$ & $6,902.74$ \\
\hline UP1128 & $4,148.03$ & $6,735.16$ \\
\hline UP1129 & $3,903.42$ & $6,562.05$ \\
\hline UP1131 & $4,732.33$ & $8,261.73$ \\
\hline UP1132 & $5,232.39$ & $7,758.57$ \\
\hline UP1133 & $4,930.07$ & $7,533.60$ \\
\hline UP1134 & $5,005.49$ & $7,444.94$ \\
\hline UP1135 & $4,771.51$ & $7,256.01$ \\
\hline UP1136 & $4,504.25$ & $7,056.59$ \\
\hline UP1137 & $4,457.78$ & $6,918.27$ \\
\hline UP1138 & $4,255.04$ & $6,752.61$ \\
\hline UP1139 & $4,020.44$ & $6,576.55$ \\
\hline UP1141 & $2,235.48$ & $8,260.76$ \\
\hline UP1142 & $2,656.01$ & $7,668.00$ \\
\hline UP1143 & $2,550.83$ & $7,301.81$ \\
\hline UP1144 & $2,494.83$ & $7,343.87$ \\
\hline UP1145 & $2,314.93$ & $7,149.69$ \\
\hline UP1146 & $2,227.04$ & $6,819.34$ \\
\hline UP1147 & $2,355.96$ & $6,512.40$ \\
\hline UP1148 & $2,194.79$ & $6,347.17$ \\
\hline UP1149 & $2,118.41$ & $6,054.77$ \\
\hline UP1151 & $4,259.52$ & $8,112.05$ \\
\hline UP1152 & $4,743.64$ & $7,608.38$ \\
\hline UP1153 & $4,446.95$ & $7,392.10$ \\
\hline UP1154 & $4,528.32$ & $7,297.54$ \\
\hline UP1155 & $4,303.94$ & $7,110.80$ \\
\hline UP1156 & $4,041.31$ & $6,919.32$ \\
\hline UP1157 & $3,990.61$ & $6,789.08$ \\
\hline UP1158 & $3,796.41$ & $6,625.09$ \\
\hline UP1159 & $3,565.79$ & $6,456.05$ \\
\hline UP1161 & $4,619.71$ & $8,125.40$ \\
\hline UP1162 & $5,108.63$ & $7,621.52$ \\
\hline UP1163 & $4,796.23$ & $7,404.72$ \\
\hline UP1164 & $4,877.24$ & $7,310.14$ \\
\hline UP1165 & $4,640.11$ & $7,122.98$ \\
\hline UP1166 & $4,363.61$ & $6,931.03$ \\
\hline UP1167 & $4,307.81$ & $6,800.59$ \\
\hline UP1168 & $4,102.53$ & $6,636.24$ \\
\hline UP1169 & $3,859.73$ & $6,466.78$ \\
\hline UP1171 & $1,554.58$ & $7,554.35$ \\
\hline UP1172 & $2,051.07$ & $6,852.80$ \\
\hline UP1173 & $1,931.54$ & $6,694.60$ \\
\hline UP1174 & $2,075.63$ & $6,414.25$ \\
\hline UP1175 & $2,041.51$ & $6,131.18$ \\
\hline UP1176 & $1,933.41$ & $5,997.26$ \\
\hline UP1177 & $1,891.08$ & $6,032.14$ \\
\hline UP1178 & $1,865.18$ & $5,776.13$ \\
\hline UP1179 & $1,770.37$ & $5,657.78$ \\
\hline
\end{tabular}




\begin{tabular}{|c|c|c|}
\hline UP1181 & $12,202.56$ & $9,408.15$ \\
\hline UP1182 & $11,706.59$ & $9,145.97$ \\
\hline UP1183 & $11,225.18$ & $8,904.21$ \\
\hline UP1184 & $11,206.40$ & $8,782.22$ \\
\hline UP1185 & $10,771.08$ & $8,550.74$ \\
\hline UP1186 & $10,347.47$ & $8,337.34$ \\
\hline UP1187 & $10,282.88$ & $8,226.52$ \\
\hline UP1188 & $9,901.20$ & $8,021.82$ \\
\hline UP1189 & $10,600.41$ & $8,054.34$ \\
\hline UP1191 & $4,735.05$ & $8,278.52$ \\
\hline UP1192 & $5,124.05$ & $7,745.19$ \\
\hline UP1193 & $4,913.71$ & $7,557.57$ \\
\hline UP1194 & $4,787.14$ & $7,392.59$ \\
\hline UP1195 & $4,470.75$ & $7,174.14$ \\
\hline UP1196 & $4,292.29$ & $7,010.65$ \\
\hline UP1197 & $4,438.11$ & $6,946.96$ \\
\hline UP1198 & $4,155.30$ & $6,752.50$ \\
\hline UP1199 & $3,999.46$ & $6,608.34$ \\
\hline UP1221 & $11,164.36$ & $9,357.31$ \\
\hline UP1222 & $11,518.49$ & $8,794.75$ \\
\hline UP1223 & $11,007.09$ & $8,553.00$ \\
\hline UP1224 & $10,977.56$ & $8,434.31$ \\
\hline UP1225 & $10,505.62$ & $8,207.77$ \\
\hline UP1226 & $10,056.29$ & $7,994.30$ \\
\hline UP1227 & $10,000.58$ & $7,875.90$ \\
\hline UP1228 & $9,586.52$ & $7,675.90$ \\
\hline UP1229 & $9,191.71$ & $7,487.28$ \\
\hline UP1231 & $13,017.54$ & $11,247.27$ \\
\hline UP1232 & $13,599.30$ & $10,695.63$ \\
\hline UP1233 & $13,011.45$ & $10,376.00$ \\
\hline UP1234 & $12,974.10$ & $10,249.74$ \\
\hline UP1235 & $12,425.70$ & $9,958.91$ \\
\hline UP1236 & $11,910.49$ & $9,676.80$ \\
\hline UP1237 & $11,858.82$ & $9,530.43$ \\
\hline UP1238 & $11,378.29$ & $9,274.51$ \\
\hline UP1239 & $10,926.47$ & $9,025.66$ \\
\hline UP1241 & $11,158.49$ & $9,121.23$ \\
\hline UP1242 & $10,679.41$ & $8,870.79$ \\
\hline UP1243 & $10,228.39$ & $8,627.85$ \\
\hline UP1244 & $10,197.35$ & $8,520.58$ \\
\hline UP1245 & $9,776.77$ & $8,299.44$ \\
\hline UP1246 & $9,380.46$ & $8,084.45$ \\
\hline UP1247 & $9,335.90$ & $7,961.61$ \\
\hline UP1248 & $8,966.50$ & $7,766.52$ \\
\hline UP1249 & $9,625.28$ & $7,787.26$ \\
\hline UP1251 & $9,942.26$ & $7,061.68$ \\
\hline UP1252 & $9,550.24$ & $6,895.75$ \\
\hline UP1253 & $9,171.01$ & $6,740.71$ \\
\hline
\end{tabular}




\begin{tabular}{|c|c|c|}
\hline UP1254 & $9,146.45$ & $6,648.06$ \\
\hline UP1255 & $8,801.10$ & $6,501.06$ \\
\hline UP1256 & $8,841.56$ & $6,309.06$ \\
\hline UP1257 & $9,027.18$ & $6,293.56$ \\
\hline UP1258 & $8,677.39$ & $6,161.82$ \\
\hline UP1259 & $8,339.58$ & $6,038.63$ \\
\hline UP1261 & $13,675.46$ & $10,380.74$ \\
\hline UP1262 & $14,265.30$ & $9,842.88$ \\
\hline UP1263 & $13,649.59$ & $9,555.55$ \\
\hline UP1264 & $13,610.06$ & $9,433.19$ \\
\hline UP1265 & $13,037.88$ & $9,170.22$ \\
\hline UP1266 & $12,498.11$ & $8,916.66$ \\
\hline UP1267 & $12,438.60$ & $8,780.23$ \\
\hline UP1268 & $11,937.32$ & $8,548.73$ \\
\hline UP1269 & $11,463.94$ & $8,325.06$ \\
\hline UP1271 & $15,459.17$ & $9,173.11$ \\
\hline UP1272 & $16,082.07$ & $8,657.85$ \\
\hline UP1273 & $15,388.79$ & $8,416.60$ \\
\hline UP1274 & $15,356.38$ & $8,300.77$ \\
\hline UP1275 & $14,727.96$ & $8,078.22$ \\
\hline UP1276 & $14,119.39$ & $7,865.37$ \\
\hline UP1277 & $14,028.07$ & $7,742.55$ \\
\hline UP1278 & $13,478.24$ & $7,546.53$ \\
\hline UP1279 & $12,944.43$ & $7,358.76$ \\
\hline UP1281 & $9,084.05$ & $7,043.37$ \\
\hline UP1282 & $8,699.28$ & $6,875.44$ \\
\hline UP1283 & $8,331.14$ & $6,716.87$ \\
\hline UP1284 & $8,303.57$ & $6,625.29$ \\
\hline UP1285 & $7,964.57$ & $6,476.51$ \\
\hline UP1286 & $8,000.18$ & $6,279.12$ \\
\hline UP1287 & $8,184.64$ & $6,262.63$ \\
\hline UP1288 & $7,841.91$ & $6,129.41$ \\
\hline UP1289 & $7,514.41$ & $6,003.43$ \\
\hline UP1291 & $(1,051.11)$ & $15,789.38$ \\
\hline UP1292 & (737.02) & $15,182.16$ \\
\hline UP1293 & (760.00) & $14,676.94$ \\
\hline UP1294 & (772.70) & $14,534.26$ \\
\hline UP1295 & (851.17) & $14,087.50$ \\
\hline UP1296 & (868.66) & $13,641.22$ \\
\hline UP1297 & (753.68) & $13,434.21$ \\
\hline UP1298 & $(825.21)$ & $13,041.87$ \\
\hline UP1299 & (840.36) & $12,648.40$ \\
\hline UP1301 & $1,004.20$ & $25,279.20$ \\
\hline UP1302 & 890.11 & $24,047.87$ \\
\hline UP1303 & $1,395.47$ & $23,866.75$ \\
\hline UP1304 & $1,455.67$ & $23,631.73$ \\
\hline UP1305 & $1,359.73$ & $22,845.41$ \\
\hline UP1306 & $1,265.94$ & $22,099.29$ \\
\hline
\end{tabular}




\begin{tabular}{|c|c|c|}
\hline UP1307 & $1,310.29$ & $21,840.22$ \\
\hline UP1308 & $1,226.64$ & $21,149.29$ \\
\hline UP1309 & $1,144.59$ & $20,492.83$ \\
\hline UP1311 & $9,392.69$ & $9,581.08$ \\
\hline UP1312 & $8,957.98$ & $9,321.75$ \\
\hline UP1313 & $8,533.49$ & $9,085.74$ \\
\hline UP1314 & $8,534.44$ & $8,965.94$ \\
\hline UP1315 & $8,154.54$ & $8,736.62$ \\
\hline UP1316 & $8,992.12$ & $8,551.96$ \\
\hline UP1317 & $13,352.33$ & $13,500.38$ \\
\hline UP1318 & $14,058.93$ & $12,724.21$ \\
\hline UP1319 & $13,500.59$ & $12,407.74$ \\
\hline UP1321 & $11,603.89$ & $7,681.99$ \\
\hline UP1322 & $10,547.35$ & $7,213.33$ \\
\hline UP1323 & $11,467.12$ & $6,895.28$ \\
\hline UP1324 & $16,318.98$ & $10,742.45$ \\
\hline UP1325 & $17,151.05$ & $10,029.14$ \\
\hline UP1326 & $16,445.62$ & $9,779.03$ \\
\hline UP1327 & $16,357.44$ & $9,633.60$ \\
\hline UP1328 & $15,716.11$ & $9,394.76$ \\
\hline UP1329 & $15,098.49$ & $9,173.23$ \\
\hline UP1331 & $11,996.17$ & $8,408.47$ \\
\hline UP1332 & $12,339.06$ & $7,866.47$ \\
\hline UP1333 & $11,788.30$ & $7,655.80$ \\
\hline UP1334 & $11,749.92$ & $7,543.50$ \\
\hline UP1335 & $11,240.61$ & $7,345.59$ \\
\hline UP1336 & $10,756.68$ & $7,159.55$ \\
\hline UP1337 & $10,692.76$ & $7,049.14$ \\
\hline UP1338 & $10,245.82$ & $6,874.36$ \\
\hline UP1339 & $9,820.55$ & $6,709.93$ \\
\hline UP1341 & $7,480.42$ & $8,658.45$ \\
\hline UP1342 & $7,158.99$ & $8,423.21$ \\
\hline UP1343 & $6,781.15$ & $8,182.05$ \\
\hline UP1344 & $6,855.67$ & $8,090.42$ \\
\hline UP1345 & $6,573.65$ & $7,882.66$ \\
\hline UP1346 & $6,238.23$ & $7,668.68$ \\
\hline UP1347 & $6,136.57$ & $7,534.17$ \\
\hline UP1348 & $5,892.02$ & $7,351.36$ \\
\hline UP1349 & $6,347.19$ & $7,355.63$ \\
\hline UP1351 & $7,883.37$ & $9,563.26$ \\
\hline UP1352 & $7,559.61$ & $9,313.18$ \\
\hline UP1353 & $7,187.49$ & $9,047.40$ \\
\hline UP1354 & $7,254.18$ & $8,963.73$ \\
\hline UP1355 & $6,970.16$ & $8,742.95$ \\
\hline UP1356 & $6,640.20$ & $8,506.83$ \\
\hline UP1357 & $6,548.07$ & $8,356.55$ \\
\hline UP1358 & $6,301.50$ & $8,162.73$ \\
\hline UP1359 & $6,776.41$ & $8,184.15$ \\
\hline
\end{tabular}




\begin{tabular}{|c|c|c|}
\hline UP1361 & $9,816.76$ & $9,741.91$ \\
\hline UP1362 & $10,252.25$ & $9,202.84$ \\
\hline UP1363 & $9,781.66$ & $8,943.39$ \\
\hline UP1364 & $9,890.20$ & $8,816.74$ \\
\hline UP1365 & $9,488.78$ & $8,636.08$ \\
\hline UP1366 & $9,072.14$ & $8,405.91$ \\
\hline UP1367 & $8,955.01$ & $8,258.49$ \\
\hline UP1368 & $8,639.12$ & $8,067.08$ \\
\hline UP1369 & $8,272.89$ & $7,863.72$ \\
\hline UP1371 & 7,991.96 & $9,425.61$ \\
\hline UP1372 & $7,589.50$ & $9,147.12$ \\
\hline UP1373 & $7,208.92$ & $8,885.60$ \\
\hline UP1374 & $7,192.14$ & $8,763.62$ \\
\hline UP1375 & $6,838.67$ & $8,517.67$ \\
\hline UP1376 & $6,504.05$ & $8,286.56$ \\
\hline UP1377 & $6,471.63$ & $8,165.84$ \\
\hline UP1378 & $6,161.12$ & $7,948.48$ \\
\hline UP1379 & $6,676.82$ & $7,964.75$ \\
\hline UP1381 & $8,456.82$ & $7,687.05$ \\
\hline UP1382 & $7,567.43$ & $7,194.88$ \\
\hline UP1383 & $8,226.11$ & $6,853.70$ \\
\hline UP1384 & $11,898.85$ & $10,721.55$ \\
\hline UP1385 & $12,535.52$ & $9,984.82$ \\
\hline UP1386 & $11,948.83$ & $9,716.94$ \\
\hline UP1387 & $11,891.88$ & $9,562.23$ \\
\hline UP1388 & $11,348.38$ & $9,310.21$ \\
\hline UP1389 & $10,834.23$ & $9,072.92$ \\
\hline UP1391 & $7,387.14$ & $8,871.68$ \\
\hline UP1392 & $7,758.56$ & $8,330.18$ \\
\hline UP1393 & $7,429.98$ & $8,111.04$ \\
\hline UP1394 & $7,402.74$ & 7,994.61 \\
\hline UP1395 & $7,075.09$ & $7,786.83$ \\
\hline UP1396 & $6,787.77$ & $7,593.45$ \\
\hline UP1397 & $6,799.44$ & $7,483.37$ \\
\hline UP1398 & $6,511.04$ & $7,299.84$ \\
\hline UP1399 & $6,258.86$ & $7,128.99$ \\
\hline UP1401 & $13,383.26$ & $7,906.58$ \\
\hline UP1402 & $12,839.55$ & $7,699.24$ \\
\hline UP1403 & $12,317.52$ & $7,505.07$ \\
\hline UP1404 & $12,285.32$ & $7,399.28$ \\
\hline UP1405 & $11,808.05$ & $7,216.17$ \\
\hline UP1406 & $11,348.92$ & $7,044.60$ \\
\hline UP1407 & $11,279.56$ & $6,942.03$ \\
\hline UP1408 & $10,860.82$ & $6,780.17$ \\
\hline UP1409 & $11,617.86$ & $6,792.37$ \\
\hline UP1411 & $9,208.11$ & $8,736.96$ \\
\hline UP1412 & $8,845.16$ & $8,514.85$ \\
\hline UP1413 & $8,430.16$ & $8,280.67$ \\
\hline
\end{tabular}




\begin{tabular}{|c|c|c|}
\hline UP1414 & $8,495.95$ & $8,197.97$ \\
\hline UP1415 & $8,177.56$ & $8,001.87$ \\
\hline UP1416 & $7,809.67$ & $7,793.87$ \\
\hline UP1417 & $7,702.67$ & $7,656.62$ \\
\hline UP1418 & $7,426.17$ & $7,484.37$ \\
\hline UP1419 & $7,959.72$ & $7,498.62$ \\
\hline UP1421 & $7,158.76$ & $7,722.14$ \\
\hline UP1422 & $6,865.30$ & $7,528.44$ \\
\hline UP1423 & $6,517.47$ & $7,328.52$ \\
\hline UP1424 & $6,584.91$ & $7,245.31$ \\
\hline UP1425 & $6,327.00$ & $7,073.89$ \\
\hline UP1426 & $6,017.72$ & $6,896.13$ \\
\hline UP1427 & $5,918.28$ & $6,775.34$ \\
\hline UP1428 & $6,318.52$ & $6,703.85$ \\
\hline UP1429 & $5,999.70$ & $6,540.42$ \\
\hline UP1431 & $7,451.34$ & $8,558.28$ \\
\hline UP1432 & $7,124.04$ & $8,340.84$ \\
\hline UP1433 & $6,810.60$ & $8,134.97$ \\
\hline UP1434 & $6,794.80$ & $8,031.75$ \\
\hline UP1435 & $6,506.45$ & $7,839.17$ \\
\hline UP1436 & $6,540.32$ & $7,597.77$ \\
\hline UP1437 & $6,704.33$ & $7,591.59$ \\
\hline UP1438 & $6,412.50$ & $7,417.98$ \\
\hline UP1439 & $6,133.39$ & $7,253.35$ \\
\hline UP1441 & $7,248.76$ & $7,638.31$ \\
\hline UP1442 & $6,951.94$ & $7,447.51$ \\
\hline UP1443 & $6,600.72$ & $7,250.56$ \\
\hline UP1444 & $6,667.71$ & $7,167.80$ \\
\hline UP1445 & $6,406.84$ & $6,998.95$ \\
\hline UP1446 & $6,094.56$ & $6,823.83$ \\
\hline UP1447 & $5,994.11$ & $6,704.04$ \\
\hline UP1448 & $6,397.67$ & $6,632.47$ \\
\hline UP1449 & $6,075.77$ & $6,471.55$ \\
\hline UP1451 & $7,406.05$ & $10,064.49$ \\
\hline UP1452 & $7,026.63$ & $9,790.95$ \\
\hline UP1453 & $6,666.74$ & $9,532.18$ \\
\hline UP1454 & $6,660.73$ & $9,418.33$ \\
\hline UP1455 & $6,328.91$ & $9,176.44$ \\
\hline UP1456 & $7,005.36$ & $8,973.85$ \\
\hline UP1457 & $10,540.82$ & $14,197.77$ \\
\hline UP1458 & $11,136.28$ & $13,398.87$ \\
\hline UP1459 & $10,663.18$ & $13,051.25$ \\
\hline UP1461 & $15,513.60$ & $10,579.93$ \\
\hline UP1462 & $14,188.62$ & $9,945.72$ \\
\hline UP1463 & $15,258.51$ & $9,468.73$ \\
\hline UP1464 & $21,738.34$ & $15,098.32$ \\
\hline UP1465 & $22,749.85$ & $14,258.58$ \\
\hline UP1466 & $21,747.94$ & $13,845.84$ \\
\hline
\end{tabular}




\begin{tabular}{|c|c|c|}
\hline UP1467 & $21,463.11$ & $13,589.04$ \\
\hline UP1468 & $20,670.70$ & $13,258.71$ \\
\hline UP1469 & $19,792.52$ & $12,893.21$ \\
\hline UP1471 & $11,664.54$ & $13,963.27$ \\
\hline UP1472 & $10,907.84$ & $13,327.64$ \\
\hline UP1473 & $11,769.21$ & $13,022.04$ \\
\hline UP1474 & $10,670.18$ & $12,919.08$ \\
\hline UP1475 & $11,233.07$ & $12,466.94$ \\
\hline UP1476 & $10,738.56$ & $12,092.67$ \\
\hline UP1477 & $10,692.63$ & $11,930.05$ \\
\hline UP1478 & $10,237.89$ & $11,581.12$ \\
\hline UP1479 & $9,804.47$ & $11,251.61$ \\
\hline UP1481 & $12,928.56$ & $12,763.05$ \\
\hline UP1482 & $12,100.35$ & $12,189.84$ \\
\hline UP1483 & $13,004.67$ & $11,873.39$ \\
\hline UP1484 & $11,831.63$ & $11,812.34$ \\
\hline UP1485 & $12,412.83$ & $11,367.56$ \\
\hline UP1486 & $11,873.55$ & $11,032.10$ \\
\hline UP1487 & $11,817.60$ & $10,879.50$ \\
\hline UP1488 & $11,321.44$ & $10,566.48$ \\
\hline UP1489 & $10,848.77$ & $10,271.12$ \\
\hline UP1491 & $9,081.11$ & $8,614.72$ \\
\hline UP1492 & $8,643.01$ & $8,369.46$ \\
\hline UP1493 & $8,228.11$ & $8,139.07$ \\
\hline UP1494 & $8,205.63$ & $8,024.83$ \\
\hline UP1495 & $7,820.88$ & $7,808.22$ \\
\hline UP1496 & $7,456.07$ & $7,604.60$ \\
\hline UP1497 & $7,415.58$ & $7,491.78$ \\
\hline UP1498 & $7,077.62$ & $7,300.33$ \\
\hline UP1499 & $7,643.58$ & $7,310.20$ \\
\hline UP1501 & $10,748.19$ & $12,614.34$ \\
\hline UP1502 & $11,293.05$ & $12,038.93$ \\
\hline UP1503 & $10,779.41$ & $11,676.26$ \\
\hline UP1504 & $10,762.59$ & $11,531.16$ \\
\hline UP1505 & $10,289.56$ & $11,192.68$ \\
\hline UP1506 & $9,839.02$ & $10,873.02$ \\
\hline UP1507 & $9,794.64$ & $10,724.30$ \\
\hline UP1508 & $9,380.39$ & $10,426.12$ \\
\hline UP1509 & $8,985.21$ & $10,144.23$ \\
\hline
\end{tabular}


ANEXO A Lista de coeficientes por prescrição

$\begin{array}{lll}\text { UP1511 } & 11,385.94 & 8,182.17 \\ \text { UP1512 } & 10,890.75 & 7,961.73 \\ \text { UP1513 } & 10,418.85 & 7,753.94 \\ \text { UP1514 } & 10,390.19 & 7,646.38 \\ \text { UP1515 } & 9,955.42 & 7,451.70 \\ \text { UP1516 } & 9,540.46 & 7,268.04 \\ \text { UP1517 } & 9,485.43 & 7,160.62 \\ \text { UP1518 } & 9,103.76 & 6,988.59 \\ \text { UP1519 } & 9,772.48 & 7,000.41 \\ \text { UP1521 } & 10,205.01 & 9,808.83 \\ \text { UP1522 } & 10,550.41 & 9,229.75 \\ \text { UP1523 } & 10,068.72 & 8,970.32 \\ \text { UP1524 } & 10,043.33 & 8,847.32 \\ \text { UP1525 } & 9,598.17 & 8,604.10 \\ \text { UP1526 } & 9,207.05 & 8,342.92 \\ \text { UP1527 } & 9,126.06 & 8,252.24 \\ \text { UP1528 } & 8,735.44 & 8,037.52 \\ \text { UP1529 } & 8,363.53 & 7,835.13 \\ \text { UP1531 } & 11,087.50 & 8,612.90 \\ \text { UP1532 } & 10,601.50 & 8,376.88 \\ \text { UP1533 } & 10,142.27 & 8,155.48 \\ \text { UP1534 } & 10,111.21 & 8,043.40 \\ \text { UP1535 } & 9,684.50 & 7,834.98 \\ \text { UP1536 } & 9,280.86 & 7,639.35 \\ \text { UP1537 } & 9,232.50 & 7,529.50\end{array}$


ANEXO A Lista de coeficientes por prescrição

$\begin{array}{lll}\text { UP1538 } & 8,857.74 & 7,345.30 \\ \text { UP1539 } & 9,514.15 & 7,363.00 \\ \text { UP1541 } & 9,192.50 & 10,555.67 \\ \text { UP1542 } & 8,779.78 & 10,252.80 \\ \text { UP1543 } & 8,386.09 & 9,966.51 \\ \text { UP1544 } & 8,372.28 & 9,841.61 \\ \text { UP1545 } & 8,009.95 & 9,574.24 \\ \text { UP1546 } & 7,663.78 & 9,321.25 \\ \text { UP1547 } & 7,626.45 & 9,193.16 \\ \text { UP1548 } & 7,308.42 & 8,957.02 \\ \text { UP1549 } & 7,873.83 & 8,998.82 \\ \text { UP1551 } & 11,302.52 & 12,091.42 \\ \text { UP1552 } & 11,853.89 & 11,524.25 \\ \text { UP1553 } & 11,318.36 & 11,180.05 \\ \text { UP1554 } & 11,297.80 & 11,038.69 \\ \text { UP1555 } & 10,804.50 & 10,717.31 \\ \text { UP1556 } & 10,334.76 & 10,413.92 \\ \text { UP1557 } & 10,285.93 & 10,269.66 \\ \text { UP1558 } & 9,853.91 & 9,986.52 \\ \text { UP1559 } & 9,441.89 & 9,718.97 \\ \text { UP1561 } & 8,425.92 & 9,343.03 \\ \text { UP1562 } & 8,054.99 & 9,090.18 \\ \text { UP1563 } & 7,700.55 & 8,850.94 \\ \text { UP1564 } & 7,685.22 & 8,737.73 \\ \text { UP1565 } & 7,359.06 & 8,514.10 \\ \text { UP1566 } & 7,046.88 & 8,302.29 \\ \text { UP1567 } & 7,009.29 & 8,186.59 \\ \text { UP1568 } & 7,424.52 & 8,115.24 \\ \text { UP1569 } & 7,097.59 & 7,918.27 \\ \text { UP1571 } & 8,180.62 & 7,873.37 \\ \text { UP1572 } & 7,827.43 & 7,678.24 \\ \text { UP1573 } & 7,489.78 & 7,493.83 \\ \text { UP1574 } & 7,468.24 & 7,395.70 \\ \text { UP1575 } & 7,157.08 & 7,222.86 \\ \text { UP1576 } & 7,192.04 & 7,001.47 \\ \text { UP1577 } & 7,365.53 & 6,990.75 \\ \text { UP1578 } & 7,050.79 & 6,835.34 \\ \text { UP1579 } & 6,750.25 & 6,688.25\end{array}$


MAX

VTP: 16882.7 UP $11+15845.05$ UP $12+16768.79$ UP $13+15487.91$ UP $14+16137.59$ UP $15+15352.88$ UP $16+15120.26$ UP $17+14507.61$ UP $18+13818.78$ UP $19+14259.8$ UP $21+14710.48$ UP $22+14046.35$ UP $23+13883.76$ UP $24+13182$ UP $25+12603.32$ UP $26+12616.1$ UP $27+11996.81$ UP $28+11489.23$ UP $29+10321.23$ UP $31+9583.96$ UP $32+10537.14$ UP33+14814.62 UP34+15828.75 UP $35+15250.01$ UP $36+15129.85$ UP $37+14673.69$ UP $38+14167.81$ UP $39+21876.75$ UP $41+20385.18$ UP $42+21498.14$ UP $43+19807.59$ UP $44+20435.63$ UP $45+19436.75$ UP $46+19221.78$ UP $47+18344.77$ UP $48+17468.12$ UP $49+13453.05$ UP $51+13826.85$ UP $52+13139.92$ UP $53+13203.99$ UP $54+12667.27$ UP $55+12058.8$ UP $56+11861.98$ UP $57+11395.37$ UP $58+10860.09$ UP $59+10854.04$ UP $61+10436.87$ UP $62+9951.89$ UP $63+10004.11$ UP $64+9636.61$ UP $65+9604.65$ UP $66+9745.54$ UP $67+9373.28$ UP $68+8943.97$ UP $69+10679.72$ UP71 +10268.71 UP72+9790.23 UP73+9843.08 UP74+9481.02 UP75+9449.47 UP76+ 9588.58 UP $77+9221.78$ UP78+8798.2 UP79+5525.4 UP81+5304.64 UP $82+5067.38$ UP $83+5099.17$ UP $84+4904.77$ UP $85+4926.45$ UP $86+5038.17$ UP $87+4839.61$ UP 88 +4627.59 UP $89+14966.01$ UP $91+13560.89$ UP $92+14602.39$ UP $93+20840$ UP $94+$ 21703.68 UP $95+20760.47$ UP $96+20594.04$ UP $97+19752.35$ UP $98+18925.78$ UP99+ 15120.55 UP $101+13560.43$ UP $102+14593.06$ UP $103+20883.36$ UP $104+21603.68$ UP $105+20664.46$ UP $106+20594.73$ UP $107+19660.9$ UP108+18837.83 UP109+ 11155.11 UP $111+10822.45$ UP $112+10538.68$ UP $113+10511.74$ UP $114+10220.4$

UP $115+9973.09$ UP $116+9999.73$ UP $117+9743.3$ UP $118+10388.43$ UP $119+10308.03$ UP $121+9868.69$ UP $122+9449.25$ UP $123+9420.74$ UP $124+9034.38$ UP $125+8664.93$ UP $126+8611.63$ UP $127+9093.71$ UP $128+8707.45$ UP $129+8811.05$ UP $131+8435.89$ UP $132+8076.9$ UP $133+8051.29$ UP $134+7720.76$ UP $135+7756.08$ UP $136+7937.12$ UP $137+7602.91$ UP $138+7283.49$ UP $139+10177.98$ UP $141+9743.37$ UP $142+9328.41$ UP $143+9300.82$ UP $144+8918.62$ UP $145+8553.13$ UP $146+8500.91$ UP $147+8978.37$ UP $148+8596.21$ UP $149+15585.98$ UP $151+14489.31$ UP $152+15416.97$ UP $153+$ 14537.86 UP $154+14626.73$ UP $155+13907.89$ UP $156+13791.87$ UP $157+13141.93$ UP $158+12511.18$ UP159+12653.75 UP $161+11789.48$ UP $162+12652.57$ UP $163+$ 11495.18 UP $164+12027$ UP $165+11469.5$ UP $166+11410.09$ UP $167+10893.5$ UP $168+$ 10404.59 UP $169+9350.66$ UP $171+9765.88$ UP $172+9290.82$ UP $173+9366.76$ UP $174+$ 9003.78 UP $175+8582.85$ UP $176+8458.29$ UP $177+8143.39$ UP $178+7773.27$ UP $179+$ 8824.17 UP $181+9229.8$ UP $182+8768.02$ UP $183+8844.46$ UP $184+8492.57$ UP $185+$ 8083.32 UP $186+7962.44$ UP187+7657.19 UP188+7297.3 UP189+6683.7 UP191+ 6381.54 UP $192+6030.19$ UP $193+6090.48$ UP194+5824.83 UP195+5512.59 UP196+ 5416.19 UP $197+5802.09$ UP $198+5481.16$ UP $199+10044.27$ UP $201+9692.75$ UP $202+$ 9291.25 UP203+9347.33 UP204+9038.47 UP205+8682.09 UP206+8572.29 UP207+ 9065.04 UP2 $08+8694.66$ UP $209+11378.73$ UP $211+11888.73$ UP $212+11320.07$ UP 213 +11287.32 UP $214+10759.91$ UP $215+10261.02$ UP $216+10206.48$ UP $217+9744.2$ UP $218+9306.4$ UP $219+10051.16$ UP $221+9699.43$ UP $222+9297.57$ UP $223+9353.76$ UP2 $24+9044.72$ UP225+8688.02 UP22 $6+8577.97$ UP227+9071.04 UP $228+8700.34$ UP229+6733.12 UP231+6461.04 UP232+6167.71 UP233+6214.3 UP $234+5975.71$ UP2 $35+5716.47$ UP236+5671.52 UP237+5463.71 UP238+5893.71 UP $239+7798.22$ UP $241+7443.84$ UP $242+7130.61$ UP $243+7102.44$ UP $244+6791.39$ UP $245+6517.17$ UP $246+6522.78$ UP2 $47+6248.81$ UP2 $48+6756.57$ UP $249+8862.91$ UP $251+9393.61$ UP $252+8990.18$ UP $253+8958.15$ UP $254+8559.93$ UP $255+8207.57$ UP $256+8215.47$ UP $257+7865.66$ UP $258+7556.89$ UP $259+9429.31$ UP $261+9057.14$ UP $262+8694.4$ UP $263+8676.35$ UP $264+8348.5$ UP $265+8386.8$ UP $266+8563.87$ UP $267+8231.61$ UP2 $68+7908.41$ UP2 $69+9514.66$ UP $271+9174.09$ UP $272+8698.83$ UP $273+8840.94$ UP $274+8541.69$ UP $275+8116.53$ UP $276+7907.94$ UP $277+8428.97$ UP $278+7996.38$ UP2 $29+9447.45$ UP $281+10011.94$ UP $282+9595.32$ UP $283+9576.11$ UP $284+9176.49$ UP $285+8812.14$ UP $286+8807.41$ UP $287+8456.97$ UP $288+8137.74$ UP $289+8680.83$ UP $291+8408.8$ UP $292+8178.69$ UP $293+8165.17$ UP2 $94+7926.94$ UP $295+7726.53$ UP $296+7760.31$ UP $297+7550.58$ UP $298+8083.03$ UP $299+7497.97$ UP $301+7878.38$ UP $302+7461.69$ UP $303+7526.65$ UP $304+7201.91$ UP $305+6832.9$ UP $306+6736.1$ UP $307+6453.93$ UP $308+6129.41$ UP $309+5126.33$ UP $311+5549.55$ UP $312+5328.59$ UP $313+5346.09$ UP $314+5135.97$ UP $315+4942.57$ UP $316+4961.45$ UP $317+4777.19$ UP $318+4607.67$ UP $319+5812.18$ UP $321+6227.99$ UP $322+5930.21$ UP $323+5986.64$ UP $324+5747.1$ UP $325+5484.02$ UP $326+5441.44$ UP $327+5233.14$ UP $328+5002.05$ UP $329+9821.49$ UP $331+9494.69$ UP $332+9185.92$ UP $333+9177.96$ UP $334+8890.89$ UP $335+8619.37$ UP $336+8598.86$ UP $337+9043.01$ UP $338+8752.57$ UP $339+9202.84$ UP $341+8920.25$ UP $342+8510.11$ UP $343+8665.08$ UP $344+8417.62$ UP $345+8051.02$ UP $346+7878.66$ UP $347+7667.65$ UP $348+8162.51$ UP $349+22036.66$ UP $351+$ 22650.97 UP $352+21478.4$ UP353+21536.41 UP354+20603.95 UP $355+19567.05$ UP $356+19222.16$ UP357+18411.47 UP358+17500.17 UP359+20581.92 UP 361+ 21145.02 UP $362+20117.87$ UP $363+20063.92$ UP $364+19159.35$ UP $365+18255.42$ UP $366+18053.04$ UP367+17261.98 UP368+16468.09 UP369+21912.96 UP371+ 
22526.1 UP $372+21471.08$ UP373+21417.55 UP $374+20489.82$ UP $375+19561.51$ UP $376+19352.75$ UP $377+18541.71$ UP $378+17726.58$ UP $379+12689.57$ UP $381+$ 13053.04 UP $382+12389.28$ UP $383+12453.72$ UP $384+11935.78$ UP $385+11347.77$ UP $386+11158.34$ UP $387+10708.05$ UP388+10190.72 UP389+10459.67 UP $391+$ 10007.15 UP $392+9575.93$ UP $393+9543.92$ UP $394+9145.94$ UP $395+8766.14$ UP $396+$ 8710.51 UP $397+9199.08$ UP $398+8802.43$ UP 399+13348.36 UP $401+13622.53$ UP 402 +12948.32 UP $403+12904.41$ UP $404+12296.46$ UP $405+11702.9$ UP $406+11591.89$ UP $407+11058.73$ UP $408+10536.71$ UP $409+11167.84$ UP $411+11540.75$ UP $412+$ 10959.8 UP $413+11018.49$ UP $414+10560.53$ UP $415+10046.18$ UP $416+9893.05$ UP 417 +9494.74 UP $418+9042.31$ UP $419+8968.88$ UP $421+8594.9$ UP $422+8163.57$ UP $423+$ 8211.76 UP $424+7882.28$ UP $425+7852.04$ UP $426+7984.5$ UP $427+7651.14$ UP $428+$ 7269.57 UP $429+10967.1$ UP $431+10495.13$ UP $432+9959.56$ UP $433+10021.08$ UP 434 +9606.74 UP $435+9131.83$ UP $436+8979.15$ UP $437+8618.88$ UP $438+9236.07$ UP 439 +8044.88 UP $441+8353.97$ UP $442+7920.83$ UP $443+7906.43$ UP $444+7509.08$ UP 445 +7128.19 UP $446+7085.06$ UP $447+6736.37$ UP $448+6401.5$ UP $449+8334.23$ UP $451+$ 7967.79 UP $452+7642.14$ UP $453+7613.11$ UP $454+7291.49$ UP $455+7006.34$ UP $456+$ 7008.5 UP $457+6725.32$ UP $458+7256.67$ UP $459+7738.21$ UP $461+8103.32$ UP $462+$ 7750.66 UP $463+7725.58$ UP $464+7380.98$ UP $465+7072.2$ UP $466+7072.61$ UP $467+$ 6769.53 UP $468+6498.43$ UP $469+9972.68$ UP $471+9538.11$ UP $472+9123.93$ UP $473+$ 9095.42 UP $474+8713.24$ UP $475+8348.44$ UP $476+8296.92$ UP $477+8768.15$ UP $478+$ 8387.05 UP $479+13849.47$ UP $481+14167.09$ UP $482+13409.31$ UP $483+13470.27$ UP $484+12877.55$ UP $485+12206.06$ UP $486+11980.72$ UP $487+11465.12$ UP $488+$ 10874.15 UP $489+13478.01$ UP $491+12967.81$ UP $492+12379.57$ UP $493+12427.43$ UP $494+11977.95$ UP $495+11934.93$ UP $496+12099.13$ UP497+11644.5 UP 498+ 11124.24 UP $499+13561.67$ UP $501+13048.66$ UP $502+12457.27$ UP $503+12505.04$ UP $504+12053.08$ UP $505+12009.75$ UP $506+12174.65$ UP $507+11717.53$ UP $508+$ 11194.49 UP $509+13488.69$ UP $511+12978.14$ UP $512+12389.49$ UP $513+12437.34$ UP $514+11987.54$ UP $515+11944.48$ UP $516+12108.77$ UP $517+11653.83$ UP $518+$ 11133.21 UP $519+13326.3$ UP $521+12821.19$ UP $522+12238.66$ UP $523+12286.69$ UP $524+11841.69$ UP $525+11799.22$ UP526+11962.18 UP527+11512.07 UP528+ 10996.84 UP $529+14945.98$ UP $531+14271.96$ UP $532+13534.24$ UP $533+13582.04$ UP 534+12992.33 UP535+14039.94 UP536+20552.4 UP537+21302.57 UP538+ 20323.13 UP $539+8681.96$ UP $541+8297.2$ UP $542+7930.5$ UP $543+7901.32$ UP $544+$ 7562.32 UP $545+7593.99$ UP $546+7778.54$ UP $547+7433.65$ UP $548+7110.33$ UP $549+$ 13573.88 UP $551+12364.98$ UP $552+13303.77$ UP $553+19029.41$ UP $554+19934.07$ UP $555+19030.31$ UP $556+18789.51$ UP $557+18064.05$ UP $558+17271.76$ UP $559+$ 5403.28 UP $561+5193.42$ UP $562+4945.24$ UP $563+5008.6$ UP $564+4824.2$ UP $565+$ 4603.59 UP $566+4547.69$ UP $567+4844.68$ UP $568+4616.42$ UP $569+9468.89$ UP $571+$ 9926.99 UP $572+9524.47$ UP $573+9425.42$ UP $574+8977.56$ UP $575+8628.19$ UP $576+$ 8686.52 UP $577+8290.61$ UP $578+7984.5$ UP $579+4873.99$ UP $581+4548.31$ UP $582+$ 4647.04 UP $583+6564.91$ UP $584+7277.13$ UP $585+6906.74$ UP $586+6751.66$ UP $587+$ 6552.43 UP $588+6227.65$ UP $589+5643.63$ UP $591+5056.33$ UP $592+5188.39$ UP 593+ 7384.69 UP $594+7914.68$ UP $595+7531.97$ UP $596+7519.51$ UP $597+7164.94$ UP $598+$ 6829.49 UP $599+6903.9$ UP $601+6491.02$ UP $602+7137.63$ UP $603+7224.32$ UP $604+$ 6931.1 UP $605+6595.37$ UP $606+6528.09$ UP $607+6274.25$ UP $608+5979.75$ UP $609+$ 5949.96 UP $611+5564.46$ UP $612+6260.8$ UP $613+6250.66$ UP $614+5976.05$ UP $615+$ 5749.22 UP $616+5802.83$ UP $617+5561.2$ UP $618+5362.87$ UP $619+5035.52$ UP $621+$ 4613.68 UP $622+4703.65$ UP $623+6513.09$ UP $624+7130.08$ UP $625+6765.88$ UP $626+$ 6675.16 UP $627+6418.69$ UP $628+6099.34$ UP $629+7479.02$ UP $631+6942.22$ UP $632+$ 7259.78 UP $633+10137.65$ UP $634+10935.81$ UP $635+10484.46$ UP $636+10368.38$ UP $637+10044.34$ UP $638+9649.21$ UP $639+3905.35$ UP $641+4518.52$ UP $642+4377.18$ UP $643+4492.1$ UP $644+4410.94$ UP $645+4285.48$ UP $646+4276.31$ UP $647+4208.34$ UP $648+4098.83$ UP $649+2935.47$ UP $651+3341.76$ UP $652+3243.9$ UP $653+3250.82$ UP $654+3129.01$ UP $655+3044.99$ UP $656+3117.47$ UP $657+3009.55$ UP $658+2936.24$ UP $659+4786.74$ UP $661+4597.23$ UP $662+4426.11$ UP $663+4435.61$ UP $664+4269.11$ UP $665+4118.97$ UP $666+4137.04$ UP $667+4381.34$ UP $668+4220.33$ UP $669+1716.12$ UP $671+1694.75$ UP $672+1628.52$ UP $673+1733.38$ UP $674+1715.21$ UP $675+1655.38$ UP $676+1653.67$ UP $677+1640.1$ UP $678+1803.6$ UP $679+2652.12$ UP $681+2591.49$ UP $682+2520.97$ UP $683+2585.02$ UP $684+2532.29$ UP $685+2470.14$ UP $686+2498.83$ UP $687+2453.51$ UP $688+2657.1$ UP $689+2431.19$ UP $691+2374.06$ UP $692+2304.46$ UP $693+2371.34$ UP $694+2321.66$ UP $695+2260.2$ UP $696+2286.58$ UP $697+2244.02$ UP $698+2437.36$ UP $699+2564$ UP $701+2963.44$ UP $702+2872.66$ UP $703+2882.14$ UP $704+2768.1$ UP705+2690.21 UP706+2762.6 UP707+2661.51 UP 708+2593.56 UP709+3948.72 UP711+3791.05 UP712+3649.04 UP713+3658.52 UP714+3519.68 UP715+3560.87 UP716+3672.02 UP717+3530.18 UP718+3402.27 UP719+5400.41 UP $721+5920.69$ UP $722+5608.5$ UP $723+5715.9$ UP $724+5498.23$ UP $725+5221.08$ UP $726+5146.81$ UP $727+4959.56$ UP $728+4716.18$ UP $729+3934.54$ UP $731+3777.32$ UP $732+3635.73$ UP $733+3645.32$ UP $734+3506.87$ UP735+3548.01 UP $736+3658.98$ 
UP737+3517.55 UP738+3390 UP739+2091.63 UP741+2016.69 UP $742+1943.38$ UP $743+1992.55$ UP $744+1927.09$ UP $745+1862.85$ UP $746+1900.02$ UP $747+1842.94$ UP748+2028.71 UP749+4794.92 UP751+4605.14 UP752+4433.78 UP753+4443.21 UP 754+4276.47 UP755+4126.12 UP756+4144.14 UP757+4388.72 UP758+4227.48 UP759+3763 UP $761+3611.23$ UP $762+3474.59$ UP $763+3485.52$ UP $764+3351.87$ UP $765+3392.41$ UP $766+3501.26$ UP $767+3364.66$ UP $768+3241.51$ UP $769+3825.86$ UP $771+3672.09$ UP $772+3533.63$ UP $773+3544.07$ UP $774+3408.67$ UP $775+3449.43$ UP776+3559.05 UP777+3420.68 UP 778+3295.92 UP779+6471.41 UP781+6272.49 UP $782+6026.6$ UP783+6094.21 UP784+5920.18 UP785+5701.92 UP786+5633.25 UP787+5483.31 UP788+5889.9 UP789+5635.1 UP791+5469.36 UP792+5258.51 UP793+5321.54 UP794+5176.25 UP795+4988.58 UP796+4924.89 UP797+5259.26 UP798+5060.06 UP799+1212.99 UP801+1277.42 UP $802+1277.36$ UP $803+1403.26$ UP $804+1461.28$ UP $805+1459.7$ UP $806+1449.23$ UP $807+1503.93$ UP $808+1759.61$ UP $809+4956.72$ UP $811+4908.69$ UP812+4710 UP813+4904.62 UP $814+4863.55$ UP $815+4682.72$ UP816+4534.88 UP $817+4505.94$ UP818+4791.76 UP $819+4818.61$ UP $821+4709.25$ UP $822+4580.29$ UP $823+4633.19$ UP $824+4537.96$ UP $825+4424.13$ UP $826+4414.17$ UP $827+4332.27$ UP $828+4668.01$ UP $829+3497.51$ UP $831+3084.1$ UP $832+3482.88$ UP $833+5144.74$ UP $834+5661.03$ UP $835+5382.38$ UP $836+5327.33$

UP $837+5116.77$ UP $838+4872.88$ UP $839+5447.56$ UP $841+5287.55$ UP $842+5082.66$ UP $843+5146.27$ UP $844+5006.01$ UP $845+4823.61$ UP $846+4761.81$ UP $847+5089.46$ UP $848+4895.73$ UP $849+3627.85$ UP $851+3534.71$ UP $852+3436.36$ UP $853+3469.85$ UP $854+3388.43$ UP $855+3301.83$ UP $856+3307.08$ UP $857+3546.71$ UP $858+3447.8$ UP $859+4632.23$ UP $861+4418.11$ UP $862+4240.17$ UP $863+4212.66$ UP $864+4024.56$ UP $865+3869.2$ UP $866+3886.97$ UP $867+4159.75$ UP $868+3990.69$ UP $869-277.61$ UP $871+127.65$ UP $872+75.24$ UP $873+178.95$ UP $874+177.85$ UP $875+130.16$ UP 876 +118.99 UP $877+120.77$ UP $878+79.2$ UP $879+3747.37$ UP $881+3567.8$ UP $882+$ 3420.52 UP883+3395.41 UP884+3237.31 UP885+3305.64 UP886+3422.91 UP887+ 3260.76 UP $888+3126.9$ UP $889+4519.91$ UP $891+4309.81$ UP $892+4135.87$ UP $893+$ 4108.97 UP $894+3924.4$ UP895+3772.58 UP $896+3791.47$ UP897+4060.18 UP898+ 3894.76 UP $899+4441.21$ UP $901+4880.47$ UP $902+4658.58$ UP $903+4805.48$ UP $904+$ 4706.47 UP $905+4507.11$ UP $906+4395.76$ UP $907+4314.37$ UP $908+4139.32$ UP $909+$ 4619.11 UP $911+4405.46$ UP $912+4228.11$ UP $913+4200.55$ UP $914+4012.86$ UP $915+$ 3858.03 UP $916+3876.07$ UP $917+4148.31$ UP $918+3979.78$ UP $919+3666.81$ UP $921+$ 3490.03 UP $922+3345.58$ UP $923+3320.87$ UP $924+3165.24$ UP $925+3233.63$ UP $926+$ 3350.01 UP $927+3190.34$ UP $928+3058.97$ UP $929+3750.09$ UP $931+3570.42$ UP $932+$ 3423.05 UP $933+3397.93$ UP $934+3239.75$ UP $935+3308.07$ UP $936+3425.37$ UP $937+$ 3263.13 UP $938+3129.18$ UP $939+3818.63$ UP $941+3636.59$ UP $942+3486.85$ UP $943+$ 3461.34 UP $944+3301.06$ UP $945+3369.39$ UP $946+3487.47$ UP $947+3323.13$ UP $948+$ 3187.1 UP $949+3886.19$ UP $951+3701.8$ UP $952+3549.8$ UP $953+3523.85$ UP $954+$ 3361.51 UP $955+3429.87$ UP $956+3548.77$ UP $957+3382.35$ UP $958+3244.31$ UP 959+ 3888.64 UP $961+3704.17$ UP $962+3552.05$ UP $963+3526.11$ UP $964+3363.7$ UP $965+$ 3432.04 UP $966+3550.94$ UP $967+3384.44$ UP $968+3246.3$ UP $969+3961.4$ UP $971+$ 3774.41 UP $972+3619.82$ UP $973+3593.43$ UP $974+3428.8$ UP $975+3497.17$ UP $976+$ 3616.93 UP $977+3448.19$ UP $978+3307.87$ UP $979+4789.83$ UP $981+5230.19$ UP $982+$ 4995.76 UP $983+5140.82$ UP $984+5030.51$ UP $985+4820.11$ UP $986+4705.73$ UP $987+$ 4614.45 UP $988+4429.69$ UP $989+8289.31$ UP $991+8569.23$ UP $992+8259.65$ UP $993+$ 8163.54 UP $994+7811.01$ UP $995+7542.58$ UP $996+7586.82$ UP $997+7274.77$ UP $998+$ 7039.53 UP $999+7180.42$ UP $1001+7550.15$ UP $1002+7389.56$ UP $1003+7524.34$ UP $1004+7262.37$ UP $1005+6902.35$ UP $1006+6757.35$ UP $1007+6533.82$ UP $1008+$ 6218.1 UP $1009+5561.87$ UP $1011+5855.07$ UP $1012+5616.75$ UP $1013+5583.84$ UP $1014+5336.1$ UP $1015+5128.38$ UP $1016+5147.69$ UP $1017+4929.35$ UP $1018+$ 4747.25 UP $1019+5809.95$ UP $1021+6205.66$ UP $1022+5951$ UP $1023+6026.21$ UP 1024 +5846.88 UP $1025+5621.06$ UP $1026+5553.34$ UP $1027+5399.11$ UP $1028+5200.95$ UP $1029+11689.12$ UP1031+10655.86 UP1032+11484.42 UP1033+16471.59 UP1034+ 17337.93 UP $1035+16532.61$ UP $1036+16301.98$ UP $1037+15678.64$ UP $1038+14972.6$ UP $1039+1272.31$ UP $1041+1669.42$ UP $1042+1532.06$ UP $1043+1610.98$ UP $1044+$ 1515.2 UP $1045+1393.25$ UP $1046+1389.88$ UP $1047+1307.48$ UP $1048+1200.38$ UP $1049+8768.2$ UP $1051+7879.26$ UP $1052+8577.95$ UP $1053+12356.29$ UP $1054+$ 13030 UP $1055+12441.22$ UP $1056+12383.82$ UP $1057+11840.28$ UP $1058+11324.46$ UP $1059+11400.53$ UP $1061+10610.74$ UP $1062+11433.23$ UP $1063+10349.44$ UP $1064+$ 10866.05 UP $1065+10354.87$ UP $1066+10305.79$ UP $1067+9832.3$ UP $1068+9384.03$ UP $1069+11532.71$ UP $1071+12149.58$ UP $1072+11569.45$ UP1073+11644.99 UP1074+ 11189.81 UP $1075+10677.16$ UP $1076+10537.62$ UP $1077+10142.79$ UP $1078+9692.77$ UP $1079+6381.56$ UP $1081+6743.92$ UP $1082+6440.05$ UP $1083+6423.69$ UP $1084+$ 6124.19 UP $1085+5858.27$ UP $1086+5869.29$ UP $1087+5605.78$ UP $1088+5372.34$ UP1089+10247.47 UP1091+9520.91 UP1092+10376.39 UP1093+9244.82 UP1094+ 9735.97 UP $1095+9340.45$ UP1096+9416.3 UP1097+8959.62 UP1098+8613.53 
UP $1099+13208.46$ UP $1101+12325.56$ UP $1102+13215.22$ UP $1103+12025.61$ UP $1104+$ 12576.54 UP $1105+12006.31$ UP $1106+11943.9$ UP $1107+11416.41$ UP $1108+10916.41$ UP1109+7252.31 UP1111+6829.04 UP1112+7526.86 UP1113+6750.7 UP1114+ 7314.02 UP $1115+6970.58$ UP $1116+6902.53$ UP $1117+6642.41$ UP $1118+6341.35$ UP1119+4673.25 UP1121+5162.89 UP $1122+4848.15$ UP $1123+4929.1$ UP $1124+$ 4690.08 UP $1125+4411.52$ UP $1126+4354.97$ UP $1127+4148.03$ UP $1128+3903.42$ UP $1129+4732.33$ UP $1131+5232.39$ UP $1132+4930.07$ UP $1133+5005.49$ UP1134+ 4771.52 UP $1135+4504.25$ UP $1136+4457.78$ UP $1137+4255.04$ UP $1138+4020.45$ UP $1139+2235.48$ UP $1141+2656.02$ UP $1142+2550.83$ UP $1143+2494.84$ UP $1144+$ 2314.93 UP $1145+2227.05$ UP $1146+2355.97$ UP $1147+2194.79$ UP $1148+2118.41$ UP $1149+4259.53$ UP $1151+4743.65$ UP $1152+4446.95$ UP $1153+4528.33$ UP1154+ 4303.94 UP $1155+4041.31$ UP $1156+3990.61$ UP $1157+3796.41$ UP $1158+3565.79$ UP $1159+4619.71$ UP $1161+5108.64$ UP $1162+4796.24$ UP $1163+4877.24$ UP $1164+$ 4640.11 UP $1165+4363.62$ UP $1166+4307.82$ UP $1167+4102.53$ UP $1168+3859.73$ UP $1169+1554.58$ UP $1171+2051.08$ UP $1172+1931.55$ UP $1173+2075.63$ UP $1174+$ 2041.51 UP $1175+1933.42$ UP $1176+1891.08$ UP $1177+1865.19$ UP $1178+1770.37$ UP $1179+12202.56$ UP $1181+11706.6$ UP $1182+11225.18$ UP $1183+11206.41$ UP $1184+$ 10771.09 UP $1185+10347.47$ UP $1186+10282.88$ UP $1187+9901.2$ UP $1188+10600.41$ UP $1189+4735.06$ UP $1191+5124.06$ UP $1192+4913.71$ UP $1193+4787.14$ UP1194+ 4470.75 UP $1195+4292.29$ UP $1196+4438.12$ UP $1197+4155.31$ UP $1198+3999.46$ UP1199+11164.36 UP1221+11518.5 UP1222+11007.1 UP1223+10977.57 UP1224+ 10505.62 UP $1225+10056.29$ UP $1226+10000.58$ UP $1227+9586.53$ UP $1228+9191.71$ UP1229+13017.54 UP1231+13599.3 UP1232+13011.46 UP1233+12974.11 UP1234+ 12425.71 UP $1235+11910.49$ UP $1236+11858.82$ UP $1237+11378.3$ UP $1238+10926.48$ UP $1239+11158.49$ UP $1241+10679.42$ UP1242+10228.39 UP1243+10197.35 UP $1244+$ 9776.77 UP $1245+9380.46$ UP $1246+9335.9$ UP $1247+8966.5$ UP $1248+9625.29$ UP 1249 +9942.27 UP1251+9550.24 UP1252+9171.01 UP1253+9146.46 UP $1254+8801.1$ UP $1255+8841.57$ UP $1256+9027.19$ UP $1257+8677.39$ UP $1258+8339.59$ UP1259+ 13675.46 UP $1261+14265.31$ UP $1262+13649.59$ UP $1263+13610.07$ UP $1264+13037.88$ UP $1265+12498.11$ UP $1266+12438.61$ UP $1267+11937.33$ UP $1268+11463.95$ UP $1269+$ 15459.17 UP $1271+16082.07$ UP $1272+15388.79$ UP $1273+15356.38$ UP $1274+14727.96$ UP1275+14119.4 UP1276+14028.07 UP1277+13478.25 UP1278+12944.44 UP1279+ 9084.06 UP $1281+8699.28$ UP $1282+8331.15$ UP $1283+8303.57$ UP $1284+7964.58$ UP $1285+8000.18$ UP $1286+8184.64$ UP $1287+7841.92$ UP $1288+7514.41$ UP $1289-$ 1051.11 UP1291 -737.02 UP1292 -760 UP1293 -772.7 UP1294 -851.17 UP1295 -868.66 UP $1296-753.68$ UP $1297-825.21$ UP1298 -840.36 UP $1299+1004.21$ UP $1301+890.12$ UP $1302+1395.47$ UP $1303+1455.68$ UP $1304+1359.73$ UP $1305+$ 1265.94 UP $1306+1310.3$ UP $1307+1226.64$ UP $1308+1144.59$ UP $1309+9392.7$ UP 1311 +8957.99 UP $1312+8533.49$ UP $1313+8534.44$ UP $1314+8154.55$ UP $1315+8992.13$ UP $1316+13352.34$ UP $1317+14058.93$ UP1318+13500.59 UP1319+11603.89 UP1321+ 10547.35 UP1322+11467.13 UP1323+16318.98 UP $1324+17151.06$ UP $1325+16445.63$ UP $1326+16357.45$ UP1327+15716.12 UP1328+15098.49 UP1329+11996.18 UP1331+ 12339.07 UP $1332+11788.3$ UP $1333+11749.92$ UP $1334+11240.62$ UP $1335+10756.68$ UP $1336+10692.76$ UP1337+10245.82 UP1338+9820.55 UP1339+7480.42 UP1341+ 7159 UP $1342+6781.15$ UP $1343+6855.67$ UP $1344+6573.65$ UP $1345+6238.24$ UP 1346 +6136.57 UP1347+5892.03 UP1348+6347.19 UP1349+7883.38 UP $1351+7559.62$ UP $1352+7187.5$ UP1353+7254.19 UP $1354+6970.17$ UP1355+6640.21 UP1356+ 6548.08 UP $1357+6301.51$ UP $1358+6776.42$ UP $1359+9816.77$ UP $1361+10252.25$ UP $1362+9781.66$ UP $1363+9890.2$ UP1364+9488.79 UP1365+9072.15 UP1366+ 8955.01 UP $1367+8639.12$ UP $1368+8272.9$ UP $1369+7991.96$ UP $1371+7589.51$ UP $1372+7208.93$ UP $1373+7192.14$ UP $1374+6838.68$ UP $1375+6504.05$ UP $1376+$ 6471.64 UP $1377+6161.12$ UP $1378+6676.83$ UP1379+8456.83 UP $1381+7567.44$ UP $1382+8226.12$ UP $1383+11898.86$ UP $1384+12535.52$ UP $1385+11948.84$ UP $1386+$ 11891.89 UP $1387+11348.39$ UP $1388+10834.23$ UP1389+7387.15 UP $1391+7758.57$ UP $1392+7429.99$ UP $1393+7402.75$ UP1394+7075.1 UP1395+6787.78 UP1396+ 6799.45 UP $1397+6511.04$ UP1398+6258.87 UP1399+13383.27 UP $1401+12839.55$ UP $1402+12317.52$ UP $1403+12285.33$ UP $1404+11808.05$ UP $1405+11348.92$ UP $1406+$ 11279.57 UP $1407+10860.82$ UP $1408+11617.86$ UP $1409+9208.11$ UP $1411+8845.17$ UP $1412+8430.17$ UP $1413+8495.95$ UP $1414+8177.57$ UP $1415+7809.67$ UP $1416+$ 7702.67 UP $1417+7426.18$ UP $1418+7959.72$ UP $1419+7158.76$ UP $1421+6865.3$ UP $1422+6517.48$ UP $1423+6584.92$ UP $1424+6327$ UP $1425+6017.73$ UP $1426+$ 5918.29 UP $1427+6318.53$ UP $1428+5999.71$ UP $1429+7451.35$ UP $1431+7124.05$ UP $1432+6810.6$ UP $1433+6794.81$ UP $1434+6506.46$ UP $1435+6540.32$ UP $1436+$ 6704.33 UP $1437+6412.51$ UP $1438+6133.39$ UP $1439+7248.76$ UP $1441+6951.94$ UP $1442+6600.73$ UP $1443+6667.71$ UP $1444+6406.84$ UP $1445+6094.57$ UP $1446+$ 5994.11 UP $1447+6397.67$ UP $1448+6075.77$ UP $1449+7406.06$ UP $1451+7026.64$ UP $1452+6666.75$ UP $1453+6660.74$ UP $1454+6328.91$ UP $1455+7005.37$ UP $1456+$ 10540.82 UP $1457+11136.29$ UP $1458+10663.19$ UP $1459+15513.6$ UP $1461+14188.63$ 
UP $1462+15258.51$ UP $1463+21738.35$ UP $1464+22749.85$ UP $1465+21747.94$ UP $1466+$ 21463.11 UP $1467+20670.71$ UP $1468+19792.52$ UP $1469+11664.54$ UP $1471+10907.85$ UP $1472+11769.22$ UP $1473+10670.19$ UP $1474+11233.08$ UP $1475+10738.56$ UP $1476+$ 10692.64 UP $1477+10237.89$ UP $1478+9804.47$ UP $1479+12928.57$ UP $1481+12100.35$ UP $1482+13004.68$ UP $1483+11831.63$ UP $1484+12412.84$ UP $1485+11873.55$ UP $1486+$ 11817.61 UP $1487+11321.44$ UP $1488+10848.77$ UP1489+9081.12 UP $1491+8643.01$ UP $1492+8228.11$ UP $1493+8205.64$ UP1494+7820.89 UP1495+7456.07 UP1496+ 7415.59 UP $1497+7077.62$ UP $1498+7643.59$ UP1499+10748.19 UP $1501+11293.06$ UP $1502+10779.41$ UP $1503+10762.6$ UP1504+10289.56 UP1505+9839.02 UP1506+ 9794.65 UP $1507+9380.39$ UP1508+8985.22 UP1509+11385.95 UP $1511+10890.76$ UP1512+10418.86 UP1513+10390.19 UP1514+9955.43 UP1515+9540.47 UP1516+ 9485.43 UP1517+9103.76 UP1518+9772.48 UP1519+10205.01 UP $1521+10550.41$ UP $1522+10068.72$ UP $1523+10043.33$ UP $1524+9598.18$ UP $1525+9207.05$ UP1526+ 9126.06 UP $1527+8735.45$ UP $1528+8363.54$ UP $1529+11087.51$ UP $1531+10601.5$ UP1532+10142.28 UP1533+10111.21 UP1534+9684.5 UP1535+9280.87 UP1536+ 9232.5 UP $1537+8857.74$ UP $1538+9514.16$ UP $1539+9192.51$ UP $1541+8779.78$ UP $1542+8386.09$ UP $1543+8372.28$ UP $1544+8009.95$ UP $1545+7663.78$ UP $1546+$ 7626.46 UP $1547+7308.42$ UP $1548+7873.84$ UP $1549+11302.53$ UP $1551+11853.89$ UP $1552+11318.36$ UP $1553+11297.81$ UP $1554+10804.5$ UP $1555+10334.77$ UP $1556+$ 10285.93 UP $1557+9853.92$ UP $1558+9441.89$ UP $1559+8425.92$ UP $1561+8055$ UP 1562 +7700.55 UP $1563+7685.23$ UP1564+7359.07 UP1565+7046.88 UP $1566+7009.3$ UP $1567+7424.52$ UP $1568+7097.6$ UP $1569+8180.63$ UP $1571+7827.43$ UP $1572+$ 7489.78 UP1573+7468.25 UP1574+7157.08 UP1575+7192.04 UP $1576+7365.54$ UP $1577+7050.79$ UP $1578+6750.25$ UP 1579 - 36.80 VMM1- 34.07 VMM2- 31.55 VMM329.21 VMM4- 27.05 VMM5- 25.05 VMM6- 23.19 VMM7- 21.47 VMM8- 19.88 VMM9- 18.41 VMM10- 17.05 VMM11- 15.78 VMM12- 14.61 VMM13- 13.53 VMM14- 12.53 VMM15- 11.60 VMM16- 10.74 VMM17- 9.95 VMM18-9.21 VMM19- 8.53 VMM20- 7.90 VMM21 SUBJECT TO

A1: UP11+UP12+UP13+UP14+UP15+UP16+UP17+UP18+UP19<260

A2: UP 21+UP 22+UP 23+UP 24+UP 25+UP 26+UP 27+UP 28+UP $29<77$

A3: UP $31+$ UP $32+$ UP $33+$ UP $34+$ UP $35+$ UP $36+$ UP $37+$ UP $38+U P 39<350$

A 4: UP 41+UP 42+UP 43+UP 44+UP 45+UP 46+UP 47+UP 48+UP $49<164.59$

A5: UP 51+UP 52+UP 53+UP 54+UP 55+UP 56+UP 57+UP 58+UP $59<109.2$

A6: UP $61+$ UP $62+U P 63+$ UP $64+U P 65+U P 66+U P 67+U P 68+U P 69<202.51$

A7: UP 71+UP 72+UP 73+UP 74+UP 75+UP76+UP77+UP78+UP79 $<218.45$

A8 : UP 81+UP 82+UP 83+UP 84+UP 85+UP 86+UP 87+UP 88+UP $89<345.61$

A9: UP 91+UP 92+UP 93+UP 94+UP 95+UP 96+UP 97+UP 98+UP $99<338.02$

A10 : UP101+UP102+UP103+UP104+UP105+UP106+UP107+UP108+UP109<

242.34

A11: UP111+UP112+UP113+UP114+UP115+UP116+UP117+UP118+UP119 < 242.4

A12: UP121+UP122+UP123+UP124+UP125+UP126+UP127+UP128+UP129 < 339.87

A13: UP131+UP132+UP133+UP134+UP135+UP136+UP137+UP138+UP139 < 133.9

A14: UP141+UP 142+UP143+UP144+UP145+UP 146+UP147+UP148+UP $149<$ 394.6

A15: UP151+UP152+UP153+UP154+UP155+UP 156+UP157+UP158+UP159 < 625.57

A16: UP161+UP162+UP163+UP 164+UP165+UP 166+UP167+UP 168+UP169 < 177.75

A17: UP171+UP172+UP173+UP 174+UP175+UP176+UP177+UP 178+UP179 <

526.09

A18: UP181+UP 182+UP 183+UP 184+UP185+UP186+UP187+UP188+UP189< 418.22

A19: UP191+UP192+UP193+UP194+UP195+UP196+UP197+UP198+UP199< 442.45

A20: UP201+UP202+UP203+UP204+UP205+UP 206+UP207+UP208+UP20 < 391.76

A21: UP 211+UP 212+UP 213+UP 214+UP215+UP 216+UP 217+UP 218+UP $219<$ 260.26

A22: UP 221+UP 222+UP 223+UP 224+UP 225+UP 226+UP 227+UP 228+UP 229 < 186.26

A23: UP 231+UP 232+UP 233+UP 234+UP 235+UP 236+UP 237+UP 238+UP $239<$ 323.54

A2 4: UP $241+U P 242+U P 243+U P 244+U P 245+U P 246+U P 247+U P 248+U P 249<$ 412.95

A25: UP 251+UP 252+UP 253+UP 254+UP255+UP 256+UP 257+UP 258+UP 259 < 
219.16

A2 6: UP 261+UP 262+UP 263+UP 264+UP 265+UP 266+UP 267+UP 268+UP $269<$

262.76

A27: UP271+UP 272+UP2 73+UP 274+UP 275+UP 276+UP277+UP 278+UP $279<$

297.77

A28: UP2 81+UP282+UP 283+UP 284+UP 285+UP 286+UP287+UP 288+UP 289 <

364.99

A29: UP2 91+UP 292+UP 293+UP 294+UP 295+UP 296+UP 297+UP 298+UP2 99 <

563.39

A30: UP 301+UP 302+UP 303+UP 304+UP 305+UP 306+UP 307+UP 308+UP $309<$

578.99

A31: UP 311+UP 312+UP 313+UP 314+UP 315+UP 316+UP 317+UP 318+UP 319 <

310.15

A32: UP 321+UP 322+UP 323+UP $324+$ UP 325+UP $326+$ UP $327+$ UP $328+U P 329<$

448.86

A33: UP 331+UP 332+UP 333+UP 334+UP 335+UP 336+UP $337+$ UP $338+U P 339<$

664.84

A34: UP $341+$ UP $342+$ UP $343+$ UP $344+$ UP $345+$ +UP $346+$ UP $347+$ UP $348+U P 349<$

387.95

A35: UP 351+UP 352+UP 353+UP $354+$ UP 355+UP 356+UP 357+UP $358+U P 359<$

242.73

A36: UP 361+UP 362+UP 363+UP 364+UP 365+UP 366+UP 367+UP $368+$ +UP $369<$

200.38

A37: UP $371+U P 372+U P 373+U P 374+U P 375+U P 376+U P 377+U P 378+U P 379<$

160.8

A38: UP 381+UP 382+UP 383+UP 384+UP 385+UP 386+UP $387+$ UP $388+U P 389<$

163.42

A39: UP 391+UP 392+UP 393+UP 394+UP 395+UP 396+UP 397+UP 398+UP 399 <

127.4

A 40: UP 401+UP 402+UP 403+UP $404+$ +UP 405+UP 4 06+UP $407+$ +UP $408+$ +UP $409<$

236.12

A41: UP 411+UP 412+UP 413+UP 414+UP 415+UP 416+UP 417+UP $418+$ +UP $419<$

140.09

A 42: UP 421+UP 422+UP 423+UP 424+UP 425+UP 426+UP 427+UP $428+U P 429<$

379.39

A43: UP 431+UP 432+UP 433+UP 434+UP 435+UP 436+UP $437+$ +UP $438+U P 439<$

108.65

A 44 : UP $441+$ +UP $442+$ +UP $443+$ +UP 444 +UP $445+$ +UP 446 +UP $447+$ +UP $448+$ +UP $449<$

128.21

A 45: UP 451+UP 452+UP 453+UP 454+UP 455+UP 456+UP 457+UP $458+$ +UP $459<$

159.3

A 46: UP 4 61+UP $462+$ +UP $463+$ +UP $464+$ UP $465+$ +UP $466+$ +UP $467+$ +UP $468+$ +UP $469<$

151.95

A47: UP 471+UP 472+UP $473+$ UP $474+$ +UP $475+$ +UP $476+$ +UP $477+$ +UP $478+$ UP $479<$

544.83

A 48 : UP $481+$ +UP $482+$ +UP $483+$ UP $484+$ UP $485+$ +UP $486+$ +UP $487+$ +UP $488+$ +UP $489<$

118.01

A49: UP 491+UP 492+UP $493+$ +UP $494+$ +UP $495+$ +UP 4 96+UP $497+$ +UP $498+$ +UP $499<$

143.17

A50: UP 501+UP 502+UP 503+UP 504+UP505+UP506+UP507+UP508+UP509 <

183.23

A51: UP 511+UP512+UP513+UP514+UP 515+UP516+UP517+UP518+UP519 <

133.49

A52: UP 521+UP522+UP523+UP524+UP 525+UP 526+UP527+UP528+UP529<

115.47

A53: UP 531+UP 532+UP533+UP 534+UP535+UP536+UP537+UP 538+UP $539<$

131.82

A54: UP541+UP542+UP543+UP544+UP545+UP546+UP547+UP548+UP549<

221.78

A55: UP551 + UP552 + UP553 + UP554 + UP555 + UP556 + UP557 + UP558 + UP559<

140.99

A56: UP561 + UP562 + UP563 + UP564 + UP565 + UP566 + UP567+UP568 + UP569<

433. 41

A57: UP571 + UP572 + UP573 + UP574 + UP575 + UP576 + UP577+UP578 + UP579<

156.09

A58: UP581 + UP582 + UP583 + UP584 + UP585 + UP586 + UP587+UP588 + UP589<

462.53

A59: UP591 + UP592+UP593+UP594+UP595+UP 596+UP597+UP598+UP599 < 
443.95

A60: UP $601+U P 602+U P 603+U P 604+U P 605+U P 606+U P 607+U P 608+U P 609<$

592.44

A61 : UP 611+UP 612+UP 613+UP 614+UP 615+UP 616+UP 617+UP 618+UP 619 <

202.84

A62: UP $621+$ UP $622+$ UP $623+$ UP $624+$ UP $625+$ UP $626+$ UP $627+$ UP $628+$ UP $629<$

403.41

A63: UP $631+$ UP $632+$ UP $633+$ UP $634+$ UP $635+$ UP $636+$ UP $637+$ UP $638+$ UP $639<$

255.77

A 64: UP $641+$ UP $642+$ UP $643+$ UP $644+$ UP $645+$ +UP $646+$ UP $647+$ UP $648+$ UP $649<$

368.46

A65: UP 651+UP 652+UP 653+UP 654+UP 655+UP 656+UP $657+$ +UP $658+$ +UP $659<$

388.32

A 66 : UP $661+$ UP $662+$ UP $663+$ +UP $664+$ UP $665+$ +UP $666+$ UP $667+$ UP $668+$ +UP $669<$

671.18

A67: UP 671+UP 672+UP 673+UP 674+UP 675+UP 676+UP 677+UP $678+U P 679<$

354.72

A 68: UP $681+$ UP $682+$ UP $683+$ UP $684+$ UP $685+$ +UP $686+$ UP $687+$ UP $688+$ +UP $689<$

281.79

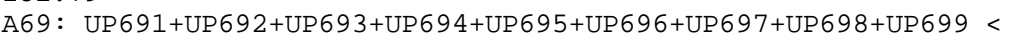

411.25

A70: UP 701+UP 702+UP 703+UP 704+UP 705+UP 706+UP 707+UP 708+UP $709<$

516.49

A71：UP711+UP 712+UP 713+UP 714+UP 715+UP 716+UP 717+UP 718+UP $719<$

322.35

A72: UP 721+UP 722+UP 723+UP 724+UP 725+UP 726+UP 727+UP 728+UP $729<$

363.73

A73: UP 731+UP 732+UP 733+UP 734+UP 735+UP 736+UP 737+UP 738+UP $739<$

794.76

A74 : UP $741+$ UP $742+$ UP $743+$ UP $744+$ UP $745+$ UP $746+$ UP $747+$ UP $748+U P 749<$

458.72

A75: UP 751+UP 752+UP 753+UP 754+UP 755+UP 756+UP 757+UP 758+UP $759<$

336.66

A76: UP 761+UP 762+UP 763+UP 764+UP 765+UP 766+UP 767+UP $768+$ UP $769<$

194.35

A77 : UP 771+UP 772+UP 773+UP 774+UP 775+UP 776+UP 777+UP 778+UP $779<$

469.58

A78: UP 781+UP 782+UP 783+UP 784+UP 785+UP 786+UP787+UP 788+UP $789<$

183.36

A79: UP 791+UP 792+UP 793+UP 794+UP 795+UP 796+UP797+UP 798+UP $799<$

436.5

A80: UP $801+$ +UP $802+$ +UP $803+$ UP $804+$ +UP $805+$ +UP $806+$ +UP $807+$ +UP $808+U P 809<$ 379.77

A81: UP 811+UP 812+UP 813+UP 814+UP 815+UP 816+UP 817+UP 818+UP $819<$

187.85

A 82 : UP $821+$ +UP $822+$ +UP $823+$ UP $824+$ +UP $825+$ +UP $826+$ +UP $827+$ UP $828+$ UP $829<$

223.49

A83: UP 831+UP 832+UP 833+UP 834+UP 835+UP 836+UP $837+$ UP $838+U P 839<$

202.83

A 84: UP $841+$ UP $842+$ +UP $843+$ UP $844+$ UP $845+$ +UP $846+$ UP $847+$ +UP $848+U P 849<$

278.45

A 85: UP 851+UP 852+UP 853+UP 854+UP 855+UP 856+UP 857+UP $858+$ +UP $859<$

209. 37

A 86: UP 861+UP 862+UP $863+$ UP $864+$ UP $865+$ +UP $866+$ UP $867+$ +UP $868+U P 869<$

222.28

A87: UP 871+UP $872+$ +UP $873+$ +UP $874+$ +UP $875+$ +UP $876+$ +UP $877+$ +UP $878+U P 879<$

210.99

A88 : UP $881+$ UP $882+$ +UP $883+$ UP $884+$ UP $885+$ +UP $886+$ +UP $887+$ +UP $888+U P 889<$

426.31

A89: UP 891+UP 892+UP 893+UP 894+UP 895+UP 896+UP 897+UP $898+U P 899<$ 365.33

A90: UP 901+UP 902+UP 903+UP 904+UP 905+UP 906+UP 907+UP $908+U P 909<$ 492.62

A91: UP 911+UP 912+UP 913+UP 914+UP 915+UP 916+UP 917+UP $918+$ +UP $919<$

257.5

A92: UP 921+UP 922+UP 923+UP 924+UP 925+UP 926+UP 927+UP $928+U P 929<$

362.7

A93: UP 931+UP 932+UP 933+UP 934+UP 935+UP 936+UP 937+UP 938+UP 939 < 
164.15

A94: UP $941+$ +UP $942+$ +UP $943+$ +UP $944+$ +UP $945+$ +UP 946 +UP $947+$ +UP $948+$ +UP $949<$

424.33

A 95: UP 951+UP 952+UP 953+UP 954+UP 955+UP 956+UP 957+UP 958+UP 959 <

362.73

A96: UP 961+UP 962+UP 963+UP 964+UP 965+UP 966+UP 967+UP $968+$ +UP $969<$

425.08

A97 : UP 971+UP 972+UP 973+UP 974+UP 975+UP 976+UP 977+UP 978+UP $979<$

413.6

A98: UP 981+UP 982+UP 983+UP 984+UP 985+UP 986+UP 987+UP $988+$ +UP $989<$

418.41

A99: UP 991+UP 992+UP 993+UP 994+UP 995+UP 996+UP 997+UP 998+UP 999 <

532.14

A100: UP1001+UP1002+UP1003+UP1004+UP1005+UP1006+UP1007+UP1008+

UP $1009<437.74$

A101: UP1011+UP1012+UP1013+UP1014+UP1015+UP1016+UP1017+UP1018+

UP $1019<396.33$

A102: UP1021+UP1022+UP1023+UP1024+UP 1025+UP1026+UP1027+UP1028+ UP1029 < 510.57

A103: UP1031+UP1032+UP1033+UP1034+UP 1035+UP1036+UP1037+UP1038+ UP $1039<90.55$

A104: UP1041+UP1042+UP1043+UP1044+UP1045+UP1046+UP1047+UP1048+ UP1049<211.31

A105: UP1051+UP1052+UP1053+UP1054+UP 1055+UP1056+UP1057+UP1058+ UP $1059<69.37$

A106: UP1061+UP1062+UP1063+UP1064+UP1065+UP1066+UP1067+UP1068+ UP $1069<57.17$

A107: UP1071+UP1072+UP1073+UP1074+UP1075+UP1076+UP1077+UP1078+ UP $1079<195.8$

A108: UP1081+UP1082+UP1083+UP 1084+UP1085+UP1086+UP1087+UP1088+ UP $1089<64.39$

A109: UP1091+UP1092+UP1093+UP1094+UP1095+UP1096+UP1097+UP1098+ UP $1099<98.99$

A110: UP1101+UP1102+UP1103+UP1104+UP1105+UP1106+UP1107+UP1108+ UP $1109<129.7$

A111: UP1111+UP1112+UP1113+UP 1114+UP1115+UP1116+UP1117+UP1118+ UP $1119<53.59$

A112: UP1121+UP1122+UP1123+UP1124+UP1125+UP1126+UP1127+UP1128+ UP $1129<12.54$

A113: UP1131+UP1132+UP1133+UP1134+UP1135+UP1136+UP1137+UP1138+ UP1139 < 121.11

A114: UP1141+UP1142+UP1143+UP1144+UP1145+UP1146+UP1147+UP1148+ UP $1149<7.67$

A115: UP1151+UP1152+UP1153+UP1154+UP1155+UP1156+UP1157+UP1158+ UP $1159<42.27$

A116: UP1161+UP1162+UP1163+UP1164+UP1165+UP1166+UP1167+UP1168+ UP $1169<8.8$

A117: UP1171+UP1172+UP1173+UP1174+UP1175+UP1176+UP1177+UP1178+ UP $1179<41.42$

A118: UP1181+UP1182+UP 1183+UP 1184+UP 1185+UP1186+UP1187+UP1188+ UP1189 < 13.8

A119: UP1191+UP1192+UP1193+UP 1194+UP 1195+UP 1196+UP 1197+UP1198+ UP1199< 58.84

A122: UP1221+UP1222+UP1223+UP1224+UP 1225+UP1226+UP1227+UP1228+ UP $1229<41.48$

A123: UP1231+UP1232+UP1233+UP 1234+UP 1235+UP 1236+UP 1237+UP1238+ UP $1239<20.78$

A124: UP1241+UP1242+UP1243+UP1244+UP1245+UP1246+UP1247+UP $1248+$

UP $1249<31.11$

A125: UP1251+UP1252+UP1253+UP1254+UP1255+UP1256+UP1257+UP1258+

UP $1259<26.39$

A126: UP1261+UP1262+UP1263+UP1264+UP1265+UP1266+UP1267+UP1268+

UP $1269<1003.07$

A127: UP1271+UP1272+UP1273+UP1274+UP1275+UP1276+UP1277+UP1278+

UP $1279<46.12$

A128: UP1281+UP1282+UP1283+UP1284+UP1285+UP1286+UP1287+UP1288+

UP $1289<41.95$ 
A129: UP1291+UP1292+UP1293+UP1294+UP1295+UP1296+UP1297+UP1298+ UP $1299<682.3$

A130: UP1301+UP1302+UP1303+UP1304+UP1305+UP1306+UP1307+UP1308+ UP1309 < 339.82

A131: UP1311+UP1312+UP1313+UP1314+UP1315+UP1316+UP1317+UP1318+ UP $1319<73.07$

A132: UP1321+UP1322+UP1323+UP1324+UP 1325+UP1326+UP1327+UP1328+ UP1329 $<29.2$

A133: UP1331+UP1332+UP1333+UP1334+UP 1335+UP1336+UP1337+UP1338+ UP1339< 94.55

A134: UP1341+UP1342+UP1343+UP1344+UP 1345+UP 1346+UP1347+UP1348+ UP1349< 117.62

A135: UP1351+UP1352+UP1353+UP1354+UP1355+UP1356+UP1357+UP1358+ UP1359 < 297.42

A136: UP1361+UP1362+UP1363+UP1364+UP 1365+UP 1366+UP1367+UP1368+ UP1369 < 40.44

A137: UP1371+UP1372+UP1373+UP 1374+UP1375+UP1376+UP 1377+UP1378+ UP1379 < 196.21

A138: UP1381+UP1382+UP1383+UP1384+UP1385+UP1386+UP1387+UP1388+ UP1389 < 258.29

A139: UP1391+UP1392+UP1393+UP1394+UP 1395+UP1396+UP 1397+UP1398+ UP1399 < 918.48

A140: UP1401+UP1402+UP1403+UP1404+UP1405+UP1406+UP1407+UP1408+ UP $1409<32.18$

A141: UP1411+UP1412+UP1413+UP1414+UP1415+UP1416+UP1417+UP1418+ UP $1419<36.14$

A142: UP1421+UP1422+UP1423+UP1424+UP1425+UP1426+UP1427+UP1428+ UP $1429<20$

A143: UP1431+UP1432+UP1433+UP1434+UP1435+UP1436+UP1437+UP1438+ UP1 $139<24$

A144: UP1441+UP1442+UP1443+UP $1444+$ +UP $1445+$ +UP $1446+$ +UP $1447+$ +UP $1448+$ UP1 $449<25$

A145: UP1451+UP1452+UP1453+UP1454+UP1455+UP1456+UP1457+UP1458+ UP $1459<44$

A146: UP1461+UP1462+UP1463+UP1464+UP1465+UP1466+UP1467+UP1468+ UP $1469<26.37$

A147: UP1471+UP1472+UP1473+UP1474+UP1475+UP1476+UP1477+UP1478+ UP $1479<53$

A148: UP1481+UP1482+UP1483+UP1484+UP1485+UP1486+UP 1487+UP 1488+ UP1 $189<30$

A149: UP1491+UP1492+UP1493+UP1494+UP 1495+UP1496+UP 1497+UP 1498+ UP1499< 5.08

A150: UP1501+UP1502+UP1503+UP1504+UP1505+UP1506+UP1507+UP1508+ UP $1509<83$

A151: UP1511+UP1512+UP1513+UP1514+UP1515+UP1516+UP1517+UP1518+

UP1519< 21.4

A152: UP1521+UP1522+UP1523+UP1524+UP1525+UP1526+UP1527+UP1528+

UP $1529<46.49$

A153: UP1531+UP1532+UP1533+UP 1534+UP1535+UP1536+UP1537+UP1538+

UP $1539<29.31$

A154 : UP1541+UP1542+UP1543+UP1544+UP1545+UP1546+UP1547+UP1548+

UP $1549<209.17$

A155: UP1551+UP1552+UP1553+UP1554+UP1555+UP1556+UP1557+UP1558+ UP $1559<78$

A156: UP1561+UP1562+UP1563+UP1564+UP1565+UP1566+UP1567+UP1568+ UP $1569<17$

A157: UP1571+UP1572+UP1573+UP1574+UP1575+UP1576+UP1577+UP1578+ UP $1579<22.5$

Prod2002:

400.31 UP $1464+400.31$ UP $1465+400.31$ UP $1466+360.5$ UP $537+360.5$ UP $538+$

360.5 UP $539+335.99$ UP $94+335.99$ UP $95+335.99$ UP $96+335.53$ UP $104+335.53$ UP $105+$

335.53 UP $106+324.81$ UP $41+324.81$ UP $42+324.81$ UP $43+311.71$ UP $1317+311.71$ UP 1318

+311.71 UP $1319+309.54$ UP $1034+309.54$ UP $1035+309.54$ UP $1036+308.03$ UP $554+$

308.03 UP 555+308.03UP 556+294.27UP $634+294.27$ UP $635+294.27 U P 636+$

291.99 UP $1324+291.99$ UP $1325+291.99$ UP $1326+288.07$ UP $1457+288.07$ UP $1458+$

288.07 UP $1459+270.19$ UP $151+270.1$ 9UP $152+270.19$ UP $153+270$ UP $1301+270$ UP $1302+$

270 UP $1303+264$ UP $11+264$ UP $12+264$ UP $13+25$ 9UP $34+25$ 9UP $35+25$ 9UP $36+$ 
258UP1471+258UP1472+258UP1473+258UP1481+258UP1482+258UP1483+ 257.62 UP $1054+257.62$ UP $1055+257.62$ UP $1056+244.73$ UP $1384+244.73$ UP $1385+$ $244.73 U P 1386+240.56 U P 1101+240.56 U P 1102+240.56 U P 1103+238.03 U P 594+$ 238.03 UP $595+238.03$ UP 596+234.33UP161+234.33UP162+234.33UP163+ 233.31 UP $1061+233.31$ UP $1062+233.31$ UP $1063+224.23$ UP $584+224.23$ UP $585+$ 224.23 UP $586+223.78$ UP $624+223.78$ UP $625+223.78$ UP $626+221.84$ UP $601+$ 221.84 UP $602+221.84$ UP $603+216.03$ UP $1091+216.03$ UP $1092+216.03$ UP $1093+$ 204.17 UP $611+204.17$ UP $612+204.17$ UP $613+198.12$ UP $1001+198.12$ UP $1002+$ 198.12 UP $1003+175.15$ UP $834+175.15$ UP $835+175.15$ UP $836+169.29$ UP $1111+$ 169.29UP1112+169.29UP1113+VMM1 - P2002 = 0

Prod2003:

418.06UP1467+418.06UP1468+418.06UP1469+354.45UP371+354.45UP372+

354 . 45UP $373+354$. 4UP 351+354 . 4UP 352 + 354 . 4UP 353+351 . 98UP 97+351 . 98UP 98+ 351.98 UP $99+351.51$ UP $107+351.51$ UP $108+351.51$ UP $109+336.84$ UP $44+336.84$ UP $45+$ 336.84 UP $46+335.37$ UP $361+335.37$ UP $362+335.37$ UP $363+321.6$ UP $1037+321.6$ UP 1038 +321.6 UP 1039+320.03UP 557+320.03UP 558+320.03UP 559+312.29UP 637+ 312.29 UP $638+312.29$ UP $639+309.87$ UP $1327+309.87$ UP $1328+309.87$ UP $1329+$ 287UP1304+287UP1305+287UP1306+280.2UP154+280.2UP155+280.2UP156+ 280UP $14+280$ UP $15+280$ UP $16+280$ UP $37+280$ UP $38+280$ UP $39+275.85$ UP $571+$ 275.85 UP $572+275.85$ UP $573+273$ UP $1474+273$ UP $1475+273$ UP $1476+273$ UP $1484+$ 273UP 1485+273UP1486+270.55UP1057+270.55UP1058+270.55UP1059+269. 3UP 1271 $+269.3 \mathrm{UP} 1272+269.3 \mathrm{UP} 1273+266.8 \mathrm{UP} 1231+266.8 \mathrm{UP} 1232+266.8 \mathrm{UP} 1233+$ 263.99 UP $1261+263.99$ UP $1262+263.99$ UP $1263+258$ UP $1501+258$ UP $1502+258$ UP $1503+$ 258UP 1551+258UP1552+258UP1553+255.72UP1387+255.72UP1388+255.72UP1389+ 252.59 UP $1104+252.59$ UP $1105+252.59$ UP $1106+252$ UP $21+252$ UP $22+252$ UP $23+$ 248.03 UP 597+248.03UP 598+248.03UP 599+245.35UP164+245.35UP165+ 245.35 UP $166+244.28$ UP $1064+244.28$ UP $1065+244.28$ UP $1066+237.83$ UP $604+$ 237.83 UP $605+237.83$ UP $606+233.77 U P 211+233.77 U P 212+233.77 U P 213+$ 232.24 UP $587+232.24$ UP $588+232.24$ UP $589+231.77$ UP $627+231.77$ UP $628+$ 231.77 UP $629+228.24$ UP $1071+228.24$ UP 1072+228.24UP1073+224.03UP 1094+ 224.03 UP 1095+224.03UP 1096+217.18UP 614+217.18UP 615+217.18UP 616+ 217.13 UP $1004+217.13$ UP $1005+217.13$ UP $1006+216.17$ UP $721+216.17$ UP $722+$ 216.17 UP $723+210.01$ UP $281+210.01$ UP $282+210.01$ UP $283+197.86$ UP $251+$ 197.86 UP $252+197.86$ UP $253+185.77$ UP $641+185.77$ UP $642+185.77$ UP $643+$ $184.16 \mathrm{UP} 837+184.16 \mathrm{UP} 838+184.16 \mathrm{UP} 839+183.4 \mathrm{UP} 1114+183.4 \mathrm{UP} 1115+$ 183. 4UP1116+168UP1291+168UP1292+168UP1293+144 . 4UP1191+144 . 4UP 1192+ 144.4 UP $1193+143.87$ UP $1131+143.87$ UP $1132+143.87$ UP $1133+143.07$ UP $1121+$ 143.07 UP $1122+143.07$ UP $1123+141.14$ UP $1161+141.14$ UP $1162+141.14$ UP $1163+$ 137.12 UP $1151+137.12$ UP $1152+137.12$ UP $1153+118.91$ UP $1141+118.91 U P 1142+$ 118.91 UP $1143+96.01$ UP $871+96.01 \mathrm{UP} 872+96.01 \mathrm{UP} 873+\mathrm{VMM} 2-\mathrm{P} 2003=0$ Prod2004:

371.47 UP $374+371.47$ UP $375+371.47$ UP $376+371.42$ UP $354+371.42$ UP $355+$ 371.42 UP $356+349.34$ UP $364+349.34$ UP $365+349.34$ UP $366+344.86 U P 47+344.86 U P 48$ +344.86 UP $49+304$ UP $1307+304$ UP $1308+304$ UP $1309+293.98 U P 481+293.98$ UP $482+$ 293.98 UP $483+288.2$ UP $157+288.2$ UP $158+288.2$ UP $159+288$ UP $17+288$ UP $18+288$ UP 19 +288 UP $1477+288$ UP $1478+288$ UP $1479+288$ UP $1487+288$ UP $1488+288$ UP $1489+$ 286.84 UP $574+286.84$ UP $575+286.84$ UP $576+286.26$ UP $1274+286.26$ UP $1275+$ 286.26 UP $1276+282.97$ UP $1234+282.97$ UP $1235+282.97$ UP $1236+279.99$ UP $1264+$

279.99UP $1265+279.99$ UP $1266+273$ UP $1504+273$ UP $1505+273$ UP $1506+273$ UP $1554+$ 273UP 1555+273UP 1556+269.87UP $401+269.87$ UP $402+269.87$ UP $403+264$. 62UP $1107+$ 264.62 UP $1108+264.62$ UP $1109+263.84$ UP $411+263.84$ UP $412+263.84$ UP $413+$ 263.52 UP $51+263.52$ UP $52+263.52$ UP $53+259$ UP $24+25$ UUP $25+259$ UP $26+257.34$ UP 381 +257.34 UP $382+257.34$ UP $383+256.37$ UP $167+256.37$ UP $168+256.37$ UP $169+$ 255.24 UP $1067+255.24$ UP $1068+255.24$ UP $1069+251.94$ UP $991+251.94$ UP $992+$ 251.94 UP $993+249.09$ UP $1221+249.09$ UP $1222+249.09$ UP $1223+247.82$ UP $607+$ 247.82 UP $608+247.82$ UP $609+247.18$ UP $1331+247.18$ UP $1332+247.18$ UP $1333+$ 245.26 UP $1074+245.26$ UP $1075+245.26 U P 1076+244.76 U P 214+244.76 U P 215+$ 244.76 UP $216+243.41$ UP $1521+243.41$ UP $1522+243.41$ UP $1523+240.03$ UP $1097+$ 240.03 UP $1098+240.03$ UP $1099+237$.39UP1361+237.39UP1362+237.39UP1363+ 232.19 UP $617+232.19$ UP $618+232.19$ UP $619+231.18 U P 724+231.18 U P 725+$ 231.18 UP $726+224.14$ UP $1007+224.14$ UP $1008+224.14$ UP 1009+224.01UP $284+$ 224.01 UP $285+224.01$ UP $286+221.97$ UP $171+221.97$ UP $172+221.97$ UP $173+$ 215.8 UUP $181+215.89$ UP $182+215.89$ UP $183+215.65$ UP $441+215.65$ UP $442+$ $215.65 U P 443+209.85$ UP $254+209.85$ UP $255+209.85 U P 256+204.18 U P 1021+$ 204.18 UP $1022+204.18$ UP $1023+204.01$ UP $301+204.01$ UP $302+204.01$ UP $303+$ 202.75UP 64 4+202.75UP 645+202.75UP 646+197. 9UP1391+197. 9UP 1392+ 197 . 9UP $1393+197.84$ UP $1011+197.84$ UP $1012+197.84$ UP $1013+193.47$ UP $1117+$ 
193.47UP1118+193.47UP1119+192.07UP 461+192.07UP 462+192.07UP 463+ 190.84 UP $1081+190.84$ UP $1082+190.84$ UP $1083+186.15$ UP $901+186.15$ UP $902+$ 186.15 UP $903+185.82$ UP $981+185.82$ UP $982+185.82$ UP $983+180.06$ UP $321+$ 180.06 UP $322+180.06$ UP 323+175UP1294+175UP1295+175UP12 96+173.86UP 651+ 173.86UP $652+173.86$ UP $653+167.92$ UP $311+167.92$ UP $312+167.92 U P 313+$ 167.85 UP $701+167.85$ UP $702+167.85$ UP $703+161.77$ UP $1041+161.77$ UP $1042+$ 161.77 UP $1043+153.87$ UP $1134+153.87$ UP $1135+153.87$ UP $1136+152.4$ UP $1124+$ 152 . 4UP1125+152.4UP1126+150.35UP1164+150.35UP1165+150.35UP 1166+ 147 . 4UP 1194+147.4UP1195+147.4UP1196+146.07UP 1154+146.07UP1155+ 146.07 UP $1156+124.12$ UP $1144+124.12$ UP $1145+124.12$ UP $1146+112.85$ UP $1171+$ 112.85 UP $1172+112.85$ UP $1173+105.01$ UP $874+105.01$ UP $875+105.01$ UP $876+$ VMM3 P2004 = 0

Prod2005:

$384.48 \mathrm{UP} 377+384.48 \mathrm{UP} 378+384.48 \mathrm{UP} 379+376.42 \mathrm{UP} 357+376.42 \mathrm{UP} 358+$ 376.42 UP $359+359.32$ UP $367+359.32$ UP $368+359.32$ UP $369+307.98 U P 484+$ 307.98 UP $485+307.98$ UP $486+303.83$ UP $577+303.83$ UP $578+303.83$ UP $579+$ $302.43 U P 1277+302.43 U P 1278+302.43 U P 1279+299.14$ UP $1237+299.14$ UP $1238+$ 299.14 UP $1239+295.98$ UP $1267+295.98$ UP $1268+295.98$ UP $1269+288$ UP $1507+$ 288UP1508+288UP1509+288UP1557+288UP1558+288UP1559+280UP1181+ 280UP $1182+280$ UP $1183+279.86$ UP $404+279.86$ UP $405+279.86$ UP $406+279.83$ UP $414+$ 279.83 UP $415+279.83$ UP $416+279.4$ 9UP $54+279.49$ UP $55+279.49$ UP $56+274.46$ UP 1401 +274.46 UP $1402+274.46$ UP $1403+272$. 3UP $384+272$. 3UP $385+272$. 3UP $386+272$ UP $27+$ 272UP $28+272$ UP $29+265.94$ UP $994+265.94$ UP $995+265.94$ UP $996+264.86$ UP $431+$ 264.86 UP $432+264.86$ UP $433+263.07$ UP $1241+263.07$ UP $1242+263.07 U P 1243+$ 262.93 UP $1224+262.93$ UP $1225+262.93$ UP $1226+260.24$ UP $1334+260.24$ UP $1335+$ $260.24 \mathrm{UP} 1336+257.8 \mathrm{UP} 1541+257.8 \mathrm{UP} 1542+257.8 \mathrm{UP} 1543+256.28 \mathrm{UP} 1524+$ 256.28 UP $1525+256.28$ UP $1526+256.27$ UP $1077+256.27$ UP $1078+256.27$ UP $1079+$ 256.19 UP $1364+256.19$ UP $1365+256.19$ UP $1366+255.75$ UP $217+255.75 U P 218+$ 255.75 UP $219+255.28 U P 1531+255.28$ UP $1532+255.28 U P 1533+253.18 U P 1511+$ 253.18 UP $1512+253.18$ UP $1513+240.18$ UP $727+240.18$ UP $728+240.18$ UP $729+$ 240.01 UP $287+240.01$ UP $288+240.01$ UP $289+239.61$ UP $111+239.61$ UP $112+$ $239.61 U P 113+237.96 U P 174+237.96 U P 175+237.96 U P 176+234.04 U P 341+$ 234.04 UP $342+234.04$ UP $343+233.1$ UP $1411+233.1$ UP $1412+233.1$ UP $1413+$ 230.88 UP $184+230.88$ UP $185+230.88$ UP $186+230.32$ UP $1491+230.32$ UP $1492+$ 230.32 UP $1493+227.85$ UP $291+227.85$ UP $292+227.85$ UP $293+227.76 U P 1371+$ 227.76 UP $1372+227.76$ UP $1373+227.68$ UP $1351+227.68$ UP $1352+227.68$ UP $1353+$ 224.19 UP $1024+224.19$ UP $1025+224.19$ UP $1026+223.84$ UP $257+223.84$ UP $258+$ 223.84 UP $259+223.73$ UP $647+223.73$ UP $648+223.73$ UP $649+223.64$ UP $444+$ 223.64UP 4 45+223.64UP 4 46+217.01UP304+217.01UP305+217.01UP306+ $210.68 \mathrm{UP} 1341+210.68 \mathrm{UP} 1342+210.68 \mathrm{UP} 1343+209$. 9UP $1394+209.9 \mathrm{UP} 1395+$ 209.9 UP $1396+209.83$ UP $1014+209.83$ UP $1015+209.83$ UP $1016+209.59$ UP $781+$ 209.59 UP $782+209.59 U P 783+203.62 U P 451+203.62$ UP $452+203.62$ UP $453+$ 203.16 UP $904+203.16$ UP $905+203.16$ UP $906+203.07 U P 464+203.07$ UP $465+$ 203.07UP 466+202.81UP 984+202.81UP 985+202.81UP 986+201.78UP $1084+$ 201.78 UP $1085+201.78$ UP $1086+198.03$ UP $241+198.03$ UP $242+198.03$ UP $243+$ 189.06 UP $324+189.06$ UP $325+189.06$ UP $326+188.85$ UP $654+188.85$ UP $655+$ 188.85 UP $656+186.27$ UP $231+186.27$ UP $232+186.27$ UP $233+186.15$ UP $811+$ 186.15 UP $812+186.15$ UP $813+185.6 U P 821+185.6 U P 822+185.6 U P 823+184$ UP $1297+$ 184 UP $1298+184$ UP $1299+181.92$ UP 314+181 . 92UP315+181. 92UP 316+181. 83UP $704+$ 181.83 UP $705+181.83$ UP $706+174.75$ UP $1044+174.75$ UP $1045+174.75$ UP $1046+$ 168.13 UP $681+168.13$ UP $682+168.13$ UP $683+161.91$ UP $691+161.91$ UP $692+$ 161.91 UP $693+160.44$ UP $1197+160.44$ UP $1198+160.44$ UP $1199+159.86$ UP $1137+$ 159.86 UP $1138+159.86$ UP $1139+157.58$ UP $1127+157.58$ UP $1128+157.58$ UP $1129+$ 156.1UP741+156.1UP742+156.1UP743+155.46UP1167+155.46UP1168+ 155.46 UP 1169+151.03UP1157+151.03UP1158+151 . 03UP1159+144 . 12UP 671+ 144.12 UP $672+144.12$ UP $673+125.17$ UP $1147+125.17$ UP $1148+125.17$ UP $1149+$ 117.8 UP $1174+117.8$ UP $1175+117.8 U P 1176+114.07 U P 801+114.07 U P 802+$ 114.07 UP $803+112.01$ UP $877+112.01$ UP $878+112.01$ UP879+VMM4 - P2005 $=0$ Prod2006: $311.98 \mathrm{UP} 487+311.98 \mathrm{UP} 488+311.98 \mathrm{UP} 489+298.27 \mathrm{UP} 1184+298.27 \mathrm{UP} 1185+$ $298.27 U P 1186+292.36$ UP $1404+292.36$ UP $1405+292.36$ UP $1406+287.93$ UP $997+$ 287.93 UP $998+287.93$ UP 999+287.86UP $407+287.86 U P 408+287.86 U P 409+$ 287.82 UP $417+287.82$ UP $418+287.82$ UP $419+287.48$ UP $57+287.48 U P 58+287.48 U P 59+$ 280.91 UP $434+280.91$ UP $435+280.91$ UP $436+279.29$ UP $387+279.29$ UP $388+$ 279.29 UP $389+279.01$ UP $1244+279.01$ UP $1245+279.01$ UP $1246+276.76$ UP $1227+$ 276.76 UP $1228+276.76$ UP $1229+273.3 U P 1337+273.3 U P 1338+273.3 U P 1339+$ 272.78 UP $1544+272.78$ UP $1545+272.78$ UP $1546+270.07 U P 331+270.07 U P 332+$ 270.07 UP $333+269.95$ UP $1534+269.95$ UP $1535+269.95$ UP $1536+269.14$ UP $1527+$ 
269.14UP1528+269.14UP1529+269.05UP1367+269.05UP1368+269.05UP1369+ 267 . 9UP $1514+267.9 \mathrm{UP} 1515+267$. 9UP $1516+265.57 \mathrm{UP} 114+265.57 \mathrm{UP} 115+$ 265.57 UP $116+259.04$ UP $344+259.04$ UP $345+259.04$ UP $346+258.27 U P 141+$ 258.27 UP $142+258.27$ UP $143+258.16$ UP $201+258.16$ UP $202+258.16$ UP $203+258.1$ UP 121 +258.1 UP $122+258.1$ UP 123+258UP1561+258UP1562+258UP1563+257.64UP 221+ 257.64 UP $222+257.64$ UP $223+252.2$ UP $271+252.2$ UP $272+252.2$ UP $273+252.08$ UP $471+$ 252.08 UP $472+252.08$ UP $473+251.83$ UP $294+251.83$ UP $295+251.83$ UP $296+$ 251.21 UP $391+251.21$ UP $392+251.21$ UP $393+251.03 U P 1414+251.03$ UP 1415+ $251.03 \mathrm{UP} 1416+247.96 \mathrm{UP} 177+247.96 \mathrm{UP} 178+247.96 \mathrm{UP} 179+244.66 \mathrm{UP} 1354+$ 244.66 UP 1355+244.66UP1356+241.15UP1494+241.15UP1495+241.15UP1496+ 240.21 UP $1027+240.21$ UP $1028+240.21$ UP $1029+239.88$ UP $187+239.88$ UP $188+$ 239.88 UP 189+237.75UP1374+237.75UP1375+237.75UP1376+231.62UP $447+$ 231.62 UP $448+231.62$ UP $449+230.55 U P 784+230.55 U P 785+230.55 U P 786+$ 228.24 UP $751+228.24$ UP $752+228.24$ UP $753+227.94$ UP $661+227.94$ UP $662+$ 227.94 UP $663+227.79$ UP $561+227.79$ UP $562+227.79$ UP $563+224.73$ UP $1344+$ 224.73 UP $1345+224.73$ UP $1346+224.01$ UP $307+224.01$ UP $308+224.01$ UP $309+$ 223.89 UP $1397+223.89$ UP $1398+223.89$ UP $1399+223.82$ UP $1017+223.82$ UP $1018+$ 223.82 UP $1019+216.6$ UP $454+216.6$ UP $455+216.6$ UP $456+216.17$ UP $907+216.17$ UP 908 +216.17 UP $909+216.08$ UP $467+216.08$ UP $468+216.08$ UP $469+216$ UP $1421+216$ UP 1422 +216 UP $1423+216$ UP $1441+216$ UP $1442+216$ UP $1443+215.79$ UP $987+215.79$ UP $988+$ 215.79 UP $989+214.7$ UP $1087+214.7$ UP $1088+214.7$ UP1089+210.25UP791+ $210.25 U P 792+210.25 U P 793+210.17 U P 814+210.17 U P 815+210.17 U P 816+$ 210.03 UP $244+210.03$ UP $245+210.03$ UP $246+209.67$ UP $841+209.67 U P 842+$ 209.67 UP $843+202.56$ UP $824+202.56$ UP $825+202.56$ UP $826+200.07$ UP $327+$ 200.07 UP $328+200.07$ UP $329+199.84$ UP $657+199.84$ UP $658+199.84$ UP $659+$ 198 .39UP 911+198.39UP 912+198.39UP913+197.83UP891+197.83UP892+ 197.83 UP $893+197.8$ UP 191+197. 8UP 192+197. 8UP193+197.76UP 861+197. 76UP 862+ 197.76 UP $863+196.28 U P 234+196.28 U P 235+196.28 U P 236+191.91 U P 317+$ 191.91 UP $318+191.91$ UP $319+191.82$ UP $707+191.82$ UP $708+191.82$ UP $709+$ 189.15 UP $684+189.15$ UP $685+189.15$ UP $686+183.74$ UP $1047+183.74$ UP $1048+$ 183.74 UP $1049+181.89$ UP $694+181.89$ UP $695+181.89$ UP $696+173.7$ UP $851+173.7$ UP 852 +173.7 UP $853+168.11$ UP 744+168.11UP745+168.11UP746+161.13UP $674+$ 161.13 UP $675+161.13$ UP $676+126.71$ UP $1177+126.71$ UP $1178+126.71$ UP $1179+$ 126.08 UP $804+126.08$ UP $805+126.08$ UP $806+$ VMM $5-$ P2006 $=0$ Prod2007: 372.7 UP $1461+347.59$ UP $491+347.59$ UP $492+347.59$ UP $493+347.57$ UP $501+$ 347.57 UP $502+347.57$ UP $503+346.73$ UP $511+346.73$ UP $512+346.73$ UP $513+$ 346.59 UP $521+346.59$ UP $522+346.59$ UP $523+330.46$ UP $531+330.46$ UP $532+$ 330.46 UP $533+323.55$ UP $101+317.99$ UP $91+316.53$ UP $1187+316.53$ UP $1188+$ 316.53 UP $1189+310.26$ UP $1407+310.26$ UP $1408+310.26 U P 1409+295.52$ UP $117+$ 295.52UP118+295.52UP119+294.96UP1247+294.96UP1248+294.96UP1249+ 294.08 UP $334+294.08$ UP $335+294.08$ UP $336+294.03$ UP $551+289.44$ UP $1031+$ 288.93 UP $437+288.93$ UP $438+288.93$ UP $439+287.77$ UP $1547+287.77$ UP $1548+$ 287.77 UP $1549+284.96$ UP $1537+284.96$ UP $1538+284.96$ UP $1539+282.69$ UP $61+$ 282.69 UP $62+282.69$ UP $63+282.62$ UP $1517+282.62$ UP $1518+282.62$ UP $1519+$ 281.42 UP $71+281.42$ UP $72+281.42$ UP $73+280.18 U P 204+280.18$ UP $205+280.18 U P 206+$ 279.81 UP $297+279.81$ UP $298+279.81$ UP $299+279.61$ UP $224+279.61$ UP $225+$ 279.61 UP $226+276.26$ UP $261+276.26$ UP $262+276.26$ UP $263+275.74$ UP $1311+$ 275.74 UP $1312+275.74$ UP $1313+274.11$ UP $1321+273.28$ UP $144+273.28$ UP $145+$ 273.28 UP $146+273.22$ UP $274+273.22$ UP $275+273.22$ UP $276+273.11$ UP $124+$ 273.11 UP 125+273.11UP126+273UP1564 +273UP1565+273UP 1566+272.04UP $347+$ 272.04 UP $348+272.04$ UP $349+271.93$ UP $1251+271.93$ UP $1252+271.93$ UP $1253+$ 270.25 UP $631+266.09$ UP $474+266.09$ UP $475+266.09$ UP $476+265.17$ UP $394+$ 265.17 UP $395+265.17$ UP $396+263.73$ UP $421+263.73$ UP $422+263.73$ UP $423+$ 262 .98UP $1417+262$. 98UP $1418+262$. 98UP $1419+258.31$ UP $1281+258$. 31 UP $1282+$ 258.31 UP $1283+258.2$ UP $131+258.2$ UP $132+258.2$ UP $133+258$ UP $1431+258$ UP $1432+$ 258UP1433+258UP1451+258UP1452+258UP1453+258UP1571+258UP1572+ 258UP1573+255.64UP1357+255.64UP1358+255.64UP1359+251.97UP1497+ 251.97 UP $1498+251.97$ UP $1499+247.74$ UP $1377+247.74$ UP $1378+247.74$ UP $1379+$ $247.52 \mathrm{UP} 787+247.52 \mathrm{UP} 788+247.52 \mathrm{UP} 789+246.25 \mathrm{UP} 541+246.25 \mathrm{UP} 542+$ 246.25 UP $543+245.25$ UP $754+245.25 U P 755+245.25 U P 756+244.94$ UP $664+$ 244.94 UP $665+244.94$ UP $666+244.77$ UP $564+244.77$ UP 565+244.77UP 566+ 244.69 UP $1051+234$ UP $31+233.74$ UP $1381+232.75$ UP $1347+232.75$ UP $1348+$ 232.75 UP $1349+231.57$ UP $457+231.57$ UP $458+231.57$ UP $459+231.27$ UP $794+$ 231.27 UP $795+231.27$ UP $796+231$ UP $1424+231$ UP $1425+231$ UP $1426+231$ UP $1444+$ 231UP $1445+231$ UP $1446+230.63$ UP $844+230$. 63UP $845+230.63$ UP $846+228$. 21UP $771+$ 228.21 UP $772+228.21$ UP $773+228.07$ UP $731+228.07$ UP $732+228.07$ UP $733+$ 228.03 UP $591+227.76$ UP $711+227.76$ UP $712+227.76$ UP $713+227.59$ UP $761+$ 
227.59 UP $762+227.59$ UP $763+224.18$ UP $817+224.18$ UP $818+224.18$ UP $819+$ 224.03 UP $247+224.03$ UP $248+224.03$ UP $249+223.51$ UP $827+223.51$ UP $828+$ 223.51 UP $829+210.41$ UP $914+210.41$ UP $915+210.41$ UP $916+209.82$ UP $894+$ 209.82UP $895+209.82$ UP $896+209.79$ UP $621+209.79$ UP $194+209.79$ UP $195+$ 209.7 UUP $196+209.74$ UP $864+209.74$ UP $865+209.74$ UP $866+208.3$ UP $237+208.3$ UP 238 $+208.3 U P 239+204.21$ UP $581+200.15 U P 687+200.15$ UP $688+200.15$ UP $689+$ 198.2 UP $971+198.2$ UP $972+198.2$ UP $973+198.17$ UP $921+198.17$ UP $922+198.17$ UP 923 +198.15 UP $951+198.15$ UP $952+198.15$ UP $953+197.97$ UP $961+197.97$ UP $962+$ 197.97 UP $963+197.86$ UP $881+197.86$ UP $882+197.86 U$ UP $883+197.85$ UP $941+$ 197.85 UP $942+197.85$ UP $943+197.82$ UP $931+197.82$ UP $932+197.82$ UP $933+$ 191.89 UP $697+191.89$ UP 698+191.89UP 699+188.67UP $854+188.67$ UP $855+$ 188.67 UP $856+186.21$ UP $81+186.21$ UP $82+186.21$ UP $83+184.12$ UP $747+184.12$ UP $748+$ 184.12 UP $749+176.14$ UP $677+176.14$ UP $678+176.14 \mathrm{UP} 679+162.14 \mathrm{UP} 831+$ 144.09 UP $807+144.09$ UP $808+144.09$ UP $809+$ VMM6 - P2007 $=0$ Prod2008: 400.31 UP $1462+372.7$ UP $1464+370.56$ UP $494+370.56$ UP $495+370.56$ UP $496+$ 370.54 UP $504+370.54$ UP $505+370.54$ UP $506+369.64$ UP $514+369.64$ UP $515+$ 369.64 UP $516+369.4$ 9UP $524+369.49$ UP $525+369.49$ UP $526+350.48 U P 534+$ 350.48 UP $535+350.48$ UP $536+335.99$ UP $92+335.53$ UP $102+330.46 U P 537+324.81 U P 41$ +323.55 UP $104+320.08$ UP $337+320.08$ UP $338+320.08$ UP $339+317.99$ UP $94+$ 309.54 UP $1032+308.03$ UP $552+301.73$ UP $64+301.73$ UP $65+301.73$ UP $66+300.38$ UP $74+$ 300.38 UP $75+300.38$ UP $76+296.19$ UP $207+296.19$ UP $208+296.19$ UP $209+295.5$ 9UP 227 +295.59 UP $228+295.59$ UP 229+294.27UP 264+294.27UP265+294.27UP266+ 294.27 UP $632+294.03$ UP 554+293. 72UP1314+293.72UP1315+293.72UP1316+ 291.99 UP $1322+289.66$ UP $1254+289.66 U P 1255+289.66 U P 1256+289.44$ UP $1034+$ 288 . 3UP $147+288$. 3UP $148+288$. 3UP $149+288.12$ UP $127+288.12$ UP $128+288.12$ UP $129+$ 288UP 1567+288UP 1568+288UP 1569+280.22UP277+280.22UP278+280.22UP279+ 280.09 UP $477+280.09$ UP $478+280.09$ UP $479+279.72$ UP $424+279.72$ UP $425+$ 279.72 UP $426+279.13$ UP $397+279.13$ UP $398+279.13 U P 399+275.74$ UP $1317+$ 274.11 UP $1324+273.33$ UP 1284+273.33UP1285+273. 33UP $1286+273.21$ UP $134+$ 273.21 UP $135+273.21$ UP $136+273$ UP $1434+273$ UP $1435+273$ UP $1436+273$ UP $1454+$ 273UP 1455+273UP 1456+272.98UP 1574+272.98UP 1575+272.98UP $1576+270.25 U P 634$ +270.19 UP $151+270$ UP $1301+264.27$ UP 757+264.27UP758+264.27UP 759+264UP11+ 263.93 UP $667+263.93$ UP $668+263.93$ UP $669+259.26$ UP $544+259.26 U P 545+$ 259.26 UP $546+259$ UP $32+258$ UP $1457+258$ UP $1471+258$ UP $1481+257$. 62 UP $1052+$ 255.76 UP $567+255.76$ UP 568+255.76UP 569+248.27UP $797+248.27 U P 798+$ $248.27 U P 799+247.6 U P 847+247.6 U P 848+247.6 U P 849+245.22$ UP $774+245.22 U P 775+$ 245.22 UP $776+245.08$ UP $734+245.08$ UP $735+245.08 U P 736+244.74$ UP $714+$ 244.74 UP $715+244.74$ UP $716+244.73$ UP $1382+244.69$ UP $1054+244.56$ UP $764+$ 244.56 UP $765+244.56$ UP $766+240.56$ UP $1101+24$ OUP $1427+240$ UP $1428+240$ UP $1429+$ 240 UP $1447+24$ OUP $1448+24$ 0UP $1449+238.03$ UP $592+234.33$ UP $161+234$ UP $34+$ 233.74 UP $1384+233.31$ UP $1061+228.03$ UP $594+224.44$ UP $917+224.44$ UP $918+$ 224.44 UP $919+224.23$ UP $582+223.8 U P 897+223.8 U P 898+223.8 U P 899+223.78 U P 622+$ 223.72 UP $867+223.72$ UP $868+223.72$ UP $869+221.84$ UP 601+216.03UP $1091+$ 215.79 UP $197+215.79$ UP $198+215.79$ UP $199+210.21$ UP $974+210.21$ UP $975+$ 210.21 UP $976+210.18$ UP $924+210.18$ UP $925+210.18$ UP $926+210.16 U P 954+$ 210.16 UP $955+210.16$ UP $956+209.97$ UP $964+209.97 U P 965+209.97$ UP $966+$ 209.85 UP $884+209.85$ UP $885+209.85$ UP $886+209.84$ UP $944+209.84$ UP $945+$ 209.84 UP $946+209.81$ UP $934+209.81$ UP $935+209.81$ UP $936+209.79$ UP $624+$ 207.64 UP $857+207.64$ UP $858+207.64$ UP $859+204.21$ UP $584+204.17$ UP $611+$ 198.12 UP $1001+196.23 U P 84+196.23 U P 85+196.23 U P 86+175.15$ UP $832+169.2$ 9UP 1111 +162.14 UP $834+$ VMM7 - P2008 $=0$ Prod2009: 418.06 UP $1463+400.31$ UP $1465+383.55$ UP $497+383.55$ UP $498+383.55$ UP $499+$ 383.52 UP $507+383.52$ UP $508+383.52$ UP $509+382$. 6UP 517+382. 6UP 518+382. 6UP 519+ 382.44 UP $527+382.44$ UP $528+382.44$ UP $529+372.7$ UP $1467+354.45$ UP $371+354.4$ UP 351 +351.98 UP $93+351.51$ UP $103+350.48$ UP $538+336.84$ UP $42+335.99$ UP $95+335.53$ UP 105 +335.37 UP $361+324.81$ UP $44+323.55$ UP $107+321.6$ UP $1033+320.03$ UP $553+$ 317.99 UP $97+312.76$ UP $67+312$. 76UP $68+312$. 76UP $69+312.29 U P 267+312.29$ UP $268+$ 312.2 9UP $269+312.29$ UP $633+311.36$ UP $77+311$. 36UP 78+311.36UP $79+309.87 U P 1323$ +309.54 UP $1035+308.03$ UP 555+307.39UP1257+307.39UP1258+307.39UP1259+ 294.27 UP $635+294.03$ UP $557+293.72$ UP $1318+291.99$ UP $1325+289.44$ UP $1037+$ 288.35 UP $1287+288.35$ UP $1288+288.35$ UP $1289+288.22$ UP $137+288.22$ UP $138+$ 288.22 UP $139+288$ UP $1437+288$ UP $1438+288$ UP $1439+288$ UP $1577+288$ UP $1578+$ 288UP1579+287 . 71UP 427+287 .71UP 428+287 . 71UP 429+287UP1302+280.2UP152+ 280UP $12+280$ UP $33+275.85$ UP $571+274.11$ UP $1327+273$ UP $1458+273$ UP $1472+$ 273UP $1482+272.27$ UP $547+272.27$ UP $549+272.11$ UP $548+270.55$ UP $1053+270.25$ UP 637 +270.19 UP $154+270$ UP $1304+269.3$ UP $1271+266.8$ UP $1231+264.24$ UP $777+$ 
264.24 UP 778+264.24UP779+264.08UP737+264.08UP738+264.08UP739+264UP14+ $263.99 \mathrm{UP} 1261+263.72 \mathrm{UP} 717+263.72 \mathrm{UP} 718+263.72 \mathrm{UP} 719+263.53 \mathrm{UP} 767+$ 263.53UP 768+263.53UP 769+259UP 35+258UP 1474+258UP1484+258UP 1501+ 258UP 1551+257.62UP1055+255.72UP1383+252 . 59UP1102+252UP21+248 . 03UP 593+ 245.35 UP $162+244.73$ UP $1385+244.69$ UP $1057+244.28$ UP $1062+240.56$ UP $1104+$ 238.03 UP $595+237.83$ UP $602+234.33$ UP $164+234$ UP $37+233.77 U P 211+233.74$ UP $1387+$ 233.31 UP $1064+232.24$ UP 583+231.77UP $623+228.24$ UP $1071+228.03$ UP $597+$ 224.23 UP $585+224.22$ UP $977+224.22$ UP $978+224.22$ UP $979+224.19$ UP $927+$ 224.1 UUP $928+224.19$ UP $929+224.17$ UP $957+224.17$ UP $958+224.17$ UP $959+$ 224.03 UP $1092+223.96$ UP $967+223.96$ UP $968+223.96$ UP $969+223.84$ UP $887+$ 223.84 UP $888+223.84$ UP $889+223.83$ UP $947+223.83$ UP $948+223.83$ UP $949+223.8$ UP 937 +223.8 UP $938+223.8$ UP $939+223.78$ UP $625+221.84$ UP $604+217.18$ UP $612+$ 217.13 UP $1002+216.17$ UP $721+216.03$ UP $1094+210.01$ UP $281+209.79 U P 627+$ 208.24 UP $87+208.24$ UP $88+208.24$ UP $89+204.21$ UP $587+204.17$ UP $614+198.12$ UP 1004 +197.86 UP $251+185.77$ UP $641+184.16$ UP $833+183.4$ UP $1112+175.15$ UP $835+$ 169.29 UP $1114+168$ UP $1291+162.14$ UP $837+144.4$ UP $1191+143.87$ UP $1131+$ 143.07 UP $1121+141.14$ UP $1161+137.12$ UP 1151+118.91UP $1141+96.01$ UP $871+$ VMM 8 $\mathrm{P} 2009=0$

Prod2010:

418.06 UP $1466+400.31$ UP $1468+371.47$ UP $372+371.42$ UP $352+360.5$ UP $539+$ 354.45 UP $374+354.4$ UP $354+351.98$ UP $96+351.51$ UP $106+349.34$ UP $362+344.86$ UP $43+$ 336.84 UP $45+335.99$ UP $98+335.53$ UP $108+335.37$ UP $364+324.81$ UP $47+321.6 U P 1036+$ 320.03 UP $556+312.29$ UP $636+311.71$ UP $1319+309.87$ UP $1326+309.54$ UP $1038+$ 308.03 UP $558+304$ UP $1303+294.27$ UP $638+293.98$ UP $481+291.99$ UP $1328+288.2$ UP 153 +288.07 UP $1459+288$ UP $13+288$ UP $1473+288$ UP $1483+287$ UP $1305+286.84$ UP $572+$ 286.26 UP $1272+282.97$ UP $1232+280.2$ UP $155+280$ UP $15+280$ UP $36+279.99$ UP $1262+$ 275.85 UP $574+273$ UP $1475+273$ UP $1485+273$ UP 1502+273UP1552+270.55UP $1056+$ 270.19 UP $157+270$ UP $1307+269.87$ UP $401+269.3$ UP $1274+266.8$ UP $1234+264.62$ UP 1103 +264 UP $17+263.99$ UP $1264+263.84$ UP $411+263.52$ UP $51+259$ UP $22+259$ UP $38+$ 258UP $1477+258$ UP $1487+258$ UP $1504+258$ UP $1554+257.62$ UP $1058+257.34$ UP $381+$ 256.37 UP $163+255.72$ UP $1386+255.24$ UP $1063+252.59$ UP $1105+252$ UP $24+251.94$ UP 991 +249.09 UP $1221+248.03$ UP $596+247.82$ UP $603+247.18$ UP $1331+245.35$ UP $165+$ 245.26 UP $1072+244.76$ UP $212+244.73$ UP $1388+244.28$ UP $1065+243.41$ UP $1521+$ 240.56 UP $1107+240.03$ UP $1093+238.03$ UP $598+237.83$ UP $605+237.39$ UP $1361+$ 234.33 UP $167+233.77$ UP $214+233.31$ UP $1067+232.24$ UP 586+232.19UP $613+$ 231.77 UP $626+231.18$ UP $722+228.24$ UP $1074+224.23$ UP $588+224.14$ UP $1003+$ 224.03 UP 1095+224.01UP282+223.78UP628+221.97UP171+221.84UP 607+ 217.18 UP $615+217.13$ UP $1005+216.17$ UP $724+216.03$ UP $1097+215.89$ UP $181+$ $215.65 U P 441+210.01$ UP $284+209.85$ UP $252+204.18 U P 1021+204.17 U P 617+$ 204.01 UP $301+202.75$ UP $642+198.12$ UP $1007+197$. 9UP $1391+197.86 U P 254+$ 197.84 UP $1011+193.47$ UP $1113+192.07$ UP $461+190.84$ UP $1081+186.15$ UP $901+$ 185.82 UP $981+185.77$ UP $644+184.16$ UP $836+183.4$ UP $1115+180.06$ UP $321+$ 175.15 UP $838+175$ UP $1292+173.86$ UP $651+169.29$ UP $1117+168$ UP $1294+167.92$ UP $311+$ 167.85 UP $701+161.77$ UP $1041+153.87$ UP $1132+152$.4UP $1122+150.35$ UP $1162+$ 147.4 UP $1192+146.07$ UP $1152+144.4$ UP $1194+143.87$ UP $1134+143.07$ UP $1124+$ 141.14 UP $1164+137.12$ UP $1154+124.12$ UP $1142+118.91$ UP $1144+112.85$ UP $1171+$ 105.01UP872+96.01UP874+VMM9 - P2010 = 0

Prod2011:

$418.06 \mathrm{UP} 1469+384.48 \mathrm{UP} 373+376.42 \mathrm{UP} 353+371.47 \mathrm{UP} 375+371.42 \mathrm{UP} 355+$ 359.32 UP $363+354.45$ UP $377+354.4$ UP $357+351.98$ UP $99+351.51$ UP $109+349.34$ UP 365 +344.86 UP $46+336.84$ UP $48+335.37$ UP $367+321.6 U P 1039+320.03$ UP $559+$ 312.29 UP $639+309.87$ UP $1329+307.98$ UP $482+304$ UP $1306+303.83$ UP $573+$ 302.43 UP $1273+299.14$ UP $1233+295.98$ UP $1263+293.98$ UP $484+288.2$ UP $156+288$ UP 16 + 288UP1476+288UP1486+288UP1503+288UP1553+287UP1308+286.84UP575+ 286.26 UP $1275+282.97$ UP $1235+280.2$ UP $158+280$ UP $18+280$ UP $39+280$ UP $1181+$ 279.99 UP $1265+279.86$ UP $402+279.83 U P 412+279.4$ 9UP $52+275.85$ UP $577+$ 274.46 UP $1401+273$ UP $1478+273$ UP $1488+273$ UP $1505+273$ UP $1555+272$. 3UP $382+$ 272UP $23+270.55$ UP $1059+269.87$ UP $404+269.3$ UP $1277+266.8$ UP $1237+265.94$ UP $992+$ 264.86 UP $431+264.62$ UP $1106+263.99$ UP $1267+263.84$ UP $414+263.52$ UP $54+$ 263.07 UP $1241+262.93$ UP $1222+260.24$ UP $1332+259$ UP $25+258$ UP $1507+258$ UP $1557+$ $257.8 U P 1541+257.34$ UP $384+256.37 U P 166+256.28 U P 1522+256.27 U P 1073+$ 256.19 UP $1362+255.75$ UP $213+255.72$ UP $1389+255.28$ UP $1531+255.24$ UP $1066+$ 253.18 UP $1511+252.59$ UP $1108+252$ UP $27+251.94$ UP $994+249.09$ UP $1224+248.03$ UP 599 +247.82 UP $606+247.18$ UP $1334+245.35$ UP $168+245.26 U P 1075+244.76$ UP $215+$ 244.28 UP $1068+243.41$ UP $1524+240.18$ UP $723+240.03$ UP 1096+240.01UP2 $83+$ 239.61 UP $111+237.96$ UP $172+237.83$ UP $608+237.39$ UP $1364+234.04$ UP $341+$ 233.77 UP $217+233.1$ UP $1411+232.24$ UP $589+232.19$ UP $616+231.77$ UP $629+$ 231.18 UP $725+230.88$ UP $182+230.32$ UP $1491+228.24$ UP $1077+227.85$ UP $291+$ 
227.76 UP $1371+227.68$ UP $1351+224.19$ UP $1022+224.14$ UP $1006+224.03$ UP $1098+$ 224.01 UP $285+223.84$ UP $253+223.73$ UP $643+223.64$ UP $442+221.97$ UP $174+$ 217.18 UP $618+217.13$ UP $1008+217.01$ UP $302+216.17$ UP $727+215.89$ UP $184+$ 215.65 UP $444+210.68$ UP $1341+210.01$ UP $287+209$. 9UP $1392+209.85$ UP $255+$ 209.83 UP $1012+209.59$ UP $781+204.18$ UP $1024+204.01$ UP $304+203.62$ UP $451+$ 203.16UP $902+203.07$ UP $462+202.81$ UP $982+202.75$ UP $645+201.78$ UP $1082+$ 198.03 UP $241+197.9$ UP $1394+197.86 U P 257+197.84$ UP $1014+193.47 U P 1116+$ 192.07 UP $464+190.84$ UP $1084+189.06$ UP $322+188.85$ UP $652+186.27$ UP $231+$

186.15 UP $811+186.15$ UP $904+185.82$ UP $984+185.77$ UP $647+185.6$ UP $821+184.16$ UP 839 +184 UP $1293+183.4$ UP $1118+181.92$ UP $312+181.83$ UP $702+180.06$ UP $324+175$ UP 1295 +174.75 UP $1042+173.86$ UP $654+168.13$ UP $681+168$ UP $1297+167.92$ UP $314+$ 167.85 UP $704+161.91$ UP $691+161.77$ UP $1044+160.44$ UP $1193+159.86$ UP $1133+$ 157.58 UP $1123+156.1$ UP $741+155.46$ UP $1163+153.87$ UP $1135+152.4$ UP $1125+$ 151.03 UP 1153+150.35UP1165+147.4UP1195+146.07UP1155+144.4UP1197+ 144.12 UP $671+143.87$ UP $1137+143.07$ UP $1127+141.14$ UP $1167+137.12$ UP $1157+$ 125.17 UP $1143+124.12$ UP $1145+118.91$ UP $1147+117.8$ UP $1172+114.07$ UP $801+$ 112.85UP1174+112.01UP873+105.01UP875+96.01UP877+VMM10 $-\mathrm{P} 2011=0$ Prod2012:

384.48 UP $376+376.42$ UP $356+371.47$ UP $378+371.42$ UP $358+359.32$ UP $366+$ 349.34 UP $368+344.86$ UP $49+311.98$ UP $483+307.98$ UP $485+304$ UP $1309+303.83$ UP $576+$ 302.43 UP $1276+299.14$ UP $1236+298.27 U P 1182+295.98$ UP $1266+293.98$ UP $487+$ 292.36 UP $1402+288.2$ UP 159+288UP 19+288UP 14 79+288UP1489+288UP 1506+ 288UP 1556+287. 93UP 993+287.86UP 403+287. 82UP 413+287. 48UP 53+286.84UP 578+ 286.26 UP $1278+282.97$ UP $1238+280.91$ UP $432+280$ UP $1184+279.99$ UP $1268+$ 279.86 UP $405+279.83$ UP $415+279.49$ UP $55+279.29$ UP $383+279.01 U P 1242+$ 276.76 UP $1223+274.46$ UP $1404+273.3$ UP $1333+273$ UP $1508+273$ UP $1558+272.78$ UP 1542 +272.3 UP $385+272$ UP $26+270.07$ UP $331+269.95$ UP $1532+269.87$ UP $407+269.14$ UP 1523 +269.05 UP $1363+267.9$ UP $1512+265.94$ UP $995+265.57$ UP $112+264.86$ UP $434+$ 264.62 UP $1109+263.84$ UP $417+263.52$ UP $57+263.07$ UP $1244+262.93$ UP $1225+$ 260.24 UP $1335+259.04$ UP $342+259$ UP $28+258.27$ UP $141+258.16$ UP $201+258.1$ UP $121+$ 258UP $1561+257.8$ UP $1544+257.64$ UP $221+257.34$ UP $387+256.37$ UP $169+256.28$ UP 1525 +256.27 UP $1076+256.19$ UP 1365+255.75UP216+255.28UP1534+255.24UP1069+ 253.18 UP $1514+252.2$ UP $271+252.08$ UP $471+251.94$ UP $997+251.83$ UP $292+$ 251.21 UP $391+251.03$ UP $1412+249.09$ UP $1227+247.96$ UP $173+247.82$ UP $609+$ $247.18 \mathrm{UP} 1337+245.26 \mathrm{UP} 1078+244.76 \mathrm{UP} 218+244.66 \mathrm{UP} 1352+243.41 \mathrm{UP} 1527+$ 241.15 UP $1492+240.21$ UP $1023+240.18$ UP $726+240.03$ UP $1099+240.01$ UP $286+$ $239.88 \mathrm{UP} 183+239.61 \mathrm{UP} 114+237.96 \mathrm{UP} 175+237.75 \mathrm{UP} 1372+237.39 \mathrm{UP} 1367+$ 234.04 UP $344+233.1$ UP $1414+232.19$ UP $619+231.62$ UP $443+231.18 U P 728+$ 230.88 UP $185+230.55$ UP $782+230.32$ UP $1494+228.24$ UP $751+227.94$ UP $661+$ 227.85 UP $294+227.79$ UP $561+227.76 U P 1374+227.68$ UP $1354+224.73$ UP $1342+$ 224.1 UUP $1025+224.14$ UP $1009+224.01$ UP $288+224.01$ UP $303+223.89$ UP $1393+$ 223.84 UP $256+223.82$ UP $1013+223.73$ UP $646+223.64$ UP $445+221.97$ UP $177+$ 217.01 UP $305+216.6$ UP $452+216.17$ UP $903+216.08 U P 463+216 U P 1421+216$ UP $1441+$ 215.89 UP $187+215.79$ UP $983+215.65$ UP $447+214.7$ UP $1083+210.68$ UP $1344+$ 210.25 UP $791+210.17$ UP $812+210.03$ UP $242+209.9$ UP $1395+209.85$ UP $258+$ 209.83 UP $1015+209.67$ UP $841+209.59$ UP $784+204.18$ UP $1027+204.01$ UP $307+$ 203.62 UP $454+203.16$ UP $905+203.07$ UP $465+202.81$ UP $985+202.75$ UP $648+$ 202.56 UP $822+201.78$ UP $1085+200.07$ UP $323+199.84$ UP $653+198.39$ UP $911+$ 198.03 UP $244+197.9$ UP $1397+197.84$ UP $1017+197.83 U P 891+197.8 U P 191+$ 197.76 UP $861+196.28$ UP $232+193.47$ UP $1119+192.07 U P 467+191.91 U P 313+$ 191.82 UP $703+190.84$ UP $1087+189.15$ UP $682+189.06$ UP $325+188.85$ UP $655+$ 186.27 UP $234+186.15$ UP $814+186.15$ UP $907+185.82$ UP $987+185.6$ UP $824+184$ UP $1296+$ 183.74 UP $1043+181.92$ UP $315+181.89$ UP $692+181.83$ UP $705+180.06$ UP $327+175$ UP 1298 +174.75 UP $1045+173.86$ UP $657+173.7$ UP $851+168.13$ UP $684+168.11$ UP $742+$ 167.92 UP $317+167.85$ UP $707+161.91$ UP $694+161.77$ UP $1047+161.13$ UP $672+$ 160.44 UP $1196+159.86$ UP $1136+157.58$ UP $1126+156.1$ UP $744+155.46$ UP $1166+$ 153.87 UP $1138+152.4$ UP $1128+151.03$ UP $1156+150.35$ UP $1168+147.4$ UP $1198+$ 146.07 UP $1158+144.12$ UP $674+126.71$ UP $1173+126.08$ UP $802+125.17 U P 1146+$ $124.12 \mathrm{UP} 1148+117.8 \mathrm{UP} 1175+114.07 \mathrm{UP} 804+112.85 \mathrm{UP} 1177+112.01 \mathrm{UP} 876+$ 105.01UP878+VMM11 - P2012 = 0 Prod2013: $384.48 \mathrm{UP} 379+376.42 \mathrm{UP} 359+372.7 \mathrm{UP} 1461+359.32 \mathrm{UP} 369+347.59 \mathrm{UP} 491+$ 347.57 UP $501+346.73$ UP $511+346.59$ UP $521+330.46$ UP $531+323.55$ UP $101+317.99$ UP 91 +316.53 UP $1183+311.98$ UP $486+310.26$ UP $1403+307.98 U P 488+303.83$ UP $579+$ 302.43 UP $1279+299.14$ UP $1239+298.27$ UP $1185+295.98$ UP $1269+295.52$ UP $113+$ 294.96 UP $1243+294.08 U P 332+294.03 U P 551+292.36 U P 1405+289.44$ UP $1031+$ 288.93 UP $433+288$ UP $1509+288$ UP $1559+287$. 93UP 996+287. 86 UP $406+287$. 82UP $416+$ 287.77 UP $1543+287.48$ UP 56+284 . 96UP 1533+282 . 69UP 61+282 . 62UP1513+ 
281.42 UP $71+280.91$ UP $435+280.18 U P 202+280$ UP $1187+279.86$ UP $408+279.83$ UP $418+$ $279.81 U P 293+279.61$ UP $222+279.49 U P 58+279.29 U P 386+279.01 U P 1245+$ 276.76 UP $1226+276.26 U P 261+275.74 U P 1311+274.46 U P 1407+274.11 U P 1321+$ 273. 3UP 1336+273.28UP142+273.22UP 272+273.11UP122+273UP 1562+272.78UP 1545 +272.3 UP $388+272.04$ UP $343+272$ UP $29+271.93$ UP $1251+270.25$ UP $631+270.07 U P 334$ +269.95 UP $1535+269.14$ UP 1526+269.05UP1366+267.9UP $1515+266.09$ UP $472+$ 265.94 UP $998+265.57$ UP $115+265.17$ UP $392+264.86 U P 437+263.73 U P 421+$ 263.07 UP $1247+262.98$ UP $1413+262.93$ UP $1228+260.24$ UP $1338+259.04$ UP $345+$ 258.31 UP $1281+258.27$ UP $144+258.2$ UP $131+258$. 16UP $204+258.1$ UP $124+258$ UP $1431+$ 258UP1451+258UP 1564+258UP1571+257.8UP 1547+257.64UP 224+256.28UP1528+ 256.27 UP $1079+256.19$ UP $1368+255.75 U P 219+255.64$ UP $1353+255.28$ UP $1537+$ 253.18UP1517+252.2UP2 74+252.08UP 4 74+251.97UP1493+251.83UP295+ 251.21 UP $394+251.03$ UP $1415+247.96$ UP $176+247.74$ UP $1373+247.52$ UP $783+$ $246.25 U P 541+245.25$ UP $752+244.94$ UP $662+244.77 U P 562+244.69 U P 1051+$ 244.66 UP 1355+241.15UP1495+240.21UP1026+240.18UP 729+240.01UP289+ 239.88 UP $186+239.61$ UP $117+237.96$ UP $178+237.75$ UP $1375+234.04$ UP $347+234$ UP $31+$ 233.74 UP $1381+233.1$ UP $1417+232.75$ UP $1343+231.62$ UP $446+231.57$ UP $453+$ 231.27 UP $792+231$ UP $1422+231$ UP $1442+230.88$ UP $188+230.63$ UP $842+230.55$ UP $785+$ 230.32 UP $1497+228.24$ UP $754+228.21$ UP $771+228.07 U P 731+228.03 U P 591+$ 227.94 UP $664+227.85$ UP $297+227.79$ UP $564+227.76$ UP $1377+227.76$ UP $711+$ 227.68 UP $1357+227.59$ UP $761+224.73 U P 1345+224.19$ UP 1028+224.18UP $813+$ 224.03 UP $243+224.01$ UP $306+223.89$ UP $1396+223.84$ UP $259+223.82$ UP $1016+$ 223.73 UP $649+223.64$ UP $448+223.51$ UP $823+217.01$ UP $308+216.6$ UP $455+216.17$ UP 906 +216.08 UP $466+216$ UP $1424+216$ UP $1444+215.79$ UP $986+214.7$ UP $1086+210.68$ UP 1347 +210.41 UP $912+210.25$ UP $794+210.17$ UP $815+210.03$ UP $245+209.9$ UP $1398+$ 209.83 UP $1018+209.82$ UP $892+209.79$ UP $621+209.79$ UP $192+209.74$ UP $862+$ 209.67 UP $844+209.59$ UP $787+208.3$ UP $233+204.21$ UP $581+203.62$ UP $457+203.16$ UP 908 +203.07 UP $468+202.81$ UP $988+202.56$ UP $825+201.78$ UP $1088+200.15$ UP $683+$ 200.07 UP $326+199.84$ UP $656+198.39$ UP $914+198.2$ UP $971+198.17$ UP $921+198.15$ UP 951 +198.03 UP $247+197.97$ UP $961+197.86$ UP $881+197.85$ UP $941+197.83 U P 894+$ 197.82 UP $931+197.8$ UP $194+197.76$ UP $864+196.28$ UP $235+191.91$ UP $316+191.89$ UP 693 +191.82 UP $706+189.15$ UP $685+189.06$ UP $328+188.85$ UP $658+188.67 U P 852+$ 186.27 UP $237+186.21$ UP $81+186.15$ UP $817+185.6 U P 827+184.12$ UP $743+184$ UP $1299+$ 183.74 UP $1046+181.92$ UP $318+181.89$ UP $695+181.83$ UP $708+176.14$ UP $673+$ 174.75 UP $1048+173.7$ UP $854+168.13$ UP $687+168.11$ UP $745+162.14$ UP $831+$ 161.91 UP $697+161.13$ UP $675+160.44$ UP1199+159.86UP1139+157.58UP1129+ 156.1UP $747+155.46$ UP $1169+151.03$ UP $1159+144.12$ UP $677+144.09$ UP $803+$ 126.71 UP $1176+126.08$ UP $805+125.17$ UP $1149+117.8$ UP $1178+114.07$ UP $807+$ $112.01 \mathrm{UP} 879+\mathrm{VMM} 12-\mathrm{P} 2013=0$ Prod2014: 372.7 UP $1462+370.56$ UP $492+370.54$ UP $502+369.64$ UP $512+369.49$ UP $522+$ 350.48 UP $532+347.59$ UP $494+347.57$ UP $504+346.73$ UP $514+346.59$ UP $524+$ 330.46 UP $534+324.81$ UP $41+323.55$ UP $102+320.08$ UP $333+317.99$ UP $92+316.53$ UP 1186 +311.98 UP $489+310.26$ UP $1406+301.73$ UP $62+300.38$ UP $72+298.27$ UP $1188+$ 296.19 UP $203+295.59$ UP $223+295.52$ UP $116+294.96$ UP $1246+294.27$ UP $262+$ 294.08 UP $335+294.03$ UP 552+293.72UP1312+292.36UP1408+289.66UP 1252+ 289.44 UP $1032+288.93$ UP $436+288$. 3UP $143+288$. 12 UP $123+288$ UP $1563+287$. 93 UP 999 +287.86 UP $409+287.82$ UP $419+287.77$ UP $1546+287.48$ UP $59+284.96$ UP $1536+$ 282.69 UP $64+282.62$ UP $1516+281.42$ UP $74+280.91$ UP $438+280.22$ UP $273+280.18$ UP 205 +280.09 UP $473+279.81$ UP $296+279.72$ UP $422+279.61$ UP $225+279.29$ UP $389+$ 279.13 UP $393+279.01$ UP $1248+276.76$ UP $1229+276.26$ UP $264+275.74$ UP $1314+$ 274.11 UP1322+273.33UP1282+273.3UP1339+273.28UP145+273.22UP $275+$ 273.21 UP 132+273.11UP125+273UP1432+273UP1452+273UP 1565+272.98UP1572+ 272.78 UP $1548+272.04$ UP $346+271.93$ UP $1254+270.25$ UP $632+270.19$ UP $151+$ 270.07 UP $337+270$ UP $1301+269.95$ UP $1538+269.14$ UP $1529+269.05$ UP $1369+$ 267.9 UP $1518+266.09$ UP $475+265.57$ UP $118+265.17$ UP $395+264.27$ UP $753+264$ UP $11+$ 263.93 UP $663+263.73$ UP $424+262.98 U P 1416+259.26 U P 542+259.04 U P 348+$ 258.31 UP $1284+258.27$ UP $147+258$. 2UP134+258.16UP207+258.1UP127+258UP1434+ 258UP1454+258UP1471+258UP1481+258UP1567+258UP1574+257.64UP 227+ 255.76 UP $563+255.64$ UP $1356+252.2$ UP $277+252.08$ UP $477+251.97$ UP $1496+$ 251.83UP 298+251.21UP 397+251.03UP1418+248.27UP 793+247.96UP179+ 247.74 UP $1376+247.6$ UP $843+247.52$ UP $786+246.25$ UP $544+245.25$ UP $755+$ 245.22 UP $772+245.08$ UP $732+244.94$ UP $665+244.77$ UP $565+244.74$ UP $712+$ 244.69 UP $1052+244.66$ UP $1358+244.56$ UP $762+241.15$ UP $1498+240.56$ UP $1101+$ 240.21 UP $1029+240$ UP $1423+240$ UP $1443+239.88$ UP $189+237.75$ UP $1378+234.33$ UP 161 +234 UP $32+233.74$ UP $1382+233.31$ UP $1061+232.75$ UP $1346+231.62$ UP $449+$ 231.57 UP $456+231.27$ UP $795+231$ UP $1425+231$ UP $1445+230.63$ UP $845+230.55$ UP $788+$ 228.24 UP $757+228.21$ UP $774+228.07$ UP $734+228.03$ UP $592+227.94$ UP $667+$ 
227.79 UP $567+227.76$ UP $714+227.59$ UP $764+224.73$ UP $1348+224.44$ UP $913+$ 224.18 UP $816+224.03$ UP $246+224.01$ UP $309+223.89$ UP $1399+223.82$ UP $1019+$ 223. 8UP $893+223.72$ UP $863+223.51$ UP $826+221.84$ UP $601+216.6$ UP $458+216.17$ UP 909 +216.08 UP $469+216.03$ UP 10 91+216UP1 $427+216$ UP $1447+215.79$ UP 989+215.79UP 193 +214.7 UP 1089+210.41UP 915+210.25UP 797+210.21UP 972+210.18UP 922+ 210.17 UP $818+210.16$ UP $952+210.03$ UP $248+209.97$ UP $962+209.85$ UP $882+$ 209.84 UP $942+209.82$ UP $895+209.81$ UP $932+209.79$ UP $622+209.79$ UP $195+$ 209.74 UP $865+209.67$ UP $847+208.3$ UP $236+207.64$ UP $853+204.21$ UP $582+204.17$ UP 611 +202.56 UP $828+200.15$ UP $686+200.07$ UP $329+199.84$ UP $659+198.39$ UP $917+$ 198.2UP 974+198.17UP 924+198.15UP954+198.12UP1001+197.97UP 964+

197.86 UP 884+197.85UP 944+197.83UP 897+197.82UP 934+197.8UP 197+197. 76UP 867 +196.28 UP $238+196.23 U P 82+191.91$ UP 319+191.89UP 696+191.82UP 709+ 189.15 UP $688+188.67$ UP $855+186.21$ UP $84+184.12$ UP $746+183.74$ UP $1049+$ 181.89 UP $698+176.14$ UP $676+173.7$ UP $857+169.29$ UP $1111+168.11$ UP $748+$ 162.14UP $832+161.13$ UP $678+144.09$ UP $806+126.71$ UP 1179+126.08UP 808+VMM13 $\mathrm{P} 2014=0$ Prod2015: 400.31 UP $1464+383.55$ UP $493+383.52$ UP $503+382.6$ UP $513+382.44$ UP $523+$ 372.7 UP $1463+370.56$ UP $495+370.54$ UP $505+369.64$ UP $515+369.49$ UP $525+360.5$ UP 533 +354.45 UP $371+354.4$ UP $351+350.48$ UP $535+347.59$ UP $497+347.57$ UP $507+$ 346.73 UP $517+346.59$ UP $527+335.99$ UP $94+335.53$ UP $104+335.37$ UP $361+324.81$ UP 42 +323.55 UP $103+320.08$ UP $336+317.99$ UP $93+316.53$ UP $1189+312.76$ UP $63+$ $312.29 U P 263+311.71$ UP $1313+311.36 U P 73+310.26 U P 1409+309.54 U P 1034+$ 308.03 UP $554+307.39$ UP $1253+301.73$ UP $65+300.38$ UP $75+296.19$ UP $206+295.59$ UP 226 +295.52 UP $119+294.96$ UP $1249+294.27$ UP $265+294.27$ UP $634+294.08$ UP $338+$ $294.03 U P 553+293.72$ UP $1315+291.99$ UP $1324+289.66$ UP $1255+289.44$ UP $1033+$ 288.93 UP $439+288.35$ UP $1283+288.3$ UP $146+288.22$ UP $133+288.12$ UP $126+$ 288.07 UP 1 453+288UP1433+288UP 1566+288UP 1573+287 . 77UP1549+287 . 71UP 423+ $284.96 \mathrm{UP} 1539+282.69 \mathrm{UP} 67+282.62 \mathrm{UP} 1519+281.42 \mathrm{UP} 77+280.22 \mathrm{UP} 276+$ 280.18 UP $208+280.09$ UP $476+279.81$ UP $299+279.72$ UP $425+279.61$ UP $228+$ 279.13 UP $396+276.26$ UP $267+275.85$ UP $571+274.11$ UP $1323+273.33$ UP $1285+$ 273.28UP 148+273.22UP 278+273.21UP135+273.11UP128+273UP 1435+273UP 1455+ 273UP $1568+272.98$ UP $1575+272.27$ UP $543+272.04$ UP $349+271.93$ UP $1257+$ 270.25 UP $633+270.19$ UP $152+270$ UP $1302+269.3$ UP $1271+266.8$ UP $1231+266.0$ 9UP 478 +265.17 UP $398+264.27$ UP $756+264.24$ UP $773+264.08$ UP $733+264$ UP $12+263.99$ UP 1261 +263.93 UP $666+263.73$ UP $427+263.72$ UP $713+263.53$ UP $763+262.98$ UP $1419+$ 259.26 UP $545+25$ 9UP $34+258$. 31UP $1287+258$. 2UP $137+258$ UP $1437+258$ UP $1472+$ 258 UP $1482+258$ UP $1501+258$ UP $1551+258$ UP $1577+257.62$ UP $1054+255.76 U P 566+$ 255.64 UP $1359+252$ UP $21+251.97$ UP $1499+248.27$ UP $796+247.74$ UP $1379+247.6$ UP 846 +247.52 UP $789+246.25$ UP $547+245.25$ UP $758+245.22$ UP $775+245.08 U P 735+$ 244.94 UP $668+244.77$ UP $568+244.74$ UP $715+244.73$ UP $1384+244.69$ UP $1053+$ 244.56 UP $765+240.56$ UP $1102+24$ 0UP $1426+24$ 0UP $1446+238$. 03 UP $594+234$. 33UP $162+$ 234 UP $33+233.77$ UP $211+233.74$ UP $1383+233.31$ UP $1062+232.75$ UP $1349+231.57$ UP 459 +231.27 UP $798+231$ UP $1428+231$ UP $1448+230.63$ UP $848+228.24$ UP $1071+228.21$ UP 777 +228.07 UP $737+228.03$ UP 593+227.76UP 717+227.59UP 767+224.44UP916+ 224.23 UP $584+224.22$ UP $973+224.19$ UP $923+224.18$ UP $819+224.17$ UP $953+$ 224.03 UP $249+223.96$ UP $963+223.84$ UP $883+223.83$ UP $943+223.8 U P 896+223.8$ UP 933 +223.78 UP $624+223.72$ UP $866+223.51$ UP $829+221.84$ UP $602+216.17$ UP $721+$ $216.03 U P 1092+215.79 U P 196+210.41$ UP $918+210.21$ UP $975+210.18 U P 925+$ 210.16 UP $955+210.01$ UP $281+209.97$ UP $965+209.85$ UP $885+209.84$ UP $945+$ 209.82UP $898+209.81$ UP $935+209.79 U P 623+209.79 U P 198+209.74$ UP $868+208.3$ UP 239 +208.24 UP $83+207.64$ UP $856+204.21$ UP $583+204.17$ UP $612+200.15$ UP $689+$ 198.2UP 977+198.17UP 927+198.15UP 957+198.12UP1002+197.97UP 967+ 197.86 UP $887+197.86$ UP 251+197.85UP 947+197.82UP 937+196.23UP 85+191.89UP 699 +188.67 UP $858+186.21$ UP $87+185.77$ UP $641+184.12$ UP $749+176.14$ UP $679+$ 175.15 UP $834+169.29$ UP $1112+168$ UP $1291+162.14$ UP $833+144.4$ UP $1191+144.09$ UP 809 +143.87 UP $1131+143.07$ UP $1121+141.14$ UP $1161+137.12$ UP $1151+118.91$ UP $1141+$ 96.01UP871+VMM14 - P2015 = 0 Prod2016: 400.31 UP $1465+383.55$ UP $496+383.52$ UP $506+382.6 U P 516+382.44$ UP $526+$ 370.56 UP $498+370.54$ UP $508+369.64$ UP $518+369.4$ 9UP $528+360.5$ UP $536+360.5$ UP 537 +354.45 UP $372+354.4$ UP $352+336.84$ UP $44+335.99$ UP $95+335.53$ UP $105+335.37$ UP 362 +324.81 UP $43+320.08$ UP $339+312.76$ UP $66+312.29$ UP $266+311.71$ UP $1316+$ 311.71 UP $1317+311.36$ UP $76+309.54$ UP $1035+308.03$ UP $555+307.39$ UP $1256+$ 301.73 UP $68+300.38$ UP $78+296.19$ UP $209+295.59$ UP $229+294.27$ UP $268+294.27$ UP 635 +293.98 UP $481+291.99$ UP $1325+289.66$ UP $1258+288.35$ UP $1286+288.3$ UP $149+$ 288.22 UP $136+288.12$ UP $129+288.07$ UP $1456+288.07$ UP $1457+288$ UP $1436+288$ UP 1569 +288 UP $1576+287.71$ UP $426+287$ UP $1304+280.22$ UP $279+280.2$ UP $154+280.09$ UP $479+$ 
280UP 14+279.72UP 428+279.13UP399+275.85UP 572+273.33UP1288+273.21UP138+ 273 UP $1438+273$ UP $1474+273$ UP $1484+272.98$ UP $1578+272.27$ UP $546+270.19$ UP $153+$ $270 U P 1303+269.87$ UP $401+269.3$ UP $1272+266.8$ UP $1232+264.27$ UP $759+264.24$ UP 776

+264.08 UP $736+264$ UP $13+263.99$ UP $1262+263.93$ UP 669+263.84UP 411+263.72UP 716 +263.53 UP $766+263.52$ UP $51+259.26$ UP $548+25$ 9UP $35+258$ UP $1473+258$ UP $1483+$ 258UP $1502+258$ UP $1552+257.62$ UP $1055+257.34$ UP $381+255.76$ UP $569+252.59$ UP 1104 +252 UP $22+251.94$ UP $991+249.09$ UP $1221+248.27$ UP $799+247.6$ UP $849+247.18 U P 1331$ +245.35 UP $164+245.22$ UP $778+245.08$ UP $738+244.74$ UP $718+244.73$ UP $1385+$

244.56 UP $768+244.28$ UP $1064+243.41$ UP $1521+240.56$ UP $1103+240$ UP $1429+240$ UP 1449 +238.03 UP $595+237.83$ UP $604+237.39$ UP $1361+234.33$ UP $163+233.77$ UP $212+$ 233.31 UP $1063+228.24$ UP 1072+224. 44UP 919+224.23UP 585+224.22UP 976+ 224.19 UP $926+224.17$ UP $956+224.03$ UP $1094+223.96$ UP $966+223.84$ UP $886+$ 223. 83UP $946+223.8$ UP $899+223.8 U P 936+223.78 U P 625+223.72$ UP $869+221.97 U P 171$ +221.84 UP $603+217.18$ UP $614+217.13$ UP $1004+216.17$ UP $722+216.03$ UP $1093+$ 215.89 UP $181+215.79 U P 199+215.65 U P 441+210.21 U P 978+210.18 U P 928+$ 210.16 UP $958+210.01$ UP $282+209.97$ UP $968+209.85$ UP $888+209.84$ UP $948+$ 209.81UP 938+208.24UP 86+207.64UP 859+204.18UP1021+204.17UP 613+ 204.01 UP $301+198.12$ UP $1003+197.9$ UP $1391+197.86$ UP $252+197.84$ UP $1011+$ 196.23 UP $88+192.07$ UP $461+190.84$ UP $1081+186.15$ UP $901+185.82$ UP $981+$ 185.77 UP $642+183.4$ UP $1114+180.06$ UP $321+175.15$ UP $835+173.86$ UP $651+$ 169.29 UP $1113+168$ UP $1292+167.92$ UP $311+167.85$ UP $701+161.77$ UP $1041+$ 144.4 UP $1192+143.87$ UP 1132+143.07UP1122+141.14UP1162+137.12UP1152+ 118.91UP1142+112.85UP1171+96.01UP872+VMM15 - P2016 = 0 Prod2017: 418.06 UP $1467+400.31$ UP $1466+383.55$ UP $499+383.52$ UP $509+382.6$ UP $519+$ 382.44 UP $529+371.47$ UP $374+371.42$ UP $354+360.5$ UP $538+354.45$ UP $373+354.4$ UP 353 +351.98 UP $97+351.51$ UP $107+349.34$ UP $364+336.84$ UP $45+335.99$ UP $96+335.53$ UP 106 +335.37 UP $363+321.6$ UP $1037+320.03$ UP $557+312.76$ UP $69+312.29 U P 269+$ 312.29 UP $637+311.71$ UP $1318+311.36$ UP $79+309.87 U P 1327+309.54 U P 1036+$ 308.03 UP $556+307.39$ UP 1259+294.27UP $636+293.98$ UP $482+291.99$ UP $1326+$ 288.35 UP $1289+288.22$ UP 139+288.07UP 1458+288UP 1439+288UP $1579+287.71$ UP 429 +287 UP $1305+286.84$ UP $574+286.26$ UP $1274+282.97$ UP $1234+280.2$ UP 155+280UP 15+ 280UP $37+280$ UP $1181+279.99$ UP $1264+275.85$ UP $573+274.46$ UP $1401+273$ UP $1475+$ 273 UP $1485+273$ UP $1504+273$ UP $1554+272.27$ UP $549+270.55$ UP $1057+269.87$ UP $402+$ 269.3 UP $1273+266.8$ UP $1233+264.86 U P 431+264.24 U P 779+264.08 U P 739+$ 263.99 UP $1263+263.84$ UP $412+263.72$ UP $719+263.53$ UP $769+263.52$ UP $52+$ 263.07 UP $1241+25$ 9UP $24+25$ 9UP $36+258$ UP $1503+258$ UP $1553+257.8$ UP $1541+$ 257.62 UP $1056+257.34$ UP $382+255.72$ UP $1387+255.28$ UP $1531+253.18$ UP $1511+$ 252.59 UP $1105+252$ UP $23+251.94$ UP $992+249.09$ UP $1222+248.03$ UP $597+247.18$ UP 1332 +245.35 UP $165+245.26$ UP 1074+244.76UP214+244.73UP1386+244.28UP1065+ 243.41 UP $1522+239.61$ UP $111+238.03$ UP $596+237.83$ UP $605+237.39$ UP $1362+$ 234.04 UP $341+233.77$ UP $213+233.1$ UP $1411+232.24$ UP $587+231.77$ UP $627+$ 231.18 UP $724+230.32$ UP $1491+228.24$ UP $1073+227.85$ UP $291+227.76 U P 1371+$ 227.68 UP $1351+224.23$ UP 586+224.22UP 979+224.19UP 929+224.17UP 959+ 224.03 UP $1095+224.01$ UP $284+223.96$ UP $969+223.84$ UP $889+223.83$ UP $949+$ 223. 8UP 939+223.78UP $626+221.97$ UP $172+217.18$ UP $615+217.13$ UP $1005+$ 216.17 UP $723+215.89$ UP $182+215.65$ UP $442+210.68$ UP $1341+210.01$ UP $283+$ 209.85 UP $254+209.59$ UP $781+208.24$ UP $89+204.18$ UP $1022+204.01$ UP $302+$ 203.62 UP $451+202.75$ UP $644+198.03$ UP $241+197.9$ UP $1392+197.86$ UP $253+$ 197.84 UP $1012+192.07$ UP $462+190.84$ UP $1082+186.27$ UP $231+186.15$ UP $811+$ 186.15 UP $902+185.82$ UP $982+185.77$ UP $643+185.6$ UP $821+184.16$ UP $837+183.4$ UP 1115 +180.06 UP $322+175.15$ UP $836+175$ UP $1294+173.86$ UP $652+168.13$ UP $681+168$ UP 1293 +167.92 UP $312+167.85$ UP $702+161.91$ UP $691+161.77$ UP $1042+156.1$ UP $741+$ 153.87 UP $1134+152.4$ UP1 $124+150.35$ UP $1164+147.4$ UP 1194+146.07UP1154+ 144.4 UP 1193+144.12UP 671+143.87UP1133+143.07UP1123+141.14UP1163+ 137.12 UP $1153+124.12$ UP $1144+118.91$ UP $1143+114.07$ UP $801+112.85$ UP $1172+$ 105.01 UP $874+96.01$ UP $873+$ VMM1 $6-$ P2017 = 0 Prod2018: 418.06 UP $1468+371.47$ UP $375+371.42$ UP $355+360.5$ UP 539+351.98UP 98+351.51UP 108 +349.34 UP $365+344.86$ UP $47+336.84$ UP $46+321.6$ UP $1038+320.03$ UP $558+$ 312.29 UP $638+311.71$ UP1319+309.87UP1328+307.98UP 484+304UP1307+ 293.98 UP $483+288.2$ UP $157+288$. 07UP $1459+288$ UP $17+288$ UP $1477+288$ UP $1487+$ 287UP1306+286. 84 UP $575+286.26$ UP $1275+282.97$ UP $1235+280.2$ UP $156+280$ UP $16+$ 280UP $38+280$ UP $1182+279.99$ UP $1265+279.86$ UP $404+279.83$ UP $414+279.4$ 9UP $54+$ 274.46 UP $1402+273$ UP $1476+273$ UP $1486+273$ UP $1505+273$ UP $1555+272$. 3UP $384+$ 270.55 UP $1058+270.07$ UP $331+269.87$ UP $403+265.94$ UP $994+264.86$ UP $432+$ 264.62 UP $1107+263.84$ UP $413+263.52$ UP $53+263.07$ UP $1242+262.93$ UP $1224+$ 
257. 8UP 1542+257.64UP221+257.34UP 383+256.37UP 167+256.28UP $1524+$ 256.19 UP $1364+255.72$ UP $1388+255.28$ UP $1532+255.24$ UP $1067+253.18$ UP $1512+$ 252.59 UP $1106+252.2$ UP $271+252.08$ UP $471+251.94$ UP $993+251.21$ UP $391+$ 249.09 UP $1223+248.03$ UP $598+247.82$ UP $607+247.18$ UP $1333+245.35$ UP $166+$ $245.26 U P 1075+244.76 U P 215+244.28 U P 1066+243.41 U P 1523+240.03 U P 1097+$ 239.61 UP $112+237.96$ UP $174+237.83$ UP $606+237.39$ UP $1363+234.04 U P 342+$ 233.1 UP $1412+232.24$ UP $588+232.19$ UP $617+231.77$ UP $628+231.18$ UP $725+$ 230.88 UP $184+230.32$ UP $1492+228.24$ UP $751+227.94$ UP $661+227.85$ UP $292+$ 227.79 UP $561+227.76$ UP $1372+227.68$ UP $1352+224.19$ UP $1024+224.14$ UP $1007+$ 224.03 UP $1096+224.01$ UP $285+223.64$ UP $444+221.97$ UP $173+217.18 U P 616+$ 217.13 UP $1006+217.01$ UP $304+216$ UP $1421+216$ UP $1441+215.89$ UP $183+215$. 65UP $443+$ $210.68 U P 1342+210.25$ UP $791+209.9 U P 1394+209.85 U P 255+209.83 U P 1014+$ 209.67 UP $841+209.59$ UP $782+204.18$ UP $1023+204.01$ UP $303+203.62$ UP $452+$ 203.16 UP $904+203.07$ UP $464+202.81$ UP $984+202.75$ UP $645+201.78$ UP $1084+$ 198.39 UP $911+198.03$ UP $242+197.9$ UP $1393+197.84$ UP 1013+197.83UP $891+$ 197.8 UP $191+197.76$ UP $861+193.47$ UP $1117+192.07$ UP $463+190.84$ UP $1083+$ 189.06 UP $324+188.85$ UP $654+186.27$ UP $232+186.15$ UP $812+186.15$ UP $903+$ 185.82 UP $983+185.6$ UP $822+184.16$ UP $838+183.4$ UP $1116+181.92$ UP $314+181.83$ UP 704 +180.06 UP $323+175$ UP $1295+174.75$ UP $1044+173.86$ UP $653+173.7$ UP $851+$ 168.13 UP $682+167.92$ UP $313+167.85$ UP $703+161.91$ UP $692+161.77$ UP $1043+$ 156.1 UP $742+153.87$ UP $1135+152.4$ UP $1125+150.35$ UP $1165+147.4$ UP $1195+$ $146.07 U P 1155+144.12$ UP $672+124.12 \mathrm{UP} 1145+117.8 \mathrm{UP} 1174+114.07 \mathrm{UP} 802+$ 112.85 UP $1173+105.01$ UP $875+$ VMM1 $7-$ P2018 $=0$

Prod2019:

418.06 UP $1469+384.48 U P 377+376.42$ UP $357+372.7 U P 1461+371.47 U P 376+$

371.42 UP $356+359.32$ UP $367+351.98$ UP $99+351.51$ UP $109+349.34$ UP $366+347.59$ UP 491 +347.57 UP 501+346.73UP511+346.59UP 521+344.86UP 48+330.46UP 531+ 323.55 UP $101+321.6$ UP $1039+320.03$ UP $559+317.99$ UP $91+312.29 U P 639+$ 309.87 UP $1329+307.98$ UP 4 85+304UP1308+303.83UP 577+302.43UP $1277+$ 299.14 UP $1237+298.27$ UP $1184+295.98$ UP $1267+294.03$ UP $551+292.36$ UP $1404+$ 289.44 UP $1031+288.2$ UP $158+288$ UP $18+288$ UP $1478+288$ UP $1488+288$ UP $1507+$ 288UP $1557+286.84$ UP $576+286.26$ UP $1276+282.97$ UP $1236+282.69$ UP $61+281.42$ UP 71

+280.91 UP $434+280$ UP $39+280$ UP $1183+279.99$ UP $1266+279.86$ UP $405+279.83$ UP $415+$ 279.4 9UP $55+279.01 U P 1244+276.26 U P 261+275.74$ UP $1311+274.46 U P 1403+$ 274.11 UP 1321+273UP1506+273UP1556+272 . 78UP1544+272 . 3UP 385+272UP27+ 271.93 UP $1251+270.55$ UP $1059+270.25$ UP $631+270.07$ UP $332+269.95 U P 1534+$ 267.9 UP $1514+265.94$ UP $995+265.57$ UP $114+264.86$ UP $433+264.62$ UP $1108+$ 263.73 UP $421+263.07$ UP $1243+262.93$ UP $1225+260.24$ UP $1335+259.04$ UP $344+259$ UP 26 +258.31 UP $1281+258.27$ UP $142+258.2$ UP $131+258.16$ UP $202+258.1$ UP $122+258$ UP 1431 +258 UP 1451+258UP 1562+258UP1571+257. 8UP1543+257.64UP 222+256.37UP168+ 256.28 UP $1525+256.27$ UP $1077+256.19$ UP $1365+255.75$ UP $217+255.72$ UP $1389+$ 255.28 UP $1533+255.24$ UP $1068+253.18$ UP $1513+252.2$ UP $272+252.08 U P 472+$ 251.83 UP $294+251.21$ UP $392+251.03$ UP $1414+248.03$ UP $599+247.82$ UP $608+$ 246.25 UP $541+245.26$ UP $1076+244.76$ UP $216+244.69$ UP $1051+244.66$ UP $1354+$ $241.15 U P 1494+240.18$ UP $727+240.03$ UP $1098+240.01 U P 287+239.61 U P 113+$ $237.96 \mathrm{UP} 175+237.75 \mathrm{UP} 1374+234.04 \mathrm{UP} 343+234 \mathrm{UP} 31+233.74 \mathrm{UP} 1381+233.1 \mathrm{UP} 1413$ +232.24 UP $589+232.19$ UP $618+231.77 U P 629+231.18$ UP $726+230.88 U P 185+$ 230.55 UP $784+230.32$ UP $1493+228.24$ UP $752+228.21$ UP $771+228.07$ UP $731+$ 228.03 UP $591+227.94$ UP $662+227.85$ UP $293+227.79$ UP $562+227.76$ UP $1373+$ 227.76 UP $711+227.68$ UP $1353+227.59$ UP $761+224.73$ UP $1344+224.19$ UP $1025+$ 224.14 UP $1008+224.01$ UP $286+223.84$ UP $257+223.73$ UP $647+223.64$ UP $445+$ 217.01 UP $305+216.6$ UP $454+216$ UP $1422+216$ UP $1442+210.68$ UP $1343+210.25$ UP $792+$

210.17 UP $814+210.03$ UP $244+209.9 U P 1395+209.85$ UP $256+209.83$ UP $1015+$ 209.79 UP $621+209.67$ UP $842+209.59$ UP $783+204.21$ UP $581+203.62$ UP $453+$ 203.16 UP $905+203.07$ UP $465+202.81$ UP $985+202.75$ UP $646+202.56$ UP $824+$ 201.78 UP 1085+198.39UP 912+198.2UP 971+198.17UP 921+198.15UP 951+ 198.03 UP $243+197.97$ UP $961+197.86$ UP $881+197.85$ UP $941+197.83$ UP $892+$ 197.82 UP $931+197.8$ UP $192+197.76$ UP $862+196.28$ UP $234+193.47 U P 1118+$ 189.15 UP $684+189.06$ UP $325+188.85$ UP $655+186.27$ UP $233+186.21$ UP $81+186.15$ UP 813 +185.6 UP $823+184.16$ UP $839+184$ UP $1297+181.92$ UP $315+181.89$ UP $694+181.83$ UP 705 +175 UP 1296+174.75UP1045+173.7UP852+168.13UP683+168.11UP744+ 162.14 UP $831+161.91$ UP $693+161.13$ UP $674+160.44$ UP $1197+159.86$ UP $1137+$ 157.58 UP $1127+156.1$ UP $743+155.46$ UP $1167+153.87$ UP $1136+152.4$ UP $1126+$ 151.03 UP $1157+150.35$ UP $1166+147.4$ UP $1196+146.07$ UP 1156+144.12UP 673+ 
126.08 UP $804+125.17$ UP $1147+124.12$ UP $1146+117.8$ UP $1175+114.07$ UP $803+$ 112.01 UP $877+105.01 \mathrm{UP} 876+\mathrm{VMM} 18-\mathrm{P} 2019=0$ Prod2020:

384.48 UP $378+376.42$ UP $358+359.32$ UP $368+347.59$ UP $492+347.57$ UP $502+$ 346.73 UP $512+346.59$ UP $522+344.86$ UP $49+330.46$ UP $532+324.81$ UP $41+311.98$ UP 487 +307.98 UP $486+304$ UP $1309+303.83$ UP $578+302$. 43UP1278+299.14UP1238+ 298.27 UP $1185+295.98$ UP $1268+294.08$ UP $334+292.36$ UP $1405+288.2$ UP $159+288$ UP 19 +288 UP $1479+288$ UP $1489+288$ UP 1508+288UP1558+287.93UP 997+287.86UP 407+ 287.82 UP $417+287.48$ UP $57+282.69$ UP $62+281.42$ UP $72+280.91$ UP $435+280.18$ UP $204+$ 279.86 UP $406+279.83$ UP $416+279.61$ UP $224+279.4$ 9UP $56+279.29$ UP $387+$ 279.01 UP $1245+276.76$ UP $1227+276.26$ UP $262+275.74$ UP $1312+273.3$ UP $1337+$ 273.28UP 14 4+273.22UP 274+273.11UP124+273UP1564+272.78UP 1545+272.3UP 386 +272 UP $28+271.93$ UP $1252+270.19$ UP $151+270.07$ UP $333+270$ UP $1301+269.95$ UP 1535 +269.14 UP 1527+269.05UP1367+267.9UP1515+266.09UP 474+265.94UP 996+ 265.57 UP $115+265.17$ UP $394+264.62$ UP $1109+264$ UP $11+263.73$ UP $422+262.93$ UP 1226 +260.24 UP $1336+259.04$ UP $345+258.31$ UP $1282+258.27$ UP $143+258.2$ UP $132+$ 258.16 UP $203+258$. 1UP $123+258$ UP $1432+258$ UP $1452+258$ UP $1471+258$ UP $1481+$ 258UP 1563+258UP 1572+257.64UP223+256.37UP169+256.28UP $1526+256.27$ UP 1078 +256.19 UP $1366+255.75$ UP $218+255.24$ UP $1069+252.2$ UP $273+252.08$ UP $473+$ 251.83 UP $295+251.21$ UP $393+251.03$ UP $1415+247.96$ UP $177+247.82$ UP $609+$ 246.25 UP $542+245.25$ UP $754+244.94$ UP $664+244.77$ UP $564+244.66$ UP $1355+$ 241.15 UP $1495+240.56$ UP $1101+240.21$ UP $1027+240.18$ UP $728+240.03$ UP $1099+$ 240.01 UP $288+239.88$ UP $187+237.96$ UP $176+237.75$ UP $1375+234.33$ UP $161+$ 233.31 UP $1061+232.19$ UP $619+231.62$ UP $447+231.27$ UP $794+231$ UP $1424+231$ UP $1444+$ $230.88 \mathrm{UP} 186+230.63 \mathrm{UP} 844+230.55 \mathrm{UP} 785+228.24 \mathrm{UP} 753+228.21 \mathrm{UP} 772+$ 228.07 UP $732+227.94$ UP $663+227.79$ UP $563+227.76$ UP $712+227.59$ UP $762+$ 224.73 UP $1345+224.19$ UP 1026+224.14UP1009+224.01UP $307+223.89$ UP $1397+$ 223.84 UP $258+223.82$ UP $1017+223.73$ UP $648+223.64$ UP $446+221.84$ UP $601+$ 217.01 UP $306+216.6$ UP $455+216.17$ UP $907+216.08$ UP $467+216.03$ UP $1091+216$ UP 1423 +216 UP $1443+215.79$ UP $987+214.7$ UP $1087+210.41$ UP $914+210.25$ UP $793+$ 210.17 UP $815+210.03$ UP $245+209.9$ UP $1396+209.83$ UP $1016+209.82$ UP $894+$ 209.79 UP $194+209.74$ UP $864+209.67$ UP $843+204.17$ UP $611+203.16$ UP $906+$ 203.07UP 466+202.81UP 986+202.56UP $825+201.78$ UP 1086+200.07UP $327+$ 199.84 UP $657+198.39$ UP $913+198.2$ UP $972+198.17$ UP $922+198.15$ UP $952+$ 198.12 UP $1001+197.97$ UP $962+197.86$ UP $882+197.85$ UP $942+197.83$ UP $893+$ 197.82 UP $932+197.8 U P 193+197.76 U P 863+196.28 U P 235+193.47 U P 1119+$ 191.91 UP $317+191.82$ UP $707+189.15$ UP $685+189.06$ UP $326+188.85$ UP $656+$ 188.67 UP $854+186.21$ UP $82+184$ UP $1298+183.74$ UP $1047+181.92$ UP $316+181.89$ UP 695 +181.83 UP $706+174.75$ UP $1046+173.7$ UP $853+169.29$ UP $1111+168.11$ UP $745+$ $161.13 \mathrm{UP} 675+160.44 \mathrm{UP} 1198+159.86 \mathrm{UP} 1138+157.58 \mathrm{UP} 1128+155.46 \mathrm{UP} 1168+$ 151.03 UP $1158+126.71$ UP $1177+126.08$ UP $805+125.17$ UP $1148+117.8$ UP $1176+$ $112.01 \mathrm{UP} 878+\mathrm{VMM} 19-\mathrm{P} 2020=0$ Prod2021: 400.31 UP $1462+384.48$ UP $379+376.42$ UP 359+372.7UP1464+370.56UP 494+ 370.54 UP $504+369.64$ UP $514+369.49$ UP $524+359.32$ UP $369+354.45$ UP $371+354.4$ UP 351 +350.48 UP $534+347.59$ UP $493+347.57$ UP $503+346.73$ UP $513+346.59$ UP $523+$ 335.99 UP $92+335.53$ UP $102+335.37$ UP $361+330.46$ UP $533+323.55$ UP $104+317.99$ UP 94 +316.53 UP $1187+311.98$ UP $488+310.26 U P 1407+309.54$ UP $1032+308.03$ UP $552+$ 303.83 UP $579+302.43 U P 1279+301.73 U P 64+300.38 U P 74+299.14$ UP $1239+$ 298.27 UP $1186+295.98$ UP $1269+295.52$ UP $117+294.96$ UP $1247+294.27$ UP $264+$ 294.27 UP $632+294.08$ UP $335+294.03$ UP 55 $4+293.72$ UP $1314+292.36$ UP $1406+$ 291.99 UP $1322+289.66$ UP $1254+289.44$ UP $1034+288.93$ UP $437+288$ UP $1509+288$ UP 1559 +287.93 UP $998+287.86$ UP $408+287.82$ UP $418+287.77$ UP $1547+287.48$ UP $58+$ 284.96 UP $1537+282.69$ UP $63+282.62$ UP $1517+281.42$ UP $73+280.91$ UP $436+$ 280.18 UP $205+279.81$ UP $297+279.72$ UP $424+279.61$ UP $225+279.29$ UP $388+$ 279.01 UP $1246+276.76$ UP $1228+276.26$ UP $263+275.85$ UP $571+275.74$ UP $1313+$ 274.11 UP $1324+273.33$ UP $1284+273.3$ UP $1338+273.28$ UP $145+273.22$ UP $275+$ 273.21 UP $134+273.11$ UP $125+273$ UP $1434+273$ UP $1454+273$ UP $1565+272.98$ UP $1574+$ 272.78 UP $1546+272.04$ UP $347+272$ UP $29+271.93$ UP $1253+270.25$ UP $634+269.95$ UP 1536 +269.3 UP $1271+269.14$ UP $1528+269.05$ UP $1368+267.9$ UP $1516+266.8$ UP $1231+$ 266.0 9UP $475+265.57$ UP $116+265.17$ UP $395+263.99$ UP $1261+263.73$ UP $423+$ 262.98 UP $1417+259.26$ UP $544+259.04$ UP $346+259$ UP $32+258.31$ UP $1283+258.2$ UP $133+$ 258UP1433+258UP1453+258UP1501+258UP1551+258UP1573+257.62UP1052+ 256.27 UP 1079+255.75UP 219+255.64UP 1357+252UP 21+251.97UP $1497+251.83$ UP 296 +251.03 UP $1416+247.96$ UP $178+247.74$ UP $1377+247.52$ UP $787+246.25$ UP $543+$ 245.25 UP $755+245.22$ UP $774+245.08$ UP $734+244.94$ UP $665+244.77$ UP $565+$ 244.74 UP $714+244.73$ UP $1382+244.69$ UP $1054+244.66$ UP $1356+244.56$ UP $764+$ 241.15 UP $1496+240.21$ UP $1028+240.18$ UP $729+240.01$ UP $289+239.88$ UP $188+$ 
238.03 UP 592+237.75UP 1376+234UP 34+233.77UP211+233.74UP 1384+232.75UP 1347 +231.62 UP $448+231.57$ UP $457+231.27$ UP $795+231$ UP $1425+231$ UP $1445+230.63$ UP 845 +230.55 UP $786+228.24$ UP $1071+228.21$ UP $773+228.07$ UP $733+228.03$ UP $594+$ 227.76 UP $713+227.59$ UP $763+224.73$ UP $1346+224.23$ UP $582+224.18$ UP $817+$ 224.03 UP $247+224.01$ UP $308+223.89$ UP $1398+223.84$ UP $259+223.82$ UP $1018+$ 223. 78UP $622+223.73$ UP $649+223.51$ UP $827+216.6$ UP $456+216.17$ UP $908+216.17$ UP 721 +216.08 UP $468+215.79$ UP $988+214.7$ UP $1088+210.41$ UP $915+210.21$ UP $974+$ 210.18 UP $924+210.17$ UP $816+210.16$ UP $954+210.03 U P 246+210.01 U P 281+$ 209.97 UP $964+209.85$ UP $884+209.84$ UP $944+209.82$ UP $895+209.81$ UP $934+$ 209.79 UP $624+209.79$ UP $195+209.74$ UP $865+208.3$ UP $237+204.21$ UP $584+202.56$ UP 826 +200.15 UP $687+200.07$ UP $328+199.84$ UP $658+198.2$ UP $973+198.17$ UP $923+$ 198.15 UP $953+197.97$ UP $963+197.86$ UP $883+197.86$ UP $251+197.85$ UP $943+$ 197.82UP 933+196.28UP 236+196.23UP 84+191.91UP 318+191.89UP 697+191.82UP 708 +189.15 UP $686+188.67$ UP $855+186.21$ UP $83+185.77$ UP $641+184.12$ UP $747+184$ UP 1299 +183.74 UP $1048+181.89$ UP $696+176.14$ UP $677+175.15$ UP $832+168.11$ UP $746+$ 168UP1291+162.14UP $834+161.13$ UP $676+160.44$ UP $1199+159.86$ UP $1139+$ 157.58UP1129+155.46UP1169+151.03UP1159+144.4UP1191+144.09UP807+ 143.87 UP $1131+143.07$ UP $1121+141.14$ UP $1161+137.12$ UP $1151+126.71$ UP $1178+$ 126.08 UP $806+125.17$ UP $1149+118.91$ UP $1141+112.01$ UP $879+96.01$ UP $871+V M M 20$ $\mathrm{P} 2021=0$ Prod2022: 370.56 UP $495+370.54$ UP 505+369. 64 UP $515+369.49$ UP $525+350.48$ UP $535+336.84$ UP 42 +330.46 UP $537+324.81$ UP $44+320.08$ UP $337+316.53$ UP $1188+311.98 U P 489+$ 310.26 UP $1408+301.73$ UP $65+300.38$ UP $75+296.19$ UP $207+295.59$ UP $227+295.52$ UP 118 +294.96 UP $1248+294.27$ UP $265+294.08$ UP $336+293.98$ UP $481+293.72$ UP $1315+$ 289.66 UP $1255+288.93$ UP $438+288.3$ UP $147+288.12$ UP $127+288$ UP $1567+287.93$ UP 999 +287.86 UP $409+287.82$ UP $419+287.77$ UP $1548+287.48$ UP $59+287$ UP $1302+$ 284.96 UP $1538+282.62$ UP $1518+280.22$ UP $277+280.2$ UP $152+280.18 U P 206+$ 280.09 UP $477+280$ UP $12+279.81$ UP $298+279.72$ UP $425+279.61$ UP $226+279.2$ UUP $389+$ 279.13 UP $397+276.76$ UP $1229+275.74$ UP $1317+273.33$ UP $1285+273.3$ UP $1339+$ 273.28 UP $146+273.22$ UP $276+273.21$ UP $135+273.11$ UP $126+273$ UP $1435+273$ UP $1455+$ 273UP14 72+273UP1482+273UP1566+272.98UP1575+272.04UP 348+269. 87UP 401+ 269.14 UP $1529+269.05$ UP $1369+266.09$ UP $476+265.17$ UP $396+264.27$ UP $757+264$ UP 14 +263.93 UP $667+263.84$ UP $411+263.52$ UP $51+262.98$ UP $1418+259.26$ UP $545+$ 258UP $1457+258$ UP $1474+258$ UP $1484+257$. 34UP 381+255 . 76UP 567+255.64UP $1358+$ 252.59 UP $1102+251.97$ UP $1498+251.94$ UP $991+249.09$ UP $1221+248.27$ UP $797+$ $247.96 \mathrm{UP} 179+247.74 \mathrm{UP} 1378+247.6 \mathrm{UP} 847+247.52 \mathrm{UP} 788+247.18 \mathrm{UP} 1331+$ 245.35 UP $162+245.25$ UP $756+245.22$ UP $775+245.08 U P 735+244.94$ UP $666+$ 244.77 UP $566+244.74$ UP $715+244.56$ UP $765+244.28$ UP $1062+243.41$ UP $1521+$ 240.56 UP $1104+240.21$ UP $1029+240$ UP $1427+240$ UP $1447+239.88$ UP $189+237.83$ UP 602 +237.39 UP $1361+234.33$ UP $164+233.31$ UP $1064+232.75$ UP $1348+231.62$ UP $449+$ 231.57 UP $458+231.27$ UP 796+231UP1426+231UP $1446+230.63$ UP $846+224.44$ UP 917+ $224.18 U P 818+224.03$ UP $248+224.03$ UP $1092+224.01$ UP 309+223.89UP1399+ 223.82 UP $1019+223.8$ UP $897+223.72$ UP $867+223.51$ UP $828+221.97$ UP $171+$ 217.18 UP $612+217.13$ UP $1002+216.17$ UP $909+216.08$ UP $469+216.03$ UP $1094+$ 215.89 UP $181+215.79$ UP $989+215.79$ UP $197+215.65$ UP $441+214.7$ UP $1089+$ 210.41 UP $916+210.21$ UP $975+210.18$ UP $925+210.16$ UP $955+209.97 U P 965+$ 209.85 UP $885+209.84$ UP $945+209.82$ UP $896+209.81$ UP $935+209.79$ UP $196+$ 209.74 UP $866+208.3$ UP $238+207.64$ UP $857+204.18 U$ UP $1021+204.01$ UP $301+$ 200.15 UP $688+200.07 U P 329+199.84$ UP $659+197.9$ UP $1391+197.84$ UP $1011+$ $196.23 U P 85+192.07 U P 461+191.91$ UP $319+191.89 U P 698+191.82 U P 709+$ 190.84 UP $1081+188.67$ UP $856+186.15$ UP $901+185.82$ UP $981+184.12$ UP $748+$ 183.74 UP $1049+183.4$ UP $1112+180.06$ UP $321+176.14$ UP $678+173.86 U P 651+$ 169.29 UP $1114+167.92$ UP $311+167.85$ UP $701+161.77$ UP $1041+144.09$ UP $808+$ 126.71UP1179+112.85UP1171+VMM21 - P2022 = 0 Ope2002:

UP $1464+$ +UP $1465+$ +UP $1466+$ +UP $537+$ +UP 538+UP 539+UP 94+UP 95+UP 96+UP $104+$ UP $105+U P 106+U P 41+U P 42+U P 43+U P 1317+$ +UP $1318+U P 1319+U P 1034+U P 1035$ + UP $1036+$ +UP $554+$ +UP 555+UP 556+UP $634+$ +UP 635+UP 636+UP $1324+$ +UP $1325+$ UP1326+UP1 $457+$ +UP $1458+$ +UP 1 459+UP 151+UP 152+UP 153+UP 1301+UP1302+ UP 1303+UP 11+UP12+UP13+UP 34+UP 35+UP 36+UP 1471+UP 1472+UP1473+ UP $1481+$ +UP $1482+$ +UP $1483+$ +UP $1054+U P 1055+U P 1056+$ +UP $1384+U P 1385+U P 1386+$ UP1101+UP 1102+UP 1103+UP 594+UP 595+UP 596+UP 161+UP 162+UP $163+$ UP $1061+$ UP $1062+$ +UP $1063+$ +UP $584+$ UP $585+$ UP $586+$ +UP $624+$ UP $625+$ UP $626+$ +UP 601 + UP 602+UP 603+UP1091+UP1092+UP1093+UP 611+UP 612+UP 613+UP1001+ UP1002+UP1003+UP 834+UP 835+UP 836+UP1111+UP1112+UP1113-0p2002 = 0 Ope2003: UP $1467+$ +UP $1468+$ +UP $1469+$ +UP 371+UP 372+UP 373+UP 351+UP 352+UP 353+UP 97 
+ UP 98+UP 99+UP107+UP 108+UP 109+UP 4 4+UP 45+UP 46+UP 361+UP $362+$

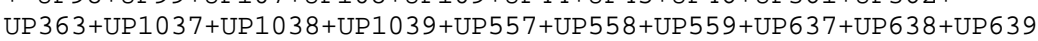
+ UP 1327+UP1328+UP1329+UP 1304+UP 1305+UP1306+UP 154+UP 155+UP 156+ UP 14+UP 15+UP 16+UP 37+UP 38+UP 39+UP 571+UP 572+UP 573+UP $1474+$ UP1475+UP1 $476+$ +UP $1484+$ +UP1 $485+$ +UP 1 486+UP1057+UP1058+UP1059+UP1271+ UP $1272+$ +UP $1273+$ +UP $1231+$ +UP1232+UP 1233+UP1261+UP1262+UP1263+UP 1501+ UP1502+UP 1503+UP 1551+UP 1552+UP1553+UP1387+UP 1388+UP1389+UP 1104+ UP 1105+UP 1106+UP 21+UP 22+UP 23+UP 597+UP 598+UP 599+UP 164+UP 165+ UP $166+$ +UP $1064+$ UP $1065+$ +UP $1066+$ +UP $604+$ +UP $605+$ +UP $606+$ +UP $211+$ +UP $212+$ +UP 213 + UP $587+$ +UP $588+$ +UP $589+$ +UP $627+$ +UP $628+$ +UP $629+$ +UP $1071+$ +UP1072+UP $1073+$ UP $1094+U P 1095+U P 1096+U P 614+U P 615+U P 616+U P 1004+U P 1005+U P 1006+$ UP 721+UP 722+UP 723+UP 281+UP 282+UP 283+UP 251+UP 252+UP 253+UP $641+$ UP $642+$ UP $643+$ +UP $837+$ +UP $838+$ +UP $839+$ +UP $1114+$ +UP $1115+$ +UP $1116+$ +UP $1291+$ UP1292+UP1293+UP1191+UP1192+UP1193+UP1131+UP1132+UP1133+UP1121+ UP1122+UP1123+UP1161+UP1162+UP1163+UP1151+UP1152+UP1153+UP1141+ UP1142+UP1143+UP 871+UP 872+UP873 - Op2003 = 0 Ope2004: UP $374+$ +UP $375+$ +UP $376+$ +UP $354+$ +UP $355+$ +UP $356+$ +UP $364+$ +UP $365+$ +UP $366+$ +UP $47+$ UP 48+UP 4 9+UP 1307+UP 1308+UP $1309+$ +UP $481+$ +UP 482+UP 4 83+UP 157+UP 158+ UP 159+UP17+UP 18+UP 19+UP 1 477+UP 1478+UP 14 79+UP 1487+UP 1488+UP 1489 + UP $574+$ +UP $575+$ +UP $576+$ +UP $1274+$ +UP $1275+$ +UP $1276+$ +UP $1234+$ +UP $1235+$ +UP $1236+$ UP $1264+$ +UP $1265+U P 1266+$ +UP $1504+$ +UP 1 505+UP 1506+UP 1554+UP 1555+UP 1556+ UP $401+$ +UP $402+$ +UP $403+$ +UP $1107+$ +UP $1108+$ +UP $1109+$ +UP $411+$ +UP $412+$ +UP $413+$ +UP 51 + UP 52+UP 53+UP 24+UP 25+UP 26+UP 381+UP 382+UP 383+UP $167+$ +UP $168+$ UP169+UP $1067+U P 1068+U P 1069+U P 991+U P 992+U P 993+U P 1221+U P 1222+$ UP1223+UP 607+UP 608+UP 609+UP1331+UP 1332+UP1333+UP 1074+UP 1075+ UP1076+UP214+UP 215+UP216+UP1521+UP1522+UP1523+UP1097+UP1098+ UP $1099+$ +UP $1361+$ +UP $1362+$ +UP $1363+$ +UP $617+$ +UP $618+$ +UP $619+U P 724+U P 725+$ UP $726+$ +UP $1007+$ +UP $1008+U P 1009+U P 284+U P 285+$ UP $286+$ +UP $171+U P 172+U P 173$ + UP 181+UP 182+UP 183+UP $441+$ +UP $442+$ +UP $443+$ +UP 254+UP 255+UP 256+UP 1021 + UP $1022+$ +UP $1023+$ +UP $301+$ +UP $302+$ +UP $303+$ +UP $644+$ UP $645+$ UP $646+$ +UP $1391+$ UP1392+UP 1393+UP 1011+UP1012+UP1013+UP1117+UP1118+UP1119+UP 461+ UP $462+$ +UP $463+U P 1081+$ UP $1082+$ +UP $1083+$ UP $901+$ +UP $902+$ +UP $903+$ +UP $981+$ +UP 982 + UP $983+$ +UP $321+$ UP $322+$ UP $323+$ UP $1294+$ +UP $1295+$ +UP 1296+UP $651+$ +UP $652+$ UP 653+UP 311+UP 312+UP 313+UP 701+UP 702+UP 703+UP 1041+UP 1042+UP 1043 + UP $1134+$ +UP $1135+$ UP $1136+$ +UP $1124+$ +UP $1125+$ +UP $1126+$ +UP $1164+U P 1165+$ +UP 1166

+ UP $1194+$ +UP $1195+$ +UP $1196+$ +UP $1154+$ +UP $1155+$ +UP $1156+$ +UP $1144+$ +UP $1145+$ +UP 1146 + UP1171+UP1172+UP1173+UP874+UP875+UP876-Op2004 = 0 Ope2005: UP $377+$ +UP $378+$ +UP $379+$ +UP $357+$ +UP $358+$ +UP $359+$ +UP $367+$ +UP $368+$ +UP $369+$ +UP $484+$ UP $485+$ +UP 486 +UP $577+$ +UP $578+$ +UP $579+$ +UP $1277+$ +UP $1278+$ +UP $1279+$ +UP $1237+$ UP1238+UP1239+UP1267+UP1268+UP1269+UP1507+UP1508+UP1509+UP1557+ UP 1558+UP 1559+UP 1181+UP 1182+UP 1183+UP $404+$ +UP 4 05+UP $406+$ +UP $414+$ UP $415+$ +UP $416+$ +UP $54+$ +UP 55+UP 56+UP $1401+$ +UP $1402+$ +UP $1403+$ +UP $384+$ +UP $385+$ UP $386+$ +UP $27+$ +UP $28+$ +UP $29+$ +UP $994+$ +UP $995+$ +UP $996+$ +UP $431+$ +UP $432+$ +UP $433+$ UP $1241+$ +UP $1242+$ +UP $1243+$ UP $1224+$ +UP $1225+$ +UP $1226+$ +UP $1334+$ +UP $1335+$ +UP $1336+$ UP1541+UP 1542+UP1543+UP1524+UP1525+UP1526+UP1077+UP1078+UP1079+ UP1364+UP 1365+UP 1366+UP 217+UP 218+UP219+UP1531+UP 1532+UP 1533+ UP 1511+UP 1512+UP 1513+UP 727+UP 728+UP 729+UP 287+UP 288+UP 289+UP 111 + UP 112+UP113+UP 174+UP175+UP176+UP 341+UP 342+UP 343+UP $1411+$ UP $1412+U P 1413+$ UP $184+U P 185+U P 186+U P 1491+U P 1492+U P 1493+U P 291+$ UP 292+UP 293+UP 1371+UP 1372+UP 1373+UP 1351+UP 1352+UP1353+UP $1024+$ UP $1025+$ +UP $1026+$ +UP $257+$ +UP $258+$ +UP $259+$ +UP $647+$ +UP $648+$ +UP $649+$ +UP $444+$ +UP 445 + UP $446+$ +UP $304+$ +UP $305+$ +UP $306+$ +UP $1341+$ UP $1342+$ +UP $1343+$ +UP $1394+$ +UP $1395+$ UP $1396+$ +UP $1014+$ +UP $1015+$ UP $1016+$ +UP $781+$ +UP $782+$ +UP $783+$ +UP $451+$ +UP $452+$ UP $453+$ +UP $904+$ +UP $905+$ +UP 906 +UP $464+$ +UP $465+$ +UP 466 +UP $984+$ +UP $985+$ +UP $986+$ UP $1084+$ +UP $1085+$ +UP $1086+$ +UP $241+$ +UP $242+$ UP $243+$ +UP $324+$ +UP $325+$ +UP $326+$ +UP 654 + UP 655+UP 656+UP 231+UP 232+UP 233+UP $811+$ +UP $812+$ +UP $813+$ +UP $821+$ +UP 822 + UP $823+U P 1297+$ +UP $1298+$ +UP 1299+UP $314+$ +UP 315+UP 316+UP $704+$ +UP $705+$ UP $706+$ +UP $1044+$ UP $1045+$ +UP $1046+$ +UP $681+$ UP $682+$ UP $683+$ +UP $691+$ UP $692+$ +UP 693 + UP1197+UP 1198+UP 1199+UP 1137+UP 1138+UP1139+UP 1127+UP $1128+$ +UP 1129 + UP741+UP 742+UP743+UP 1167+UP 1168+UP1169+UP1157+UP1158+UP1159+ UP $671+$ UP $672+$ +UP $673+$ UP $1147+$ UP $1148+$ UP $1149+$ UP $1174+$ +UP $1175+U P 1176+$ UP $801+U P 802+U P 803+U P 877+U P 878+U P 879-0 p 2005=0$ Ope2006: UP $487+$ +UP $488+$ +UP $489+$ +UP $1184+$ +UP $1185+$ +UP $1186+$ +UP $1404+$ +UP $1405+$ +UP $1406+$ UP $997+$ +UP $998+$ +UP $999+$ +UP $407+$ +UP $408+$ +UP 409 +UP $417+$ +UP $418+$ +UP $419+$ +UP $57+$ UP 58+UP 59+UP 4 34+UP 435+UP 436+UP $387+$ +UP $388+$ +UP 389+UP $1244+$ +UP $1245+$ 
UP1246+UP 1227+UP1228+UP1229+UP1337+UP1338+UP1339+UP1544+UP1545+ UP $1546+$ +UP $331+$ +UP $332+$ +UP $333+$ +UP $1534+$ UP $1535+$ +UP 1536+UP $1527+$ +UP $1528+$ UP $1529+$ +UP $1367+$ +UP 1368+UP 1369+UP1514+UP 1515+UP1516+UP 114+UP115+ UP $116+$ +UP 344 +UP $345+$ +UP 346 +UP $141+$ +UP $142+$ +UP $143+$ +UP 201+UP 202+UP 203+ UP121+UP122+UP123+UP1561+UP1562+UP1563+UP221+UP 222+UP 223+UP 271 + UP $272+$ +UP $273+$ +UP $471+$ +UP $472+$ +UP $473+$ +UP $294+$ +UP 2 95+UP $296+$ +UP $391+$ +UP 392 + UP 393+UP $1414+$ +UP $1415+$ +UP $1416+$ +UP 177+UP 178+UP179+UP1354+UP1355+ UP $1356+$ +UP $1494+$ +UP $1495+$ +UP $1496+$ +UP $1027+$ +UP $1028+$ +UP $1029+$ +UP $187+$ +UP $188+$ UP $189+$ +UP $1374+$ +UP $1375+$ +UP $1376+$ +UP $447+$ UP $448+$ +UP $449+$ +UP $784+$ +UP $785+$ +UP 786 + UP $751+$ UP $752+$ UP $753+$ UP $661+$ UP $662+$ UP $663+$ UP $561+$ UP $562+$ +UP $563+$ UP 1344 + UP $1345+$ +UP $1346+$ +UP $307+U P 308+U P 309+$ +UP $1397+$ +UP 1398+UP 1399+UP $1017+$ UP $1018+$ +UP $1019+$ +UP $454+$ +UP $455+$ +UP $456+$ +UP $907+$ +UP $908+$ +UP $909+$ +UP $467+$ +UP 468 + UP 469+UP 1421+UP 1422+UP 1423+UP $1441+$ +UP 1442+UP $1443+$ +UP $987+$ +UP $988+$ UP 989+UP 1087+UP 1088+UP 1089+UP 791+UP 792+UP 793+UP 814+UP 815+UP 816 + UP $244+$ +UP $245+$ +UP $246+$ +UP $841+$ +UP $842+$ +UP $843+$ +UP $824+$ +UP $825+$ +UP $826+$ +UP 327 + UP $328+$ +UP $329+$ +UP $657+$ +UP $658+$ +UP $659+$ +UP $911+$ +UP $912+$ +UP $913+$ +UP $891+$ +UP 892

+ UP $893+$ +UP 191+UP 192+UP 193+UP $861+$ UP $862+$ +UP $863+$ +UP $234+$ +UP $235+$ +UP 236

+ UP $317+$ +UP $318+$ UP $319+$ +UP $707+$ +UP $708+$ +UP $709+$ +UP $684+$ +UP $685+$ +UP $686+$ +UP 1047 + UP $1048+$ UP $1049+$ +UP $694+$ +UP $695+$ +UP $696+$ +UP $851+$ +UP $852+$ +UP $853+U P 744+$ UP $745+$ +UP $746+$ +UP $674+$ +UP $675+$ +UP $676+$ +UP $1177+$ UP $1178+$ +UP $1179+$ +UP $804+$ +UP 805 + UP $806-0 \mathrm{p} 2006=0$

Ope2007: UP $1461+$ UP $491+$ +UP $492+$ +UP $493+$ +UP $501+$ +UP $502+$ +UP $503+$ +UP $511+$ +UP $512+$ +UP $513+$ UP 521+UP 522+UP 523+UP 531+UP 532+UP 533+UP 101+UP 91+UP 1187+UP $1188+$ UP1189+UP 1407+UP1408+UP1409+UP117+UP118+UP119+UP 1247+UP1248+ UP $1249+$ +UP $334+$ +UP $335+$ +UP $336+$ +UP 551+UP $1031+$ +UP $437+$ +UP $438+$ +UP $439+$ +UP 1547 + UP1548+UP1549+UP1537+UP1538+UP1539+UP 61+UP 62+UP 63+UP1517+ UP 1518+UP 1519+UP 71+UP 72+UP 73+UP 204+UP 205+UP206+UP297+UP 298+ UP 2 99+UP 22 4+UP 225+UP 22 6+UP 2 61+UP 2 62+UP 2 63+UP 1311+UP $1312+$ +UP 1313 + UP1321+UP 144+UP 145+UP 146+UP 274+UP 275+UP 276+UP 124+UP125+UP 126 + UP $1564+$ +UP 1 $565+$ +UP $1566+$ UP $347+$ +UP $348+$ +UP $349+$ +UP $1251+$ UP $1252+$ +UP $1253+$ UP $631+$ UP $474+$ +UP $475+$ +UP $476+$ +UP $394+$ +UP $395+$ +UP $396+$ +UP $421+U P 422+U P 423+$ UP $1417+$ +UP $1418+$ +UP $1419+$ +UP 1281+UP 1282+UP 1283+UP 131+UP 132+UP133+ UP $1431+$ UP $1432+$ +UP $1433+$ +UP 1 451+UP 1452+UP 1453+UP 1571+UP 1572+UP 1573

+ UP1357+UP 1358+UP 1359+UP 1497+UP 1498+UP1499+UP 1377+UP 1378+UP 1379

+ UP $787+$ +UP $788+$ +UP $789+$ +UP $541+$ UP $542+$ +UP $543+$ UP $754+$ +UP $755+$ +UP $756+$ UP 664

+ UP $665+$ UP $666+$ UP $564+$ +UP $565+$ UP $566+$ UP $1051+$ UP $31+$ +UP $1381+$ UP $1347+$ UP1 $348+U P 1349+U P 457+U P 458+U P 459+U P 794+U P 795+U P 796+U P 1424+$ UP $1425+$ +UP $1426+$ +UP $1444+$ UP $1445+$ +UP $1446+$ +UP $844+$ +UP $845+$ +UP $846+$ +UP $771+$ UP $772+$ UP $773+$ UP $731+$ UP $732+$ +UP $733+$ UP 591+UP $711+U P 712+U P 713+U P 761+$ UP $762+$ +UP $763+$ +UP $817+$ +UP $818+$ +UP $819+$ +UP $247+$ +UP $248+$ +UP $249+$ +UP $827+$ +UP $828+$ UP $829+$ +UP $914+$ +UP $915+$ +UP 916 +UP $894+$ +UP $895+$ +UP $896+$ +UP $621+$ +UP $194+$ +UP $195+$ UP 196+UP 864+UP 865+UP 866+UP 237+UP 238+UP 239+UP 581+UP 687+UP 688+ UP $689+$ +UP $971+$ +UP $972+$ +UP $973+$ +UP $921+$ +UP $922+$ +UP $923+$ +UP $951+$ +UP $952+$ +UP $953+$ UP $961+$ UP $962+$ +UP $963+$ +UP $881+$ +UP $882+$ +UP $883+$ +UP $941+$ +UP $942+$ +UP $943+$ +UP $931+$ UP $932+$ +UP $933+$ +UP $697+$ +UP $698+$ +UP $699+$ +UP $854+$ +UP $855+$ +UP 856 +UP $81+$ +UP $82+$ UP $83+$ +UP $747+$ +UP $748+$ +UP $749+$ +UP $677+U P$ 678+UP $679+$ +UP $831+$ +UP $807+U P 808+$ UP $809-0$ Op2007 = 0 Ope2008:

UP $1462+$ +UP $1464+$ +UP $494+$ +UP $495+$ +UP $496+$ +UP $504+$ +UP $505+$ +UP 506 +UP $514+$ +UP 515 + UP $516+$ +UP $524+$ +UP $525+$ +UP $526+$ +UP $534+$ +UP $535+$ +UP $536+$ +UP $92+$ +UP $102+$ +UP $537+$

UP $41+$ +UP $104+$ +UP $337+$ +UP $338+$ +UP $339+$ +UP $94+$ +UP $1032+$ +UP 552+UP $64+$ +UP $65+$ UP $66+$ +UP $74+$ +UP $75+$ +UP $76+$ +UP $207+$ +UP 208+UP $209+$ +UP $227+$ +UP $228+U P 229+$ UP $264+$ +UP $265+$ +UP $266+$ +UP $632+$ +UP $554+$ +UP $1314+$ +UP $1315+$ +UP $1316+$ +UP $1322+$ UP $1254+$ +UP $1255+$ +UP $1256+$ +UP $1034+$ +UP $147+$ +UP $148+$ +UP $149+$ +UP $127+$ +UP $128+$ UP 129+UP 1567+UP 1568+UP 1569+UP 277+UP 278+UP 279+UP $477+$ +UP $478+$ +UP 479 + UP $424+$ +UP $425+$ +UP $426+$ +UP $397+$ +UP $398+$ +UP $399+$ +UP $1317+$ +UP $1324+$ +UP $1284+$ UP 1285+UP 1286+UP 134+UP 135+UP 136+UP 1434+UP1435+UP 1436+UP $1454+$ UP $1455+$ +UP $1456+$ +UP $1574+$ +UP $1575+$ +UP 1576+UP $634+$ +UP 151+UP $1301+$ +UP $757+$ UP $758+$ +UP $759+$ +UP $11+$ UP $667+$ +UP $668+$ +UP $669+$ +UP $544+$ +UP $545+$ +UP $546+$ +UP $32+$ UP $1457+$ +UP $1471+$ +UP $1481+$ UP $1052+$ +UP $567+$ +UP $568+$ +UP $569+$ +UP $797+$ +UP $798+$ UP $799+$ +UP $847+$ +UP $848+$ +UP $849+$ +UP $774+$ +UP $775+$ UP $776+$ +UP $734+$ +UP $735+$ +UP $736+$ UP $714+$ +UP $715+$ +UP $716+$ +UP $1382+$ +UP $1054+$ UP $764+$ +UP $765+$ +UP $766+$ +UP $1101+$ UP $1427+$ +UP $1428+$ +UP $1429+$ +UP $1447+$ +UP $1448+$ +UP $1449+$ +UP 592+UP 161+UP $34+$ UP $1384+$ +UP $1061+$ +UP $594+$ +UP $917+$ +UP $918+$ +UP $919+$ +UP $582+$ +UP $897+$ +UP $898+$ +UP 899 + UP $622+$ +UP $867+$ +UP $868+$ UP $869+$ +UP $601+$ +UP $1091+$ +UP $197+$ +UP $198+$ +UP $199+$ +UP 974

+ UP $975+$ +UP $976+$ +UP 924 +UP 925+UP 926 +UP 954 +UP 955+UP $956+$ +UP $964+$ +UP 965 
+ UP $966+$ +UP $884+$ +UP $885+$ +UP 886 +UP $944+$ +UP $945+$ +UP 946 +UP $934+$ +UP $935+$ +UP 936 + UP $624+$ +UP $857+$ +UP $858+$ +UP $859+$ +UP $584+$ +UP $611+$ +UP $1001+$ +UP $84+$ +UP $85+$ +UP $86+$ UP $832+U P 1111+U P 834-$ Op2008 $=0$

Ope2009:

UP $1463+$ +UP $1465+$ +UP $497+$ +UP $498+$ +UP $499+$ +UP $507+$ +UP $508+$ +UP $509+$ +UP $517+$ +UP 518

+ UP $519+$ +UP $527+$ +UP $528+$ +UP 529+UP $1467+$ +UP $371+$ +UP 351+UP 93+UP $103+$ +UP 538

+ UP $42+$ +UP 95+UP $105+$ +UP $361+$ +UP $44+$ +UP $107+$ +UP $1033+$ +UP 553+UP $97+U P 67+$ UP $68+$ +UP $69+$ +UP $267+$ +UP $268+$ +UP $269+$ +UP $633+$ +UP $77+$ +UP $78+$ +UP $79+$ UP $1323+$ UP1035+UP 555+UP 1257+UP 1258+UP1259+UP 635+UP 557+UP 1318+UP $1325+$ UP1037+UP1287+UP1288+UP1289+UP137+UP138+UP139+UP1437+UP1438+ UP $1439+$ +UP $1577+$ +UP $1578+$ +UP $1579+$ +UP $427+$ +UP $428+$ +UP $429+$ +UP $1302+U P 152+$ UP12+UP 33+UP 571+UP 1327+UP1458+UP 1472+UP1482+UP $547+$ +UP $549+$ +UP 548 + UP1053+UP 637+UP 154+UP 1304+UP1271+UP1231+UP 777+UP778+UP 779+ UP737+UP738+UP 739+UP14+UP1261+UP717+UP 718+UP 719+UP 767+UP768+ UP 769+UP 35+UP 1474+UP 1484+UP 1501+UP 1551+UP 1055+UP 1383+UP 1102+ UP $21+$ +UP 593+UP 162+UP $1385+$ +UP $1057+$ +UP $1062+$ UP $1104+$ +UP $595+$ +UP $602+$ +UP 164 + UP $37+$ +UP $211+$ +UP $1387+$ +UP $1064+$ +UP 583+UP 623+UP 1071+UP 597+UP 585+ UP $977+$ +UP $978+$ +UP $979+$ +UP $927+$ +UP $928+$ +UP $929+$ +UP $957+$ +UP $958+$ +UP $959+$ +UP $1092+$ UP $967+$ +UP $968+$ +UP $969+$ +UP $887+$ +UP $888+$ +UP $889+$ +UP $947+$ +UP $948+$ +UP $949+$ +UP $937+$ UP $938+$ +UP $939+$ +UP $625+$ +UP $604+$ +UP $612+$ +UP $1002+$ +UP $721+$ +UP $1094+$ +UP $281+$ +UP 627 + UP 87+UP 8 8+UP 89+UP 587+UP 614+UP $1004+$ +UP 251+UP 641+UP 833+UP1112+ UP 835+UP 1114+UP 1291+UP 837+UP1191+UP 1131+UP1121+UP 1161+UP 1151+ UP1141+UP871 - Op2009 = 0

Ope2010:

UP $1466+$ +UP $1468+$ +UP $372+$ +UP $352+$ +UP $539+$ +UP $374+$ +UP $354+$ +UP $96+$ +UP $106+$ +UP $362+$ UP $43+$ +UP 4 5+UP 98+UP $108+$ +UP $364+$ +UP $47+$ +UP $1036+$ +UP 556+UP 636+UP $1319+$ UP1326+UP 1038+UP 558+UP 1303+UP 638+UP 481+UP 1328+UP 153+UP $1459+$ UP 13+UP 1473+UP 1483+UP 1305+UP 572+UP 1272+UP 1232+UP 155+UP 15+UP 36 + UP1262+UP $574+$ +UP $1475+$ +UP1485+UP1502+UP1552+UP1056+UP157+UP1307+ UP $401+$ +UP $1274+$ +UP 1234+UP 1103+UP17+UP 1264+UP 411+UP 51+UP 22+UP $38+$ UP $1477+$ +UP $1487+$ +UP $1504+$ +UP 1554+UP $1058+$ +UP 381+UP 163+UP $1386+$ +UP $1063+$ UP1 $105+$ +UP $24+$ +UP $991+$ UP $1221+$ UP $596+$ +UP $603+$ +UP $1331+$ +UP $165+$ +UP $1072+$ +UP 212 + UP1388+UP1065+UP1521+UP1107+UP1093+UP 598+UP 605+UP1361+UP167+ UP $214+$ +UP $1067+$ +UP $586+$ +UP $613+$ +UP $626+$ +UP $722+$ +UP $1074+$ +UP $588+$ +UP $1003+$ UP $1095+$ +UP $282+$ +UP $628+$ +UP $171+$ +UP $607+$ +UP $615+$ +UP $1005+$ +UP $724+$ +UP $1097+$ +UP 181 + UP $441+$ +UP $284+$ +UP $252+$ +UP $1021+$ +UP $617+$ +UP $301+$ +UP $642+$ +UP $1007+$ +UP $1391+$ UP $254+$ +UP $1011+$ +UP $1113+$ +UP $461+$ +UP $1081+$ UP $901+$ +UP $981+$ +UP $644+$ +UP $836+$ UP $1115+$ +UP $321+$ +UP $838+U P 1292+U P 651+U P 1117+U P 1294+U P 311+U P 701+$ UP $1041+$ +UP1132+UP1122+UP1162+UP1192+UP1152+UP1194+UP1134+UP1124+ UP 1164+UP 1154+UP1142+UP1144+UP1171+UP872+UP 874 - Op2010 = 0 Ope2011:

UP $1469+$ +UP $373+$ +UP $353+$ +UP $375+$ +UP $355+$ +UP $363+$ +UP $377+$ +UP 357+UP $99+U P 109+$ UP $365+$ +UP $46+$ +UP $48+$ +UP $367+$ +UP $1039+$ +UP $559+$ +UP $639+$ +UP $1329+$ +UP $482+$ +UP $1306+$ UP 573+UP 1273+UP1233+UP 1263+UP 484+UP 156+UP 16+UP 1476+UP 1486+ UP1503+UP1553+UP1308+UP 575+UP1275+UP1235+UP158+UP18+UP 39+ UP $1181+$ +UP $1265+$ +UP $402+$ +UP $412+$ +UP $52+$ +UP $577+$ +UP $1401+$ +UP $1478+$ +UP $1488+$ UP $1505+$ +UP $1555+$ +UP $382+$ +UP 23+UP $1059+$ +UP $404+$ +UP $1277+$ +UP $1237+$ +UP $992+$ UP $431+$ +UP $1106+$ +UP $1267+$ +UP $414+$ +UP $54+$ +UP $1241+$ +UP 1222+UP 1332+UP $25+$ UP1507+UP 1557+UP 1541+UP 384+UP166+UP1522+UP1073+UP 1362+UP213+ UP $1389+$ +UP $1531+$ +UP $1066+$ +UP $1511+$ +UP $1108+$ +UP 27+UP $994+$ +UP $1224+$ +UP $599+$ UP $606+$ +UP $1334+$ +UP $168+$ +UP $1075+$ +UP $215+$ +UP $1068+$ +UP $1524+$ +UP $723+$ +UP $1096+$ UP $283+$ +UP $111+$ UP $172+$ +UP $608+$ +UP $1364+$ +UP $341+$ +UP $217+$ +UP $1411+$ +UP $589+$ +UP 616 + UP 629+UP 725+UP 182+UP 1491+UP 1077+UP 291+UP1371+UP1351+UP $1022+$ UP $1006+$ +UP $1098+$ +UP 285+UP 253+UP 643+UP $442+$ +UP 174+UP 618+UP $1008+$ +UP 302 + UP $727+$ +UP $184+$ +UP $444+$ UP $1341+$ +UP $287+$ +UP $1392+$ +UP 255+UP $1012+$ +UP $781+$ UP $1024+$ +UP $304+$ +UP $451+$ UP $902+$ +UP $462+$ +UP $982+$ +UP $645+$ +UP $1082+$ +UP $241+$ +UP 1394 + UP 257+UP $1014+$ +UP $1116+$ +UP $464+$ +UP $1084+$ +UP $322+$ +UP 652+UP $231+$ +UP $811+$ UP $904+$ +UP $984+$ +UP $647+$ +UP $821+$ +UP $839+$ +UP $1293+$ +UP $1118+$ +UP $312+$ +UP $702+$ +UP 324 + UP 1295+UP $1042+$ +UP $654+$ +UP $681+$ +UP $1297+$ +UP $314+$ +UP $704+$ +UP $691+U P 1044+$ UP $1193+U P 1133+U P 1123+U P 741+U P 1163+U P 1135+U P 1125+U P 1153+U P 1165+$ UP1195+UP1155+UP1197+UP 671+UP 1137+UP1127+UP1167+UP1157+UP1143+ UP1145+UP1147+UP1172+UP 801+UP1174+UP 873+UP875+UP877-0p2011 = 0 Ope2012: UP $376+$ +UP 356 +UP $378+$ +UP $358+$ +UP $366+$ +UP $368+$ +UP $49+$ +UP $483+$ +UP $485+$ +UP $1309+$ UP $576+$ +UP $1276+$ +UP $1236+$ +UP $1182+$ +UP $1266+$ +UP $487+$ +UP $1402+$ +UP $159+$ +UP $19+$ UP $1479+$ +UP $1489+$ +UP $1506+$ +UP $1556+$ +UP $993+$ +UP $403+$ +UP $413+$ +UP $53+$ +UP $578+$ UP $1278+$ +UP $1238+$ +UP $432+$ +UP $1184+$ +UP $1268+$ +UP $405+$ +UP $415+$ +UP $55+$ +UP $383+$ UP 1242+UP 1223+UP 1404+UP1333+UP 1508+UP 1558+UP 1542+UP 385+UP 26+ 
UP 331+UP 1532+UP 407+UP 1523+UP 1363+UP 1512+UP 995+UP 112+UP $434+$ UP $1109+U P 417+U P 57+U P 1244+U P 1225+U P 1335+$ UP $342+$ +UP $28+U P 141+$ UP 201 + UP121+UP 1561+UP 1544+UP 221+UP 387+UP 169+UP 1525+UP 1076+UP 1365+ UP2 16+UP1534+UP1069+UP1514+UP 271+UP 4 71+UP 997+UP 292+UP 391+ UP 1412+UP 1227+UP173+UP 609+UP 1337+UP 1078+UP 218+UP 1352+UP1527+ UP $1492+$ +UP $1023+$ +UP $726+$ +UP $1099+$ +UP $286+$ +UP $183+$ +UP $114+$ +UP $175+$ +UP $1372+$ UP $1367+$ +UP $344+$ +UP $1414+$ +UP $619+$ +UP $443+$ +UP $728+$ +UP 185+UP $782+$ +UP $1494+$ UP 751+UP 661+UP 294+UP 561+UP 1374+UP 1354+UP1342+UP 1025+UP1009+ UP $288+$ +UP $303+$ +UP $1393+$ +UP $256+$ +UP $1013+$ UP $646+$ +UP $445+$ +UP $177+$ +UP $305+$ +UP 452 + UP 903+UP 463+UP1421+UP1441+UP 187+UP 983+UP 4 47+UP1083+UP1344+ UP $791+$ +UP $812+$ +UP $242+$ UP $1395+$ +UP $258+$ +UP $1015+$ UP $841+$ +UP $784+$ +UP $1027+$ +UP 307

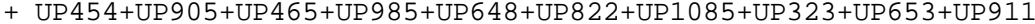
+ UP $244+$ +UP $1397+$ +UP $1017+$ +UP $891+$ +UP 191+UP $861+$ +UP 232+UP 1119+UP $467+$ UP $313+$ +UP $703+$ +UP $1087+$ +UP $682+$ +UP $325+$ +UP $655+$ +UP $234+$ +UP $814+$ +UP $907+$ +UP $987+$ UP $824+$ +UP $1296+$ +UP $1043+$ +UP $315+$ +UP $692+$ +UP $705+$ +UP $327+$ +UP $1298+U P 1045+$ UP $657+$ +UP $851+$ +UP $684+$ +UP $742+$ +UP $317+$ +UP $707+$ +UP $694+$ +UP $1047+$ +UP $672+$ +UP 1196 + UP1136+UP $1126+$ UP $744+$ +UP $1166+$ +UP $1138+$ UP $1128+$ +UP 1156+UP $1168+U P 1198$ + UP1158+UP 674+UP 1173+UP 802+UP 1146+UP1148+UP1175+UP $804+$ +UP $1177+$ UP $876+$ UP $878-$ Op2012 $=0$

Ope2013:

UP 379+UP 359+UP $1461+$ +UP 369+UP $491+$ +UP 501+UP 511+UP 521+UP 531+UP $101+$

UP 91+UP 1183+UP 486+UP $1403+$ +UP $488+$ +UP $579+$ +UP 1279+UP $1239+$ +UP $1185+$ UP $1269+$ +UP $113+$ +UP $1243+$ +UP $332+$ +UP $551+$ +UP $1405+$ +UP $1031+$ +UP $433+$ +UP $1509+$ UP $1559+$ +UP $996+$ +UP 406 +UP $416+$ +UP $1543+$ +UP 56 +UP 1533+UP 61+UP $1513+U P 71+$ UP $435+$ +UP 202+UP $1187+$ +UP $408+$ +UP $418+$ +UP 293+UP 222+UP $58+U P 386+$ +UP $1245+$ UP $1226+$ +UP 261+UP $1311+$ UP $1407+$ +UP 1321+UP 1336+UP 142+UP 272+UP $122+$ UP $1562+$ +UP $1545+$ +UP $388+$ +UP $343+$ +UP 29+UP $1251+$ +UP 631+UP $334+$ +UP $1535+$ UP $1526+$ +UP 1366+UP 1515+UP $472+$ +UP $998+U P 115+U P 392+U P 437+U P 421+$ UP $1247+$ +UP $1413+$ UP $1228+$ UP $1338+$ +UP $345+$ UP $1281+$ +UP $144+$ +UP $131+$ +UP $204+$ UP $124+$ +UP 1 $431+$ +UP $1451+$ +UP 1564+UP 1571+UP 1547+UP 224+UP1528+UP 1079+ UP1368+UP 219+UP 1353+UP 1537+UP 1517+UP 274+UP 4 74+UP 1493+UP 295+ UP $394+$ +UP $1415+$ +UP $176+$ UP $1373+$ UP $783+$ +UP $541+$ +UP $752+$ +UP $662+$ UP $562+$ UP $1051+$ +UP $1355+$ +UP $1495+$ +UP $1026+$ +UP $729+$ +UP $289+$ +UP 186+UP $117+$ +UP $178+$ UP $1375+$ +UP $347+$ +UP $31+$ +UP $1381+$ +UP $1417+$ UP $1343+$ +UP $446+$ +UP $453+$ +UP $792+$ UP $1422+$ UP $1442+$ UP $188+$ +UP $842+$ UP $785+$ +UP $1497+$ UP $754+$ +UP $771+$ +UP $731+$ +UP 591 + UP $664+$ +UP $297+$ +UP $564+$ +UP $1377+$ UP $711+$ +UP $1357+$ +UP $761+$ +UP $1345+$ +UP $1028+$ UP $813+$ +UP $243+$ +UP $306+$ +UP $1396+$ +UP $259+$ +UP $1016+$ +UP $649+$ +UP $448+$ +UP $823+$ +UP 308 + UP 455+UP 906+UP $466+$ +UP $1424+$ +UP $1444+$ +UP $986+$ +UP $1086+$ +UP $1347+$ +UP $912+$ UP $794+$ +UP $815+$ +UP $245+$ +UP $1398+$ +UP $1018+$ +UP $892+$ +UP $621+$ +UP $192+$ +UP $862+U P 844$ + UP $787+$ +UP $233+$ +UP $581+$ UP $457+$ +UP $908+$ +UP $468+$ +UP $988+$ +UP $825+$ +UP $1088+$ +UP 683

+ UP $326+$ +UP $656+$ +UP $914+$ +UP $971+$ +UP $921+$ +UP $951+$ +UP $247+$ +UP $961+$ +UP $881+$ +UP 941 + UP $894+$ +UP $931+$ +UP $194+$ +UP $864+$ +UP $235+$ +UP $316+$ +UP $693+$ +UP $706+$ +UP $685+$ +UP 328

+ UP $658+$ +UP $852+$ +UP $237+$ +UP $81+$ +UP $817+$ +UP $827+$ +UP $743+$ +UP $1299+$ +UP $1046+$ +UP 318

+ UP $695+$ +UP $708+$ +UP $673+$ UP $1048+U P 854+U P$ $687+$ UP $745+$ +UP $831+U P$ 6 $97+$ +UP 675

+ UP1199+UP1139+UP1129+UP 747+UP1169+UP 1159+UP 677+UP 803+UP1176+ UP 805+UP1149+UP 1178+UP 807+UP879 - Op2013 = 0

Ope2014:

UP $1462+$ +UP $492+$ +UP $502+$ +UP $512+$ +UP $522+$ +UP $532+$ +UP $494+$ +UP $504+$ +UP 514 +UP $524+$ UP $534+$ +UP $41+$ +UP $102+$ +UP $333+$ +UP $92+$ +UP $1186+$ +UP $489+$ +UP $1406+$ +UP $62+U P 72+$ UP $1188+$ +UP $203+$ +UP $223+$ +UP $116+$ +UP $1246+$ +UP $262+$ +UP $335+$ +UP $552+$ +UP $1312+$ UP $1408+$ +UP $1252+$ +UP $1032+$ +UP $436+$ +UP $143+$ +UP 123+UP 1563+UP 999+UP $409+$ UP $419+$ +UP 1546 +UP 59+UP $1536+$ +UP $64+$ +UP $1516+$ +UP $74+$ +UP 4 38+UP $273+$ +UP $205+$ UP $473+$ +UP 2 96+UP 422+UP 225+UP 389+UP 393+UP 1248+UP 1229+UP 264+UP 1314 + UP 1322+UP 1282+UP 1339+UP 145+UP 275+UP 132+UP 125+UP 1432+UP 1452+ UP 1565+UP1572+UP 1548+UP 346+UP1254+UP 632+UP151+UP $337+$ +UP $1301+$ UP 1538+UP 1529+UP 1369+UP 1518+UP 4 75+UP 118+UP 395+UP 753+UP 11+UP 663 + UP $424+$ +UP $1416+$ +UP $542+$ +UP $348+$ +UP $1284+$ +UP $147+$ +UP 134+UP $207+$ +UP $127+$ UP $1434+$ +UP $1454+$ +UP $1471+$ UP 1 481+UP 1567+UP 1574+UP 227+UP 563+UP 1356+ UP $277+U P 477+U P 1496+U P 298+U P 397+U P 1418+U P 793+U P 179+U P 1376+$ UP $843+$ UP $786+$ +UP $544+$ UP $755+$ UP $772+$ UP $732+$ +UP $665+$ +UP $565+$ +UP $712+$ +UP $1052+$ UP 1358+UP 7 62+UP 1498+UP1101+UP1029+UP1423+UP 1443+UP189+UP1378+ UP 161+UP 32+UP 1382+UP $1061+$ UP $1346+$ +UP $449+$ +UP $456+$ +UP $795+$ +UP $1425+$ UP $1445+$ +UP $845+$ +UP $788+$ +UP $757+$ +UP $774+$ +UP $734+$ +UP 592+UP $667+$ +UP $567+$ +UP $714+$ UP $764+$ +UP $1348+$ +UP $913+$ +UP $816+$ +UP $246+$ +UP $309+$ +UP $1399+$ +UP $1019+$ +UP $893+$ +UP 863 + UP 826 +UP 601+UP 458+UP 909+UP 469+UP1091+UP1427+UP1447+UP 989+ UP 193+UP $1089+$ +UP $915+$ +UP $797+$ +UP $972+$ +UP $922+$ +UP $818+$ +UP $952+$ +UP $248+$ +UP $962+$ UP $882+$ +UP $942+$ +UP $895+$ +UP $932+$ +UP $622+U P 195+U P 865+U P 847+U P 236+U P 853+$ 
UP $582+$ +UP $611+$ +UP $828+$ +UP 686 +UP $329+$ +UP 659 +UP $917+$ +UP $974+$ +UP $924+$ +UP $954+$ UP $1001+$ +UP $964+$ +UP $884+$ +UP $944+$ +UP $897+$ +UP $934+$ +UP $197+$ +UP $867+$ +UP $238+$ +UP $82+$ UP $319+$ +UP $696+$ +UP $709+$ +UP $688+$ +UP $855+U P 84+U P 746+U P 1049+$ +UP $698+U P 676+$ UP 857+UP1111+UP 748+UP 832+UP 678+UP806+UP1179+UP808-0p2014=0 Ope2015:

UP $1464+$ +UP $493+$ +UP $503+$ +UP $513+$ +UP $523+$ +UP $1463+$ +UP 495 +UP $505+$ +UP $515+$ +UP 525 + UP 533+UP $371+$ +UP 351+UP 535+UP $497+$ +UP $507+$ +UP 517+UP $527+$ +UP $94+$ +UP $104+$ UP $361+$ +UP $42+$ +UP $103+$ +UP $336+$ +UP 93+UP 1189+UP 63+UP 263+UP 1313+UP 73+ UP $1409+$ +UP $1034+$ +UP $554+$ +UP $1253+$ +UP $65+$ +UP $75+$ +UP $206+$ +UP 22 6+UP 119+UP 1249 + UP $265+$ +UP $634+$ +UP $338+$ +UP $553+$ +UP $1315+$ +UP $1324+$ +UP $1255+$ +UP $1033+$ +UP $439+$ UP1283+UP 146+UP 133+UP 126+UP 1453+UP 1433+UP 1566+UP 1573+UP 1549+ UP 423+UP 1539+UP 67+UP1519+UP 77+UP2 76+UP 208+UP 4 76+UP 299+UP 425+ UP $228+$ +UP $396+$ +UP $267+$ +UP $571+$ +UP $1323+$ UP $1285+$ +UP $148+$ +UP $278+$ +UP $135+$ +UP 128 + UP1435+UP 1455+UP 1568+UP 1575+UP $543+$ +UP 349 +UP 1257+UP 633+UP152+ UP 1302+UP 1271+UP 1231+UP 4 78+UP 398+UP 756+UP 773+UP 733+UP 12+UP 1261 + UP $666+$ +UP $427+$ +UP $713+$ UP $763+$ +UP1419+UP 545+UP $34+U P 1287+U P 137+$ UP $1437+$ +UP $1472+$ +UP 1 482+UP 1501+UP1551+UP 1577+UP 1054+UP 566+UP1359+ UP $21+$ +UP $1499+$ +UP $796+$ +UP $1379+$ +UP $846+$ +UP $789+$ +UP $547+$ +UP $758+$ +UP $775+$ +UP $735+$ UP $668+$ +UP $568+$ +UP $715+$ +UP $1384+$ +UP $1053+$ +UP $765+$ +UP $1102+$ +UP $1426+$ +UP $1446+$ UP $594+$ +UP $162+U P 33+U P 211+U P 1383+U P 1062+U P 1349+U P 459+U P 798+U P 1428$ + UP1448+UP 848+UP1071+UP777+UP737+UP 593+UP717+UP 767+UP $916+$ UP $584+$ +UP 973+UP 923+UP 819+UP 953+UP $249+$ +UP 963+UP 883+UP 943+UP $896+$ UP $933+$ +UP $624+$ +UP $866+$ +UP $829+$ +UP $602+$ +UP $721+$ +UP $1092+$ +UP $196+$ +UP $918+$ +UP $975+$ UP $925+$ +UP $955+$ +UP $281+$ +UP $965+$ +UP $885+$ +UP $945+$ +UP $898+$ +UP $935+$ +UP $623+$ +UP $198+$ UP $868+$ +UP $239+$ +UP $83+$ +UP $856+$ +UP $583+$ +UP $612+$ +UP $689+$ +UP $977+$ +UP $927+$ +UP $957+$ UP $1002+$ +UP $967+U P 887+$ +UP $251+$ +UP $947+$ +UP $937+$ +UP $85+$ +UP 699 +UP $858+U P 87+$ UP $641+$ +UP $749+$ +UP $679+$ +UP $834+$ +UP $1112+$ +UP $1291+$ +UP $833+$ +UP $1191+$ +UP $809+$ UP1131+UP1121+UP1161+UP1151+UP1141+UP $871-0$ P2015 = 0 Ope2016:

UP $1465+$ +UP 496 +UP 506 +UP 516+UP 526 +UP $498+$ +UP 508 +UP $518+$ +UP $528+$ +UP $536+$ UP $537+$ +UP $372+$ +UP $352+$ +UP $44+$ +UP $95+$ +UP $105+$ +UP $362+$ +UP $43+$ +UP $339+$ +UP $66+$ UP $266+$ +UP $1316+$ +UP $1317+$ +UP $76+$ +UP $1035+$ +UP 555+UP $1256+$ +UP $68+$ +UP $78+$ +UP $209+$ UP $229+$ +UP $268+$ +UP $635+$ UP $481+$ +UP $1325+$ +UP $1258+$ +UP $1286+$ +UP $149+$ +UP $136+$ +UP 129 + UP1456+UP1457+UP1436+UP1569+UP 1576+UP 426+UP1304+UP 279+UP 154+ UP $479+$ +UP 1 4+UP $428+$ +UP $399+$ +UP $572+$ +UP $1288+$ +UP $138+$ +UP $1438+$ +UP $1474+$ +UP 1484 + UP1578+UP 546+UP 153+UP1303+UP 401+UP1272+UP1232+UP759+UP $776+$ UP $736+$ +UP 13+UP $1262+$ +UP $669+$ +UP $411+$ UP $716+$ +UP $766+$ +UP $51+$ +UP $548+$ +UP $35+$ UP $1473+$ +UP1 $483+$ +UP 1502+UP 1552+UP 1055+UP 381+UP 569+UP1104+UP 22+ UP $991+$ UP $1221+$ UP $799+$ +UP $849+$ UP $1331+$ UP $164+$ UP $778+$ +UP $738+$ +UP $718+U P 1385$ + UP $768+U P 1064+U P 1521+U P 1103+U P 1429+U P 1449+$ +UP 595+UP $604+U P 1361+$ UP 163+UP 212+UP 1063+UP 1072+UP 919+UP 585+UP 976+UP 92 6+UP $956+$ +UP 1094 + UP $966+$ +UP $886+$ +UP $946+$ +UP $899+$ +UP $936+$ +UP $625+U P$ 8 $69+U P 171+U P$ 603+UP 614 + UP1004+UP722+UP1093+UP181+UP199+UP 4 41+UP 978+UP 928+UP 958+ UP $282+$ +UP $968+$ +UP $888+$ +UP $948+$ +UP $938+$ +UP $86+$ +UP $859+$ +UP $1021+$ +UP $613+$ +UP $301+$ UP $1003+$ +UP $1391+$ +UP 252+UP 1011+UP $88+$ +UP $461+$ UP $1081+$ UP $901+$ +UP $981+$ UP 642 + UP 1114+UP 321+UP 835+UP 651+UP 1113+UP 1292+UP 311+UP 701+UP $1041+$ UP1192+UP1132+UP1122+UP1162+UP1152+UP1142+UP1171+UP872 - Op2016 =

Ope2017:

UP $1467+$ +UP $1466+$ +UP $499+$ +UP $509+$ +UP $519+$ +UP $529+$ +UP $374+$ +UP $354+$ +UP $538+$ +UP 373 + UP $353+$ +UP $97+$ +UP $107+$ UP $364+U P 45+U P 96+U P 106+U P 363+U P 1037+U P 557+$ UP 69+UP 269+UP 637+UP $1318+$ +UP $79+U P 1327+$ +UP $1036+$ +UP $556+$ +UP $1259+$ +UP 636 + UP 482+UP1326+UP1289+UP139+UP1458+UP1439+UP1579+UP 429+UP1305+ UP $574+$ +UP 1274+UP 1234+UP 155+UP 15+UP 37+UP 1181+UP 12 64+UP 573+UP 1401 + UP1475+UP1485+UP1504+UP1554+UP 549+UP1057+UP 402+UP1273+UP1233+ UP 431+UP 779+UP 739+UP 1263+UP 412+UP 719+UP 769+UP 52+UP 1241+UP 24+ UP 36+UP 1503+UP 1553+UP 1541+UP 1056+UP 382+UP 1387+UP 1531+UP 1511+ UP1105+UP 23+UP 992+UP 1222+UP 597+UP $1332+$ +UP 165+UP $1074+$ +UP $214+$ UP $1386+$ +UP $1065+$ +UP $1522+$ UP $111+$ UP $596+$ +UP $605+$ UP $1362+$ +UP $341+$ UP $213+$ UP1411+UP 587+UP $627+$ +UP $724+$ +UP 1491+UP1073+UP 291+UP1371+UP1351+ UP 586 +UP $979+$ +UP $929+$ +UP 959 +UP $1095+$ +UP $284+$ +UP $969+$ +UP $889+$ +UP 949 +UP $939+$ UP 626 +UP $172+$ +UP $615+$ +UP $1005+$ +UP $723+$ +UP $182+$ +UP $442+$ +UP $1341+$ +UP $283+$ +UP 254 + UP $781+$ +UP $89+$ +UP $1022+U P 302+U P 451+U P 644+U P 241+U P 1392+U P 253+$ UP $1012+U P 462+U P 1082+U P 231+$ UP $811+$ +UP $902+$ +UP $982+$ +UP $643+$ +UP $821+$ +UP 837 + UP1115+UP 322+UP 836+UP 1294+UP 652+UP 681+UP 1293+UP 312+UP $702+$ UP $691+$ UP $1042+$ +UP $741+$ +UP $1134+$ +UP $1124+$ +UP $1164+$ +UP $1194+$ +UP $1154+$ +UP $1193+$ UP $671+$ UP $1133+$ UP $1123+$ UP $1163+$ UP $1153+$ UP $1144+$ +UP $1143+$ UP $801+$ +UP $1172+$ UP $874+$ UP $873-0$ Op2017 = 0 
Ope2018:

UP $1468+$ +UP $375+$ +UP $355+$ +UP $539+$ +UP $98+$ +UP $108+$ +UP 365+UP 4 7+UP $46+$ +UP $1038+$ UP 558+UP 638+UP 1319+UP 1328+UP 484+UP 1307+UP 483+UP157+UP 1459+UP 17 + UP1477+UP1487+UP1306+UP 575+UP1275+UP1235+UP156+UP16+UP 38+ UP $1182+$ +UP $1265+$ +UP $404+$ +UP $414+$ +UP $54+$ +UP $1402+$ +UP $1476+$ +UP $1486+$ +UP $1505+$ UP $1555+$ +UP $384+$ +UP $1058+$ UP $331+$ +UP $403+$ +UP $994+$ +UP $432+$ +UP $1107+$ +UP $413+$ +UP 53 + UP1242+UP1224+UP 1334+UP25+UP141+UP201+UP121+UP1561+UP1542+ UP221+UP 383+UP167+UP1524+UP 1364+UP 1388+UP1532+UP $1067+$ +UP 1512+ UP $1106+$ +UP $271+U P 471+$ UP $993+U P 391+U P 1223+U P 598+$ UP $607+$ UP $1333+$ UP 166 + UP $1075+$ +UP $215+$ +UP $1066+$ +UP $1523+$ +UP $1097+$ +UP $112+$ +UP $174+$ +UP $606+$ +UP $1363+$ UP $342+$ UP $1412+$ +UP $588+$ UP $617+$ UP $628+$ UP $725+$ UP $184+$ +UP $1492+$ +UP $751+$ +UP 661 + UP2 92+UP 561+UP 1372+UP 1352+UP1024+UP1007+UP 1096+UP 285+UP $444+$ UP $173+$ +UP $616+$ +UP $1006+$ +UP $304+$ +UP $1421+$ UP $1441+$ +UP 183+UP $443+$ UP $1342+$ UP $791+$ +UP 1394+UP 255+UP 1014+UP $841+$ +UP $782+$ +UP 1023+UP $303+U P 452+U P ~ 904$ + UP $464+$ +UP $984+$ +UP $645+$ +UP $1084+$ +UP $911+$ +UP $242+$ +UP $1393+$ +UP $1013+$ +UP $891+$ UP 191+UP $861+$ +UP 1117+UP 463+UP 1083+UP $324+$ +UP 654+UP 232+UP $812+$ +UP 903

+ UP 983+UP 822+UP 838+UP 1116+UP 314+UP $704+$ +UP 323+UP 1295+UP $1044+$ UP 653+UP 851+UP 682+UP 313+UP 703+UP 692+UP $1043+U P 742+U P 1135+U P 1125$ + UP1165+UP1195+UP1155+UP 672+UP1145+UP1174+UP 802+UP1173+UP 875 Op2018 = 0

Ope2019: UP $1469+$ +UP $377+$ +UP $357+$ +UP $1461+$ +UP $376+$ +UP 356 +UP $367+$ +UP $99+$ +UP $109+$ +UP $366+$ UP $491+$ +UP $501+$ +UP $511+$ UP $521+$ UP $48+$ +UP $531+$ UP $101+$ +UP $1039+$ +UP $559+U P 91+$ UP 639+UP 1329+UP 485+UP 1308+UP 577+UP 1277+UP 1237+UP 1184+UP 1267+ UP 551+UP $1404+$ +UP1031+UP158+UP18+UP 1478+UP1488+UP1507+UP1557+ UP $576+$ +UP $1276+$ +UP $1236+$ +UP $61+$ +UP $71+$ +UP $434+$ +UP 39+UP $1183+$ +UP $1266+$ +UP $405+$ UP $415+$ +UP 55+UP 1244+UP 261+UP 1311+UP $1403+$ +UP1321+UP1506+UP 1556+ UP $1544+$ +UP 385+UP 27+UP 1251+UP 1059+UP 631+UP 332+UP 1534+UP1514+ UP $995+$ +UP $114+$ +UP $433+$ +UP $1108+$ +UP $421+$ +UP $1243+$ +UP $1225+$ +UP $1335+$ +UP $344+$ +UP 26 + UP1281+UP142+UP131+UP202+UP122+UP1431+UP1451+UP1562+UP1571+ UP1543+UP 222+UP 168+UP1525+UP1077+UP1365+UP 217+UP1389+UP1533+ UP $1068+$ +UP 1513+UP 272+UP $472+$ +UP $294+$ +UP $392+$ +UP $1414+$ +UP $599+$ +UP $608+$ +UP 541 + UP $1076+$ +UP $216+$ +UP $1051+$ UP $1354+$ +UP $1494+$ +UP $727+$ +UP $1098+$ +UP $287+$ +UP $113+$ UP $175+$ +UP $1374+$ +UP $343+$ +UP $31+$ UP $1381+$ UP $1413+$ +UP $589+$ +UP $618+$ +UP $629+$ +UP 726 + UP 185+UP 784+UP 1493+UP 752+UP 771+UP 731+UP 591+UP 662+UP $293+$ +UP 562 + UP $1373+$ +UP $711+$ +UP $1353+$ +UP $761+$ +UP $1344+$ +UP 1025+UP 1008+UP 286+UP 257+ UP $647+$ +UP $445+$ +UP $305+$ +UP $454+$ +UP $1422+$ +UP $1442+$ +UP $1343+$ +UP $792+$ +UP $814+$ +UP 244 + UP $1395+$ +UP $256+$ +UP $1015+$ +UP $621+$ +UP $842+$ +UP $783+$ +UP $581+$ +UP $453+$ +UP $905+$ UP 4 65+UP 985+UP $646+$ +UP $824+$ +UP $1085+$ +UP $912+$ +UP $971+$ +UP $921+$ +UP $951+$ +UP $243+$ UP $961+$ +UP $881+$ UP $941+$ UP $892+$ +UP $931+$ UP $192+$ +UP $862+$ +UP $234+$ +UP $1118+$ +UP $684+$ UP $325+$ +UP 655+UP 233+UP 81+UP 813+UP 823+UP 839+UP 1297+UP 315+UP $694+$ UP 705+UP 1296+UP 10 45+UP 852+UP 683+UP 744 +UP 831+UP 693+UP $674+$ +UP 1197 + UP $1137+$ +UP $1127+$ UP $743+$ UP $1167+$ UP $1136+$ UP $1126+$ +UP $1157+$ +UP $1166+$ +UP 1196 + UP1156+UP 673+UP $804+U P 1147+$ +UP $1146+$ +UP 1175+UP 803+UP $877+$ +UP 876 Op2019=0

Ope2020:

UP $378+$ +UP $358+$ +UP $368+$ +UP $492+$ +UP $502+$ +UP $512+$ +UP $522+$ +UP $49+$ +UP $532+$ +UP $41+$ UP $487+$ +UP $486+$ +UP $1309+$ +UP $578+$ +UP $1278+$ +UP $1238+$ +UP 1185+UP $1268+U P 334+$ UP $1405+$ +UP 159+UP 19+UP 14 79+UP 1489+UP1508+UP 1558+UP $997+$ +UP $407+$ UP $417+$ +UP $57+$ +UP $62+$ +UP $72+$ +UP $435+$ +UP $204+$ +UP $406+$ +UP $416+$ +UP $224+$ +UP $56+$ UP $387+$ +UP $1245+$ +UP $1227+$ +UP $262+$ +UP $1312+$ +UP $1337+U P 144+U P 274+U P 124+$ UP $1564+$ +UP $1545+$ +UP $386+$ +UP $28+$ +UP $1252+$ +UP $151+$ +UP $333+$ +UP $1301+$ +UP $1535+$ UP $1527+$ +UP $1367+$ +UP $1515+$ +UP $474+$ +UP $996+$ +UP $115+$ +UP $394+$ +UP $1109+$ +UP $11+$ +UP 422 + UP1226+UP1336+UP 345+UP1282+UP143+UP132+UP203+UP123+UP1432+ UP 1452+UP 1471+UP1481+UP 1563+UP 1572+UP 223+UP 169+UP1526+UP 1078+ UP $1366+$ +UP $218+$ +UP $1069+$ +UP $273+$ +UP $473+$ +UP 295+UP 393+UP $1415+$ +UP $177+$ +UP 609 + UP $542+$ +UP $754+$ +UP $664+$ +UP $564+$ +UP $1355+$ +UP $1495+$ +UP $1101+U P 1027+U P 728+$ UP $1099+U P 288+U P 187+$ UP $176+$ +UP $1375+U P 161+$ UP $1061+$ +UP $619+U P 447+$ UP 794 + UP $1424+$ +UP $1444+$ +UP $186+$ +UP $844+$ +UP $785+$ +UP $753+$ +UP $772+$ +UP $732+$ +UP $663+$ UP $563+$ +UP $712+$ +UP $762+$ UP $1345+$ +UP $1026+$ +UP $1009+$ +UP $307+$ +UP $1397+$ +UP $258+$ UP $1017+$ +UP $648+$ UP $446+$ UP $601+$ UP $306+$ +UP $455+$ UP $907+$ +UP $467+$ +UP $1091+$ +UP 1423 + UP $1443+$ +UP $987+$ +UP $1087+$ +UP $914+$ +UP $793+$ +UP $815+$ +UP $245+$ +UP $1396+U P 1016+$ UP $894+$ +UP $194+$ +UP $864+$ +UP $843+$ +UP $611+$ +UP $906+$ +UP $466+$ +UP $986+$ +UP $825+$ +UP $1086+$ UP $327+$ +UP $657+$ +UP $913+$ +UP $972+$ +UP $922+$ +UP $952+$ +UP $1001+$ +UP $962+$ +UP $882+$ +UP $942+$ UP $893+$ +UP $932+$ +UP $193+$ +UP $863+$ +UP $235+$ +UP $1119+$ +UP $317+$ +UP $707+$ +UP $685+$ +UP $326+$ UP 656 +UP $854+$ +UP $82+$ +UP $1298+$ +UP $1047+$ +UP 316 +UP $695+$ +UP $706+$ +UP 1046 +UP 853 
+ UP1111+UP 745+UP 675+UP1198+UP1138+UP1128+UP1168+UP1158+UP1177+ UP $805+$ UP $1148+$ UP $1176+$ UP $878-0$ - $2020=0$ Ope2021:

UP $1462+$ +UP $379+$ +UP $359+$ +UP $1464+$ +UP $494+$ +UP 504 +UP 514 +UP $524+$ +UP $369+$ +UP 371 + UP $351+$ UP $534+$ +UP $493+$ +UP $503+$ +UP $513+$ +UP $523+$ +UP $92+$ +UP $102+$ +UP $361+$ +UP $533+$ UP $104+$ +UP $94+$ +UP $1187+$ UP $488+$ +UP $1407+$ +UP $1032+$ +UP $552+$ +UP $579+$ +UP $1279+$ +UP 64 + UP $74+$ +UP 1239+UP $1186+$ +UP 1269+UP $117+$ +UP $1247+$ +UP 264+UP $632+$ +UP $335+$ UP 554+UP $1314+$ +UP $1406+$ +UP 1322+UP 1254+UP 1034+UP 437+UP 150 9+UP 1559+ UP 998+UP $408+$ +UP $418+$ +UP $1547+$ +UP 58+UP $1537+$ +UP 63+UP 1517+UP $73+$ +UP $436+$ UP $205+$ +UP $297+$ +UP $424+$ +UP $225+$ +UP $388+$ +UP $1246+$ +UP $1228+$ +UP $263+$ +UP $571+$ +UP 1313 + UP1324+UP 1284+UP 1338+UP 145+UP 275+UP 134+UP 125+UP 1434+UP $1454+$ UP1565+UP 1574+UP 1546+UP 34 7+UP 29+UP1253+UP 634+UP1536+UP1271+ UP $1528+$ +UP $1368+$ +UP $1516+$ +UP $1231+$ +UP $475+$ UP $116+$ +UP $395+$ +UP $1261+$ +UP $423+$ UP $1417+$ +UP $544+$ +UP $346+$ +UP 32+UP1283+UP133+UP1433+UP 1453+UP1501+ UP1551+UP 1573+UP1052+UP 1079+UP 219+UP 1357+UP21+UP 1497+UP 296+ UP $1416+$ +UP $178+$ +UP $1377+$ +UP $787+$ +UP $543+$ +UP $755+$ +UP $774+$ +UP $734+$ +UP $665+$ +UP 565 + UP $714+$ +UP 1382+UP 1054+UP 1356+UP 764+UP 1496+UP1028+UP 729+UP 289+ UP $188+$ +UP $592+$ +UP $1376+$ +UP $34+$ +UP $211+$ UP $1384+$ +UP $1347+$ +UP $448+$ +UP $457+$ +UP 795 + UP $1425+$ +UP $1445+$ UP $845+$ +UP $786+$ +UP $1071+$ UP 773+UP 733+UP $594+$ +UP $713+$ UP $763+$ UP $1346+$ +UP $582+$ +UP $817+$ +UP $247+$ UP $308+$ +UP $1398+$ +UP $259+$ +UP $1018+$ +UP 622 + UP $649+$ +UP $827+$ +UP $456+$ UP $908+$ +UP $721+$ +UP $468+$ +UP $988+$ +UP $1088+$ +UP $915+$ +UP 974

+ UP $924+$ +UP $816+$ +UP $954+$ +UP $246+$ +UP $281+$ +UP $964+$ +UP $884+$ +UP $944+$ +UP $895+$ +UP 934 + UP $624+$ +UP $195+$ +UP $865+$ +UP $237+$ +UP $584+$ +UP $826+$ +UP $687+$ +UP $328+$ +UP $658+$ +UP 973 + UP 923+UP 953+UP $963+$ UP $883+$ +UP $251+$ +UP $943+$ +UP $933+$ +UP $236+$ +UP $84+$ +UP $318+$ UP $697+$ +UP $708+$ +UP 686 +UP $855+$ +UP $83+U P 641+$ UP $747+$ +UP $1299+U P 1048+U P 696+$ UP $677+$ +UP $832+U P 746+$ +UP $1291+$ +UP $834+U P$ 676+UP 1199+UP $1139+$ +UP $1129+$ UP1169+UP1159+UP1191+UP 807+UP 1131+UP1121+UP1161+UP 1151+UP 1178+ UP $806+U P 1149+U P 1141+$ UP $879+$ UP $871-0$ - $2021=0$ Ope2022: UP $495+$ +UP 505+UP 515+UP 525+UP 535+UP 42+UP 537+UP 44 +UP $337+$ +UP $1188+$ UP $489+$ +UP $1408+$ +UP $65+$ +UP $75+$ +UP $207+$ +UP $227+$ +UP $118+$ +UP $1248+$ +UP $265+$ +UP $336+$ UP $481+$ +UP $1315+$ +UP $1255+$ UP $438+$ +UP $147+$ +UP $127+$ +UP $1567+$ +UP $999+$ +UP $409+$ +UP 419 + UP 1548+UP 59+UP 1302+UP 1538+UP 1518+UP 277+UP 152+UP 206+UP $477+$ UP 12+UP 2 98+UP 425+UP 22 6+UP 389+UP 397+UP 1229+UP $1317+$ +UP 1285+UP 1339 + UP $146+$ +UP $276+$ +UP $135+$ +UP $126+$ UP $1435+$ UP $1455+$ UP $1472+$ +UP $1482+$ +UP $1566+$ UP $1575+$ +UP $348+$ +UP $401+$ +UP $1529+$ +UP $1369+$ +UP $476+$ UP $396+$ +UP $757+$ +UP $14+$ +UP 667 + UP $411+$ +UP $51+$ +UP $1418+$ +UP $545+$ +UP $1457+$ +UP $1474+$ +UP $1484+$ +UP $381+$ +UP $567+$ UP1358+UP 1102+UP 1498+UP 991+UP1221+UP 797+UP179+UP $1378+U P 847+$ UP $788+$ +UP $1331+$ UP $162+$ +UP $756+$ UP $775+$ UP $735+$ +UP $666+$ +UP $566+$ +UP $715+$ +UP $765+$ UP $1062+$ +UP 1521+UP $1104+$ +UP1029+UP $1427+$ +UP $1447+$ +UP $189+$ +UP $602+$ +UP $1361+$ UP $164+$ +UP $1064+$ +UP $1348+$ +UP $449+$ +UP $458+$ +UP $796+$ +UP $1426+$ +UP $1446+$ +UP $846+$ UP $917+$ +UP $818+$ +UP $248+$ +UP $1092+$ +UP 309 +UP $1399+$ +UP $1019+$ +UP $897+$ +UP $867+$ +UP 828 + UP171+UP 612+UP1002+UP 909+UP 469+UP1094+UP181+UP 989+UP197+ UP $441+$ +UP $1089+$ +UP $916+$ +UP $975+$ +UP $925+$ +UP $955+$ +UP $965+$ +UP $885+$ +UP $945+$ +UP $896+$ UP $935+$ +UP $196+$ +UP $866+$ +UP $238+$ +UP $857+$ +UP $1021+$ +UP $301+$ +UP $688+$ +UP $329+$ +UP $659+$ UP 1391+UP 1011+UP 85+UP $461+$ UP $319+$ +UP $698+$ +UP $709+$ +UP $1081+$ +UP $856+$ +UP 901

+ UP 981+UP $748+$ +UP $1049+$ +UP $1112+$ +UP $321+$ UP $678+$ +UP $651+$ +UP $1114+U P 311+$ UP701+UP1041+UP 808+UP1179+UP1171 - Op2022 = 0

Op $2002<=4500$

Op2003<=4500

op $2004<=4500$

Op $2005<=4500$

Op $2006<=4500$

Op2007<=4500

Op $2008<=4500$

Op2009< $=4500$

Op2 $010<=4500$

Op2011<=4500

Op2012<=4500

Op $2013<=4500$

Op $2014<=4500$

Op $2015<=4500$

Op2016<=4500

Op $2017<=4500$

Op2018< $=4500$

Op $2019<=4500$

Op2020<=4500

Op $2021<=4500$ 


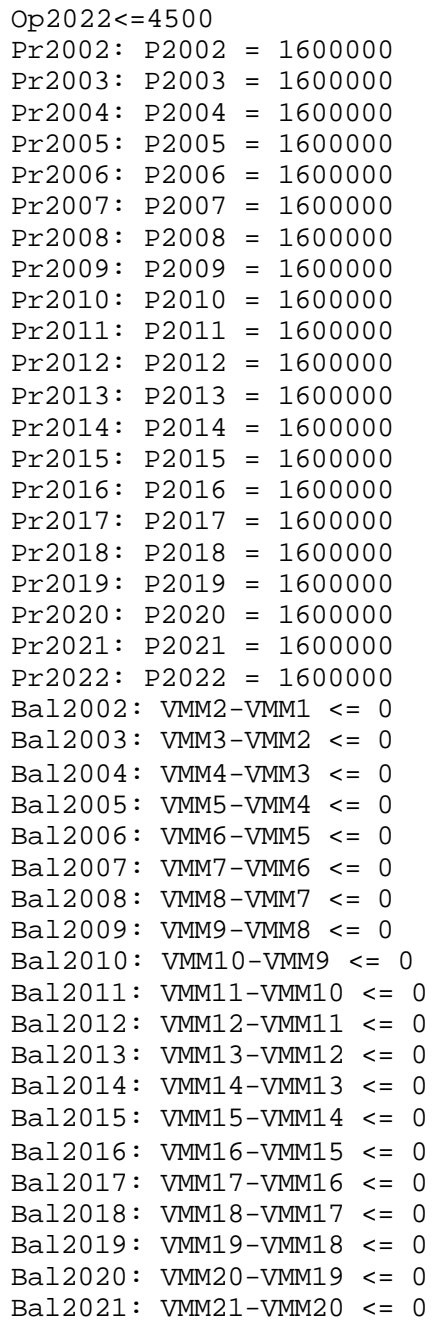

END 


\section{REFERÊNCIAS BIBLIOGRÁFICAS}

BAER, W. A economia brasileira. 5 ed. São Paulo: Nobel, 1996. 416p.

BRAZEE, R. J.; BULTE, E. Optimal harvesting and thinning with stochastic prices. Forest Science, v 46, p. 23-30, 2000

CAIXETA FILHO, J. V. Pesquisa operacional: técnicas de otimização aplicadas a sistemas agroindustriais. Piracicaba: O autor, 2000. 212p.

CARNIERI, C. Planejamento florestal otimizado via redes de manejo. In: ENCONTRO BRASILEIRO DE PLANEJAMENTO FLORESTAL, 1., Curitiba, 1989. Anais. Curitiba: EMBRAPA,CNPF, 1989. p.173-184.

CLUTTER, J. L.; FORTSON, J. C.; PIENAAR, L. V.; BRISTER, G. H.; BAILEY, R. L. Timber management: a quantitative approach 2.ed. Malabar: Krieger, 1992. $333 p$.

DAVIS, L. S.; JOHNSON, K. N. Forest management. 3.ed. New York: McGraw-Hill, 1987. 790p.

DYKSTRA, D. P. Mathematical programming for natural resource management . New York: McGraw-Hill, 1984. 318p. 
EAKIN, M. Brazil: the once and future country. 2 ed. New York: St. Martin's Griffin, 1998. 301p.

FALCÃO, A.; BORGES, J. B. Programação linear e gestão estratégica em recursos florestais. Revista Florestal, v 12, n 1 p. 93-98 , 1998

FAUSTMANN, M. On the determination of the value which forest land and immature stands pose for forestry. In: GANE, M. (Ed.) Martin Faustmann and the evolution of discounted cash flow. Oxford: Oxford Institute, 1849. 54p. (Paper 42).

FLYNN, R.; SHIELD, E. Eucalyptus : progress in higher value utilization - a global review. Washington: Robert Flynn Associates; Economic Forestry Associates, 1999. 212p. (Relatório apresentado à IP do Brasil Ltda.)

HILLIER, F. S.; LIEBERMAN, G. J. Operations research. San Francisco: HoldenDay, 1967. 800p.

JOHNSON, K. N.; SCHEURMAN, H. L. Techniques for prescribing optimal timber harvest and investment under different objectives: discussion and synthesis. Forest Science, v. 18, n. 1, p. 1-31, 1977

KLEMPERER, W. D Forest resource economics and finance. New York: McGrawHill, 1996. 512p.

LEUSCHNER, W. A. Introduction to forest resource management. 2.ed. Malabar: Krieger, 1992. 298p.

MACHADO, C. C.; LOPES, E. S.; BIRRO, M. H. B. Elementos básicos do transporte florestal rodoviário. Viçosa: Editora UFV, 2000. 167p. 
MARTINI, E. L.; LEITE, N. B. Planejamento florestal, a importância e a aplicação da programação linear. In: ENCONTRO BRASILEIRO DE ECONOMIA FLORESTAL, 1., Curitiba, 1988. Anais. Curitiba: EMBRAPA,CNPF, 1988. p 545570.

PEREIRA, L. C. B. Economia brasileira: uma introdução crítica. 3 ed. São Paulo: Editora 34, 2000. 222p.

PUKKALA, T.; POHJONEN, V. Use of linear programming in land use planning in the Ethiopian highlands. Silva Fennica, v. 24, n. 2, p. 235-247, 1990

REZENDE, J. L. P.; OLIVEIRA, A. D. Análise econômica e social de projetos florestais. Viçosa: Editora UFV, 2001. 389p.

RODRIGUES, F. L. Regulação de florestas equiâneas utilizando programação linear. Viçosa , 1997. 117p. Dissertação (Mestrado) - Universidade Federal de Viçosa

RODRIGUEZ, L. C. E.; BORGES, J. B. Técnicas matemáticas para determinação de níveis sustentáveis de produção florestal. Revista Florestal, v 12, n 1/2 p. 83-89. 1998.

RODRIGUEZ, L. C. E. Técnicas quantitativas para a gestão de florestas plantadas. Apostila do $6^{\circ}$ Programa de Reciclagem em Métodos Quantitativos, Planejamento da Produção Florestal (Modelos de Otimização), Piracicaba: ESALQ, 2001. 103p.

RODRIGUEZ, L. C. E.; MARTINI, E. L. Definição da seqüência operacional de corte e plantio em áreas de reforma de eucaliptais. In: ENCONTRO BRASILEIRO DE PlaneJAMENTO FloRESTAL, 1., Curitiba, 1989. Anais. Curitiba: Embrapa, CNPF, 1989. p. 63-72 
RODRIGUEZ, L. C. E. Matemática financeira na gestão florestal. Apostila do $4^{0}$ Programa de Reciclagem em Métodos Quantitativos, Avaliação de Projetos Florestais (Técnica de Matemática Financeira), Piracicaba: ESALQ, 1999. 66p.

RODRIGUEZ, L. C. E.; MOREIRA, R. M. Gerenciamento de florestas de eucalipto com modelos de programação linear. IPEF Série Técnica, v. 6, n. 19, p.1-15, 1989.

RODRIGUEZ, L. C. E.; AMARAL, T. M. Ordenamento sustentável das florestas de eucaliptos plantadas para a produção de celulose no Brasil. In: SIMPÓSIO IBEROAMERICANO DE GESTÃO E ECONOMIA FlORESTAL, 1., Porto Seguro, 2001. Série Técnica IPEF, v14, n.34, p. 150-158, 2001.

SIITONEN, M. Experiences in the use of forest management planning models. Silva Fennica, v. 27, n. 2, p. 167-178, 1993

SOUSA, R. A. T. M. Análise do fluxo de transporte rodoviário de toras curtas de eucalipto para algumas indústrias de celulose e chapas de composição no Estado de São Paulo. Piracicaba, 2000. 115p. Tese (Doutorado) - Escola Superior de Agricultura "Luiz de Queiroz", Universidade de São Paulo.

TAHA, H. A. Operations research. 6.ed. New Jersey: Prentice Hall, 1997. 916p.

WILLIAMS, H. P. Model building in mathematical programming. 4. ed. New York: John Wiley, 1999. 354p.

ZOBEL, B. J.; SPRAGUE, J. R. Juvenile wood in forest trees .New York: Springer Series in Wood Science, 1998. 299p. 